Cochrane Database of Systematic Reviews

\title{
Oxycodone for cancer-related pain (Review)
}

Schmidt-Hansen M, Bennett MI, Arnold S, Bromham N, Hilgart JS

Schmidt-Hansen M, Bennett MI, Arnold S, Bromham N, Hilgart JS.

Oxycodone for cancer-related pain.

Cochrane Database of Systematic Reviews 2017, Issue 8. Art. No.: CD003870.

DOI: 10.1002/14651858.CD003870.pub6.

www.cochranelibrary.com 
TABLE OF CONTENTS

HEADER

ABSTRACT

PLAIN LANGUAGE SUMMARY

SUMMARY OF FINDINGS

BACKGROUND

OBJECTIVES

METHODS

RESULTS

Figure 1.

Figure 2.

Figure 3.

Figure 4.

DISCUSSION

AUTHORS' CONCLUSIONS

ACKNOWLEDGEMENTS

REFERENCES

CHARACTERISTICS OF STUDIES

DATA AND ANALYSES

Analysis 1.1. Comparison 1 Pain, Outcome 1 Pain intensity and pain relief.

Analysis 2.1. Comparison 2 Adverse events, Outcome 1 Any adverse events.

Analysis 2.2. Comparison 2 Adverse events, Outcome 2 Asthenia.

Analysis 2.3. Comparison 2 Adverse events, Outcome 3 Confusion.

Analysis 2.4. Comparison 2 Adverse events, Outcome 4 Constipation.

Analysis 2.5. Comparison 2 Adverse events, Outcome 5 Dizziness/lightheadedness.

Analysis 2.6. Comparison 2 Adverse events, Outcome 6 Drowsiness/somnolence.

Analysis 2.7. Comparison 2 Adverse events, Outcome 7 Dry mouth.

Analysis 2.8. Comparison 2 Adverse events, Outcome 8 Dysuria.

Analysis 2.9. Comparison 2 Adverse events, Outcome 9 Hallucinations.

Analysis 2.10. Comparison 2 Adverse events, Outcome 10 Headache.

Analysis 2.11. Comparison 2 Adverse events, Outcome 11 Insomnia.

Analysis 2.12. Comparison 2 Adverse events, Outcome 12 Nausea.

Analysis 2.13. Comparison 2 Adverse events, Outcome 13 Nervousness.

Analysis 2.14. Comparison 2 Adverse events, Outcome 14 Pruritus.

Analysis 2.15. Comparison 2 Adverse events, Outcome 15 Sweating.

Analysis 2.16. Comparison 2 Adverse events, Outcome 16 Vomiting.

Analysis 2.17. Comparison 2 Adverse events, Outcome 17 Discontinuation due to adverse events. ADDITIONAL TABLES

APPENDICES

WHAT'S NEW

HISTORY

CONTRIBUTIONS OF AUTHORS

DECLARATIONS OF INTEREST

DIFFERENCES BETWEEN PROTOCOL AND REVIEW

NOTES

INDEX TERMS 
[Intervention Review]

\section{Oxycodone for cancer-related pain}

Mia Schmidt-Hansen ${ }^{1}$, Michael I Bennett ${ }^{2}$, Stephanie Arnold ${ }^{3}$, Nathan Bromham ${ }^{1}$, Jennifer S Hilgart ${ }^{4}$

1National Guideline Alliance, Royal College of Obstetricians and Gynaecologists, London, UK. 2Leeds Institute of Health Sciences, University of Leeds, Leeds, UK. ${ }^{3}$ Royal College of Obstetricians and Gynaecologists, London, UK. ${ }^{4}$ National Collaborating Centre for Cancer, Cardiff, UK

Contact address: Mia Schmidt-Hansen, National Guideline Alliance, Royal College of Obstetricians and Gynaecologists, 27 Sussex Pl, Regent's Park, London, NW1 4RG, UK. sapms@cf.ac.uk.

Editorial group: Cochrane Pain, Palliative and Supportive Care Group.

Publication status and date: Stable (no update expected for reasons given in 'What's new'), published in Issue 3, 2019.

Citation: Schmidt-Hansen M, Bennett MI, Arnold S, Bromham N, Hilgart JS. Oxycodone for cancer-related pain. Cochrane Database of Systematic Reviews 2017, Issue 8. Art. No.: CD003870. DOI: 10.1002/14651858.CD003870.pub6.

Copyright ( 2019 The Cochrane Collaboration. Published by John Wiley \& Sons, Ltd.

\section{A B S T R A C T}

\section{Background}

Many people with cancer experience moderate to severe pain that requires treatment with strong opioids, such as oxycodone and morphine. Strong opioids are, however, not effective for pain in all people, neither are they well-tolerated by all people. The aim of this review was to assess whether oxycodone is associated with better pain relief and tolerability than other analgesic options for adults with cancer pain. This is an updated version of the original Cochrane review published in 2015, Issue 2 on oxycodone for cancer-related pain.

\section{Objectives}

To assess the effectiveness and tolerability of oxycodone by any route of administration for pain in adults with cancer.

\section{Search methods}

For this update, we searched the Cochrane Central Register of Controlled Trials (CENTRAL) in the Cochrane Library, MEDLINE and MEDLINE In-Process (Ovid), Embase (Ovid), Science Citation Index, Conference Proceedings Citation Index - Science (ISI Web of Science), BIOSIS (ISI), and PsycINFO (Ovid) to November 2016. We also searched four trial registries, checked the bibliographic references of relevant studies, and contacted the authors of the included studies. We applied no language, date, or publication status restrictions.

\section{Selection criteria}

We included randomised controlled trials (parallel group or cross-over) comparing oxycodone (any formulation or route of administration) with placebo or an active drug (including oxycodone) for cancer background pain in adults by examining pain intensity/relief, adverse events, quality of life, and participant preference.

\section{Data collection and analysis}

Two review authors independently extracted data and assessed the included studies using standard Cochrane methodology. We metaanalysed pain intensity data using the generic inverse variance method, and adverse events using the Mantel-Haenszel method, or summarised these data narratively along with the quality of life and participant preference data. We assessed the overall quality of the evidence using GRADE.

\section{Main results}

For this update, we identified six new studies (1258 participants) for inclusion. In total, we included 23 studies which enrolled/randomised 2648 participants, with 2144 of these analysed for efficacy and 2363 for safety. The studies examined a number of different drug comparisons. 
Pooled analysis of three of the four studies comparing controlled-release (CR) oxycodone to immediate-release (IR) oxycodone showed that the ability of CR and IR oxycodone to provide pain relief were similar (standardised mean difference (SMD) $0.1,95 \%$ confidence interval (CI) -0.06 to 0.26 ; low quality evidence). Pooled analyses of adverse events showed no significant differences between CR and IR oxycodone for asthenia (risk ratio (RR) $0.58,95 \% \mathrm{Cl} 0.2$ to 1.68 ), confusion (RR $0.78,95 \% \mathrm{Cl} 0.2$ to 3.02), constipation ( $\mathrm{RR} 0.71,95 \% \mathrm{Cl} 0.45$ to 1.13 ), dizziness/lightheadedness (RR $0.74,95 \% \mathrm{Cl} 0.4$ to 1.37 ), drowsiness/somnolence (RR $1.03,95 \% \mathrm{Cl} 0.69$ to 1.54 ), dry mouth (RR $1.14,95 \%$ $\mathrm{Cl} 0.48$ to 2.75), insomnia (RR $1.04,95 \% \mathrm{Cl} 0.31$ to 3.53 ), nausea (RR $0.85,95 \% \mathrm{Cl} 0.56$ to 1.28 ), nervousness ( $\mathrm{RR} 0.57,95 \% \mathrm{Cl} 0.2$ to 1.64 ), pruritus ( $\mathrm{RR} 1.46,95 \% \mathrm{Cl} 0.65$ to 3.25), vomiting (RR $0.66,95 \% \mathrm{Cl} 0.38$ to 1.15 ), and discontinuation due to adverse events (RR $0.6,95 \%$ $\mathrm{Cl} 0.29$ to 1.22). The quality of the evidence was very low for all these adverse events. Three of the four studies found similar results for treatment acceptability.

Pooled analysis of seven of the nine studies comparing CR oxycodone to CR morphine indicated that pain relief was significantly better after treatment with CR morphine than CR oxycodone (SMD $0.14,95 \% \mathrm{Cl} 0.01$ to 0.27 ; low quality evidence). However, sensitivity analysis did not corroborate this result (SMD $0.12,95 \% \mathrm{Cl}-0.02$ to 0.26$)$.

Pooled analyses of adverse events showed no significant differences between CR oxycodone and CR morphine for confusion (RR $1.0195 \% \mathrm{Cl}$ 0.78 to 1.31 ), constipation ( $R R 0.98,95 \% \mathrm{Cl} 0.82$ to 1.16 ), dizziness/lightheadedness (RR $0.76,95 \% \mathrm{Cl} 0.33$ to 1.76 ), drowsiness/somnolence (RR $0.9,95 \% \mathrm{Cl} 0.75$ to 1.08 ), dry mouth (RR $1.01,95 \% \mathrm{Cl} 0.8$ to 1.26 ), dysuria (RR $0.71,95 \% \mathrm{Cl} 0.4$ to 1.26 ), nausea ( $\mathrm{RR} 1.02,95 \% \mathrm{Cl} 0.82$ to 1.26), pruritus ( $\mathrm{RR} 0.81,95 \% \mathrm{Cl} 0.51$ to 1.29 ), vomiting (RR $0.94,95 \% \mathrm{Cl} 0.68$ to 1.29 ), and discontinuation due to adverse events (RR 1.06 , $95 \% \mathrm{Cl} 0.43$ to 2.6$)$. However, the RR for hallucinations was significantly lower after treatment with CR oxycodone compared to CR morphine (RR $0.52,95 \% \mathrm{Cl} 0.28$ to 0.97 ). The quality of the evidence was very low for all these adverse events. There were no marked differences in treatment acceptability or quality of life ratings.

The remaining studies either compared oxycodone in various formulations or compared oxycodone to different alternative opioids. None found any clear superiority or inferiority of oxycodone for cancer pain, neither as an analgesic agent nor in terms of adverse event rates and treatment acceptability.

The quality of this evidence base was limited by the high or unclear risk of bias of the studies and by imprecision due to low or very low event rates or participant numbers for many outcomes.

\section{Authors' conclusions}

The conclusions have not changed since the previous version of this review. The data suggest that oxycodone offers similar levels of pain relief and overall adverse events to other strong opioids including morphine. Although we identified a clinically insignificant benefit on pain relief in favour of CR morphine over CR oxycodone, this did not persist following sensitivity analysis and so we do not consider this important. However, in this updated analysis, we found that hallucinations occurred less often with CR oxycodone than with CR morphine, but the quality of this evidence was very low so this finding should be treated with utmost caution. Our conclusions are consistent with other reviews and suggest that while the reliability of the evidence base is low, given the absence of important differences within this analysis it seems unlikely that larger head to head studies of oxycodone versus morphine are justified, although well-designed trials comparing oxycodone to other strong analgesics may well be useful. For clinical purposes, oxycodone or morphine can be used as firstline oral opioids for relief of cancer pain in adults.

\section{PLAIN LANGUAGE SUMMARY}

\section{Oxycodone for cancer-related pain in adults}

\section{Background}

Many people with cancer experience moderate to severe pain that requires treatment with strong painkillers that are classified as opioids.

Oxycodone and morphine are examples of these opioids that are used for the relief of cancer pain. However, strong painkillers are not effective for pain in all people neither are they well-tolerated by all people. The aim of this review was to assess whether oxycodone is associated with better pain relief and tolerability than other strong painkillers for adults with cancer pain.

\section{Study characteristics}

For this update, in November 2016, we found six more relevant studies. In total, we included 23 studies with 2648 participants. These studies compared the painkilling ability (benefit) and side effects (harms) of different types of oxycodone to each other or to other strong painkillers.

\section{Key results}

Generally, the studies showed that oxycodone is an equally effective strong painkiller whether taken every six or every 12 hours, and equally effective as other strong pain killers, such as morphine. 
All the strong painkillers examined in the studies were also associated with a number of unwanted effects, such as vomiting, constipation, and drowsiness. Overall, these do not differ between oxycodone and the other strong painkillers. Hallucinations (where people experience imaginary things, e.g. hearing voices) are much less common as a side effect but we found that they were less likely with oxycodone than within morphine.

Overall, we found that the current evidence is comprised of studies that contained small numbers of participants of which many (19\%) did not complete the studies. However, since there was very little difference between oxycodone and morphine, more research in this area is unlikely. Studies looking at oxycodone compared to other strong pain killers may be useful.

\section{Quality of the evidence}

We rated the quality of the evidence from studies using four levels: very low, low, moderate, or high. Very low quality evidence means that we are very uncertain about the results. High quality evidence means that we are very confident in the results. Overall the quality of the evidence was low or very low, downgraded because of issues with study quality and size. 


\section{SUMMARY OF FINDINGS}

\section{Summary of findings for the main comparison. CR oxycodone compared with IR oxycodone for cancer-related pain in adults}

CR oxycodone compared with IR oxycodone for cancer-related pain in adults

Patient or population: adults with cancer-related pain

Settings: in- or outpatients

Intervention: CR oxycodone

Comparison: IR oxycodone

\begin{tabular}{|c|c|c|c|c|c|c|}
\hline \multirow[t]{3}{*}{ Outcomes } & \multicolumn{2}{|c|}{ Illustrative comparative risks ${ }^{\star}(95 \% \mathrm{Cl})$} & \multirow{3}{*}{$\begin{array}{l}\text { Relative effect } \\
(95 \% \mathrm{CI})\end{array}$} & \multirow{3}{*}{$\begin{array}{l}\text { No of partici- } \\
\text { pants } \\
\text { (studies) }\end{array}$} & \multirow{3}{*}{$\begin{array}{l}\text { Quality of the } \\
\text { evidence } \\
\text { (GRADE) }\end{array}$} & \multirow[t]{3}{*}{ Comments } \\
\hline & Assumed risk & Corresponding risk & & & & \\
\hline & IR oxycodone & CR oxycodone & & & & \\
\hline $\begin{array}{l}\text { Pain intensity } \\
\text { (various pain intensi- } \\
\text { ty scales; SMD) }\end{array}$ & \multicolumn{2}{|c|}{$\begin{array}{l}\text { The mean pain intensity in the CR oxycodone group was } \\
\mathbf{0 . 1} \text { standard deviations higher ( } 0.06 \text { lower to } 0.26 \text { higher) than } \\
\text { in the IR oxycodone group }\end{array}$} & $\begin{array}{l}\text { SMD } 0.1(-0.06 \text { to } \\
0.26)\end{array}$ & $\begin{array}{l}578 \\
\text { (3 studies) }\end{array}$ & $\begin{array}{l}\oplus \oplus \odot \odot \\
\text { low } 1\end{array}$ & - \\
\hline $\begin{array}{l}\text { Constipation } \\
\text { (Event rate) }\end{array}$ & 224 per 1000 & $\begin{array}{l}\mathbf{1 5 9} \text { per } \mathbf{1 0 0 0} \\
\text { (101 to } 253)\end{array}$ & $\begin{array}{l}\text { RR } \mathbf{0 . 7 1} \\
\text { (0.45 to } 1.13)\end{array}$ & $\begin{array}{l}317 \\
\text { (3 studies) }\end{array}$ & $\begin{array}{l}\oplus \ominus \ominus \ominus \\
\text { very low } 2,3\end{array}$ & - \\
\hline $\begin{array}{l}\text { Drowsiness/somno- } \\
\text { lence } \\
\text { (Event rate) }\end{array}$ & 224 per 1000 & $\begin{array}{l}\mathbf{2 3 0} \text { per } 1000 \\
\text { (154 to } 344)\end{array}$ & $\begin{array}{l}\text { RR } 1.03 \\
\text { (0.69 to } 1.54)\end{array}$ & $\begin{array}{l}317 \\
\text { (3 studies) }\end{array}$ & $\begin{array}{l}\oplus \odot \ominus \ominus \\
\text { very low } 2,3\end{array}$ & - \\
\hline $\begin{array}{l}\text { Vomiting } \\
\text { (Event rate) }\end{array}$ & 174 per 1000 & $\begin{array}{l}115 \text { per } 1000 \\
\text { (66 to } 200)\end{array}$ & $\begin{array}{l}\text { RR } \mathbf{0 . 6 6} \\
(0.38 \text { to } 1.15)\end{array}$ & $\begin{array}{l}317 \\
\text { (3 studies) }\end{array}$ & $\begin{array}{l}\oplus \ominus \ominus \ominus \\
\text { very low } 2,3\end{array}$ & - \\
\hline Quality of life & $\begin{array}{l}\text { No data availa } \\
\text { not pooled); } 57\end{array}$ & $\begin{array}{l}\text { e appeared to be no differences in tre } \\
\text { tts ( } 3 \text { studies); quality of the evidence }\end{array}$ & $\begin{array}{l}\text { ent acceptability } \\
\text {. } 1\end{array}$ & en the treatme & oups (measure & various sca \\
\hline
\end{tabular}


${ }^{*}$ The assumed risk is reported as the observed risk in the control group across studies. The corresponding risk (and its $95 \%$ confidence interval) is based on the assumed risk in the comparison group and the relative effect of the intervention (and its $95 \% \mathrm{Cl}$ ).

CI: confidence interval; CR: controlled release; IR: immediate-release; RR: risk ratio; SMD: standardised mean difference.

GRADE Working Group grades of evidence

High quality: we are very confident that the true effect lies close to that of the estimate of the effect.

Moderate quality: we are moderately confident in the effect estimate; the true effect is likely to be close to the estimate of effect, but there is a possibility that it is substantially different.

Low quality: our confidence in the effect estimate is limited; the true effect may be substantially different from the estimate of the effect.

Very low quality: we have very little confidence in the effect estimate; the true effect is likely to be substantially different from the estimate of effect.

${ }^{1}$ Downgraded twice for very serious limitations to study quality due to risk of bias (attrition bias and under-reporting of the domain of selection bias).

2 Downgraded twice for imprecision due to very low event rates.

3 Downgraded twice for very serious limitations to study quality due to risk of bias (performance/detection bias, and inadequate titration and under-reporting of the domains of selection, performance, detection and attrition bias, and whether the participants were adequately titrated).

\section{Summary of findings 2. CR oxycodone compared with CR morphine for cancer-related pain in adults}

\section{CR oxycodone compared with CR morphine for cancer-related pain in adults}

Patient or population: adults with cancer-related pain

Settings: in- or outpatients

Intervention: CR oxycodone

Comparison: CR morphine

\begin{tabular}{|c|c|c|c|c|c|c|}
\hline \multirow[t]{3}{*}{ Outcomes } & \multicolumn{2}{|c|}{ Illustrative comparative risks* $(95 \% \mathrm{CI})$} & \multirow{3}{*}{$\begin{array}{l}\text { Relative effect } \\
(95 \% \mathrm{CI})\end{array}$} & \multirow{3}{*}{$\begin{array}{l}\text { No of Partici- } \\
\text { pants } \\
\text { (studies) }\end{array}$} & \multirow{3}{*}{$\begin{array}{l}\text { Quality of the } \\
\text { evidence } \\
\text { (GRADE) }\end{array}$} & \multirow[t]{3}{*}{ Comments } \\
\hline & Assumed risk & Corresponding risk & & & & \\
\hline & CR morphine & CR oxycodone & & & & \\
\hline Pain intensity & $\begin{array}{l}\text { The mean pain } \\
\text { dard deviatior }\end{array}$ & $\begin{array}{l}\text { e CR oxycodone group was } \mathbf{0 . 1 4} \text { stan- } \\
\text { lower to } 0.27 \text { higher) than in the CR }\end{array}$ & $\begin{array}{l}\text { SMD } 0.14 \text { (0.01 to } \\
0.27 \text { ) }\end{array}$ & $\begin{array}{l}882 \\
\text { (7 studies) }\end{array}$ & $\begin{array}{l}\oplus \oplus \ominus \ominus \\
\text { low }{ }^{1}\end{array}$ & - \\
\hline
\end{tabular}




\begin{tabular}{|c|c|c|c|c|c|c|}
\hline $\begin{array}{l}\text { (various pain inten- } \\
\text { sity scales; SMD) }\end{array}$ & & & & & & \\
\hline $\begin{array}{l}\text { Constipation } \\
\text { (Event rate) }\end{array}$ & 355 per 1000 & $\begin{array}{l}348 \text { per } \mathbf{1 0 0 0} \\
\text { (291 to } 412 \text { ) }\end{array}$ & $\begin{array}{l}\mathbf{R R} 0.98 \\
(0.82 \text { to } 1.16)\end{array}$ & $\begin{array}{l}797 \\
\text { (5 studies) }\end{array}$ & $\begin{array}{l}\oplus \ominus \ominus \ominus \\
\text { very low } 2,4\end{array}$ & - \\
\hline $\begin{array}{l}\text { Drowsiness/som- } \\
\text { nolence } \\
\text { (Event rate) }\end{array}$ & 337 per 1000 & $\begin{array}{l}\mathbf{3 0 3} \text { per } \mathbf{1 0 0 0} \\
\text { (253 to } 364)\end{array}$ & $\begin{array}{l}\text { RR } 0.9 \\
\text { (0.75 to } 1.08)\end{array}$ & $\begin{array}{l}798 \\
\text { (5 studies) }\end{array}$ & $\begin{array}{l}\oplus \ominus \ominus \ominus \\
\text { very low } 2,4\end{array}$ & - \\
\hline $\begin{array}{l}\text { Nausea } \\
\text { (Event rate) }\end{array}$ & 266 per 1000 & $\begin{array}{l}\mathbf{2 7 2} \text { per } \mathbf{1 0 0 0} \\
\text { (218 to } 336)\end{array}$ & $\begin{array}{l}\text { RR } 1.02 \\
\text { (0.82 to } 1.26)\end{array}$ & $\begin{array}{l}798 \\
\text { (5 studies) }\end{array}$ & $\begin{array}{l}\oplus \ominus \ominus \ominus \\
\text { very low } 2,4\end{array}$ & - \\
\hline $\begin{array}{l}\text { Vomiting } \\
\text { (Event rate) }\end{array}$ & 161 per 1000 & $\begin{array}{l}151 \text { per } 1000 \\
(109 \text { to } 207)\end{array}$ & $\begin{array}{l}\mathbf{R R} \mathbf{0 . 9 4} \\
(0.68 \text { to } 1.29)\end{array}$ & $\begin{array}{l}798 \\
\text { ( } 5 \text { studies) }\end{array}$ & $\begin{array}{l}\oplus \odot \odot \ominus \\
\text { very low } 3,4\end{array}$ & - \\
\hline Quality of life & $\begin{array}{l}\text { No data availa } \\
\text { (measured on }\end{array}$ & $\begin{array}{l}\text { codone appears to be associated with } \\
\text { not pooled); } 149 \text { participants ( } 3 \text { studie }\end{array}$ & $\begin{array}{l}\text { imilar or lower } t \\
\text {; quality of the }\end{array}$ & $\begin{array}{l}\text { nt acceptabi } \\
\text { e very low. }\end{array}$ & an CR morphine & - \\
\hline $\begin{array}{l}\text { Participant prefer- } \\
\text { ence }\end{array}$ & $\begin{array}{l}8 / 23 \text { participar } \\
\text { preferred treat }\end{array}$ & $\begin{array}{l}\text { R oxycodone while } 11 / 23 \text { participants } \\
\text { morphine (non-significant difference). }\end{array}$ & - & $\begin{array}{l}23 \\
\text { (1 study) }\end{array}$ & $\begin{array}{l}\oplus \odot \ominus \ominus \\
\text { very low } 3,5\end{array}$ & - \\
\hline
\end{tabular}

*The assumed risk is reported as the observed risk in the control group across studies. The corresponding risk (and its $95 \%$ confidence interval) is based on the assumed risk in the comparison group and the relative effect of the intervention (and its $95 \% \mathrm{Cl}$ ).

CI: confidence interval; CR: controlled release; RR: risk ratio; SMD: standardised mean difference.

GRADE Working Group grades of evidence

High quality: we are very confident that the true effect lies close to that of the estimate of the effect.

Moderate quality: we are moderately confident in the effect estimate; the true effect is likely to be close to the estimate of effect, but there is a possibility that it is substantially different.

Low quality: our confidence in the effect estimate is limited; the true effect may be substantially different from the estimate of the effect.

Very low quality: we have very little confidence in the effect estimate; the true effect is likely to be substantially different from the estimate of effect.

1 Downgraded twice for very serious limitations to study quality due to risk of bias (performance/detection bias and attrition bias and under-reporting of the domain of selection bias).

2 Downgraded once for imprecision due to low event rates/participant numbers.

$a$

3 Downgraded twice for imprecision due to very low event rates/participant numbers. 
Downgraded twice for very serious limitations to study quality due to risk of bias (attrition bias and under-reporting of the domain of selection bias) 


\section{B A C K G R O U N D}

This review is an update of a previously published review in The Cochrane Database of Systematic Reviews, 2015, Issue 2 on oxycodone for cancer-related pain.

\section{Description of the condition}

Pain from cancer can be caused by direct invasion of a tumour into soft tissue or bone and is often a presenting symptom at the time of diagnosis of cancer. One European survey published in 2009 found that, of 5000 people with cancer (including 617 communitybased National Health Service (NHS) patients in the UK), 72\% experienced pain (77\% of UK patients) which was of moderate to severe intensity in $90 \%$ of this group (Breivik 2009). This is consistent with a systematic review that demonstrated cancer pain prevalence of up to $75 \%$ in advanced disease, and that at least $30 \%$ of people with cancer are undertreated (Greco 2014). Recent research has also shown that less than half of all people with cancer that die are prescribed a strong opioid, and that median treatment duration is only nine weeks before death (Ziegler 2016). Pain in people with cancer may also be caused by cancer treatments and by comorbid conditions. In this review, we define cancer pain as pain arising as a direct consequence of the cancer, and not from other aetiologies.

\section{Description of the intervention}

Oxycodone is a strong opioid analgesic indicated for the treatment of moderate to severe chronic pain, including cancer pain. It is available orally as immediate-release (IR) solution and tablets (for four-hourly dosing) and as sustained (controlled (CR)) release tablets (for 12-hourly dosing). It is also available as a parenteral injection. In some countries, oxycodone is available as a compound with paracetamol (acetaminophen) or ibuprofen.

\section{How the intervention might work}

Oxycodone works primarily as an agonist of mu-opioid receptors in the spinal cord and brain. It has some activity at kappaopioid receptors (which are also involved in nociception or analgesia) though the importance of this mechanism in the overall analgesic effect of oxycodone is unclear. Despite animal studies suggesting differences in pharmacodynamics, these have not been demonstrated in clinical studies to date. Therefore, the shared mechanism of action to other strong opioids (i.e. agonist activity at mu-opioid receptors) means that clinical benefits and adverse effects are likely to be similar. However, important differences exist in the pharmacokinetics of strong opioids (e.g. morphine undergoes second-phase elimination via glucuronidation, while oxycodone undergoes extensive first-phase metabolism via CYP2D6 and CYP3A4 pathways) so clinical equivalence cannot be inferred (Gudin 2012; Leppert 2010).

\section{Why it is important to do this review}

The World Health Organization (WHO) published the Method for Cancer Pain Relief (WHO analgesic ladder) in 1986 (WHO 1986), which advocates a stepwise approach to analgesia for cancer pain and revolutionised the use of oral opioids. It recommended that morphine be used first line for moderate to severe cancer pain. Observational studies have suggested that this approach results in pain control for $73 \%$ of people (Bennett 2008) with a mean reduction in pain intensity of $65 \%$ (Ventafridda 1987).
Many people with cancer experience moderate to severe pain that requires treatment with strong analgesics. Oxycodone and morphine are examples of strong opioids that are used for the relief of cancer pain. However, strong opioids are not effective for pain in all people, neither are they well tolerated by all people. Guidance by the European Association for Palliative Care on the use of opioids in cancer pain suggests that oxycodone could be used as first-line treatment of moderate to severe cancer pain as an alternative to morphine (Caraceni 2012). The aim of this review is to assess whether oxycodone is associated with better pain relief and tolerability than other analgesic options for people with cancer pain. The protocol for this review was updated from Reid 2010.

\section{OB JECTIVES}

To assess the effectiveness and tolerability of oxycodone by any route of administration for pain in adults with cancer.

\section{METHODS}

\section{Criteria for considering studies for this review \\ Types of studies}

Randomised controlled trials (RCTs), with parallel-group or crossover design, comparing oxycodone (any formulation and any route of administration) with placebo or an active drug (including oxycodone) for cancer background pain. We did not examine studies on breakthrough pain.

\section{Types of participants}

Adults (aged $\geq 18$ years) with cancer pain.

\section{Types of interventions}

Oxycodone (any dose, formulation, and route of administration) versus oxycodone (any dose, formulation, and route of administration).

Oxycodone (any dose, formulation, and route of administration) versus other active drug (any dose, formulation, and route of administration).

Oxycodone (any dose, formulation, and route of administration) versus placebo.

\section{Types of outcome measures}

\section{Primary outcomes}

- Pain intensity and pain relief, which we have treated as measures of essentially the same thing, albeit from opposite starting points (i.e. effectiveness is demonstrated by pain intensity going down and by pain relief going up). The majority of the included studies reported pain intensity, with much fewer studies reporting pain relief. We therefore meta-analysed pain intensity (see also Measures of treatment effect; Data synthesis) and not pain relief, but also reported narratively any analyses of pain relief reported by the included studies.

Both these outcomes had to be participant-reported and could be reported in any transparent manner (e.g. by using numerical or verbal rating scales). We did not consider these outcomes when reported by physicians, nurses, or carers. If possible, we aimed 
to distinguish between nociceptive and neuropathic pain, but the data were not presented in a manner that made this possible.

\section{Secondary outcomes}

- Adverse events (e.g. constipation, nausea, vomiting, drowsiness, confusion, respiratory depression).

- Quality of life (or treatment acceptability as a proxy).

- Participant preference.

We considered all these outcomes as they were reported in the included studies.

\section{Search methods for identification of studies}

We applied no language, date, or publication status (published in full, published as abstract, unpublished) restrictions to the search.

\section{Electronic searches}

For this update, we identified relevant trials by searching the following databases:

- Cochrane Central Register of Controlled Trials (CENTRAL) in the Cochrane Library (Issue 10 of 12, 2016);

- MEDLINE and MEDLINE In-Process (Ovid) (1946 to 29 November 2016);

- Embase (Ovid) (1947 to 29 November 2016);

- Science Citation Index (Web of Science) (1899 to 29 November 2016);

- Conference Proceedings Citation Index - Science (Web of Science) (1990 to 29 November 2016);

- BIOSIS (Web of Science) (1926 to 29 November 2016);

- PsycINFO (Ovid) (1806 to November week 3 2016).

We applied the Cochrane highly sensitive search strategy for identifying RCTs to this search (Lefebvre 2011). These searches were run for the original review in March 2014 when PubMed was also searched. We did not search PubMed for this update as it did not yield any records that were not found by the other databases in the original review. The search strategies used can be found in Appendix 1.

\section{Searching other resources}

We also searched Clinicaltrials.gov (13 March 2014), metaRegister of Controlled Trials (mRCT) (3 March 2014), EU Clinical Trials Register (3 March 2014), and WHO International Clinical Trials Registry Platform (ICTRP) (3 March 2014) as complementary sources for related studies. In an update search run on 6 December 2016, we searched Clinicaltrials.gov, EU Clinical Trials Register, WHO International Clinical Trials Registry Platform (ICTRP), and UK Clinical Trials Gateway (UKCTG), but not metaRegister of Controlled Trials (mRCT) as this is no longer available, but rather signposted to EU Clinical Trials Register and UK Clinical Trials Gateway (UKCTG). For both the previous review and the update, we checked the bibliographic references of relevant identified studies to find additional trials not identified by the electronic searches and contacted authors of the included studies to ask if they knew of any other relevant studies.

\section{Data collection and analysis}

\section{Selection of studies}

Two review authors (MSH, NB) assessed the titles and abstracts of all the studies identified by the search for potential inclusion. We independently considered the full records of all potentially relevant studies for inclusion by applying the selection criteria outlined in the Criteria for considering studies for this review section. We resolved any disagreements by discussion. We did not restrict the inclusion criteria by date, language, or publication status (published in full, published as abstract, unpublished).

\section{Data extraction and management}

Using a standardised data extraction form, two review authors (MSH, JSH) extracted data pertaining to study design, participant details (including age, cancer characteristics, previous analgesic medication, and setting), interventions (including details about titration), and outcomes. We resolved any disagreements by discussion. If there were studies for which only a subgroup of the participants met the inclusion criteria for the current review, we would have only extracted data on this subgroup provided randomisation had not been broken; however, no such studies were identified for inclusion.

\section{Assessment of risk of bias in included studies}

Two review authors (MSH and JSH or NB) independently assessed the methodological quality of each of the included studies by using the 'Risk of bias' assessment method outlined in the Cochrane Handbook for Systematic Reviews of Interventions (Higgins 2011). For each study, we assessed the risk of bias for the following domains: selection bias (study level; two items; random sequence generation and allocation concealment), performance bias (outcome level; two items; blinding of participants and blinding of treating personnel), detection bias (outcome level; one item; blinding of outcome assessment), attrition bias (outcome level; one item; incomplete outcome data), and reporting bias (study level; one item; selective reporting). For the question on allocation concealment, in the absence of explicit explanation about allocation concealment, we accepted 'central randomisation' as sufficient indication of adequate allocation concealment and consequently rated such studies as low risk of bias for this item. We also included an item that assessed the adequacy of titration (with judgements made based on any available relevant information, including design features, inclusion criteria, and interim pain assessments) and another item that captured whether data were available for both time periods in cross-over trials. Each of the 'Risk of bias' items required a 'low risk,' 'high risk,' or 'unclear risk' response. We also documented the reasons for each response in accordance with Higgins 2011, and resolved any disagreements on the 'Risk of bias' ratings through discussion. For the item assessing whether data were available for both time periods in cross-over trials, we inputted 'unclear' and 'not applicable' as the rating and reason for parallel-group trials.

\section{Measures of treatment effect}

For pain intensity, we extracted the means and standard deviations (SD) and we used these to estimate the standardised mean difference (SMD) between the treatments along with the 95\% confidence interval $(\mathrm{Cl})$, as the outcome was not measured on the same scale across studies. For adverse events, we extracted event 
rates to calculate risk ratios (RR) with $95 \% \mathrm{Cls}$ as the summary estimates (see also Data synthesis).

\section{Unit of analysis issues}

The participant was the unit of analysis, but in a number of cases the data reported in the included cross-over trials could not otherwise be incorporated into the analyses (see Dealing with missing data), so we included them as if the design had been parallel-group. Higgins 2011 (in Chapter 16) pointed out that this approach, while giving rise to unit of analysis error, is nevertheless conservative as it results in an underweighting of the data. However, in order to assess the impact of this strategy, we also performed sensitivity analyses when we included cross-over trial data in this manner by excluding the cross-over trials from the meta-analyses.

\section{Dealing with missing data}

In cases where data were missing, we contacted the authors to request the missing data. This strategy did not result in any additional data. We limited imputation of missing data to the imputation of missing SDs, either by calculating the SD if enough information was available or by using SDs from similar samples or studies, both according to the methods outlined by Higgins 2011. We only imputed SDs for pain intensity for Lux 2014, which were not reported for the subgroup of participants with malignant pain, by using the reported SDs for the whole sample of participants with either malignant $(n=31)$ or non-malignant pain $(n=15)$, and for Yu 2014 for the primary outcome of the study "mean pain at its worst in the past 24 hours" by using the standard deviations for the same outcome measured at baseline in the full analysis set. We recorded the dropout/missing data rates in the 'Risk of bias' tables under the items on attrition bias and in the 'Participants' section of the Characteristics of included studies table, and we addressed the potential effect of the missing data on the results in the Discussion. It was not possible to assess the impact of missing data in sensitivity analyses due to the low number of included studies within each comparison. In all cases, we aimed to perform intention-to-treat (ITT) analyses.

\section{Assessment of heterogeneity}

We assessed heterogeneity by using the $\mathrm{I}^{2}$ statistic. We considered 12 values above $50 \%$ to represent substantial heterogeneity in line with Higgins 2011, and we planned to assess potential sources of heterogeneity through subgroup analyses as outlined in Subgroup analysis and investigation of heterogeneity.

\section{Assessment of reporting biases}

In addition to implementing the comprehensive search strategy outlined in the Search methods for identification of studies section, the risk of outcome reporting bias was illustrated in the 'Risk of bias' summary figures that we constructed for each study and each type of assessed bias.

\section{Data synthesis}

We entered the data extracted from the included studies into Review Manager 5 (RevMan 2014), which was used for data synthesis. We analysed pain intensity using the generic inverse variance method in accordance with Higgins 2011. As the $\mathrm{I}^{2}$ statistic was not above $50 \%$, we used a fixed-effect model. However, given the limitations of this analysis strategy as outlined in the Unit of analysis issues section, we also considered the results of the individual studies. We meta-analysed the adverse events data by using the Mantel-Haenszel method; however, as this method is not suitable for cross-over trial data, we only included the data from parallel-group trials in these analyses. In addition, we have also presented all reported adverse events from the included studies in tables.

\section{Quality of the evidence}

We used the GRADE system to rank the quality of the evidence using the GRADEprofiler Guideline Development Tool software (GRADEpro GDT 2015), and the guidelines provided in Chapter 12.2 of the Cochrane Handbook for Systematic Reviews of Interventions (Higgins 2011).

The GRADE approach uses five considerations (study limitations, consistency of effect, imprecision, indirectness, and publication bias) to assess the quality of the body of evidence for each outcome. The GRADE system uses the following criteria for assigning grade of evidence:

- high: we are very confident that the true effect lies close to that of the estimate of the effect;

- moderate: we are moderately confident in the effect estimate; the true effect is likely to be close to the estimate of effect, but there is a possibility that it is substantially different;

- low: our confidence in the effect estimate is limited; the true effect may be substantially different from the estimate of the effect;

- very low: we have very little confidence in the effect estimate; the true effect is likely to be substantially different from the estimate of effect.

We decreased the grade rating by one (-1) or two (-2) if we identified:

- serious (-1) or very serious (-2) limitation to study quality;

- important inconsistency $(-1)$;

- some (-1) or major (-2) uncertainty about directness;

- imprecise (-1) or very imprecise data (-2);

- high probability of reporting bias (-1).

\section{'Summary of findings' tables}

We included two 'Summary of findings' tables to present the main findings in a transparent and simple tabular format. In particular, we included key information concerning the quality of evidence, the magnitude of effect of the interventions examined, and the sum of available data on the outcomes pain intensity, adverse events (constipation, drowsiness/somnolence, nausea, and vomiting), quality of life (or treatment acceptability as a proxy) and participant preference.

\section{Subgroup analysis and investigation of heterogeneity}

Different aspects of the trials are likely to contribute heterogeneity to the proposed main analyses. If there were sufficient data, we therefore planned to perform subgroup analyses based on doses, titration, formulations (e.g. IR, sustained-release), routes of administration (e.g. oral, rectal), length of the trials, and populations (e.g. opioid-naive participants). We grouped the studies by formulation and route of administration, but as there 
were insufficient data, we were unable to perform any further subgroup analyses.

\section{Sensitivity analysis}

If sufficient data had been available, we planned to examine the robustness of the meta-analyses by conducting sensitivity analyses using different components of the 'Risk of bias' assessment, particularly those relating to whether allocation concealment and blinding were adequate. We also planned to conduct further sensitivity analyses to examine the impact of missing data on the results if a large proportion of the studies were at an 'unknown' or 'high risk' of attrition bias and, finally, we planned to use sensitivity analyses to examine whether publication status and trial size influenced the results. Unfortunately, we were unable to perform any such sensitivity analyses due to the low number of studies within each comparison.

\section{RESULTS}

\section{Description of studies}

\section{Results of the search}

The updated searches of the electronic databases retrieved 345 records (see Electronic searches). Our searches of the trials registers identified 23 further studies. Our screening of the reference lists of the included publications did not reveal any additional RCTs. We therefore had a total of 368 records.

Once duplicates had been removed, we had 267 records. We excluded 257 records based on titles and abstracts. We obtained the full text of the remaining 10 records. We excluded five studies for this update (see Characteristics of excluded studies table). We did not identify any ongoing studies for this update.

From the search, we included five studies reported in five references (Corli 2016; Lux 2014; Su 2015; Yu 2014; Zhang 2014), of which three had originally been included under 'ongoing studies.' Another of the ongoing studies was published in full after the update search, but before the publication of the updated review, and we also included this study (Zecca 2016), so in total there were six new studies. For a further description of our screening process, see the study flow diagram (Figure 1). 
Figure 1. Study flow diagram. PICO: $\mathrm{P}=$ patient, problem, or population; $\mathrm{I}=$ intervention; $\mathrm{C}=$ comparison, control, or comparator; $0=$ outcome.

17 studies (22 records)
included in previous review of
which 7 studies ( 10 records)
were included in quantitative
synthesis

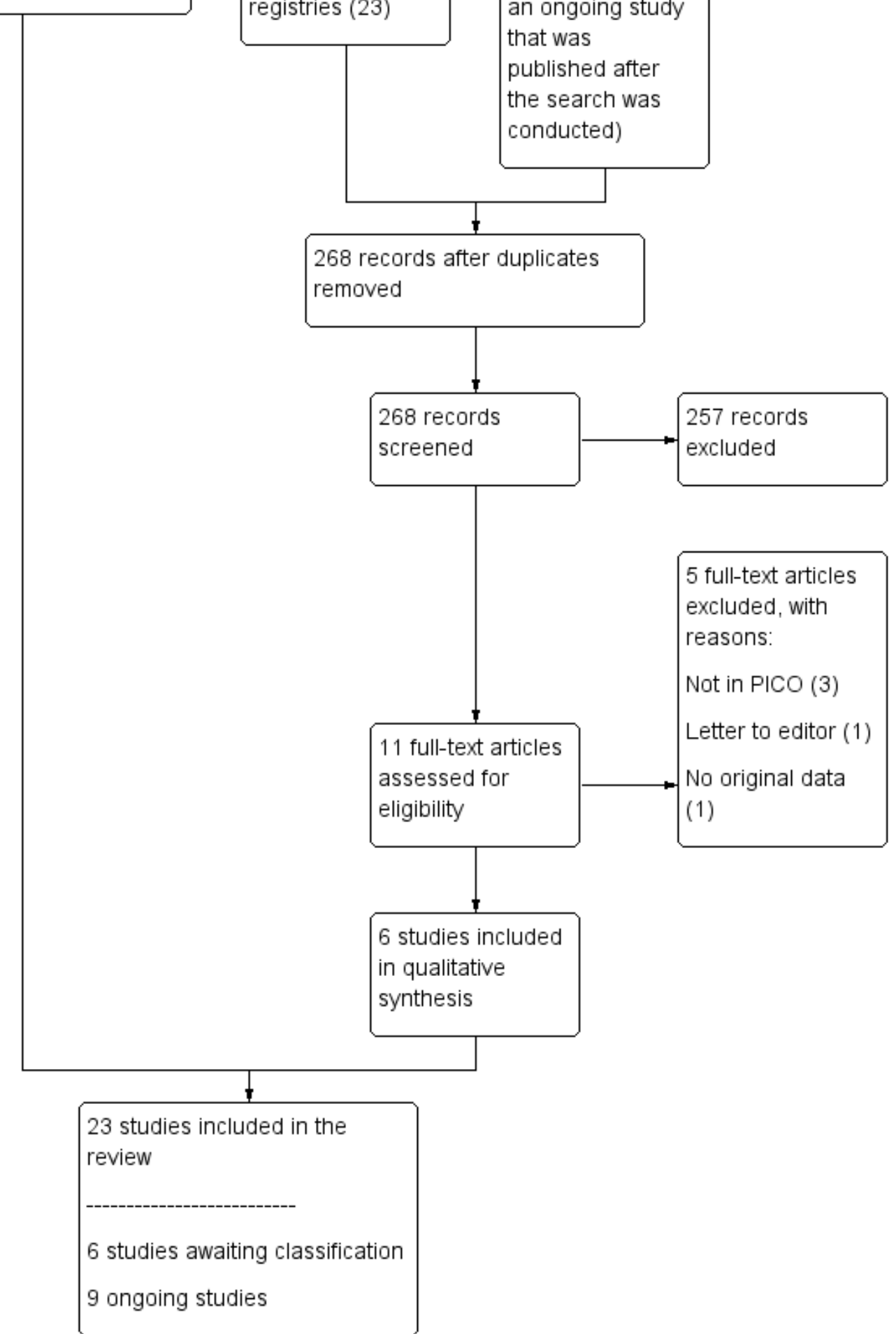

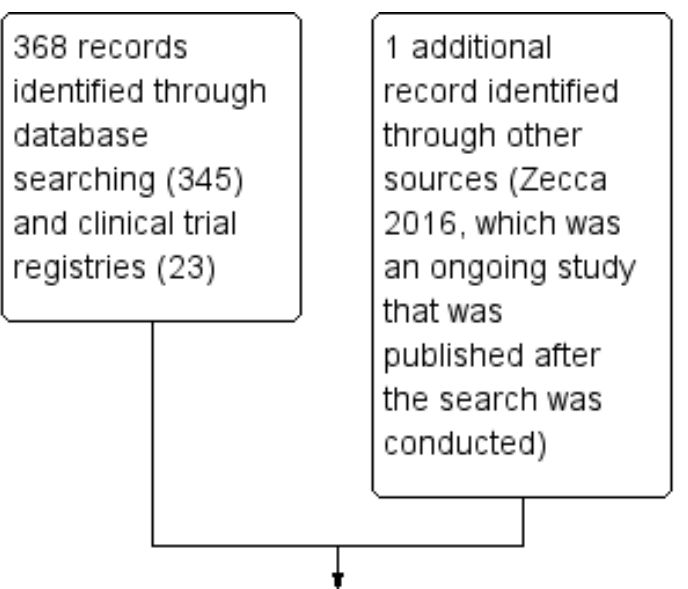

268 records after duplicates removed 
Figure 1. (Continued)

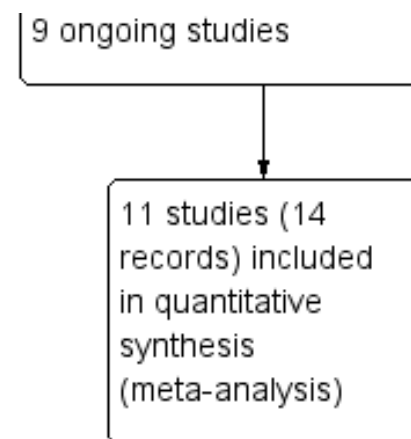

In total, we included 23 studies and excluded 63 studies in this review. There are six studies awaiting classification, and nine ongoing studies.

\section{Included studies}

The six new studies included an additional 1258 randomised participants, such that the 23 included studies enrolled/ randomised 2648 participants (1347 men, 1109 women; for the remaining 192 participants gender was not specified) with 2144 of these analysed for efficacy and 2363 for safety. The reported mean/median ages of the participant populations in the studies ranged from 45 years to 68.8 years. Eleven of the studies were cross-over trials (Beaver 1978a; Beaver 1978b; Bruera 1998; Gabrail 2004; Hagen 1997; Heiskanen 1997; Kalso 1990; Lauretti 2003; Leow 1995; Lux 2014; Stambaugh 2001), and 12 were parallel-group trials (Corli 2016; Imanaka 2013; Kaplan 1998; Mercadante 2010; MucciLoRusso 1998; Parris 1998; Riley 2015; Salzman 1999; Su 2015; Yu 2014; Zecca 2016; Zhang 2014), with eight of the studies conducted in the USA (Beaver 1978a; Beaver 1978b; Gabrail 2004; Kaplan 1998; Mucci-LoRusso 1998; Parris 1998; Salzman 1999; Stambaugh 2001); two in Canada (Bruera 1998; Hagen 1997); two in Finland (Heiskanen 1997; Kalso 1990); three in China (Su 2015; Yu 2014; Zhang 2014); three in Italy (Corli 2016; Mercadante 2010; Zecca 2016); and one each in Germany/Poland/Switzerland (Lux 2014), Australia (Leow 1995), Brazil (Lauretti 2003), the UK (Riley 2015), and Japan/Korea (Imanaka 2013). The length of the trials ranged from single-dose treatment to one year, and the studies reported the following comparisons:

- CR oxycodone versus IR oxycodone (Kaplan 1998; Parris 1998; Salzman 1999; Stambaugh 2001);

- CR oxycodone versus extended-release (ER) oxycodone (Lux 2014);

- CR oxycodone versus CR morphine (Bruera 1998; Corli 2016; Heiskanen 1997; Lauretti 2003; Mercadante 2010; MucciLoRusso 1998; Riley 2015; Zecca 2016; Zhang 2014), with one of these studies including a further two arms of transdermal (TD) buprenorphine and TD fentanyl (Corli 2016); and one of the studies comparing two different brands of slow-release morphine to CR oxycodone (Zhang 2014);

- CR oxycodone versus CR hydromorphone (Hagen 1997);

- CR oxycodone versus ER hydromorphone (Yu 2014);

- CR oxycodone versus ER oxymorphone (Gabrail 2004);

- CR oxycodone versus ER tapentadol (Imanaka 2013);

- CR oxycodone versus TD fentanyl (Corli 2016; Su 2015);
- CR oxycodone versus TD buprenorphine (Corli 2016);

- intravenous (IV) oxycodone versus rectal oxycodone (Leow 1995);

- IV oxycodone followed by IR oxycodone versus IV morphine followed by IR morphine (Kalso 1990);

- intramuscular (IM) oxycodone versus oral oxycodone (Beaver 1978a);

- IM oxycodone versus IM morphine versus IM codeine (Beaver 1978b).

See also Characteristics of included studies table for further details about the studies.

\section{Excluded studies}

For this update, we excluded five studies. Of the records identified by the original and the update search, altogether we excluded 63 studies. A number of the studies identified in the searches compared oxycodone in combination with another drug (e.g. naloxone or acetaminophen) against oxycodone alone or placebo. Such studies were not included as they would not answer our primary question, which concerned the effectiveness of oxycodone for cancer pain. The majority of the 63 studies were excluded because they did not include the population or comparison of interest (36 studies), while others were excluded because they were systematic (11) or narrative reviews (six), not RCTs/RCT-based analyses (seven), letters to the editor (two), or case reports (one). See also Characteristics of excluded studies table.

\section{Studies awaiting classification}

Six studies are awaiting classification because they are either ongoing but of unclear relevance, or published in such a way that not enough information is available to ascertain whether they meet the inclusion criteria (e.g. as an abstract only). In some cases, we have attempted to contact the authors, but have not successfully obtained a response. We await further information, including study completion and publication, before we can ascertain their relevance to the current review and classify them accordingly. See also Characteristics of studies awaiting classification table.

\section{Ongoing studies}

Nine studies are ongoing. These studies examine some new drug comparisons involving oxycodone compared to those reported in this review, and some comparisons that have already been included. Upon their completion and publication, we hope to be 
able to include data from all of them in future updates of this review. See also Characteristics of ongoing studies table.

\section{Risk of bias in included studies}

See Figure 2 and Figure 3 for summaries of the 'risk of bias' judgements made for the included studies. 
Figure 2. Risk of bias summary: review authors' judgements about each risk of bias item for each included study.

\begin{tabular}{|c|c|c|c|c|c|c|c|c|c|c|c|c|}
\hline & 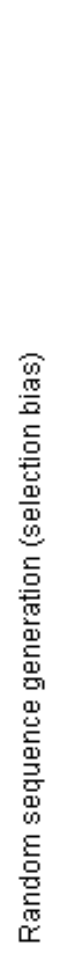 & 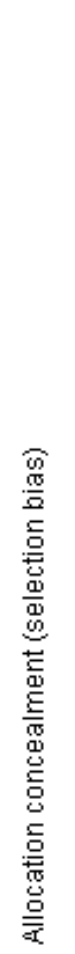 & 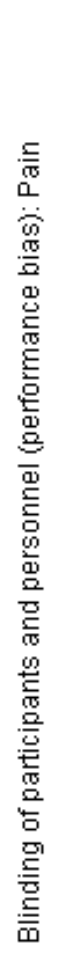 & 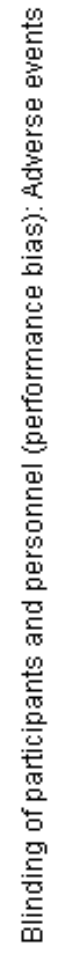 & 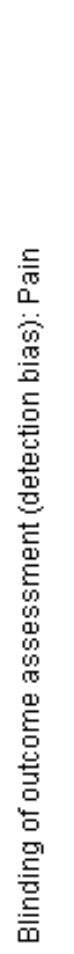 & 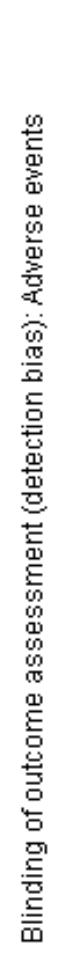 & 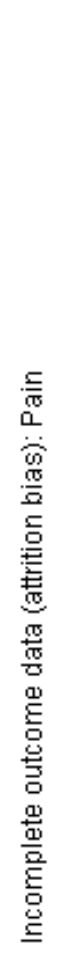 & 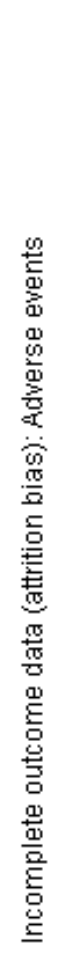 & 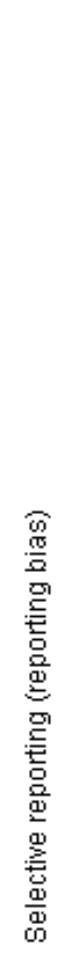 & 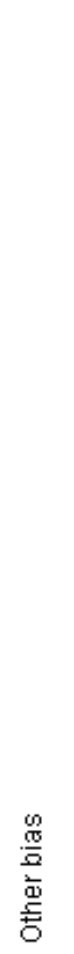 & 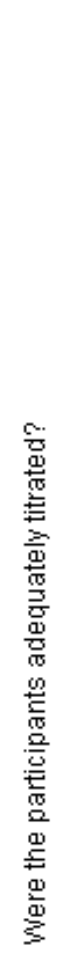 & 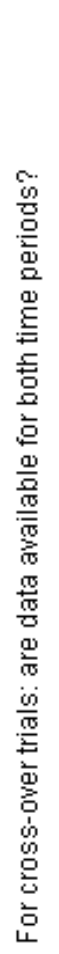 \\
\hline Beaver 1978a & $?$ & $?$ & $\odot$ & $\odot$ & $\odot$ & + & $?$ & $?$ & $\Theta$ & $?$ & $?$ & $\odot$ \\
\hline Beaver 1978b & $?$ & $?$ & $\odot$ & $\odot$ & $\odot$ & $\odot$ & $?$ & $?$ & $\odot$ & $?$ & $?$ & $\odot$ \\
\hline Bruera 1998 & $?$ & $?$ & $\odot$ & $\odot$ & + & $\odot$ & $\Theta$ & 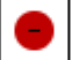 & 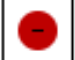 & $\odot$ & $\odot$ & $\odot$ \\
\hline Corli 2016 & + & + & $\odot$ & $\odot$ & $\odot$ & $\odot$ & $\odot$ & $\odot$ & $\odot$ & $\odot$ & $\odot$ & $?$ \\
\hline Gabrail 2004 & $?$ & $?$ & $?$ & $?$ & $?$ & $?$ & $\Theta$ & $?$ & $\odot$ & $\odot$ & $\odot$ & $\odot$ \\
\hline Hagen 1997 & $?$ & $?$ & $\odot$ & $\odot$ & $\odot$ & $\odot$ & $\odot$ & 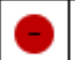 & $?$ & $\odot$ & $\odot$ & $\odot$ \\
\hline Heiskanen 1997 & + & + & $\odot$ & $?$ & $\odot$ & $?$ & $\odot$ & $\odot$ & $\odot$ & $\odot$ & $\odot$ & $\odot$ \\
\hline Imanaka 2013 & + & $\odot$ & $\odot$ & $\odot$ & $\odot$ & $\odot$ & $\Theta$ & $\odot$ & $\odot$ & $\odot$ & $\odot$ & $?$ \\
\hline Kalso 1990 & $?$ & $?$ & $?$ & $?$ & $?$ & $?$ & + & + & + & $\odot$ & + & $\odot$ \\
\hline Kaplan 1998 & $?$ & $?$ & + & $\odot$ & + & $\odot$ & $\odot$ & + & + & $\odot$ & $\odot$ & $?$ \\
\hline Lauretti 2003 & $?$ & $?$ & + & $\odot$ & + & + & $?$ & $?$ & $\odot$ & $\odot$ & $\odot$ & $\odot$ \\
\hline Leow 1995 & $?$ & $?$ & $\odot$ & $\odot$ & $\odot$ & 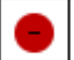 & 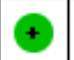 & $\odot$ & $\odot$ & $\odot$ & $?$ & $\odot$ \\
\hline Lux 2014 & $\odot$ & + & $\odot$ & + & + & + & $\Theta$ & $?$ & $\Theta$ & $\odot$ & $\odot$ & + \\
\hline Mercadante 2010 & $?$ & $?$ & $\odot$ & $\odot$ & $\odot$ & $\odot$ & $\odot$ & $\Theta$ & $\odot$ & $\odot$ & $?$ & $?$ \\
\hline Mucci-LoRusso 1998 & $?$ & $?$ & $\odot$ & $\odot$ & + & $\odot$ & $\odot$ & + & $\odot$ & $\odot$ & $\odot$ & $?$ \\
\hline Parris 1998 & $?$ & $?$ & $\odot$ & $?$ & + & $?$ & + & + & + & $\odot$ & + & $?$ \\
\hline Riley 2015 & + & $?$ & $\odot$ & $\Theta$ & $\odot$ & $\odot$ & $\odot$ & $\Theta$ & 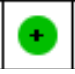 & + & + & $?$ \\
\hline
\end{tabular}


Figure 2. (Continued)

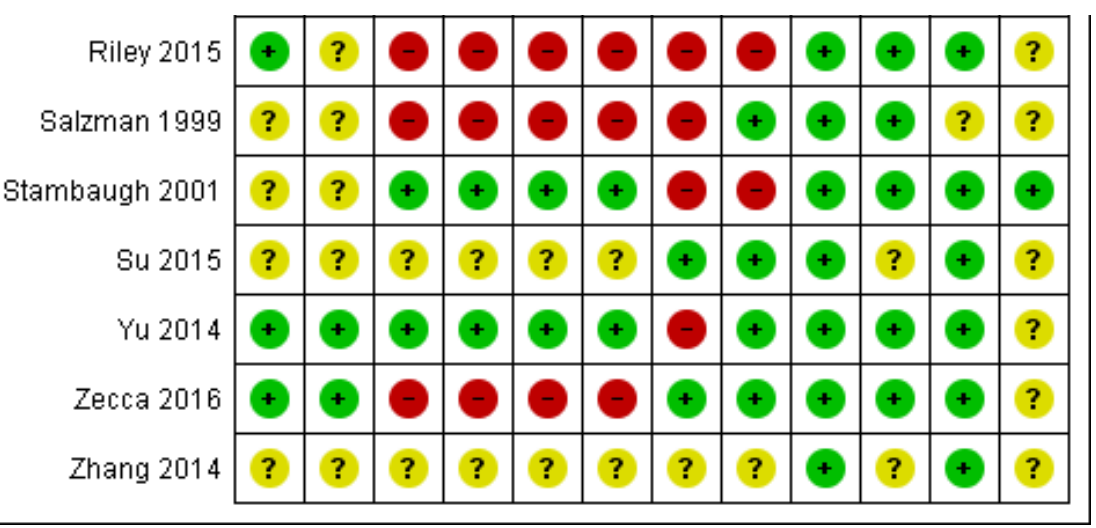

Figure 3. Risk of bias graph: review authors' judgements about each risk of bias item presented as percentages across all included studies.

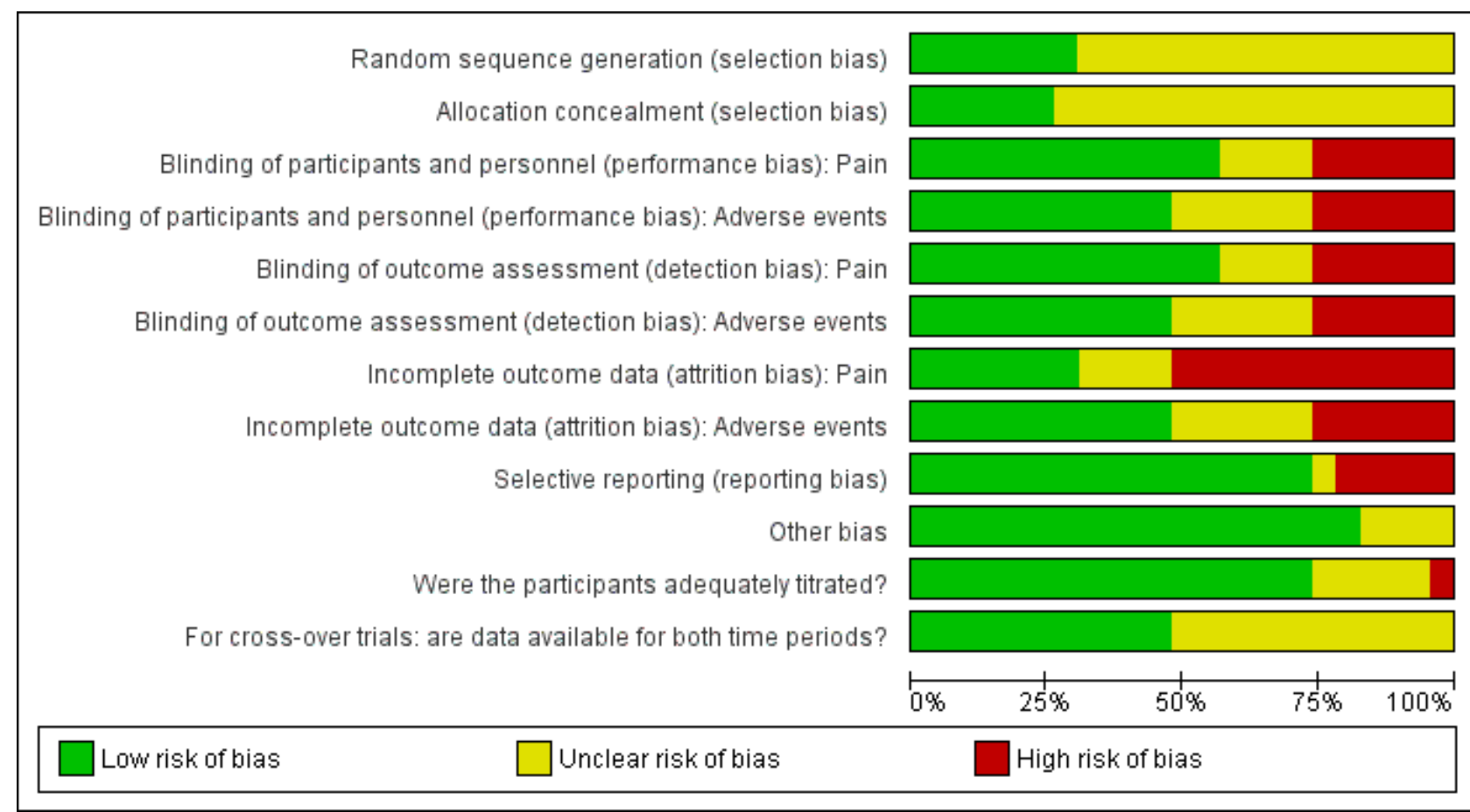

\section{Allocation}

In all but seven studies, not enough information was reported to assess whether the methods employed to generate the randomisation sequence and to ensure allocation concealment were adequate. Six of these seven studies were considered to be at low risk of bias for both items (Corli 2016; Heiskanen 1997; Imanaka 2013; Lux 2014; Yu 2014; Zecca 2016), while the seventh study was considered at low risk of bias for randomisation sequence but at unclear risk of bias for allocation concealment (Riley 2015). Only seven studies reported enough information for us to make a judgement that the treatment groups were comparable at baseline (Corli 2016; Imanaka 2013; Kaplan 1998; Riley 2015; Salzman 1999; Su 2015; Zhang 2014). Two further studies reported that the groups were comparable at baseline apart from there being more participants with bone metastasis and an Eastern
Cooperative Oncology Group (ECOG) performance status of 3 in the hydromorphone group than in the oxycodone group (Yu 2014), or there being more participants with a Karnofsky Performance Status (from 0 to 100 ) $\leqq 70$ in the CR oxycodone group than in the CR morphine group (Zecca 2016). In the remaining studies, it was unclear whether the participant selection methods employed had resulted in comparable, balanced groups at the start of the study.

\section{Blinding}

The problem of under-reporting was also an issue when assigning risk of bias estimates to the items assessing performance and detection bias, that is, blinding. In no instance was it directly and unequivocally reported who was blinded, so we had to infer, on the basis of supplementary information, whether we were reasonably certain that blinding had been adequately executed 
for a given individual (that is, participant, treating personnel, outcome assessors, or a combination of these, where not the participants themselves). On this basis, the risk of performance bias was considered to be low for the primary outcome of pain in 13 of the studies (Beaver 1978a; Beaver 1978b; Bruera 1998; Hagen 1997; Heiskanen 1997; Imanaka 2013; Kaplan 1998; Lauretti 2003; Lux 2014; Mucci-LoRusso 1998; Parris 1998; Stambaugh 2001; Yu 2014), unclear in four studies (Gabrail 2004; Kalso 1990; Su 2015; Zhang 2014), and high in six of the studies that were all described as openlabel (Corli 2016; Leow 1995; Mercadante 2010; Riley 2015; Salzman 1999; Zecca 2016). For adverse events, the risk of performance bias was low in 11 studies (Beaver 1978a; Beaver 1978b; Bruera 1998; Hagen 1997; Imanaka 2013; Kaplan 1998; Lauretti 2003; Lux 2014; Mucci-LoRusso 1998; Stambaugh 2001; Yu 2014), unclear in six studies (Gabrail 2004; Heiskanen 1997; Kalso 1990; Parris 1998; Su 2015; Zhang 2014), and high in the same six open-label studies as was the case for pain (Corli 2016; Leow 1995; Mercadante 2010; Riley 2015; Salzman 1999; Zecca 2016). The pattern of judgements was identical for detection bias, for both outcomes. This was the case for the primary outcome of pain because, according to our criteria, this outcome had to be participant reported. It was therefore at risk of detection bias to the same extent that it was at risk of performance bias since both depend on participant blinding. As is also evident from the bias judgements (see Characteristics of included studies table), when a study was described as double-blind but did not describe who was blinded, additional information in the studies generally led us to the conclusion that at least the participants seemed to be blinded, although we did not feel able to gauge with sufficient confidence who else might have been blinded. Given that it was not always clear who assessed the adverse events, this accounts for the similar judgements for performance and detection bias for this outcome.

\section{Incomplete outcome data}

Overall the data from only $81 \%$ of the total number of enrolled/ randomised participants were analysed for pain and $89.2 \%$ for adverse events, which indicates that attrition bias was a substantial problem in this data set, with only seven studies considered at low risk (Corli 2016; Kalso 1990; Kaplan 1998; Leow 1995; Parris 1998; Su 2015; Zecca 2016), and 12 studies considered at high risk (Bruera 1998; Gabrail 2004; Hagen 1997; Heiskanen 1997; Imanaka 2013; Lux 2014; Mercadante 2010; Mucci-LoRusso 1998; Riley 2015; Salzman 1999; Stambaugh 2001; Yu 2014), while four studies were at unclear risk (Beaver 1978a; Beaver 1978b; Lauretti 2003; Zhang 2014) for the primary outcome of pain. For adverse events, the risk of attrition bias was slightly less with 11 studies considered at low risk (Corli 2016; Kalso 1990; Kaplan 1998; Imanaka 2013; Leow 1995; Mucci-LoRusso 1998; Parris 1998; Salzman 1999; Su 2015; Yu 2014; Zecca 2016), and six studies considered at high risk (Bruera 1998; Hagen 1997; Heiskanen 1997; Mercadante 2010; Riley 2015; Stambaugh 2001), while six studies were at unclear risk (Beaver 1978a; Beaver 1978b; Gabrail 2004; Lauretti 2003; Lux 2014; Zhang 2014).

\section{Selective reporting}

Seventeen of the included studies were not considered to be at risk of selective reporting bias, whereas five of the studies either did not report adverse events or did not report them in a manner so they could be scrutinised for (and potentially included in) an evidence synthesis (Beaver 1978a; Beaver 1978b; Bruera 1998; Lauretti 2003; Lux 2014); these studies were therefore judged at high risk. One study only reported four adverse events in a transparent manner and was therefore considered at unclear risk of reporting bias (Hagen 1997).

\section{Other potential sources of bias}

The participants appeared to be adequately titrated in the majority of the studies (Bruera 1998; Corli 2016; Gabrail 2004; Hagen 1997; Heiskanen 1997; Imanaka 2013; Kalso 1990; Lauretti 2003; Lux 2014; Mucci-LoRusso 1998; Parris 1998; Riley 2015; Stambaugh 2001; Su 2015; Yu 2014; Zecca 2016; Zhang 2014), although this was unclear in four studies (Beaver 1978a; Beaver 1978b; Leow 1995; Mercadante 2010), and not the case in one study (Kaplan 1998). One study examined titration as its main objective (Salzman 1999). For all 11 cross-over trials, data were available for all cross-over phases. Only four studies undertook ITT analyses for both efficacy and safety (Leow 1995; Parris 1998; Stambaugh 2001; Zhang 2014), with a further three studies performing these analyses for safety only (Kalso 1990; Salzman 1999) or for efficacy only (Corli 2016; Riley 2015). In one study, it was unclear whether ITT analyses had been undertaken (Su 2015). The remaining studies did not perform ITT for any of the outcomes. The vast majority of the included studies had received commercial funding or had authors who were employees of the drug manufacturers, or both (Beaver 1978a; Beaver 1978b; Gabrail 2004; Hagen 1997; Heiskanen 1997; Imanaka 2013; Kaplan 1998; Leow 1995; Lux 2014; Mucci-LoRusso 1998; Parris 1998; Salzman 1999; Stambaugh 2001; Yu 2014; Zecca 2016). Only three studies were considered free from the potential influence of commercial funding (Corli 2016; Kalso 1990; Riley 2015), with a further five studies having unclear status (Bruera 1998; Lauretti 2003; Mercadante 2010; Su 2015; Zhang 2014). All the included studies were considered at low risk of any other biases (e.g. carry-over effects in the cross-over trials) with the exception of four studies which were judged to be at unclear risk of other bias due to the manner in which the trials were reported (Beaver 1978a; Beaver 1978b; Su 2015; Zhang 2014).

\section{Effects of interventions}

See: Summary of findings for the main comparison $C R$ oxycodone compared with IR oxycodone for cancer-related pain in adults; Summary of findings 2 CR oxycodone compared with CR morphine for cancer-related pain in adults

Analysis 1.1 and Figure 4 shows the pain intensity scores for each of the listed treatment groups, subgrouped according to overall treatment comparisons. We felt that presenting the pain intensity data this way for the studies where it was possible gave a comprehensive overview of the pain intensity data for the majority of the included studies, although the actual analyses should be treated with some caution as outlined in the Unit of analysis issues section. 
Figure 4. Forest plot of comparison: 1 Pain, outcome: 1.1 Pain intensity and pain relief.

\begin{tabular}{|c|c|c|c|c|c|c|c|c|c|}
\hline \multirow{2}{*}{ Study or Subgroup } & \multicolumn{3}{|c|}{ Oxycodone } & \multicolumn{3}{|c|}{ Comparison } & \multicolumn{2}{|c|}{ Std. Mean Difference } & \multirow{2}{*}{$\begin{array}{c}\text { Std. Mean Difference } \\
\text { IV, Fixed, } 95 \% \mathrm{Cl}\end{array}$} \\
\hline & Mean & SD & Total & Mean & SD & Total & Weight & IV, Fixed, 95\% Cl & \\
\hline \multicolumn{9}{|c|}{ 1.1.1 Controlled-release (CR) oxycodone vs immediate-release (IR) oxycodone } & \\
\hline Kaplan $1998(1)$ & 1.3 & 1.25 & 156 & 1.3 & 1.25 & 156 & $54.2 \%$ & $0.00[-0.22,0.22]$ & \\
\hline Parris $1998(2)$ & 1.4 & 1.01 & 103 & 1.1 & 1.01 & 103 & $35.4 \%$ & $0.30[0.02,0.57]$ & \\
\hline Stambaugh 2001 (3) & 2.7 & 1.9 & 30 & 2.8 & 1.9 & 30 & $10.4 \%$ & $-0.05[-0.56,0.45]$ & \\
\hline Subtotal $(95 \% \mathrm{Cl})$ & & & 289 & & & 289 & $100.0 \%$ & $0.10[-0.06,0.26]$ & \\
\hline \multicolumn{9}{|c|}{$\begin{array}{l}\text { Heterogeneity: } \mathrm{Chi}^{2}=3.08, \mathrm{df}=2(\mathrm{P}=0.21) ; \mathrm{l}^{2}=35 \% \\
\text { Test for overall effect: } Z=1.19(\mathrm{P}=0.23)\end{array}$} & \\
\hline \multicolumn{9}{|c|}{ 1.1.2 CR oxycodone vs extended-release (ER) oxycodone } & \\
\hline Lux $2014(4)$ & 14.76 & 17.4 & 31 & 13.46 & 16.47 & 31 & $100.0 \%$ & $0.08[-0.42,0.57]$ & \\
\hline Subtotal $(95 \% \mathrm{Cl})$ & & & 31 & & & 31 & $100.0 \%$ & $0.08[-0.42,0.57]$ & \\
\hline \multicolumn{10}{|c|}{ Heterogeneity: Not applicable } \\
\hline \multicolumn{10}{|c|}{ Test for overall effect: $Z=0.30(P=0.77)$} \\
\hline \multicolumn{10}{|c|}{ 1.1.3 CR oxycodone vs CR morphine } \\
\hline Bruera 1998 & 24.3 & 20 & 23 & 22.9 & 21 & 23 & $5.2 \%$ & $0.07[-0.51,0.65]$ & \\
\hline Corli 2016 & 2.9 & 2.1 & 125 & 2.6 & 2.1 & 122 & $28.1 \%$ & $0.14[-0.11,0.39]$ & \\
\hline Heiskanen 1997 & 0.99 & 0.62 & 27 & 0.77 & 0.36 & 27 & $6.0 \%$ & $0.43[-0.11,0.97]$ & \\
\hline Mercadante $2010(5)$ & 3.15 & 3 & 19 & 2.35 & 2.36 & 20 & $4.4 \%$ & $0.29[-0.34,0.92]$ & \\
\hline Mucci-LoRusso 1998 & 1.3 & 0.89 & 79 & 1 & 0.89 & 79 & $17.8 \%$ & $0.34[0.02,0.65]$ & \\
\hline Riley 2015 & 2.05 & 1.71 & 80 & 2.36 & 2.18 & 85 & $18.8 \%$ & $-0.16[-0.46,0.15]$ & \\
\hline Zecca 2016 & 3.51 & 1.99 & 85 & 3.27 & 1.71 & 88 & $19.7 \%$ & $0.13[-0.17,0.43]$ & \\
\hline Subtotal $(95 \% \mathrm{Cl})$ & & & 438 & & & 444 & $100.0 \%$ & $0.14[0.01,0.27]$ & \\
\hline \multirow{2}{*}{\multicolumn{10}{|c|}{$\begin{array}{l}\text { Heterogeneity: } \mathrm{Chi}^{2}=6.49, \mathrm{df}=6(\mathrm{P}=0.37) ; \mathrm{I}^{2}=7 \% \\
\text { Test for overall effect: } Z=2.04(P=0.04)\end{array}$}} \\
\hline & & & & & & & & & \\
\hline \multicolumn{10}{|c|}{ 1.1.4 CR oxycodone vs CR hydromorphone } \\
\hline Hagen 1997 & 28 & 22.27 & 31 & 31 & 22.27 & 31 & $100.0 \%$ & $-0.13[-0.63,0.37]$ & \\
\hline Subtotal $(95 \% \mathrm{Cl})$ & & & 31 & & & 31 & $100.0 \%$ & $-0.13[-0.63,0.37]$ & \\
\hline \multirow{2}{*}{\multicolumn{10}{|c|}{$\begin{array}{l}\text { Heterogeneity: Not applicable } \\
\text { Test for overall effect: } Z=0.52(P=0.60)\end{array}$}} \\
\hline & & & & & & & & & \\
\hline 1.1.5 CR oxycodone vs & ER hydrc & morph & one & & & & & & \\
\hline Yu $2014(6)$ & 5.1 & 1.92 & 41 & 4.9 & 2.07 & 40 & $100.0 \%$ & $0.10[-0.34,0.54]$ & \\
\hline Subtotal $(95 \% \mathrm{Cl})$ & & & 41 & & & 40 & $100.0 \%$ & $0.10[-0.34,0.54]$ & \\
\hline Heterogeneity: Not app & cable & & & & & & & & \\
\hline Test for overall effect: $Z$ & $=0.45(\mathrm{P}$ & $=0.66)$ & & & & & & & \\
\hline 1.1.6 CR oxycodone vs & ER oxym & orphon & & & & & & & \\
\hline Gabrail 2004 & 2.8 & 1.3 & 37 & 2.5 & 1.3 & 37 & $100.0 \%$ & $0.23[-0.23,0.69]$ & \\
\hline Subtotal (95\% Cl) & & & 37 & & & 37 & $100.0 \%$ & $0.23[-0.23,0.69]$ & \\
\hline Heterogeneity: Not app & cable & & & & & & & & \\
\hline Test for overall effect: $Z$ & $=0.98(\mathrm{P}$ & $=0.33)$ & & & & & & & \\
\hline 1.1.7 CR oxycodone vs & ER taper & tadol & & & & & & & \\
\hline Imanaka 2013 & 2.57 & 2.027 & 139 & 2.69 & 2.223 & 126 & $100.0 \%$ & $-0.06[-0.30,0.18]$ & \\
\hline Subtotal $(95 \% \mathrm{Cl})$ & & & 139 & & & 126 & $100.0 \%$ & $-0.06[-0.30,0.18]$ & \\
\hline Heterogeneity: Not app & cable & & & & & & & & \\
\hline Test for overall effect: $Z$ & $=0.46(\mathrm{P}$ & $=0.65)$ & & & & & & & \\
\hline 1.1.8 CR oxycodone vs & transder & mal (TD & D) fenta & anyl & & & & & \\
\hline Corli 2016 & 2.9 & 2.1 & 125 & 2.8 & 2.2 & 124 & $75.7 \%$ & $0.05[-0.20,0.29]$ & \\
\hline Su 2015 & 3.02 & 2.19 & 42 & 3.13 & 2.16 & 38 & $24.3 \%$ & $-0.05[-0.49,0.39]$ & \\
\hline Subtotal $(95 \% \mathrm{Cl})$ & & & 167 & & & 162 & $100.0 \%$ & $0.02[-0.19,0.24]$ & \\
\hline Heterogeneity: $\mathrm{Chi}^{2}=0$ & $4, d f=1$ & $(P=0.7$ & $71) ; 1^{2}=$ & & & & & & \\
\hline Test for overall effect: $Z$ & $=0.21(\mathrm{P}$ & $=0.84)$ & & & & & & & \\
\hline 1.1.9 CR oxycodone vs & TD bupre & enorphil & & & & & & & \\
\hline Corli 2016 & 2.9 & 2.1 & 125 & 2.7 & 1.9 & 127 & $100.0 \%$ & $0.10[-0.15,0.35]$ & \\
\hline Subtotal (95\% Cl) & & & 125 & & & 127 & $100.0 \%$ & $0.10[-0.15,0.35]$ & \\
\hline Heterogeneity: Not app & cable & & & & & & & & \\
\hline Test for overall effect: $Z$ & $=0.79(\mathrm{P}$ & $=0.43)$ & & & & & & & \\
\hline 1.1.10 IR oxycodone vs & IR morp & hine & & & & & & & \\
\hline Kalso 1990 & 1.3 & 1.2 & 19 & 1.5 & 1.4 & 19 & $100.0 \%$ & $-0.15[-0.79,0.49]$ & \\
\hline Subtotal $(95 \% \mathrm{Cl})$ & & & 19 & & & 19 & $100.0 \%$ & $-0.15[-0.79,0.49]$ & \\
\hline Heterogeneity: Not app & cable & & & & & & & & \\
\hline Test for overall effect: $Z$ & $=0.46(\mathrm{P}$ & $=0.64)$ & & & & & & & \\
\hline
\end{tabular}


Figure 4. (Continued)

Test for overall effect: $Z=0.46(P=0.64)$

Test for subgroup differences: $\mathrm{Chi}^{2}=3.92, \mathrm{df}=9(\mathrm{P}=0.92) \mathrm{I}^{2}=0 \%$

Footnotes

(1) CR oxycodone is 'oxycodone' group, IR oxycodone is 'comparison' group.

(2) CR oxycodone is 'oxycodone' group, IR oxycodone is 'comparison' group.

(3) CR oxycodone is 'oxycodone' group, IR oxycodone is 'comparison' group.

(4) SDs were not reported so we used SDs for overall per-protocol population (46 participants) including people with non-cancer pain.

(5) Week 4 data.

(6) Mean pain at its worst in past 24 hours (primary outcome); however, SDs not reported so we used SDs for same outcome measured at baseline in full..

\section{Controlled-release oxycodone versus immediate-release oxycodone}

Four studies compared CR oxycodone to IR oxycodone (Kaplan 1998; Parris 1998; Salzman 1999; Stambaugh 2001).

\section{Pain intensity and pain relief}

Pooled analysis showed that there was no statistically significant difference in pain intensity after treatment with either CR or IR oxycodone (SMD $0.1,95 \% \mathrm{Cl}-0.06$ to $0.26, \mathrm{I}^{2}=35 \%$ ) (Analysis 1.1 ; Figure 4), which was also in line with the finding that none of the included studies reported that pain intensity differed between the treatment groups. Salzman 1999 could not be included in the pooled analysis due to the design of the study, so is instead summarised narratively below. Sensitivity analysis excluding the cross-over trial (Stambaugh 2001) did not change the overall results (SMD 0.12, 95\% $\mathrm{Cl}-0.06$ to 0.29 ).

Salzman 1999 examined in a parallel-group trial lasting up to 21 days whether $C R$ oxycodone could be used as readily as IR oxycodone for titration to stable pain control and found that $22 / 24$ and $19 / 24$ participants in the CR and IR groups, respectively, achieved stable pain control within a mean time of 1.6 days (SE = 0.4 ) and 1.7 days $(S E=0.6)$, respectively.

We judged the quality of evidence for this outcome to be low. We downgraded the quality of evidence by two levels for very serious limitations to study quality due to risk of bias (arising from underreporting and attrition bias). See Summary of findings for the main comparison.

\section{Adverse events}

Pooled analyses of adverse events showed no significant difference between treatment with $\mathrm{CR}$ oxycodone and IR oxycodone for asthenia ( $R R 0.58,95 \% \mathrm{Cl} 0.2$ to $1.68, \mathrm{I}^{2}=30 \%$; Analysis 2.2 ), confusion (RR $0.78,95 \% \mathrm{Cl} 0.2$ to $3.02, \mathrm{I}^{2}=25 \%$; Analysis 2.3 ), constipation (RR $0.71,95 \% \mathrm{Cl} 0.45$ to $1.13, \mathrm{I}^{2}=38 \%$; Analysis 2.4 ), dizziness/lightheadedness (RR $0.74,95 \% \mathrm{Cl} 0.4$ to $1.37, \mathrm{I}^{2}=15 \%$; Analysis 2.5), drowsiness/somnolence (RR $1.03,95 \% \mathrm{Cl} 0.69$ to 1.54 , $\mathrm{I}^{2}=0 \%$; Analysis 2.6), dry mouth (RR $1.14,95 \% \mathrm{Cl} 0.48$ to $2.75, \mathrm{I}^{2}=$ $0 \%$; Analysis 2.7), insomnia (RR $1.04,95 \% \mathrm{Cl} 0.31$ to $3.53, \mathrm{I}=35 \%$; Analysis 2.11), nausea (RR $0.85,95 \% \mathrm{Cl} 0.56$ to $1.28, \mathrm{I}^{2}=0 \%$; Analysis 2.12), nervousness ( $\mathrm{RR} 0.57,95 \% \mathrm{Cl} 0.2$ to $1.64, \mathrm{I}^{2}=0 \%$; Analysis 2.13), pruritus ( $R R 1.46,95 \% \mathrm{Cl} 0.65$ to $3.25, \mathrm{I}^{2}=33 \%$; Analysis 2.14), vomiting ( $\mathrm{RR} 0.66,95 \% \mathrm{Cl} 0.38$ to $1.15, \mathrm{I}^{2}=18 \%$; Analysis 2.16 ), and discontinuation due to adverse events (RR $0.6,95 \% \mathrm{Cl} 0.29$ to $1.22, \mathrm{I}^{2}$ $=0 \%$; Analysis 2.17). The $\mathrm{I}^{2}$ statistic was $61 \%$ for headache and $55 \%$ for sweating so the results reported for these two adverse events in Analysis 2.10 and Analysis 2.15 should be disregarded. Parris 1998 analysed 109 participants for safety evaluation; however, it is unclear which group had 55 and which had 54 participants. In the meta-analyses of adverse events, we allocated 54 participants to the CR oxycodone group and 55 to the IR oxycodone group. Sensitivity analyses showed that allocating 55 participants to the CR oxycodone group and 54 participants to the IR oxycodone group made no difference to the conclusions.

In a parallel-group trial lasting five days, Parris 1998 reported that all the adverse events observed during the study resolved. Stambaugh 2001 conducted a cross-over study with a duration of three to seven days per phase, and stated that: "The study showed similar incidences and numbers of reports of individual adverse events considered related to the IR and CR drug" (page 505), but did not report any formal statistical comparisons of the adverse event rates between the study groups. Table 1 contains all the adverse events reported by the included studies comparing CR oxycodone and IR oxycodone.

We judged the quality of evidence for adverse events to be very low in all cases. We downgraded the quality of evidence by two levels for very serious limitations to study quality due to risk of bias (arising from under-reporting, performance/detection bias, inadequate titration, attrition bias, or a combination of these); and we downgraded the quality of the evidence by one or two levels due to imprecision (arising from low or very low event rates).

\section{Quality of life}

There were no data for quality of life, but Kaplan 1998 reported in a parallel-group study lasting six days that there was no difference in treatment acceptability between the study groups (mean at study end 3.2, SE 0.1, in both groups), and Parris 1998 found no significant differences in acceptability of treatment between the study groups. In Stambaugh 2001, 30/30 and 29/30 participants rated IR and CR oxycodone, respectively, as of 'fair', 'good' or 'excellent' acceptability during the last 24 hours of the treatment phases, with 24/30 and 22/30 participants rating the drugs 'good' or 'excellent', respectively. We judged the quality of evidence for this outcome to be low. We downgraded the quality of evidence by two levels for very serious limitations to study quality due to risk of bias (arising from under-reporting and attrition bias)

\section{Participant preference}

None of the studies reported data for participant preference.

See also Summary of findings for the main comparison. 


\section{Controlled-release oxycodone versus extended-release oxycodone}

One study compared CR oxycodone to ER oxycodone (Lux 2014).

\section{Pain intensity and pain relief}

Lux 2014 found no difference in pain intensity between CR and ER oxycodone in a cross-over trial with each of the two phases lasting 10 days (Analysis 1.1; Figure 4). We judged the quality of evidence for this outcome to be low. We downgraded the quality of evidence by one level for serious limitations to study quality due to risk of bias (arising from attrition bias) and by one level due to imprecision (arising from low participant numbers).

\section{Adverse events}

Lux 2014 also included participants with non-malignant pain and only reported adverse events for the whole sample. Therefore, we have not reported results for adverse events.

\section{Quality of life}

The study did not report quality of life.

\section{Participant preference}

The study did not report participant preference.

\section{Controlled-release oxycodone versus controlled-release morphine}

Nine studies compared CR oxycodone to CR morphine (Bruera 1998; Corli 2016; Heiskanen 1997; Lauretti 2003; Mercadante 2010; MucciLoRusso 1998; Riley 2015; Zecca 2016; Zhang 2014).

\section{Pain intensity and pain relief}

Pooled analysis including Bruera 1998; Corli 2016; Heiskanen 1997, Mercadante 2010; Mucci-LoRusso 1998; Riley 2015; and Zecca 2016 showed that the pain intensity scores were significantly lower after treatment with CR morphine than with CR oxycodone (SMD 0.14 $95 \% \mathrm{Cl} 0.01$ to $0.27, \mathrm{I}^{2}=7 \%$ ) (Analysis 1.1; Figure 4) (Bruera 1998; Corli 2016; Heiskanen 1997; Mercadante 2010; Mucci-LoRusso 1998; Riley 2015; Zecca 2016). Using the SD of the baseline average pain score of the full sample (200 participants; SD 1.94) in Riley 2015 to express this SMD as a difference in Brief Pain Inventory scores ( 0 to 10 numerical rating scale from no pain to worst pain imaginable) between the treatments gave an estimated difference of 0.27 between the treatments, which was not clinically significant. Moreover, sensitivity analysis excluding the two cross-over trials (Bruera 1998, Heiskanen 1997) did not find a significant difference between CR oxycodone and CR morphine (SMD 0.12, 95\% Cl -0.02 to $\left.0.26, I^{2}=24 \%\right)$. Two studies could not be included in the pooled analysis due to the design of the study (Lauretti 2003) or because pain intensity was not reported (Zhang 2014), and the results of these studies are therefore summarised narratively.

Lauretti 2003 conducted a two-phase (each lasting 14 days) crossover study to examine IR morphine consumption (which was the main outcome) during treatment with $C R$ oxycodone and $C R$ morphine, keeping the ratio of $\mathrm{CR}$ oxycodone and $\mathrm{CR}$ morphine constant (1:1.8). IR morphine was used as rescue medication and the participants were allowed to take as much as necessary to keep visual analogue scale (VAS) pain score below 4 . The participants consumed $38 \%$ more IR morphine during treatment with $C R$ morphine than with CR oxycodone. Lauretti 2003 concluded that the results indicated that $\mathrm{CR}$ oxycodone combined with IR morphine was associated with superior analgesia and lower, or similar, rates of adverse events (see 'Adverse events' below) than a combination of CR and IR morphine.

In a four-arm parallel-group trial lasting 28 days, Corli 2016 compared $\mathrm{CR}$ oxycodone with $\mathrm{CR}$ morphine (and also included a TD fentanyl and a TD buprenorphine arm), and found that the $\mathrm{CR}$ oxycodone and $\mathrm{CR}$ morphine treatment groups did not differ significantly in terms of requirement for additional opioids (CR oxycodone 33/125 participants; CR morphine 36/122 participants; $P=0.59)$, the opioid escalation index $>5 \%(C R$ oxycodone $24 / 125$ participants; CR morphine 13/122 participants; $P$ $=0.06$ ), or premature discontinuations for pain-related reasons (CR oxycodone $19 / 125$ participants; CR morphine 33/122 participants; $P$ $=0.05$ ); however, the proportion of participants requiring adjuvant drugs were significantly higher in the CR oxycodone group (CR oxycodone 102/125 participants; CR morphine 84/122 participants; $P=0.02$ ), were significantly higher in the $C R$ oxycodone group whereas the proportion of participants requiring switches (CR oxycodone 15/125 participants; CR morphine 27/122 participants; $P=0.03$ ) were significantly lower in the $C R$ oxycodone group compared to the CR morphine group.

Mucci-LoRusso 1998 conducted a parallel-group trial lasting up to 12 days and found that $40 / 48$ and $42 / 52$ participants achieved stable pain control after receiving CR oxycodone and CR morphine, respectively, within a median of 2 days for both groups (ranges were 1 to 10 and 1 to 9 days, respectively).

In an open-label, parallel-group trial of one-year duration, Riley 2015 compared CR oxycodone to CR morphine and found that $67 \%$ and $62 \%$ of the participants achieved a response to first line oxycodone and morphine, respectively, and that this was not a significant difference. Moreover, in the participants who achieved a response to their assigned first line treatment none of the five pain indices studied (that is 'worst pain', 'least pain', 'average pain', 'pain right now', and 'percentage relief') differed significantly between the treatment groups.

Zecca 2016, in a parallel-group trial lasting two weeks and comparing $\mathrm{CR}$ oxycodone to $\mathrm{CR}$ morphine, reported that opioid dose escalation did not differ significantly between treatments (CR oxycodone $8.3 \%$; CR morphine $6.5 \%$ ).

Zhang 2014 conducted a three-arm parallel-group trial of unknown duration comparing $C R$ oxycodone to $C R$ morphine and $C R$ MS Contin and found that pain relief rates (i.e. participants experiencing at least moderate pain relief) of the three groups did not differ significantly (CR oxycodone 53/57 participants; CR morphine 51/57 participants; CR MS Contin 52/57 participants; $\mathrm{P}=$ $0.62)$.

We judged the quality of evidence for this outcome to be low. We downgraded the quality of evidence by two levels for very serious limitations to study quality due to risk of bias (arising from under-reporting, performance/detection bias, and attrition bias). See Summary of findings 2.

\section{Adverse events}

Pooled analyses of adverse events showed no significant difference between treatment with $\mathrm{CR}$ oxycodone and $\mathrm{CR}$ morphine for 
confusion (RR $1.01,95 \% \mathrm{Cl} 0.78$ to $1.31, \mathrm{I}^{2}=16 \%$; Analysis 2.3 ), constipation ( $\mathrm{RR} 0.98,95 \% \mathrm{Cl} 0.82$ to $1.16, \mathrm{I}^{2}=33 \%$; Analysis 2.4 ), dizziness/lightheadedness (RR $0.76,95 \% \mathrm{Cl} 0.33$ to $1.76, \mathrm{I}^{2}=0 \%$; Analysis 2.5), drowsiness/somnolence (RR $0.9,95 \% \mathrm{Cl} 0.75$ to 1.08 , $\mathrm{I}^{2}=0 \%$; Analysis 2.6), dry mouth (RR $1.01,95 \% \mathrm{Cl} 0.8$ to $1.26, \mathrm{I}^{2}$ $=32 \%$; Analysis 2.7 ), dysuria (RR $0.71,95 \% \mathrm{Cl} 0.4$ to $1.26, \mathrm{I} 2=0 \%$; Analysis 2.8), nausea (RR $1.02,95 \% \mathrm{Cl} 0.82$ to $1.26, \mathrm{I}^{2}=0 \%$; Analysis 2.12), pruritus ( $R R 0.81,95 \% \mathrm{Cl} 0.51$ to $1.29,12=0 \%$; Analysis 2.14 ), vomiting (RR $0.94,95 \% \mathrm{Cl} 0.68$ to $1.29, \mathrm{I}^{2}=2 \%$; Analysis 2.16 ), and discontinuation due to adverse events (RR $1.06,95 \% \mathrm{Cl} 0.43$ to 2.6, $1^{2}=48 \%$; Analysis 2.17). However, the RR for hallucinations was significantly lower after treatment with $\mathrm{CR}$ oxycodone than after $\mathrm{CR}$ morphine (RR $0.52,95 \% \mathrm{Cl} 0.28$ to $0.97, \mathrm{I}^{2}=0 \%$; Analysis 2.9). The $1^{2}$ statistic was $53 \%$ for 'any adverse events' so the results reported for this outcome (Analysis 2.1) should be disregarded. Zhang 2014 compared CR oxycodone to both CR morphine and CR MS Contin. In the meta-analyses of adverse events, we included CR morphine as the comparison group. Sensitivity analyses substituting the $C R$ morphine data with the CR MS Contin data showed that whether the comparison group was CR morphine or CR MS Contin made no difference to the conclusions.

Bruera 1998 reported that: "There were no statistically significant differences by treatment in mean severity for any of the elicited adverse events or in the frequency of reporting of unelicited events" (page 3225), but presented only data on sedation and nausea VAS ratings. Corli 2016 found no significant differences between the two treatment groups in the incidences of gastralgia and breathlessness, whether they were 'any degree' or 'severe.' Severe but not 'any degree' muscle spasm myoclonus occurred significantly more often in the CR morphine group than in the CR oxycodone group. Heiskanen 1997 conducted a cross-over trial lasting three to six days per phase and found that vomiting was significantly more common during morphine treatment while constipation was significantly more common during oxycodone treatment; and reported no other significant differences in adverse event rates between the drugs. In a parallel-group trial lasting four weeks (with an extension of another four weeks), Mercadante 2010 found no significant differences in the reported adverse events between the groups. Lauretti 2003 found that CR and IR morphine were associated with more nausea and vomiting compared to the combination of CR oxycodone and IR morphine. Riley 2015 reported that there were no significant differences in adverse event reaction scores between oxycodone and morphine, either in firstline responders or non-responders. Table 2 contains all the adverse events reported by the included studies comparing CR oxycodone and CR morphine.

We judged the quality of evidence for this outcome to be very low in all cases. We downgraded the quality of evidence by two levels for very serious limitations to study quality due to risk of bias (arising from under-reporting, performance/detection bias, attrition bias, or a combination of these), and we downgraded the quality of the evidence by one or two levels due to imprecision (arising from low or very low event rates).

\section{Quality of life}

Mucci-LoRusso 1998 reported no clinically significant changes in quality of life for either treatment group, but did not show results or analyses. The authors also found that $74 \%$ and $77 \%$ of the CR oxycodone and CR morphine participants, respectively, rated the acceptability of treatment as good to excellent (non-significant) and that the mean acceptability ratings at the study end did not differ significantly between the CR oxycodone (mean 4, SE = 0.1) and $\mathrm{CR}$ morphine (mean 3.9, SE $=0.1$ ) participants. Heiskanen 1997 found that the mean daily acceptability of treatment ratings were significantly higher for morphine $(3.49 / 5 ; \mathrm{SE}=0.12)$ than for oxycodone (3.19/5; SE = 0.11), but Lauretti 2003 also found that CR and IR morphine were associated with a similar acceptance to the study drugs compared to the combination of CR oxycodone and IR morphine. We judged the quality of evidence for this outcome to be very low. We downgraded the quality of evidence by two levels for very serious limitations to study quality due to risk of bias (arising from under-reporting and attrition bias), and we downgraded one level for imprecision (arising from low participant numbers).

\section{Participant preference}

In a cross-over trial with each phase lasting seven days, Bruera 1998 reported that $8 / 23$ participants preferred CR oxycodone treatment while $11 / 23$ participants preferred treatment with CR morphine (non-significant difference). We judged the quality of evidence for this outcome to be very low. We downgraded the quality of evidence by two levels for very serious limitations to study quality due to risk of bias (arising from under-reporting and attrition bias), and we downgraded the quality of the evidence by two levels due to imprecision (arising from very low participant numbers).

See also Summary of findings 2.

\section{Controlled-release oxycodone versus controlled-release hydromorphone}

One study compared CR oxycodone to CR hydromorphone (Hagen 1997).

\section{Pain intensity and pain relief}

In a cross-over trial lasting seven days per phase, Hagen 1997 found no difference in pain intensity between treatment with $C R$ oxycodone and CR hydromorphone (Analysis 1.1; Figure 4). We judged the quality of evidence for this outcome to be very low. We downgraded the quality of evidence by two levels for very serious limitations to study quality due to risk of bias (arising from underreporting and attrition bias), and two levels for imprecision (arising from very low participant numbers).

\section{Adverse events}

Hagen 1997 observed no differences in frequency of adverse events between treatment groups with the exception of drowsiness, which occurred more frequently during treatment with oxycodone (see Table 3). We judged the quality of evidence for this outcome to be very low. We downgraded the quality of evidence by two levels for very serious limitations to study quality due to risk of bias (arising from under-reporting and attrition bias), and two levels for imprecision (arising from very low participant numbers).

\section{Quality of life}

The study did not report quality of life.

\section{Participant preference}

Hagen 1997 found that $25.8 \%$ of participants had no treatment preference with approximately half of the remaining participants preferring oxycodone $(35.5 \%)$ while the other half preferred 
hydromorphone (38.7\%). We judged the quality of evidence for this outcome to be very low. We downgraded the quality of evidence by two levels for very serious limitations to study quality due to risk of bias (arising from under-reporting and attrition bias), and two levels for imprecision (arising from very low participant numbers).

\section{Controlled-release oxycodone versus extended release hydromorphone}

One study compared CR oxycodone to ER hydromorphone (Yu 2014).

\section{Pain intensity and pain relief}

In a 28-day parallel-group trial, Yu 2014 found no differences in pain intensity or pain relief between treatment with CR oxycodone and ER hydromorphone on any of the following pain measures: mean pain at its worst in past 24 hours (CR oxycodone 5.1; ER hydromorphone 4.9; Analysis 1.1; Figure 4), mean pain on average (CR oxycodone 3.3; ER hydromorphone 2.9), mean pain at its least in past 24 hours (CR oxycodone 1.9; ER hydromorphone 1.6), mean pain 'right now' (CR oxycodone 2.8; ER hydromorphone 2.7), mean pain relief in past 24 hours (CR oxycodone $62.2 \%$; ER hydromorphone $64.5 \%$ ), and the number of rescue medication doses taken during overall maintenance phase (CR oxycodone 29.3; ER hydromorphone 24.2). We judged the quality of evidence for this outcome to be very low. We downgraded the quality of evidence by one level for serious limitations to study quality due to risk of bias (arising from attrition bias), and two levels for imprecision (arising from very low participant numbers).

\section{Adverse events}

Yu 2014 reported that the observed adverse events were similar between the treatment groups, and that they did not differ significantly in duration of persistence for vomiting, constipation, nausea, dizziness, pyrexia, and decreased appetite, but presented no further formal statistical analyses (see Table 3). We judged the quality of evidence for this outcome to be low. We downgraded the quality of evidence by two levels for imprecision (arising from very low participant numbers).

\section{Quality of life}

The study did not report quality of life.

\section{Participant preference}

The study did not report participant preference.

\section{Controlled-release oxycodone versus extended release oxymorphone}

One study compared CR oxycodone to ER oxymorphone (Gabrail 2004).

\section{Pain intensity and pain relief}

Gabrail 2004, in a cross-over trial with each phase lasting seven to 10 days, found clinically indistinguishable mean 24-hour average daily pain intensity ratings between the two treatments (Analysis 1.1 and Figure 4). We judged the quality of evidence for this outcome to be very low. We downgraded the quality of evidence by two levels for very serious limitations to study quality due to risk of bias (arising from under-reporting and attrition bias), and by two levels for imprecision (arising from very low participant numbers).

\section{Adverse events}

Gabrail 2004 reported that the adverse event rates were similar between the drugs, although no formal statistical analyses were presented (see Table 3), and no participants withdrew due to abnormal laboratory values, insufficient analgesia, or loss to follow-up. We judged the quality of evidence for this outcome to be very low. We downgraded the quality of evidence by two levels for very serious limitations to study quality due to risk of bias (arising from under-reporting of the domains of selection, performance, detection, and attrition bias), and by two levels for imprecision (arising from very low participant numbers).

\section{Quality of life}

Gabrail 2004 reported that no differences were observed in quality of life (general activity, mood, walking ability, normal work, relationships with others, sleep, and enjoyment of life) between the drugs. We judged the quality of evidence for this outcome to be very low. We downgraded the quality of evidence by two levels for very serious limitations to study quality due to risk of bias (arising from under-reporting of the domains of selection, performance, detection, and attrition bias), and by two levels for imprecision (arising from very low participant numbers).

\section{Participant preference}

The study reported no data for participant preference, but Gabrail 2004 found that $78.3 \%$ of participants rated oxycodone as 'excellent,' 'very good,' or 'good' with $86.4 \%$ of the participants giving oxymorphone such ratings. We judged the quality of evidence for this outcome to be very low. We downgraded the quality of evidence by two levels for very serious limitations to study quality due to risk of bias (arising from under-reporting of the domains of selection, performance, and detection bias), and by two levels for imprecision (arising from very low participant numbers).

\section{Controlled-release oxycodone versus extended release tapentadol}

One study compared CR oxycodone to ER tapentadol (Imanaka 2013).

\section{Pain intensity and pain relief}

Imanaka 2013, in a parallel-group trial of four weeks' duration, found equal analgesia between the study groups (see Analysis 1.1; Figure 4) with $82 / 139$ CR oxycodone participants and 80/126 ER tapentadol participants reporting $\geq 30 \%$ improvement in pain intensity during the last three days of treatment, and 59/139 CR oxycodone participants and ER 63/126 tapentadol participants reporting $\geq 50 \%$ improvement in pain intensity during the last three days of treatment. We judged the quality of evidence for this outcome to be low. We downgraded the quality of evidence by one level for serious limitations to study quality due to risk of bias (arising from attrition bias), and by one level for imprecision (arising from low participant numbers).

\section{Adverse events}

Inspection of Table 3 suggested that the adverse event rates were comparable between the treatment groups, but Imanaka 2013 did not present any formal statistical analyses of this apparent equality. We judged the quality of evidence for this outcome to be moderate or low, depending on the event rates of the individual adverse 
events. We downgraded the quality of evidence by one or two levels for imprecision (arising from low or very low event rates).

\section{Quality of life}

The study did not report quality of life.

\section{Participant preference}

The study did not report participant preference.

\section{Controlled-release oxycodone versus transdermal fentanyl}

Two studies compared CR oxycodone to TD fentanyl (Corli 2016; Su 2015).

\section{Pain intensity and pain relief}

Pooled analysis including Corli 2016 and Su 2015 showed that the pain intensity scores after treatment with $\mathrm{CR}$ oxycodone and TD fentanyl did not differ significantly (SMD $0.02,95 \% \mathrm{Cl}-0.19$ to 0.24 , $12=0 \%$ ) (Analysis 1.1; Figure 4).

Corli 2016 compared CR oxycodone with TD fentanyl in a four-arm trial of 28 days' duration, which also included a TD buprenorphine and a CR morphine group, and found that the CR oxycodone and TD fentanyl groups did not differ significantly in terms of the requirement for additional opioids (CR oxycodone 33/125 participants; TD fentanyl $46 / 124$ participants; $P=0.08$ ), premature discontinuations for pain-related reasons (CR oxycodone 19/125 participants; TD fentanyl $18 / 124$ participants; $P=1$ ), proportion of participants requiring adjuvant drugs (CR oxycodone 102/125 participants; TD fentanyl 100/124 participants; $P=0.87$ ), or proportion of participants requiring switches (CR oxycodone $15 / 125$ participants; TD fentanyl $16 / 124$ participants; $P=0.85$ ). However, a significantly higher proportion of participants in the CR fentanyl group required a mean increase in the opioid daily dose $>5 \%$ according to the opioid escalation index compared to the oxycodone group (CR oxycodone 24/125 participants; TD fentanyl $45 / 124$ participants; $P=0.003$ ). In a parallel-group trial lasting two weeks, Su 2015 reported no differences between groups treated with CR oxycodone or TD fentanyl in pain relief (CR oxycodone $90.48 \%$; TD fentanyl $92.11 \%$ ) or pain intensity measured by response categories (CR oxycodone 15 complete response, 21 partial response, 2 minor response, 4 no response; TD fentanyl: 13 complete response, 20 partial response, 2 minor response, 3 no response).

We judged the quality of evidence for this outcome to be very low. We downgraded the quality of evidence by two levels for very serious limitations to study quality due to risk of bias (arising from under-reporting, performance bias, and detection bias), and by one level for imprecision (arising from low participant numbers).

\section{Adverse events}

Pooled analysis of the event rates for constipation and dysuria revealed that the $\mathrm{I}^{2}$ statistic was $83 \%$ for constipation, so the results listed in Analysis 2.4 for this treatment subgroup should be ignored, and that there was no significant difference between treatment groups for dysuria (RR $1.15,95 \% \mathrm{Cl} 0.62$ to $2.16, \mathrm{I} 2=0 \%$ ).

Corli 2016 found no significant differences between the two treatment groups in the incidences of the following adverse events, whether they were 'any degree' or 'severe': drowsiness, confusion, nausea, vomiting, constipation, dry mouth, hallucinations, gastralgia, muscle spasm myoclonus, breathlessness, and itching. Su 2015 reported that the rates of nausea and vomiting $(P=0.026)$ and constipation $(P=0.022)$ were significantly higher in the $C R$ oxycodone group than in the TD fentanyl group, and that the rates of dizziness and lethargy did not differ significantly between the groups (all $P>0.65$ ). We judged the quality of evidence for this outcome to be very low. We downgraded the quality of evidence by two levels for very serious limitations to study quality due to risk of bias (arising from under-reporting, performance bias, and detection bias), and by one or two levels (depending on the event rates of the individual adverse events) for imprecision (arising from low or very low event rates). See Table 4.

\section{Quality of life}

Su 2015 found no differences in quality of life as measured by the Karnofsky Performance Status (from 0 to 100) (CR oxycodone mean 75.79; TD fentanyl mean 74.05). We judged the quality of evidence for this outcome to be very low. We downgraded the quality of evidence by two levels for very serious limitations to study quality due to risk of bias (arising from under-reporting of the domains of selection, performance, and detection bias), and by two levels for imprecision (arising from very low participant numbers).

\section{Participant preference}

Neither study reported participant preference.

\section{Controlled-release oxycodone versus transdermal buprenorphine}

\section{Pain intensity and pain relief}

Corli 2016 compared CR oxycodone with TD buprenorphine in a four-arm trial of 28 days' duration, which also included a TD fentanyl and a CR morphine group, and found no significant difference between CR oxycodone and TD buprenorphine groups in terms of pain intensity (Analysis 1.1; Figure 4). Corli 2016 found no significant differences between the groups in terms of requirement for additional opioids (CR oxycodone 33/125 participants; TD buprenorphine $48 / 127$ participants; $P=0.06$ ), opioid escalation index $>5 \%$ (CR oxycodone 24/125 participants; TD buprenorphine $18 / 127$ participants; $P=0.31$ ), premature discontinuations for pain-related reasons (CR oxycodone 19/125 participants; TD buprenorphine 26/127 participants; $P=0.32$ ), proportion of participants requiring adjuvant drugs (CR oxycodone 102/125 participants; TD buprenorphine 100/127 participants; $P=0.64$ ), or proportion of participants requiring switches (CR oxycodone $15 / 125$ participants; TD buprenorphine $21 / 127$ participants; $P=$ 0.37 ). We judged the quality of evidence for this outcome to be very low. We downgraded the quality of evidence by two levels for very serious limitations to study quality due to risk of bias (arising from performance bias and detection bias), and by one level for imprecision (arising from low participant numbers).

\section{Adverse events}

Corli 2016 found no significant differences between the two treatment groups in the incidences of the following adverse events, whether they were 'any degree' or 'severe:' drowsiness, confusion, nausea, vomiting, constipation, dry mouth, hallucinations, gastralgia, dysuria, muscle spasm myoclonus, and itching. 'Any degree,' but not severe, breathlessness occurred more often in the TD buprenorphine group than in the CR oxycodone group. We judged the quality of evidence for this outcome to be very low. 
We downgraded the quality of evidence by two levels for very serious limitations to study quality due to risk of bias (arising from performance bias and detection bias), and by one or two levels (depending on the event rates for the individual adverse events) for imprecision (arising from low or very low event rates). See Table 4.

\section{Quality of life}

Neither study reported quality of life.

\section{Participant preference}

Neither study reported participant preference.

\section{Intravenous oxycodone versus rectal oxycodone}

One study compared IV oxycodone to rectal oxycodone (Leow 1995).

\section{Pain intensity and pain relief}

Leow 1995 conducted a single-dose cross-over study in 12 participants, with each phase lasting 24 hours, and found that while IV oxycodone was associated with faster onset of pain relief relative to rectal oxycodone, rectal oxycodone was associated with a longer duration of pain relief compared to IV oxycodone. We judged the quality of evidence for this outcome to be very low. We downgraded the quality of evidence by two levels for very serious limitations to study quality due to risk of bias (arising from under-reporting and performance bias and detection bias), and by two levels for imprecision (arising from very low participant numbers).

\section{Adverse events}

Leow 1995 reported no significant differences in the adverse event profiles for the two study arms (see Table 3). We judged the quality of evidence for this outcome to be very low. We downgraded the quality of evidence by two levels for very serious limitations to study quality due to risk of bias (arising from under-reporting, performance bias and detection bias), and by two levels for imprecision (arising from very low participant numbers).

\section{Quality of life}

The study did not report quality of life.

\section{Participant preference}

The study did not report participant preference.

\section{Intravenous oxycodone followed by immediate-release oxycodone versus intravenous morphine followed by immediate-release morphine}

One study compared IV oxycodone followed by IR oxycodone to IV morphine followed by IR morphine (Kalso 1990).

\section{Pain intensity and pain relief}

In a cross-over study comparing IV oxycodone titration (two days) followed by IR oxycodone titration (two days) with IV morphine titration (two days) followed by IR morphine titration (two days) in 19 analysed participants, Kalso 1990 found that the participants achieved equal analgesia with both drugs, but around 30\% more IV oxycodone was needed compared to IV morphine and around $25 \%$ less IR oxycodone was needed than IR morphine to achieve this. We judged the quality of evidence for this outcome to be very low. We downgraded the quality of evidence by two levels for very serious limitations to study quality due to risk of bias (arising from under-reporting of the domains of selection, performance, and detection bias), and by two levels for imprecision (arising from very low participant numbers).

\section{Adverse events}

Kalso 1990 found that nausea was significantly more common with oral morphine treatment compared to the other three treatment modalities (see also Table 3). We judged the quality of evidence for this outcome to be very low. We downgraded the quality of evidence by two levels for very serious limitations to study quality due to risk of bias (arising from under-reporting of the domains of selection, performance, and detection bias), and by two levels for imprecision (arising from very low participant numbers).

\section{Quality of life}

The study did not report quality of life.

\section{Participant preference}

Kalso 1990 reported that 10 participants expressed no treatment preference while five participants preferred oxycodone while another five participants preferred treatment with morphine. We judged the quality of evidence for this outcome to be very low. We downgraded the quality of evidence by two levels for very serious limitations to study quality due to risk of bias (arising from underreporting of the domains of selection, performance, and detection bias), and by two levels for imprecision (arising from very low participant numbers).

\section{Intramuscular oxycodone versus oral oxycodone}

One study compared IM oxycodone to oral oxycodone (Beaver 1978a).

\section{Pain intensity and pain relief}

In a single-dose, cross-over study, Beaver 1978a compared $5 \mathrm{mg}$ and $15 \mathrm{mg} \mathrm{IM}$ oxycodone to $10 \mathrm{mg}$ and $30 \mathrm{mg}$ oral oxycodone in 17 participants of whom 13 completed at least one cross-over round of the study medications. Beaver 1978a reported that oral oxycodone was 0.57 (95\% Cl 0.22 to 1.84$)$ times as potent as IM oxycodone for pain relief and $0.78(95 \% \mathrm{Cl} 0.3$ to 8.82$)$ times as potent for change in pain intensity. We judged the quality of evidence for this outcome to be very low. We downgraded the quality of evidence by two levels for very serious limitations to study quality due to risk of bias (arising from under-reporting of the domains of selection and attrition bias), and by two levels for imprecision (arising from very low participant numbers).

\section{Adverse events}

Beaver 1978a reported that the adverse effects for both oral and IM oxycodone, although infrequent, were related to dose, but otherwise provided no further details on the observed adverse effects. We judged the quality of evidence for this outcome to be very low. We downgraded the quality of evidence by two levels for very serious limitations to study quality due to risk of bias (arising from under-reporting of the domains of selection and attrition bias), and by two levels for imprecision (arising from very low participant numbers).

\section{Quality of life}

The study did not report quality of life. 


\section{Participant preference}

The study did not report participant preference.

\section{Intramuscular oxycodone versus intramuscular morphine versus intramuscular codeine}

Two studies (reported in one publication) compared IM oxycodone, IM morphine and IM codeine (Beaver 1978b).

\section{Pain intensity and pain relief}

In another single-dose, cross-over study Beaver 1978b compared $7.5 \mathrm{mg}, 15 \mathrm{mg}$ and $30 \mathrm{mg} \mathrm{IM}$ oxycodone to $8 \mathrm{mg}, 16 \mathrm{mg}$ and $32 \mathrm{mg}$ IM morphine in 34 participants of whom 28 completed at least one round of the study drugs. In this study, IM oxycodone was found to be $0.74(95 \% \mathrm{Cl} 0.36$ to 1.2$)$ times as potent as IM morphine for pain relief and $0.68(95 \% \mathrm{Cl} 0.32$ to 1.07$)$ times as potent as IM morphine for change in pain intensity. In a further study of similar design Beaver 1978b compared $7.5 \mathrm{mg}, 15 \mathrm{mg}$ and $30 \mathrm{mg}$ IM oxycodone to $90 \mathrm{mg}$ and $180 \mathrm{mg}$ IM codeine and to $16 \mathrm{mg} \mathrm{IM}$ morphine in 30 participants of whom 26 completed at least one cross-over round of the study medications. Beaver $1978 \mathrm{~b}$ reported that IM oxycodone was $10.72(95 \% \mathrm{Cl}$ not reported) times as potent as IM codeine for pain relief and $8.44(95 \% \mathrm{Cl} 2.13$ to 44.69$)$ times as potent as IM codeine for change in pain intensity. We judged the quality of evidence for this outcome to be very low. We downgraded the quality of evidence by two levels for very serious limitations to study quality due to risk of bias (arising from under-reporting of the domains of selection and attrition bias), and by two levels for imprecision (arising from very low participant numbers).

\section{Adverse events}

Beaver 1978b noted that in both studies side effects typical of narcotic analgesics were observed, although not in sufficient numbers to allow meaningful analysis, and they reported no further details on adverse events. We judged the quality of evidence for this outcome to be very low. We downgraded the quality of evidence by two levels for very serious limitations to study quality due to risk of bias (arising from under-reporting of the domains of selection and attrition bias), and by two levels for imprecision (arising from very low participant numbers).

\section{Quality of life}

The studies did not report quality of life.

\section{Participant preference}

The studies did not report participant preference.

\section{DISCUSSION}

For the current update, we identified six additional studies for inclusion, which allowed us to perform further meta-analyses, principally on the adverse event data. We were also able to examine four new treatment comparisons with oxycodone, and assess the robustness of our primary pain intensity meta-analyses by performing sensitivity analyses. Although these analyses found that $\mathrm{CR}$ oxycodone was associated with a higher pain intensity, and therefore less pain relief, and a lower risk of hallucinations compared to CR morphine, the updated results and conclusions are broadly speaking the same as the original review because the (current) finding of inferior pain relief by CR oxycodone compared to $C R$ morphine was only statistically and not clinically significant as the effect size was very small. It was also not supported by sensitivity analyses, and the finding of a lower risk of hallucinations with treatment with CR oxycodone compared to CR morphine was based on very low event rates (see 'For clinicians' in Implications for practice).

\section{Summary of main results}

Overall, we included 23 studies which enrolled/randomised 2648 participants, with 2144 of these analysed for efficacy and 2363 for safety. The studies examined a number of different drug comparisons.

Four studies compared CR oxycodone to IR oxycodone, and pooled analysis of three of these studies showed that there was no difference in pain intensity after treatment with either CR or IR oxycodone (SMD $0.1,95 \% \mathrm{Cl}-0.06$ to 0.26 ). This is also in line with the finding that none of the included studies reported that the pain intensity differed between the treatment groups. Pooled analyses of the adverse event data from three of the studies found no differences between the treatments in RRs for any of the adverse events, and the fourth study, which could not be included in the pooled analyses, reported no differences in adverse events either. Three of the four studies also found no difference in treatment acceptability between the comparisons. We noted that IR oxycodone was given every six hours rather than every four hours in these studies. This might have biased the efficacy data in favour of CR oxycodone; however, the adverse effect data suggest that giving IR oxycodone every four hours (more frequently) would have resulted in greater adverse effects, which would have mitigated advantages in efficacy.

Nine studies compared CR oxycodone to CR morphine and pooled analysis of seven of these nine studies suggested that pain intensity did differ significantly between the treatments (SMD 0.14, 95\% $\mathrm{Cl} 0.01$ to 0.27 ). However, this result was not corroborated by a sensitivity analysis that excluded the two cross-over trials included in the overall analysis (SMD $0.12,95 \% \mathrm{Cl}-0.02$ to 0.26 ). There were no marked differences in terms of treatment acceptability or quality of life ratings observed between the treatments. Zhang 2014 also found no significant differences in pain relief rates between CR oxycodone, CR morphine and CR MS Contin. Pooled analyses of the adverse event rates also found no differences between the treatments for any of the adverse events, with the exception of hallucinations, which participants treated with $C R$ morphine were at almost double the risk of experiencing compared to participants treated with CR oxycodone. However, these findings contrast somewhat with those reported in Lauretti 2003, which was different in design to the other four studies and examined IR morphine consumption during treatment with $\mathrm{CR}$ oxycodone and $C R$ morphine while keeping the ratio of $C R$ oxycodone and CR morphine constant. Lauretti 2003 found that the participants consumed 38\% more IR morphine during treatment with CR morphine than with CR oxycodone, and that CR and IR morphine was associated with more nausea and vomiting and a similar acceptance to the study drugs compared to the combination of $\mathrm{CR}$ oxycodone and IR morphine, and therefore concluded that $\mathrm{CR}$ oxycodone combined with IR morphine is associated with superior analgesia and lower or similar rates of adverse events than a combination of $\mathrm{CR}$ and IR morphine.

Two studies compared CR oxycodone to TD fentanyl and pooled analysis of them found that the pain intensity scores after 
treatment with $\mathrm{CR}$ oxycodone and TD fentanyl did not differ significantly (SMD $0.02,95 \% \mathrm{Cl}-0.19$ to 0.24 ). One of the studies also found that quality of life did not differ between the treatments, but there was some disagreement between the study results in terms of adverse events with one of the studies finding that the rates of nausea and vomiting, and constipation were significantly higher in the CR oxycodone group than in the TD fentanyl group, whereas the other study reported no treatment group differences in (these and other) adverse event rates.

The remaining studies all compared either oxycodone in different formulations or oxycodone to different alternative opioids and none of them found any clear superiority or inferiority of oxycodone for cancer pain, neither as an analgesic agent nor in terms of adverse event rates or treatment acceptability.

\section{Overall completeness and applicability of evidence}

Although the findings of this review are applicable to the population and comparisons defined for this review, that is, adults with cancer who need treatment with strong opioids for cancer pain, they should be taken in the context that this review found 23 studies that were eligible for inclusion and these studies reported on 13 different comparisons involving oxycodone and included only 2648 participants. Moreover, for some of the outcomes (participant preference and quality of life) there were extremely few data available. To somewhat mitigate this shortfall, we reported treatment acceptability as a proxy. However, that does not change the fact that the evidence base for the effectiveness and tolerability of oxycodone (relative or absolute) for pain in adults with cancer was very limited and it did not allow us to examine the effectiveness and tolerability of oxycodone in detail through participant or treatment subgroup analyses. The current evidence base would therefore benefit from more well-designed, large RCTs.

\section{Quality of the evidence}

The quality of the evidence for all the outcomes was low or very low, meaning we have little confidence in the effect estimate and the true effect may be substantially different from the estimate of the effect. This is due to imprecision (low participant numbers) in some cases, and serious or very serious study limitations in all cases. In general, the assessment of the quality of the included studies was limited by a great extent of under-reporting in the studies, especially for the participant selection items (random sequence generation and allocation concealment), while blinding appeared to be reasonably well undertaken overall, both in terms of treatment performance and outcome assessment. However, as is not unusual for pain research, the results were substantially compromised by attrition, with data missing from just under $20 \%$ of the enrolled/randomised participants for efficacy, and from more than $10 \%$ for safety. These are substantial proportions and, while it did not appear to be selective attrition, the results must be interpreted with caution.

\section{Potential biases in the review process}

We undertook the review according to the methods specified in our protocol, which were all in line with the recommendations of Cochrane as outlined in the Cochrane Handbook for Systematic Reviews of Interventions (Higgins 2011), and included a thorough search strategy designed to maximise the chances of identifying all relevant studies. Contacting authors resulted in no additional studies being identified, that is, the review therefore only contains data from published studies, some of which have not reported all the outcome data despite having apparently collected these data. The review may therefore be at some risk of publication bias, although publication bias is usually associated with positive results, and the majority of the included studies did not find significant differences between their treatment groups in terms of efficacy and safety. Although, our meta-analyses of pain intensity included data from cross-over studies that were analysed as if they were parallel-group studies, which as outlined in Unit of analysis issues results in unit of analysis error (although, in turn, this leads to an under-weighting rather than over-weighting of the data), the results were also subjected to sensitivity analyses that excluded the cross-over trials, and that needed to confirm the results in order for them to be accepted as true results.

\section{Agreements and disagreements with other studies or reviews}

King 2011 conducted a systematic review without meta-analysis that also included observational studies and concluded that, "There is no evidence from the included trials of a significant difference in analgesia or adverse effects between oxycodone and morphine or hydromorphone" (page 454). Caraceni 2011 reached a similar conclusion in their systematic review without metaanalysis. Bekkering 2011 and Reid 2006 both included metaanalyses in their systematic reviews and they also concluded that the effectiveness of oxycodone and morphine did not significantly differ, although the inclusion criteria employed by Bekkering 2011 differed from ours, with Bekkering 2011 excluding cross-over trials and including trials of chronic non-malignant pain, whereas the publication of Reid 2006 before the trial of Mercadante 2010 precluded its inclusion. That said, the conclusions of all these reviews are all in agreement with those that we have reached in this review dealing with the same comparisons as the aforementioned reviews.

\section{AUTHORS' CONCLUSIONS}

\section{Implications for practice}

Since the last version of this review, none of the new relevant studies have provided additional information to change the conclusions.

\section{For adults with cancer pain}

We found low quality evidence that oxycodone offers similar levels of pain relief and overall adverse effects as morphine for adults with cancer. Although we identified a clinically insignificant benefit on pain relief in favour of controlled-release (CR) morphine compared to $\mathrm{CR}$ oxycodone, this did not persist following sensitivity analysis and so we do not consider this important. We did find an increased frequency of hallucinations after treatment with CR morphine (7.8\%) compared to CR oxycodone (4\%).

\section{For clinicians}

We found low quality evidence that oxycodone offers similar levels of cancer pain relief and adverse events to other strong opioids including morphine, which is commonly considered the gold standard strong opioid. Although we identified a clinically insignificant benefit on pain relief in favour of $C R$ morphine compared to CR oxycodone, this did not persist following sensitivity analysis and so we do not consider this important. We found 
an increased risk of hallucinations with CR morphine but we also found a numerically higher frequency of myoclonus (another excitatory opioid adverse effect) with CR oxycodone and we did not find any differences in reported drowsiness or confusion. The interpretation of increased relative risk of hallucinations should therefore be treated with caution given the low quality of evidence.

\section{For policy makers}

The findings of this review are consistent with current international guidance on using oxycodone or morphine as first-line opioids for adults with cancer-related pain.

\section{For funders of the intervention}

We did not undertake cost-effectiveness analysis.

\section{Implications for research}

\section{General}

We found that the current evidence base is comprised of studies that contained small numbers of participants in which there was a significant (19\%) dropout rate. For example, the direct comparison meta-analysis between oxycodone and morphine was based on fewer than 450 cancer participants in each treatment group; this was a very small evidence base. However, given the absence of important differences within this analysis, it seems unlikely that larger head to head studies of oxycodone versus morphine will be justified.

\section{Design}

There were no implications for the design of future clinical studies.

\section{Measurement (endpoints)}

For future cancer pain studies, developing a single outcome that combines good pain control (no more than mild on a verbal rating scale) with acceptable adverse effects (perhaps no more than mild severity on any adverse event) would enable a clearer comparison between any analgesics used in this context.

\section{ACKNOWLEDGEMENTS}

We would like to thank Yuhong Yuan (Department of Medicine, Division of Gastroenterology McMaster University, Canada) and YuTian Xiao (School of Clinical Medicine, Fudan University, China) for help with the translation of Chinese papers and Joanne Abbott at the Cochrane Pain, Palliative and Supportive Care Review Group (PaPaS) for her assistance in devising and executing the search strategy.

Cochrane Review Group funding acknowledgement: this project was supported by the National Institute for Health Research (NIHR), via Cochrane Infrastructure funding to Cochrane PaPaS. The views and opinions expressed therein are those of the authors and do not necessarily reflect those of the Systematic Reviews Programme, NIHR, National Health Service, or the Department of Health. 


\section{RE F E R E N C E S}

\section{References to studies included in this review}

Beaver 1978a \{published data only\}

Beaver WT, Wallenstein SL, Rogers A, Houde RW. Analgesic studies of codeine and oxycodone in patients with cancer. I. Comparisons of oral with intramuscular codeine and of oral with intramuscular oxycodone. Journal of Pharmacology and Experimental Therapeutics 1978;207(1):92-100.

\section{Beaver 1978b \{published data only\}}

Beaver WT, Wallenstein SL, Rogers A, Houde RW. Analgesic studies of codeine and oxycodone in patients with cancer. II. Comparisons of intramuscular oxycodone with intramuscular morphine and codeine. Journal of Pharmacology and Experimental Therapeutics 1978;207(1):101-8.

\section{Bruera 1998 \{published data only\}}

Bruera E, Belzile M, Pituskin E, Fainsinger R, Darke A, Harsanyi Z, et al. Randomized, double-blind, cross-over trial comparing safety and efficacy of oral controlled-release oxycodone with controlled-release morphine in patients with cancer pain. Journal of Clinical Oncology 1998;16(10):3222-9.

Comerford T, Bruera E. Efficacy of controlled-release oxycodone. Journal of Clinical Oncology 1999;17:738.

\section{Corli 2016 \{published data only\}}

Corli O, Floriani I, Roberto A, Montanari M, Galli F, Greco MT, et al on behalf of the CERP Study of Pain Group. Are strong opioids equally effective and safe in the treatment of chronic cancer pain? A multicenter randomized phase IV 'real life' trial on the variability of response to opioids. Annals of Oncology 2016;27:1107-15.

\section{Gabrail 2004 \{published data only\}}

Gabrail NY, Dvergsten C, Ahdieh H. Establishing the dosage equivalency of oxymorphone extended release and oxycodone controlled release in patients with cancer pain: a randomized controlled study. Current Medical Research and Opinion 2004;20(6):911-8.

Gabrail NY, Dvergsten C, Ma T, Frailey A, Ahdieh H. Oxymorphone extended-release (ER) provides safe, effective, and rapid analgesia during opioid radiation: results of a randomized, double-blind, crossover, comparative study with oxycodone controlled-release (CR) [abstract]. Proceedings of the American Society of Clinical Oncology 2003:737.

\section{Hagen 1997 \{published data only\}}

Hagen NA, Babul N. Comparative clinical efficacy and safety of a novel controlled-release oxycodone formulation and controlled-release hydromorphone in the treatment of cancer pain. Cancer 1997;79(7):1428-37.

\section{Heiskanen 1997 \{published data only\}}

Heiskanen T, Kalso E. Controlled-release oxycodone and morphine in cancer related pain. Pain 1997;73(1):37-45.

Heiskanen TE, Ruismaki PM, Seppala TA, Kalso EA. Morphine or oxycodone in cancer pain?. Acta Oncologica 2000;39(8):941-7.
Imanaka 2013 \{published data only\}

Imanaka K, Tominaga Y, Etropolski M, Van Hove I, Ohsaka M, Wanibe M, et al. Efficacy and safety of oral tapentadol extended release in Japanese and Korean patients with moderate to severe, chronic malignant tumor-related pain. Current Medical Research and Opinion 2013;29:1399-409.

Kalso 1990 \{published data only\}

Kalso E, Vainio A. Morphine and oxycodone hydrochloride in the management of cancer pain. Clinical Pharmacology and Therapeutics 1990;47(5):639-46.

Kalso E, Vainio A, Mattila MJ, Rosenberg PH, Seppala T. Morphine and oxycodone in the management of cancer pain: plasma levels determined by chemical and radioreceptor assays. Pharmacology \& Toxicology 1990;67(4):322-8.

Kaplan 1998 \{published data only\}

Kaplan R, Parris WC, Citron ML, Zhukovsky D, Reder RF, Buckley BJ, et al. Comparison of controlled-release and immediate-release oxycodone tablets in patients with cancer pain. Journal of Clinical Oncology 1998;16(10):3230-7.

Lauretti 2003 \{published data only\}

Lauretti GR, Oliveira GM, Pereira NL. Comparison of sustainedrelease morphine with sustained-release oxycodone in advanced cancer patients. British Journal of Cancer 2003;89(11):2027-30.

Leow 1995 \{published data only\}

Leow KP, Cramond T, Smith MT. Pharmacokinetics and pharmacodynamics of oxycodone when given intravenously and rectally to adult patients with cancer pain. Anesthesia and Analgesia 1995;80(2):296-302.

\section{Lux 2014 \{published data only\}}

Lux EA, Janecki M, Maritz MA. Clinical evaluation of the first oxycodone once daily prolonged release tablet in moderate to severe chronic pain: a randomized, double-blind, multicenter, cross-over, non-inferiority study to investigate efficacy and safety in comparison with an established oxycodone twice daily prolonged release tablet. Current Medical Research and Opinion 2014;30(11):2365-75.

\section{Mercadante 2010 \{published data only\}}

Mercadante S, Tirelli W, David F, Arcara C, Fulfaro F, Casuccio A, et al. Morphine versus oxycodone in pancreatic cancer pain: a randomized controlled study. Clinical Journal of Pain 2010;26(9):794-7.

\section{Mucci-LoRusso 1998 \{published data only\}}

Mucci-LoRusso P, Berman BS, Silberstein PT, Citron ML, Bressler L, Weinstein SM, et al. Controlled-release oxycodone compared with controlled-release morphine in the treatment of cancer pain: A randomized, double-blind, parallel-group study. European Journal of Pain 1998;2(3):239-49. 


\section{Parris 1998 \{published data only\}}

Parris WC, Johnson BW Jr, Croghan MK, Moore MR, Khojasteh A, Reder RF, et al. The use of controlled-release oxycodone for the treatment of chronic cancer pain: a randomized, doubleblind study. Journal of Pain and Symptom Management 1998;16(4):205-11.

\section{Riley 2015 \{published data only\}}

Riley J, Branford R, Droney J, Gretton S, Sato H, Kennett A, et al. Morphine or oxycodone for cancer-related pain? A randomised, open-label, controlled trial. Journal of Pain and Symptom Management 2015;49(2):161-72.

Riley J, Branford R, Droney J, Gretton S, Sato H, Thick M, et al. A randomised controlled trial of oral morphine versus oral oxycodone for the treatment of pain in cancer patients. Palliative Medicine 2012;26(4):386.

\section{Salzman 1999 \{published data only\}}

Salzman RT, Roberts MS, Wild J, Fabian C, Reder RF, Goldenheim PD. Can a controlled-release oral dose form of oxycodone be used as readily as an immediate-release form for the purpose of titrating to stable pain control?. Journal of Pain and Symptom Management 1999;18(4):271-9.

\section{Stambaugh 2001 \{published data only\}}

Stambaugh JE, Reder RF, Stambaugh M. Doubleblind, randomized, two-period crossover efficacy and pharmacokinetic comparison of immediate-release oxycodone (IR) and controlled-release oxycodone (CR) in cancer patients with pain. Clinical Pharmacology and Therapeutics 1997;61(2):197.

Stambaugh JE, Reder RF, Stambaugh MD, Stambaugh H, Davis M. Double-blind, randomized comparison of the analgesic and pharmacokinetic profiles of controlled-and immediaterelease oral oxycodone in cancer pain patients. Journal of Clinical Pharmacology 2001;41(5):500-6.

\section{Su 2015 \{published data only\}}

Su J, Zhu Y, Wu W, Luo Y. Observation of curative effects and adverse effects of oxycodone hydrochloride controlled-release tablets and fentanyl transdermal patches on the treatment of moderate or severe cancer pain. Anti-Tumor Pharmacy 2015;5(6):444-8.

\section{Yu 2014 \{published data only\}}

Yu S, Shen W, Yu L, Hou Y, Han J, Richards HM. Safety and efficacy of once-daily hydromorphone extended-release versus twice-daily oxycodone hydrochloride controlledrelease in Chinese patients with cancer pain: A phase 3 , randomized, double-blind, multicenter study. Journal of Pain 2014;15(8):835-44.

\section{Zecca 2016 \{published data only\}}

Zecca E, Brunelli C, Bracchi P, Biancofiore G, De Sangro C, Bortolussi R, et al. Comparison of the tolerability profile of controlled-release oral morphine and oxycodone for cancer pain treatment. An open-label randomized controlled trial. Journal of Pain and Symptom Management 2016;52(6):783-94.
Zhang 2014 \{published data only\}

Zhang W-Z, Yu W-J, Zhao X-L, He B-X. Pharmacoeconomics evaluation of morphone, MS Contin and oxycodone in the treatment of cancer pain. Asian Pacific Journal of Cancer Prevention 2014;15(20):8797-800.

\section{References to studies excluded from this review}

\section{Ahmedzai 2012 \{published data only\}}

Ahmedzai SH, Friedemann N, Bar-Sela G, Bjorn B, Leyendecker P, Hopp M. A randomized, double-blind, activecontrolled, double-dummy, parallel-group study to determine the safety and efficacy of oxycodone/naloxone prolongedrelease tablets in patients with moderate/severe, chronic cancer pain. Palliative Medicine 2012;26(1):50-60.

\section{Awerbuch 2011 \{published data only\}}

Awerbuch MS. Should opioids be used for chronic non-cancer pain?. Medical Journal of Australia 2011;195(5):264-5.

Bekkering 2011 \{published data only\}

Bekkering GE, Soares-Weiser K, Reid K, Kessels AG, Dahan A, Treede RD, et al. Can morphine still be considered to be the standard for treating chronic pain? A systematic review including pair-wise and network meta-analyses. Current Medical Research and Opinion 2011;27:1477-91.

\section{Bell 2006 \{published data only\}}

Bell RF, Wisloff T, Eccleston C, Kalso E. Controlled clinical trials in cancer pain. How controlled should they be? A qualitative systematic review. British Journal of Cancer 2006;94(11):1559-67.

\section{Borchgrevink 2004 \{published data only\}}

Borchgrevink PC, Klepstad P, Kongsgaard UE, Kaasa S. Use of opioids against severe cancer pain [Bruk av opioider mot sterke kreftrelaterte smerter]. Tidsskrift for Den Norske Laegeforening 2004;124(3):337-8

\section{Caraceni 2011 \{published data only\}}

Caraceni A, Pigni A, Brunelli C. Is oral morphine still the first choice opioid for moderate to severe cancer pain? A systematic review within the European Palliative Care Research Collaborative guidelines project. Palliative Medicine 2011;25:402-9.

\section{Carroll 2011 \{published data only\}}

Carroll EMA, Kamboj SK, Conroy L, Tookman A, Williams AC, Jones $L$, et al. Facial affect processing in patients receiving opioid treatment in palliative care: Preferential processing of threat in pain catastrophizers. Journal of Pain and Symptom Management 2011;41(6):975-85.

\section{Chary 1994 \{published data only\}}

Chary S, Goughnour BR, Moulin DE, Thorpe WR, Harsanyi Z, Darke AC. The dose-response relationship of controlled-release codeine (Codeine Contin) in chronic cancer pain. Journal of Pain and Symptom Management 1994;9(6):363-71. 


\section{Chen 2009 \{published data only\}}

Chen HP, Jiang JJ, Li JX. Efficacy and safety of oxycodoneacetaminophen for moderate and severe visceral pain in advanced cancer patients. Chinese Journal of New Drugs 2009;18(10):920-2.

\section{De Conno 1991 \{published data only\}}

De Conno F, Ripamonti C, Sbanotto A, Barletta L, Zecca E, Martini C, et al. A clinical study on the use of codeine, oxycodone, dextropropoxyphene, buprenorphine, and pentazocine in cancer pain. Journal of Pain and Symptom Management 1991;6(7):423-7.

\section{Dunlop 2013 \{published data only\}}

Dunlop W, Neufeld K. Quality of life benefits and cost impact of prolonged release oxycodone/naloxone versus prolonged release oxycodone in patients with moderate to severe pain and opioid-induced constipation despite the use of 2 laxatives: A UK cost utility analysis. Value in Health 2013;16(7):A384.

\section{Fallon 2011 \{published data only\}}

Fallon MT, Laird BJA. A systematic review of combination step III opioid therapy in cancer pain: an EPCRC opioid guideline project. Palliative Medicine 2011;25(5):597-603.

\section{Garassino 2010 \{published data only\}}

Garassino MC, Febbraro A, lorno V, Carbone A, Spagnoletti I, Isa L, et al. Randomized phase ii trial (NCT00637975) evaluating activity and toxicity of fixed dose of oxycodone and increasing dose of pregabalin versus increasing dose of oxycodone and fixed dose of pregabalin for the treatment of oncological neuropathic pain (neuropain-01). Annals of Oncology 2010;21:viii363.

\section{Garassino 2011 \{published data only\}}

Garassino MC, Bianchi A, Febbraro A, Spagnoletti I, Iorno V, Bramati A, et al. Final results of a randomized phase II trial (NCT00637975) evaluating activity and toxicity of fixed-dose oxycodone and increasing dose of pregabalin versus increasing dose of oxycodone and fixed-dose pregabalin for the treatment of oncologic neuropathic pain (NEUROPAIN-01). Journal of Clinical Oncology. Conference: ASCO Annual Meeting 2011;29(15 Suppl 1):9028.

\section{Garassino 2013 \{published data only\}}

Garassino MC, Piva S, Verde N, Spagnoletti I, Iorno V, Carbone C, et al. Randomised phase II trial (NCT00637975) evaluating activity and toxicity of two different escalating strategies for pregabalin and oxycodone combination therapy for neuropathic pain in cancer patients. PloS One 2013;8(4):e59981.

\section{George 2003 \{published data only\}}

George B, Douard MC, Dubreuil ML. Oxycodone: Alternative therapy in the management of chronic cancer pain [L'oxycodone: Alternative therapeutique dans la prise en charge de la douleur chronique d'origine cancereuse]. Cahiers d'Anesthesiologie 2003;51:HS7-12.

\section{Hanks 2002 \{published data only\}}

Hanks G. Morphine and other opioids in the treatment of cancer pain?. International Journal of Cancer. Supplement = Journal International du Cancer. Supplement 2002;13:5.

\section{Hongmei 2013 \{published data only\}}

Hongmei X, Jianwen S. Compound matrine injection in liver carcinoma pain: A clinical study. Journal of Gastroenterology and Hepatology 2013;28:790.

Igarashi 2015 \{published data only\}

Igarashi T, Abe K, Miura T, Kinoshita H. Oxycodone frequently induced nausea and vomiting in oxycodone-naive patients with hepatic dysfunction. Journal of Palliative Medicine 2015;18(5):399.

Katz 2008 \{published data only\}

Katz MH, Kotabe S. Decreasing use of controlled-release oxycodone - Response. Medical Care 2008;46(9):1002.

\section{Kim 2015 \{published data only\}}

Kim HJ, Kim YS, Park SH. Opioid rotation versus combination for cancer patients with chronic uncontrolled pain: a randomized study. BMC Palliative Care 2015;14:41.

\section{King 2011 \{published data only\}}

King SJ, Reid C, Forbes K, Hanks G. A systematic review of oxycodone in the management of cancer pain. Palliative Medicine 2011;25:454-70.

\section{Koyyalagunta 2012 \{published data only\}}

Koyyalagunta D, Bruera E, Solanki DR, Nouri KH, Burton AW, Toro MP, et al. A systematic review of randomized trials on the effectiveness of opioids for cancer pain. Pain Physician 2012;15(3 Suppl):ES39-58.

\section{Kummer 2011 \{published data only\}}

Kummer O, Hammann F, Moser C, Schaller O, Drewe J, Krahenbuhl S. Effect of the inhibition of CYP3A4 or CYP2D6 on the pharmacokinetics and pharmacodynamics of oxycodone. European Journal of Clinical Pharmacology 2011;67(1):63-71.

LeBon 2009 \{published data only\}

LeBon B, Zeppetella G, Higginson IJ. Effectiveness of topical administration of opioids in palliative care: a systematic review. Journal of Pain and Symptom Management 2009;37(5):913-7.

Leppert 2011 \{published data only\}

Leppert W, Ahmedzai SH, Uhl R, Kremers W, Hopp M. Long-term efficacy and safety of the fixed combination oxycodone and naloxone prolonged release (PR) in patients with chronic cancer pain. European Journal of Pain Supplements 2011;5(1):172.

\section{Li 2008 \{published data only\}}

Li RC, He BS. Therapeutic outcome of Tylox for cancer pain in malignant tumor patients with bone metastasis. Chinese Journal of New Drugs 2008;17(18):1619-21.

\section{Li 2010 \{published data only\}}

Li XM, Liu DQ, Wu HY, Yang C, Yang L. Controlled-release oxycodone alone or combined with gabapentin for 
management of malignant neuropathic pain. Chinese Journal of Cancer Research 2010;22(1):80-6.

\section{Ma 2016 \{published data only\}}

Ma H, Liu Y, Huang L, Zeng XT, Jin SH, Yue GJ, et al. The adverse events of oxycodone in cancer-related pain: a systematic review and meta-analysis of randomized controlled trials. Medicine (Hagerstown) 2016;95(15):e3341.

\section{Marineo 2012 \{published data only\}}

Marineo G, Iorno V, Gandini C, Moschini V, Smith TJ. Scrambler therapy may relieve chronic neuropathic pain more effectively than guideline-based drug management: Results of a pilot, randomized, controlled trial. Journal of Pain and Symptom Management 2012;43(1):87-95.

\section{Meng 2008 \{published data only\}}

Meng XT Xian Dai Zhong Xi Yi Jie He Za Zhi. Effectiveness observation on oxycodone hydrochloride controlled-release tablets for cancer pain. Modern Journal of Integrated Traditional Chinese and Western Medicine 2008;17(2):199-200.

\section{Moertel 1974 \{published data only\}}

Moertel CG, Ahmann DL, Taylor WF, Schwartau N. Relief of pain by oral medications. A controlled evaluation of analgesic combinations. Journal of the American Medical Association 1974;229(1):55-9.

\section{Moksnes 2012 \{published data only\}}

Moksnes K, Kaasa S, Paulsen Ã, Rosland JH, Spigset O, Dale O. Serum concentrations of opioids when comparing two switching strategies to methadone for cancer pain. European Journal of Clinical Pharmacology 2012;8:1147-56.

\section{Nadstawek 2008 \{published data only\}}

Nadstawek J, Leyendecker P, Hopp M, Ruckes C, Wirz S, Fleischer W, et al. Patient assessment of a novel therapeutic approach for the treatment of severe, chronic pain.

International Journal of Clinical Practice 2008;62(8):1159-67.

\section{Nalamachu 2013 \{published data only\}}

Nalamachu S, Rauck R, Dillaha L, Parikh N. Lack of correlation between the dose of fentanyl sublingual spray for breakthrough cancer pain and the dose of around-the-clock opioid for persistent pain. Journal of Pain 2013;1:S74.

\section{NCT01859715 \{published data only\}}

NCT01859715. Emergency department (ED) drug interaction in emergency department patients. clinicaltrials.gov/ct2/show/ results/NCT01859715 Date first received: 1 May 2013.

\section{NCT01885182 \{published data only\}}

NCT01885182. Targin cancer pain. clinicaltrials.gov/ct2/show/ NCT01885182 Date first received: 19 June 2013.

\section{Nunez Olarte 2008 \{published data only\}}

Nunez Olarte JM. Oxycodone and the challenge of neuropathic cancer pain: a review. Oncology 2008;74:83-90.

\section{Oosten 2015 \{published data only\}}

Oosten AW, Oldenmenger WH, Mathijssen RH, van der Rijt CC. A systematic review of prospective studies reporting adverse events of commonly used opioids for cancer-related pain: a call for the use of standardized outcome measures. Journal of Pain 2015;16(10):935-46.

Pang 2009 \{published data only\}

Pang J, Jie BJ, Li YP. Efficacy of oxycodone-acetominophen by different administrations in controlling moderate to severe cancer pain and break-out pain. Chinese Journal of New Drugs 2009;18(18):1767-70,1776.

\section{Passik 2014 \{published data only\}}

Passik SD, Narayana A, Yang R. Aberrant drug-related behavior observed during a 12-week open-label extension period of a study involving patients taking chronic opioid therapy for persistent pain and fentanyl buccal tablet or traditional short-acting opioid for breakthrough pain. Pain Medicine 2014;15(8):1365-72.

\section{Reid 2006 \{published data only\}}

Reid CM, Martin RM, Sterne JAC, Davies AN, Hanks GW. Oxycodone for cancer-related pain: Meta-analysis of randomized controlled trials. Archives of Internal Medicine 2006;166:837-43.

\section{Rentz 2009 \{published data only\}}

Rentz AM, Yu R, Muller-Lissner S, Leyendecker P. Validation of the Bowel Function Index to detect clinically meaningful changes in opioid-induced constipation. Journal of Medical Economics 2009;12(4):371-83.

Shi 2008 \{published data only\}

Shi L, Xiong HH, Yang L, Yu SY. Analgesic effect of oxycodoneacetaminophen tablets in patients with cervical cancer. Chinese Journal of New Drugs 2008;17:1884-5.

\section{Sima 2010a \{published data only\}}

Sima L, Wu X, Fang W, Li F. Oxycodone/acetaminophen addition to constant opioids in metastatic bone pain: A randomized, double-blinded, controlled, multicenter trial. Journal of Clinical Oncology 2010;28(15 Suppl 1):e19691.

\section{Sima 2010b \{published data only\}}

Sima L, Wu X, Fang W. Oxycodone/acetaminophen combination tablet in patients with metastatic bone pain: A randomized, double-blinded, placebo-controlled trial. Annals of Oncology 2010;21:378.

\section{Sima 2012 \{published data only\}}

Sima L, Fang WX, Wu XM, Li F. Efficacy of oxycodone/ paracetamol for patients with bone-cancer pain: a multicenter, randomized, double-blinded, placebo-controlled trial. Journal of Clinical Pharmacy and Therapeutics 2012;37(1):27-31.

\section{Stambaugh 1980a \{published data only\}}

Stambaugh JEJ, Tejada F, Trudnowski RJ. Double-blind comparisons of zomepirac and oxycodone with aspirin phenacetin caffeine in cancer pain. Journal of Clinical Pharmacology 1980;20(4):261-70. 
Stambaugh 1980b \{published data only\}

Stambaugh JEJ. Analgesic equivalence of Tylox ${ }^{\circledR}$ and Percodan ${ }^{\circledR}$ : Double-blind crossover study of patients with pain from malignancy. Current Therapeutic Research, Clinical and Experimental 1980;27(2):302-8.

\section{Stambaugh 1981 \{published data only\}}

Stambaugh JE Jr, Sarajian C. Analgesic efficacy of zomepirac sodium in patients with pain due to cancer. Journal of Clinical Pharmacology 1981;21:501-7.

\section{Stambaugh 1985 \{published data only\}}

Stambaugh JEJ, McAdams J. A double-blind comparison of ibuprofen vs. placebo in reducing oxycodone-acetaminophen dosage in chronic cancer pain. Clinical Research 1985;33:458A.

\section{Stambaugh 1987 \{published data only\}}

Stambaugh JE, McAdams J. Comparison of the efficacy and safety of oral xorphanol, acetaminophen/oxycodone and placebo in chronic cancer pain. International Journal of Clinical Pharmacology and Therapeutics 1987;41:229.

\section{Stambaugh 1990 \{published data only\}}

Stambaugh J, Drew J, Johnson J. Comparison of flurbiprofen (Ansaid), oxycodone APAP and placebo in cancer pain, after single and repeat oral doses. Clinical Pharmacology and Therapeutics 1990;47:187.

\section{Stambaugh 1991 \{published data only\}}

Stambaugh JE. Multidose analgesic studies in chronic pain models. Advances in Pain Research and Therapy 1991;18:151-63.

\section{Taeron 2002 \{published data only\}}

Taeron C. Extended release oxycodone. An oral opioid analgesic for cancer patients with chronic pain. Revue De L'Infirmiere 2002;85:47-9.

\section{Wallace 2013 \{published data only\}}

Wallace E, Twomey M, Victory R, O'Reilly M. Intravesical baclofen, bupivacaine, and oxycodone for the relief of bladder spasm. Journal of Palliative Care 2013;29(1):49-51.

Wang 2012 \{published data only\}

Wang YM, Liu ZW, Liu JL, Zhang L. Efficacy and tolerability of oxycodone in moderate-severe cancer-related pain: A metaanalysis of randomized controlled trials. Experimental and Therapeutic Medicine 2012;4(2):249-54.

\section{Watanabe 2008 \{published data only\}}

Watanabe S, Pereira J, Tarumi Y, Hanson J, Bruera E. A randomized double-blind crossover comparison of continuous and intermittent subcutaneous administration of opioid for cancer pain. Journal of Palliative Medicine 2008;11(4):570-4.

Wu 2009 \{published data only\}

Wu H, Ouyang QC, Liu LP, Wang PH. Safety and efficacy of oxycodone/acetaminophen in treatment of moderate and advanced cancer pain. Chinese Journal of Cancer Prevention and Treatment 2009;18:1432-4.
Wu 2015 \{published data only\}

Wu H, Chen Y, Shen Q, Cao X, Lu L. Application of controlledrelease oxycodone and oral immediate-release morphine in the titration treatment of cancer pain [着弪考酮缓释片联合吗啡片在 癌痛滴定治疗中的应用]. Anti-Tumor Pharmacy 2015;2:112-5.

\section{Xiong 2008 \{published data only\}}

Xiong J, Liang C, Wu X, Zhao YX, Fu L, Zhou YF. Efficacy and safety of oxycodone-acetaminophen tablet in 142 patients with different types of moderate and advanced cancer pain. Chinese Journal of New Drugs 2008;21:1877-9, 1900.

Xu 2008 \{published data only\}

Xu LH, Quan SC, Wu LB. Treatment beginning with minute dose oxycontin with advanced stage cancer pain. Modern Journal of Integrated Traditional Chinese and Western Medicine 2008;6:859-60.

\section{Zou 2009 \{published data only\}}

Zou J, Wang Q, Liu L. Efficacy of oxycodone-acetaminophen as an adjuvant of opioid analgesics for cancer pain. Chinese Journal of New Drugs 2009;18(10):923-4.

\section{References to studies awaiting assessment}

2012-001578-26 \{unpublished data only\}

\section{Aurilio 2009 \{published data only\}}

Aurilio C, Sansone P, Pace MC, Passavanti MB, Romano SV Pota V. Evaluation of efficacy and safety of prolonged-release oxycodone at different dosages for the treatment of severe chronic pain. Pain Practice 2009;9:103.

JapicCTI-090789/090/091 \{unpublished data only\}

NCT00378937 \{unpublished data only\}

NCT00726830 \{unpublished data only\}

Song 2009 \{published data only\}

Song JF, Zhao YL, Zhou HM, Wang HJ, Li KY. Efficacies of oxycodone and morphine sulfate sustained-release tablets in treating moderate and severe cancer pain. Chinese Journal of New Drugs 2009;18(4):337-9.

\section{References to ongoing studies}

2008-002273-12 \{unpublished data only\}

Long term opioid administration in oncologic chronic pain: open label, prospective study on efficacy, safety and pharmacogenetic factors. Ongoing study Not reported.

\section{9-013118-28 \{unpublished data only\}}

Bukkaalinen fentanyyli syöpäpotilaiden toimenpidekivun hoidossa ("The buccal fentanyl in cancer pain management measure"). Ongoing study Not reported. 
Elsayem 2010 \{unpublished data only\}

Elsayem AF, Bain KT, Palmer JL, Bearden J, Fisch M. A randomized comparison of oral methadone as a "first-switch" opioid versus opioid switching between sustained-release morphine and oxycodone for oncology outpatients with pain management problems. Journal of Clinical Oncology 2010;28(15 Suppl 1):TPS324.

\section{JapicCTI-132338 \{unpublished data only\}}

DS-7113b phase III study: A randomized double-blind comparison study with immediate release (IR) oxycodone in opioid-naive patients with cancer pain. 2013.

\section{NCT00916890 \{unpublished data only\}}

Chronic Administration of Opioids in Cancer Chronic Pain:an Open Prospective Study on Efficacy, Safety and Pharmacogenetic Factors Influence. Ongoing study February 2009.

\section{NCT01165281 \{unpublished data only\}}

A Randomized, Double-Blind, Active Controlled, Optimal Dose Titration, Multicenter Study to Evaluate the Safety and Efficacy of Oral JNS024 Extended Release (ER) in Japanese and Korean Subjects With Moderate to Severe Chronic Malignant Tumor Related Cancer Pain. Ongoing study August 2012.

\section{NCT01675622 \{unpublished data only\}}

A Comparative Study of Immediate-Release Oxycodone Capsules Versus Immediate-Release Morphine Tablets for the Treatment of Chinese Patients With Cancer Pain.. Ongoing study December 2010.

\section{NCT02084355 \{unpublished data only\}}

NCT02084355. Study of opioid rotation versus opioid escalation in patients with moderate to severe cancer pain. clinicaltrials.gov/ct2/show/NCT02084355 Date first received: 5 March 2014.

\section{UMIN000011756 \{unpublished data only\}}

Odanaka M. Randomized study of fentanyl citrate versus oxycodone hydrochloride hydrate in patients with unresectable advanced pancreatic cancer. upload.umin.ac.jp/cgi-open-bin/ctr/ctr.cgi? function=brows\&action=brows\&type=sum Date first registered: 13 September 2013.

\section{Additional references}

\section{Bennett 2008}

Bennett MI. What evidence do we have that the $\mathrm{WHO}$ analgesic ladder is effective in cancer pain?. In: McQuay HJ, Moore $\mathrm{R}$, Kalso E editor(s). Systematic Reviews in Pain Research; Methodology Refined. Seattle (WA): IASP Press, 2008:303-13.

\section{Breivik 2009}

Breivik H, Cherny N, Collett B, de Conno F, Filbet M, Foubert AJ, et al. Cancer-related pain: a pan-European survey of prevalence, treatment, and patient attitudes. Annals of Oncology 2009;20:1420-33.

\section{Caraceni 2012}

Caraceni A, Hanks GW, Kaasa S, Bennett MI, Brunelli C, Cherny $\mathrm{N}$, et al. Use of opioid analgesics in the treatment of cancer pain: evidence based recommendations from the EAPC. Lancet Oncology 2012;13:e58-68.

\section{GRADEpro GDT 2015 [Computer program]}

McMaster University, 2015 (developed by Evidence Prime, Inc.). GRADEpro Guideline Development Tool [Software]. McMaster University, 2015 (developed by Evidence Prime, Inc.), 2015.

\section{Greco 2014}

Greco MT, Roberto A, Corli O, Deandrea S, Bandieri E, Cavuto S, et al. Quality of cancer pain management: an update of a systematic review of under-treatment of patients with cancer. Journal of Clinical Oncology 2014;32(36):4149-54.

\section{Gudin 2012}

Gudin J. Opioid therapies and cytochrome P450 interactions. Journal of Pain and Symptom Management 2012;44:S4-14.

\section{Higgins 2011}

Higgins JPT, Green S, editor(s). Cochrane Handbook for Systematic Reviews of Interventions Version 5.1.0 (updated March 2011). The Cochrane Collaboration, 2011. Available from handbook.cochrane.org.

\section{Lefebvre 2011}

Lefebvre C, Manheimer E, Glanville J. Chapter 6: Searching for studies. In: Higgins JP, Green S, editor(s). Cochrane Handbook for Systematic Reviews of Interventions Version 5.1.0 (updated March 2011). The Cochrane Collaboration, 2011. Available from handbook.cochrane.org.

\section{Leppert 2010}

Leppert W. Role of oxycodone and oxycodone/naloxone in cancer pain management. Pharmacological Report 2010;62:578-91.

\section{RevMan 2014 [Computer program]}

The Nordic Cochrane Centre, The Cochrane Collaboration. Review Manager (RevMan). Version 5.3. Copenhagen: The Nordic Cochrane Centre, The Cochrane Collaboration, 2014

Ventafridda 198

Ventafridda V, Tamburini M, Caraceni A, De Conno F, Naldi F. A validation study of the WHO method for cancer pain relief. Cancer 1987;59:851-6.

\section{WHO 1986}

World Health Organization (WHO). Cancer Pain Relief. WHO, Geneva 1986.

\section{Ziegler 2016}

Ziegler LE, Mulvey MR, Blenkinsopp A, Petty D, Bennett MI. Opioid prescribing for cancer patients in the last year of life: a longitudinal population cohort study. Pain 2016;157(11):2445-51. 


\section{References to other published versions of this review}

\section{Reid 2010}

Reid CM, Davies AN, Hanks GW, Martin RM, Sterne JAC. Oxycodone for cancer-related pain. Cochrane Database of Systematic Reviews 2010, Issue 3. [DOI: 10.1002/14651858.CD003870.pub3]

\section{Schmidt-Hansen 2015}

Schmidt-Hansen, M, Bennett, MI, Hilgart, J. Oxycodone for cancer pain in adult patients. JAMA 2015;314:1282-3.

\section{Schmidt-Hansen 2018}

Schmidt-Hansen, M, Bennett, MI, Arnold, S, Bromham, N, Hilgart, JS. Efficacy, tolerability and acceptability of oxycodone for cancer-related pain in adults: an updated Cochrane systematic review. BMJ Supportive \& Palliative Care 2018;8:117-28.

\title{
CHARACTERISTICS OF STUDIES
}

Characteristics of included studies [ordered by study ID]

\section{Beaver 1978a}

\begin{tabular}{|c|c|}
\hline Methods & $\begin{array}{l}\text { Design: randomised, double-blind, cross-over trial. } \\
\text { Year: not reported. } \\
\text { Country: USA. }\end{array}$ \\
\hline Participants & $\begin{array}{l}\text { Participants: } 17 \text { participants entered, "13 patients completed at least one round" (see 'Interventions' } \\
\text { below) and were analysed for efficacy ("The } 4 \text { patients who failed to complete a single round did so for } \\
\text { reasons extraneous to the drugs under study"); } 5 \text { men/ } 8 \text { women, mean (range) age } 51 \text { ( } 23-68) \text { years. } \\
\text { "One of these patients appeared twice in the study, and } 5 \text { completed a second round, yielding } 19 \text { cross- } \\
\text { over comparisons." } \\
\text { Inclusion criteria: "The subjects were patients with a variety of malignant tumours on the wards of } \\
\text { James Ewing Hospital. Each patient was first examined to ascertain the nature and location of his or } \\
\text { her pain, the extent of disease, prior experience with narcotics and analgesic drugs and ability to com- } \\
\text { municate meaningful information about pain. At this time, the patient was also told how the studies } \\
\text { were to be conducted and that, while all test medications might appear the same, they would actually } \\
\text { include a number of different drugs, some probably more effective than others in relieving pain. Many } \\
\text { of the patients had had some prior experience with oral or parenteral narcotics, and several had a his- } \\
\text { tory of sufficient recent narcotic use to warrant the assumption that they possessed some tolerance } \\
\text { to narcotics. Patients were placed on a routine analgesic other than those included in the study during } \\
\text { nonstudy hours, and, insofar as was possible, concomitant administration of psychoactive drugs was } \\
\text { avoided." }\end{array}$ \\
\hline & Exclusion criteria: see 'Inclusion criteria.' No other information provided. \\
\hline
\end{tabular}

Interventions

\author{
Oxycodone arm \\ - Drug: oxycodone + oral placebo. \\ - Dose/dosing: $5 \mathrm{mg}$. \\ - Formulation: Intramuscular \\ - Route of administration: Intramuscular \\ - Length of treatment: appears to be single dose. \\ - Titration schedule: no titration.
}

- Rescue medication: assessed by participant "hourly for 6 hours after administration of the study medication or until pain returned to the premedication level and a routine analgesic was administered (if at least $3 \mathrm{hr}$ [hours] had elapsed since administration of the study medication)." No further information reported.

- Other medication: see 'Rescue medication' and 'Inclusion criteria.' 


\section{Comparison arm 1}

- Drug: oxycodone + oral placebo.

- Dose or dosing: $15 \mathrm{mg}$.

- Formulation: Intramuscular

- Route of administration: Intramuscular

- Length of treatment: appears to be single dose.

- Titration schedule: no titration.

- Rescue medication: assessed by participant "hourly for 6 hours after administration of the study medication or until pain returned to the premedication level and a routine analgesic was administered (if at least $3 \mathrm{hr}$ [hours] had elapsed since administration of the study medication)." No further information reported.

- Other medication: see 'Rescue medication' and 'Inclusion criteria.'

\section{Comparison arm 2}

- Drug: oxycodone + intramuscular placebo

- Dose or dosing: $10 \mathrm{mg}$

- Formulation: Immediate-release?

- Route of administration: oral.

- Length of treatment: appears to be single dose.

- Titration schedule: no titration.

- Rescue medication: assessed by participant "hourly for 6 hours after administration of the study medication or until pain returned to the premedication level and a routine analgesic was administered (if at least $3 \mathrm{hr}$ [hours] had elapsed since administration of the study medication)." No further information reported.

- Other medication: see 'Rescue medication' and 'Inclusion criteria.'

\section{Comparison arm 3}

- Drug: oxycodone + intramuscular placebo

- Dose or dosing: $30 \mathrm{mg}$

- Formulation: Immediate-release?

- Route of administration: oral.

- Length of treatment: appeared to be single dose.

- Titration schedule: no titration.

- Rescue medication: assessed by participant "hourly for 6 hours after administration of the study medication or until pain returned to the premedication level and a routine analgesic was administered (if at least $3 \mathrm{hr}$ [hours] had elapsed since administration of the study medication)." No further information reported.

- Other medication: see 'Rescue medication' and 'Inclusion criteria.'

- For cross-over trials, cross-over schedule: "Treatments were assigned to patients according to a series of randomly chosen Latin squares, and each study medication was administered on a separate day. Each patient received a low and a high dose of both the "standard" and the "test drug," chosen at equi- 
Beaver 1978a (Continued)

log intervals. Unless a patient completed all doses of the crossover comparison or "round," his data were excluded from the relative potency analysis. After completing the first round, some patients were able to repeat the course, allowing for comparison of replicate rounds within the same individual."

Outcomes

- Pain intensity: assessed by participant "hourly for 6 hours after administration of the study medication or until pain returned to the premedication level and a routine analgesic was administered (if at least $3 \mathrm{hr}$ [hours] had elapsed since administration of the study medication);" using a 4-point categorical scale $(0=$ none, 1 = slight, 2 = moderate, 3 = severe $)$.

- Pain relief: assessed by participant hourly for 6 hours after administration of the study medication or until pain returned to the premedication level and a routine analgesic was administered (if at least 3 hours had elapsed since administration of the study medication); using a 5-point categorical scale $(0=$ none, 1 = slight, 2 = moderate, 3 = lots, 4 = complete).

"Patients who were remedicated before $6 \mathrm{hr}$ [hours] elapsed after administration of a study medication were assigned scores of zero ( 0 ) for change in pain intensity and pain relief for the remaining observation points of the 6 -hr observation period."

- Adverse effects: "The observer also recorded apparent and volunteered side-effects, but leading questions were avoided."

Notes

- Study free of commercial funding? No: "This work was supported by grants awarded by the Committee on Problems of Drug Dependence, National Academy of Sciences, National Research Council, from funds contributed by a group of interested pharmaceutical manufacturers, and by National Cancer Institute Grant CA-08748."

- Groups comparable at baseline? No participant details reported by initial treatment allocation.

- ITT analyses undertaken? No: "Unless a patient completed all doses of the crossover comparison or "round," his data were excluded from the relative potency analysis."

\section{Risk of bias}

\begin{tabular}{|c|c|c|}
\hline Bias & Authors' judgement & Support for judgement \\
\hline $\begin{array}{l}\text { Random sequence genera- } \\
\text { tion (selection bias) }\end{array}$ & Unclear risk & $\begin{array}{l}\text { "Treatments were assigned to patients according to a series of randomly cho- } \\
\text { sen Latin squares." No further information reported }\end{array}$ \\
\hline $\begin{array}{l}\text { Allocation concealment } \\
\text { (selection bias) }\end{array}$ & Unclear risk & See cell above \\
\hline $\begin{array}{l}\text { Blinding of participants } \\
\text { and personnel (perfor- } \\
\text { mance bias) } \\
\text { Pain }\end{array}$ & Low risk & $\begin{array}{l}\text { "Neither the patient nor the observer was aware of the identity of the medica- } \\
\text { tions, which were physically indistinguishable and identified only by a numeri- } \\
\text { cal code on individual dosage envelopes. To maintain double-blind conditions, } \\
\text { both capsules and an injection, one of which was a dummy, were administered } \\
\text { each time a patient was given a study medication." }\end{array}$ \\
\hline $\begin{array}{l}\text { Blinding of participants } \\
\text { and personnel (perfor- } \\
\text { mance bias) } \\
\text { Adverse events }\end{array}$ & Low risk & See cell above \\
\hline
\end{tabular}

$\begin{array}{lll}\text { Blinding of outcome as- } & \text { Low risk } & \text { Participant reported. See cell above } \\ \text { sessment (detection bias) }\end{array}$

Pain

\begin{tabular}{|c|c|c|}
\hline $\begin{array}{l}\text { Blinding of outcome as- } \\
\text { sessment (detection bias) } \\
\text { Adverse events }\end{array}$ & Low risk & Participant reported. See cell above \\
\hline
\end{tabular}


Beaver 1978a (Continued)

Incomplete outcome data Unclear risk (attrition bias)

Pain
Data from 13/17 participants reported. "One of these patients appeared twice in the study, and 5 completed a second round, yielding 19 crossover comparisons."
Incomplete outcome data Unclear risk (attrition bias)

Adverse events
Data from 13/17 participants reported. "One of these patients appeared twice in the study, and 5 completed a second round, yielding 19 crossover comparisons."

\section{Selective reporting (re- High risk} porting bias)
No side effects or adverse events reported in detail: "The side-effects are both intramuscular and oral oxycodone were dose-related and qualitatively similar to those noted in the codeine study." (which were also not reported in any detail at all: "While a dose-response regression was generally evident, side-effects did not occur with sufficient frequency to allow meaningful analysis.")

\begin{tabular}{lll}
\hline Other bias & Unclear risk & It is unclear if this study is subject to a high risk of other biases \\
\hline $\begin{array}{l}\text { Were the participants ade- } \\
\text { quately titrated? }\end{array}$ & Unclear risk & Not enough information provided \\
\hline $\begin{array}{l}\text { For cross-over trials: are } \\
\text { data available for both }\end{array}$ & Low risk & Yes, data are available from all the cross-over periods \\
time periods?
\end{tabular}

\section{Beaver 1978b}

Methods Design: randomised, double-blind, cross-over trial.

Year: not reported.

Country: USA.

Participants

\begin{abstract}
"The patient population and method of evaluating analgesic efficacy were similar to those employed in the oral/parenteral analgesic relative potency assays of codeine and oxycodone described in the previous paper" (Beaver 1978a).
\end{abstract}

Paper contained 2 studies:

'Intramuscular morphine and oxycodone' and 'intramuscular codeine, oxycodone and morphine'

'Intramuscular morphine and oxycodone'

Participants: 34 participants entered, "28 patients completed at least one round" (see 'Interventions' below) and were analysed for efficacy ("All of the patients who failed to complete a single round did so for reasons extraneous to the drugs under study"); 14 men/14 women, mean (range) age 46 (23-68) years. "Of the 28 patients participating in the study, 4 appeared twice in a single series, and 2 appeared in each of two series. Twenty-four patients completed a second round, yielding a total of 58 crossover comparisons."

'Intramuscular codeine, oxycodone and morphine'

Participants: 30 participants entered, "26 completed at least one round" (see 'Interventions' below) and were analysed for efficacy ("The 4 who failed to complete a single round did so for reasons extraneous to the drugs under study"); 14 men/12 women, mean (range) age 45 (23-80) years. "Series I was carried out in 11 patients, one of whom appeared twice in the series and 10 of whom completed a second round, yielding 22 cross-over comparisons of 90 and $180 \mathrm{mg}$ of codeine, 7.5 and $15 \mathrm{mg}$ of oxycodone and $16 \mathrm{mg}$ of morphine. Series II consisted of 27 cross-over comparisons in 16 patients of 90 and 180 $\mathrm{mg}$ codeine, 15 and $30 \mathrm{mg}$ of oxycodone, and $16 \mathrm{mg}$ of morphine. One patient appeared in both Series I and Series II." 
Inclusion criteria: see above.

Exclusion criteria: see above.

\section{'Intramuscular morphine and oxycodone':}

"This assay consisted of three series, each comparing two doses of morphine sulfate (the standard) with two doses of oxycodone hydrochloride (the test drug) by intramuscular injection." "The distribution of patients and doses in the various series is presented in table 1. In general, the more obviously tolerant patients were given series II treatments, which consisted of double the dosage in series I."

\section{Oxycodone arm}

- Drug: oxycodone hydrochloride.

- Dose or dosing: series I: $7.5 \mathrm{mg}$ and $15 \mathrm{mg}$; series II and III: $15 \mathrm{mg}$ and $30 \mathrm{mg}$.

- Formulation: Intramuscular

- Route of administration: Intramuscular

- Length of treatment: appears to be single dose.

- Titration schedule: no titration.

- Rescue medication: "Assessed by patient "hourly for 6 hours after administration of the study medication or until pain returned to the premedication level and a routine analgesic was administered (if at least $3 \mathrm{hr}$ [hours] had elapsed since administration of the study medication)." No further information reported.

- Other medication: see 'Rescue medication' and 'Inclusion criteria.'

\section{Comparison arm}

- Drug: morphine sulphate.

- Dose or dosing: series I and III: $8 \mathrm{mg}$ and $16 \mathrm{mg}$; series II: $16 \mathrm{mg}$ and $32 \mathrm{mg}$.

- Formulation: Intramuscular

- Route of administration: Intramuscular

- Length of treatment: appeared to be single dose.

- Titration schedule: no titration.

- Rescue medication: "Assessed by patient "hourly for 6 hours after administration of the study medication or until pain returned to the premedication level and a routine analgesic was administered (if at least $3 \mathrm{hr}$ [hours] had elapsed since administration of the study medication)." No further information reported.

- Other medication: see 'Rescue medication' and 'Inclusion criteria.'

\section{'Intramuscular codeine, oxycodone and morphine':}

"This assay consisted of two series, each comparing 90 and $180 \mathrm{mg}$ codeine phosphate (the standard) with two doses of oxycodone hydrochloride (the test drug) and a single $16 \mathrm{mg}$ dose of morphine sulfate."

\section{Oxycodone arm}

- Drug: oxycodone hydrochloride.

- Dose or dosing: series I: $7.5 \mathrm{mg}$ and $15 \mathrm{mg}$; series II: $15 \mathrm{mg}$ and $30 \mathrm{mg}$.

- Formulation: Intramuscular 
- Route of administration: Intramuscular

- Length of treatment: appeared to be single dose.

- Titration schedule: no titration.

- Rescue medication: "Assessed by patient "hourly for 6 hours after administration of the study medication or until pain returned to the premedication level and a routine analgesic was administered (if at least $3 \mathrm{hr}$ [hours] had elapsed since administration of the study medication)." No further information reported.

- Other medication: see 'Rescue medication' and 'Inclusion criteria.'

\section{Comparison arm 1}

- Drug: morphine sulphate.

- Dose or dosing: series I and II: $16 \mathrm{mg}$.

- Formulation: Intramuscular

- Route of administration: Intramuscular

- Length of treatment: appeared to be single dose.

- Titration schedule: no titration.

- Rescue medication: "Assessed by patient "hourly for 6 hours after administration of the study medication or until pain returned to the premedication level and a routine analgesic was administered (if at least $3 \mathrm{hr}$ [hours] had elapsed since administration of the study medication)." No further information reported.

- Other medication: see 'Rescue medication' and 'Inclusion criteria.'

Comparison arm 2

- Drug: codeine phosphate.

- Dose/dosing: series I and II: $90 \mathrm{mg}$ and $180 \mathrm{mg}$.

- Formulation: Intramuscular

- Route of administration: Intramuscular

- Length of treatment: appeared to be single dose.

- Titration schedule: no titration.

- Rescue medication: "Assessed by patient "hourly for 6 hours after administration of the study medication or until pain returned to the premedication level and a routine analgesic was administered (if at least $3 \mathrm{hr}$ [hours] had elapsed since administration of the study medication)." No further information reported.

- Other medication: see 'Rescue medication' and 'Inclusion criteria.'

- For cross-over trials, cross-over schedule: "Treatments were assigned to patients according to a series of randomly chosen Latin squares, and each study medication was administered on a separate day. Each patient received a low and a high dose of both the "standard" and the "test drug," chosen at equilog intervals. Unless a patient completed all doses of the cross-over comparison or "round," his data were excluded from the relative potency analysis. After completing the first round, some patients were able to repeat the course, allowing for comparison of replicate rounds within the same individual." 
least $3 \mathrm{hr}$ [hours] had elapsed since administration of the study medication);" using a 4-point categorical scale $(0=$ none, 1 = slight, 2 = moderate, 3 = severe $)$.

- Pain relief: assessed by participant hourly for 6 hours after administration of the study medication or until pain returned to the premedication level and a routine analgesic was administered (if at least $3 \mathrm{hr}$ had elapsed since administration of the study medication); using a 5-point categorical scale $(0=$ none, 1 = slight, 2 = moderate, 3 = lots, 4 = complete).

"Patients who were remedicated before $6 \mathrm{hr}$ elapsed after administration of a study medication were assigned scores of zero (0) for change in pain intensity and pain relief for the remaining observation points of the 6-hr observation period."

- Adverse effects: "The observer also recorded apparent and volunteered side-effects, but leading questions were avoided." Committee on Problems of Drug Dependence, National Academy of Sciences, National Research Council, from funds contributed by a group of interested pharmaceutical manufacturers, and by National Cancer Institute Grant CA-08748."

- Groups comparable at baseline? No participant details reported by initial treatment allocation.

- ITT analyses undertaken? No: "Unless a patient completed all doses of the crossover comparison or "round," his data were excluded from the relative potency analysis."

\section{Risk of bias}

\begin{tabular}{|c|c|c|}
\hline Bias & Authors' judgement & Support for judgement \\
\hline $\begin{array}{l}\text { Random sequence genera- } \\
\text { tion (selection bias) }\end{array}$ & Unclear risk & $\begin{array}{l}\text { "Treatments were assigned to patients according to a series of randomly cho- } \\
\text { sen Latin squares". No further information reported }\end{array}$ \\
\hline $\begin{array}{l}\text { Allocation concealment } \\
\text { (selection bias) }\end{array}$ & Unclear risk & See cell above \\
\hline $\begin{array}{l}\text { Blinding of participants } \\
\text { and personnel (perfor- } \\
\text { mance bias) } \\
\text { Pain }\end{array}$ & Low risk & $\begin{array}{l}\text { "Neither the patient nor the observer was aware of the identity of the medica- } \\
\text { tions, which were physically indistinguishable and identified only by a numeri- } \\
\text { cal code on individual dosage envelopes. To maintain double-blind conditions, } \\
\text { both capsules and an injection, one of which was a dummy, were administered } \\
\text { each time a patient was given a study medication." From Beaver 1978a }\end{array}$ \\
\hline $\begin{array}{l}\text { Blinding of participants } \\
\text { and personnel (perfor- } \\
\text { mance bias) } \\
\text { Adverse events }\end{array}$ & Low risk & See cell above \\
\hline
\end{tabular}

\begin{tabular}{|c|c|c|}
\hline $\begin{array}{l}\text { Blinding of outcome as- } \\
\text { sessment (detection bias) } \\
\text { Pain }\end{array}$ & Low risk & Participant reported. See cell above \\
\hline $\begin{array}{l}\text { Blinding of outcome as- } \\
\text { sessment (detection bias) } \\
\text { Adverse events }\end{array}$ & Low risk & Participant reported. See cell above \\
\hline $\begin{array}{l}\text { Incomplete outcome data } \\
\text { (attrition bias) } \\
\text { Pain }\end{array}$ & Unclear risk & $\begin{array}{l}\text { Data included from } 28 / 34 \text { and } 26 / 30 \text { participants in the two studies, respec- } \\
\text { tively }\end{array}$ \\
\hline $\begin{array}{l}\text { Incomplete outcome data } \\
\text { (attrition bias) }\end{array}$ & Unclear risk & $\begin{array}{l}\text { Data included from } 28 / 34 \text { and } 26 / 30 \text { participants in the two studies, respec- } \\
\text { tively }\end{array}$ \\
\hline
\end{tabular}


Beaver 1978b (Continued)

Adverse events

Selective reporting (re- High risk porting bias)

No side effects or adverse events reported in detail: Study 1: "While side-effects observed after both morphine and oxycodone were typical of the narcotic analgesics, they did not occur with sufficient frequency to allow a meaningful comparison of the side-effect liability of the two drugs. Noteworthy was the virtual absence of side-effects in patients in series II, an observation consistent with these patients' substantial tolerance to narcotics." Study 2: "Side-effects were qualitatively similar to those noted in the oxycodone-morphine comparison, but they did not occur with sufficient frequency to allow a meaningful comparison among treatments."

\begin{tabular}{lll}
\hline Other bias & Unclear risk & It is unclear if this study is subject to a high risk of other biases \\
\hline $\begin{array}{l}\text { Were the participants ade- } \\
\text { quately titrated? }\end{array}$ & Unclear risk & Not enough information provided \\
\hline
\end{tabular}

For cross-over trials: are Low risk Yes, data are available from all the cross-over periods

data available for both

time periods?

Bruera 1998

Methods Design: randomised, double-blind, cross-over trial.

Year: not reported.

Country: Canada.

Participants

Participants: 32 participants entered, 23 participants analysed for efficacy and VAS variables ( 5 participants dropped out during the CR morphine phase: 3 in phase 1,2 in phase $2 ; 1$ due to lack of pain control and adverse event, 1 due to protocol violation, 3 due to adverse events; 4 participants dropped out during the CR oxycodone phase: 2 in phase 1, 2 in phase 2; 1 due to lack of pain control, 2 due to adverse events, 1 was lost to follow-up); 13 women, 10 men; age not reported; cancer type: lung (7), breast (7), prostate (1), other (8): cancer stage not reported; type of pain not reported; setting: palliative care programme; previous analgesic medication: IR morphine (8), CR morphine (10), IR oxycodone \pm acetaminophen (11), CR hydromorphone (1), CR codeine (1), IR codeine + acetaminophen (1); duration of opioid use: $6.6( \pm 10)$ months; duration of chronic pain: $8( \pm 13)$ months.

Inclusion criteria: "The study included 32 patients from the Palliative Care Program at the Cross Cancer Institute and Grey Nuns Hospital in Edmonton, Canada. All patients were $\geq 18$ years of age, gave written informed consent, had pain due to cancer, and were receiving treatment with an oral opioid analgesic at study entry. Life expectancy for all patients was estimated by the treating physician to be at least 4 months."

Exclusion criteria: use of active anticancer therapy, with the exception of hormones, within 2 weeks of study entry; physical or mental inability to answer questions and comply with the treatment protocol; history of intolerance of oxycodone or any related compound; impaired renal or hepatic function; significantly impaired ventilatory function (clinically present dyspnoea at rest); current use of an investigational drug; pregnancy or lactation; unwillingness or inability to co-operate or give written, informed consent; and inability to take oral medications.

Interventions
Oxycodone arm
- Drug: oxycodone + placebo morphine.
- Dose and dosing: mean dose $46.5( \pm 57)$ mg every 12 hours
- Formulation: Controlled-release $(\mathrm{CR})$




\author{
- Route of administration: oral. \\ - Length of treatment: 7 days. \\ - Titration schedule: " $\geq 3$ day prestudy history of stable analgesia (defined as a daily rescue opioid con- \\ sumption $\leq 20 \%$ of the scheduled daily opioid dose)."
}

- Rescue medication: Immediate-release oxycodone hydrocloride, at doses of ca $10 \%$ of daily scheduled opioid dose. Mean daily number of doses $2.3( \pm 2.3)$.

- Other medication: no other analgesic agents. All other prestudy medications were maintained with no changes allowed later than 72 hours before randomisation.

\title{
Comparison arm
}

- Drug: morphine + placebo oxycodone.

- Dose and dosing: mean dose $=72.6( \pm 102)$ mg every 12 hours

- Formulation: Controlled-release (CR)

- Route of administration: oral.

- Length of treatment: 7 days.

- Titration schedule: " $\geq 3$ day prestudy history of stable analgesia (defined as a daily rescue opioid consumption $\leq 20 \%$ of the scheduled daily opioid dose)."

- Rescue medication: Immediate-release (IR) morphine, at doses of ca $10 \%$ of daily scheduled opioid dose. Mean daily number of doses $1.7( \pm 2.1)$.

- Other medication: no other analgesic agents, all other prestudy medications were maintained with no changes allowed later than 72 hours before randomisation.

"Patients who had been receiving narcotic analgesics other than morphine or single-entity oxycodone before the start of the study were transferred to an equianalgesic oral dose of controlled-release oxycodone or controlled-release morphine at the start of phase 1 . The initial dose of controlled-release oxycodone was determined busing a 1:1.5 conversion ratio between controlled-release oxycodone and controlled-release morphine."

- For cross-over trials, cross-over schedule: on day 8 participants crossed over to receive the alternative drug and placebo at a dose equivalent to that received at the start of phase 1 . During both study phases, blind-labelled dose adjustments were permitted if participants required more than 3 rescue analgesic doses over 24 hours.

Outcomes

- Pain intensity: assessed by participant 4 times per day before dosing and at the end of each phase; $100-\mathrm{mm}$ VAS $(0=$ no pain to $100=$ worst possible pain $)$ and 5 -point categorical scale $(0=$ no pain to $4=$ worst possible pain).

- Overall effectiveness of the study medication: assessed by participant on days 8 and 15; verbal rating scale $(0=$ not effective to $3=$ highly effective).

- Nausea and sedation: days 8 and 15; 100-mm VAS ( 0 = no nausea or sedation to 100 extreme nausea or sedation).

- Adverse events: recorded by participants; checklist (nausea, vomiting, constipation, dry mouth, drowsiness, dizziness, difficulty concentrating, fatigue, poor sleep, vivid dreams, hallucinations, headache, agitation, twitching, itching, sweating (from $0=$ none to $4=$ intolerable) and non-directed adverse events questionnaire.

- Treatment preference: assessed by participants and investigators at the end of study.

Notes

- Study free of commercial funding? Unclear. No information provided.

- Groups comparable at baseline? No participant details reported by initial treatment allocation. 
Bruera 1998 (Continued)

- ITT analyses undertaken? No for efficacy or VAS variables where the analyses restricted to the 23/32 participants who completed both study phases. Safety variables were analysed for all enrolled participants.

\section{Risk of bias}

\begin{tabular}{|c|c|c|}
\hline Bias & Authors' judgement & Support for judgement \\
\hline $\begin{array}{l}\text { Random sequence genera- } \\
\text { tion (selection bias) }\end{array}$ & Unclear risk & Participants were randomised. No further information provided. \\
\hline $\begin{array}{l}\text { Allocation concealment } \\
\text { (selection bias) }\end{array}$ & Unclear risk & See cell above \\
\hline \multirow[t]{2}{*}{$\begin{array}{l}\text { Blinding of participants } \\
\text { and personnel (perfor- } \\
\text { mance bias) } \\
\text { Pain }\end{array}$} & Low risk & $\begin{array}{l}\text { "Blinding was maintained by the double-dummy technique using matching } \\
\text { placebos of controlled release oxycodone and controlled-release morphine. } \\
\text { The immediate-release oxycodone and morphine formulations were also } \\
\text { blinded." }\end{array}$ \\
\hline & & Trial labelled as 'double-blind' \\
\hline
\end{tabular}

\begin{tabular}{ll}
\hline $\begin{array}{l}\text { Blinding of participants } \\
\text { and personnel (perfor- }\end{array}$ & Low risk \\
$\begin{array}{l}\text { mance bias) } \\
\text { Adverse events }\end{array}$ & $\begin{array}{l}\text { "Blinding was maintained by the double-dummy technique using matching } \\
\text { The immediate-release oxycodone and morphine formulations were also } \\
\text { blinded." }\end{array}$ \\
& Trial labelled as 'double-blind' \\
\hline
\end{tabular}

Blinding of outcome as- $\quad$ Low risk cell above. Outcome was participant-reported
sessment (detection bias)
Pain

Blinding of outcome as- $\quad$ Low risk see cell above. Outcome was participant-reported
sessment (detection bias)
Adverse events

\begin{tabular}{lll}
\hline $\begin{array}{l}\text { Incomplete outcome data } \\
\text { (attrition bias) } \\
\text { Pain }\end{array}$ & High risk & 23/32 participants analysed. \\
\hline $\begin{array}{l}\text { Incomplete outcome data } \\
\text { (attrition bias) } \\
\text { Adverse events }\end{array}$ & High risk & The only safety data analyses that are reported analysed 23/32 participants \\
\hline $\begin{array}{l}\text { Selective reporting (re- } \\
\text { porting bias) }\end{array}$ & High risk & $\begin{array}{l}\text { The majority of the adverse events are not reported beyond the sentence } \\
\text { "There were no statistically significant differences by treatment in mean sever- } \\
\text { ity for any of the elicited adverse events or in frequency of reporting of un- } \\
\text { elicited events." }\end{array}$
\end{tabular}

\begin{tabular}{ll}
\hline Other bias $\quad$ Low risk & $\begin{array}{l}\text { The authors report that "There was no evidence of period or sequence (car- } \\
\text { ry-over) effect." No other biases were identified }\end{array}$ \\
\hline
\end{tabular}

Were the participants ade- Low risk The participants were probably adequately titrated
quately titrated?

$\begin{aligned} & \text { For cross-over trials: are } \quad \text { Low risk } \\ & \text { data available for both }\end{aligned}$
time periods?


Year: 2011-2014.

Country: Italy.

\section{Participants}

Participants: of 520 randomised participants, 515 included in safety analyses and 498 included in ITT analyses.

- Morphine: 122 participants, 67 men, 55 women; mean (SD) age 67.5 ( \pm 11.7$)$ years; cancer type: lung/ pleura (34), colon/rectum (11), breast (17), prostate (6), pancreas (14), genitourinary (10), oesophagus/stomach/duodenum (3), head/neck (9), gynaecological (11), myeloma (1), sarcoma (0), other (6); tumour metastatic: yes (101); ongoing cancer therapy (53); previous administration of weak opioids for the background pain (88); type of pain: only nociceptive (98), only neuropathic (0), nociceptive and neuropathic (23), insufficient information to classify (1), missing (0).

- Oxycodone: 125 participants, 72 men, 53 women; mean (SD) age $66.9( \pm 11.1)$ years; cancer type: lung/ pleura (31), colon/rectum (14), breast (16), prostate (13), pancreas (8), genitourinary (8), oesophagus/stomach/duodenum (8), head/neck (8), gynaecological (6), myeloma (4), sarcoma (2), other (7); tumour metastatic: yes (112); ongoing cancer therapy (48); previous administration of weak opioids for the background pain (81); type of pain: only nociceptive (106), only neuropathic (0), nociceptive and neuropathic (18), insufficient information to classify (1), missing (0).

- Buprenorphine: 127 participants, 68 men, 59 women; mean (SD) age 65.2 ( \pm 13.5 ) years; cancer type: lung/pleura (39), colon/rectum (15), breast (22), prostate (4), pancreas (13), genitourinary (3), oesophagus/stomach/duodenum (1), head/neck (13), gynaecological (8), myeloma (2), sarcoma (3), other (4); tumour metastatic: yes (107); ongoing cancer therapy (48); previous administration of weak opioids for the background pain (89); type of pain: only nociceptive (102), only neuropathic (1), nociceptive and neuropathic (23), insufficient information to classify (1), missing (0).

- Fentanyl: 124 participants, 70 men, 54 women; mean (SD) age 68 ( \pm 10.6$)$ years; cancer type: lung/ pleura (37), colon/rectum (17), breast (10), prostate (6), pancreas (4), genitourinary (10), oesophagus/stomach/duodenum (6), head/neck (12), gynaecological (9), myeloma (5), sarcoma (3), other (5); tumour metastatic: yes (104); ongoing cancer therapy (42); previous administration of weak opioids for the background pain (85); type of pain: only nociceptive (106), only neuropathic (0), nociceptive and neuropathic (15), insufficient information to classify (2), missing (1).

Inclusion criteria: Participants with diagnostic (histological or cytological) evidence of locally advanced or metastatic solid tumour; with persistent moderate to severe cancer pain (average pain intensity $\geq 4$, measured on a 0-10 numerical rating scale (NRS) and related to the last 24 hours); requiring for the first time an analgesic treatment with third step WHO sopioids; aged $>18$ years.

Exclusion criteria: Participants with a diagnosis of primary brain tumour or leukaemia, or undergoing concurrent radiotherapy, first-line chemotherapy started 7 days before randomisation, or on any nonpharmacological analgesic treatment or with preexisting renal failure.

- Drug: oxycodone.

- Dose and dosing: "The initial dose of opioid was based on the recommendations of the European Association for Palliative care." "The suggested initial daily dose was $60 \mathrm{mg}$ of oral M[orphine] for participant with previous WHO step II treatment or half of this (30 mg/day) for opioid-naïve participants. The doses of the other opioids were regulated on the basis of the oral M equivalent dose ratio." Protocol lists $40 \mathrm{mg} / 24$ hours. Mean ( \pm SD) initial dose (as oral morphine equivalent daily dose) $44.6( \pm 16) \mathrm{mg} /$ day. Mean $( \pm \mathrm{SD}$ ) final dose (as oral morphine equivalent daily dose) $71.1( \pm 60.8) \mathrm{mg} /$ day.

- Formulation: Controlled-release

- Route of administration: oral. 


\begin{abstract}
- Length of treatment: 28 days.
- Titration schedule: "During the follow-up [active treatment phase], any adjustments necessary for better control of pain was allowed for clinical and ethical reasons. Physicians could change the dose, add another opioid or adjuvant drug or change the opioid (switch). In case of constantly unsatisfactory analgesia or severe toxicity, the opioid could be discontinued."
\end{abstract}

- Rescue medication: not reported.

- Other medication: see 'Titration schedule.'

Comparison arm 1

- Drug: morphine.

- Dose and dosing: "The initial dose of opioid was based on the recommendations of the European Association for Palliative care." The suggested initial daily dose was $60 \mathrm{mg} / 24$ hours for participants who had previously received WHO step-II opioids and $30 \mathrm{mg} / 24$ hours for opioid-naive participants. Mean ( \pm $\mathrm{SD})$ initial dose $45.7( \pm 16.2) \mathrm{mg} /$ day. Mean $( \pm \mathrm{SD})$ final dose $58.9( \pm 38.6) \mathrm{mg} /$ day.

- Formulation: Controlled-release

- Route of administration: oral.

- Length of treatment: 28 days.

- Titration schedule: "During the follow-up [active treatment phase], any adjustments necessary for better control of pain was allowed for clinical and ethical reasons. Physicians could change the dose, add another opioid or adjuvant drug or change the opioid (switch). In case of constantly unsatisfactory analgesia or severe toxicity, the opioid could be discontinued."

- Rescue medication: not reported.

- Other medication: see 'Titration schedule.'

Comparison arm 2

- Drug: buprenorphine.

- Dose and dosing: "The initial dose of opioid was based on the recommendations of the European Association for Palliative care" "The suggested initial daily dose was $60 \mathrm{mg}$ of oral M[orphine] for participants with previous WHO step II treatment or half of this (30 mg/day) for opioid-naïve participants. The doses of the other opioids were regulated on the basis of the oral M equivalent dose ratio." Protocol listed $35 \mu \mathrm{g} /$ hour. Mean (SD) initial dose (as oral morphine equivalent daily dose) 53.7 (12.5) mg/day. Mean ( \pm SD) final dose (as oral morphine equivalent daily dose) $80.1( \pm 40.4) \mathrm{mg} /$ day.

- Formulation: patch.

- Route of administration: Transdermal

- Length of treatment: 28 days.

- Titration schedule: "During the follow-up [active treatment phase], any adjustments necessary for better control of pain was allowed for clinical and ethical reasons. Physicians could change the dose, add another opioid or adjuvant drug or change the opioid (switch). In case of constantly unsatisfactory analgesia or severe toxicity, the opioid could be discontinued."

- Rescue medication: not reported.

- Other medication: see 'Titration schedule.'

Comparison arm 3

- Drug: fentanyl. 
Corli 2016 (Continued)

- Dose and dosing: "The initial dose of opioid was based on the recommendations of the European Association for Palliative care" The suggested initial daily dose was $60 \mathrm{mg}$ of oral M[orphine] for participants with previous WHO step II treatment or half of this (30 mg/day) for opioid-naïve participants. The doses of the other opioids were regulated on the basis of the oral M equivalent dose ratio." Protocol lists $25 \mu \mathrm{g} /$ hour. Mean ( \pm SD) initial dose (as oral morphine equivalent daily dose) $53.4( \pm 14.2) \mathrm{mg} /$ day. Mean ( \pm SD) final dose (as oral morphine equivalent daily dose) $111.4( \pm 74.9) \mathrm{mg} /$ day.

- Formulation: patch.

- Route of administration: Transdermal

- Length of treatment: 28 days.

- Titration schedule: "During the follow-up [active treatment phase], any adjustments necessary for better control of pain was allowed for clinical and ethical reasons. Physicians could change the dose, add another opioid or adjuvant drug or change the opioid (switch). In case of constantly unsatisfactory analgesia or severe toxicity, the opioid could be discontinued."

- Rescue medication: not reported.

- Other medication: see 'Titration schedule.'

Outcomes - Pain intensity (average and worst) measured on a 0 to 10 NRS

- Adverse events

Notes - Study free of commercial funding? Study particularly funded by Grünenthal-Italia, but funder "had no role in study design, data collection and analysis, decision to publish or preparation of the manuscript."

- Groups comparable at baseline? No inferential statistics reported. Treatment groups appear to be reasonably comparable at baseline.

- ITT analyses undertaken? Yes for efficacy; no for safety (which considered the participants for the treatment received).

\section{Risk of bias}

Bias Authors' judgement Support for judgement

Random sequence genera- Low risk Central randomisation.

tion (selection bias)

\begin{tabular}{lll}
\hline $\begin{array}{l}\text { Allocation concealment } \\
\text { (selection bias) }\end{array}$ & Low risk & See cell above \\
\hline $\begin{array}{l}\text { Blinding of participants } \\
\text { and personnel (perfor- } \\
\text { mance bias) }\end{array}$ & High risk & Open-label. \\
Pain & \\
\hline
\end{tabular}

Blinding of participants High risk
and personnel (perfor-
mance bias)
Adverse events

\begin{tabular}{|c|c|}
\hline $\begin{array}{l}\text { Blinding of outcome as- } \\
\text { sessment (detection bias) } \\
\text { Pain }\end{array}$ & High risk \\
\hline
\end{tabular}


Corli 2016 (Continued)

$\begin{array}{lll}\text { Blinding of outcome as- } & \text { High risk } & \text { Open-label. } \\ \text { sessment (detection bias) } & \end{array}$

Adverse events

\begin{tabular}{|c|c|c|}
\hline $\begin{array}{l}\text { Incomplete outcome data } \\
\text { (attrition bias) } \\
\text { Pain }\end{array}$ & Low risk & $498 / 520$ randomised participants were included in the analyses. \\
\hline $\begin{array}{l}\text { Incomplete outcome data } \\
\text { (attrition bias) } \\
\text { Adverse events }\end{array}$ & Low risk & $515 / 520$ randomised participants were included in the safety analyses \\
\hline $\begin{array}{l}\text { Selective reporting (re- } \\
\text { porting bias) }\end{array}$ & Low risk & All the obvious outcomes appear to be reported \\
\hline Other bias & Low risk & The study does not appear to be subject to other bias \\
\hline $\begin{array}{l}\text { Were the participants ade- } \\
\text { quately titrated? }\end{array}$ & Low risk & The participants appear to be adequately titrated \\
\hline $\begin{array}{l}\text { For cross-over trials: are } \\
\text { data available for both } \\
\text { time periods? }\end{array}$ & Unclear risk & Not applicable \\
\hline
\end{tabular}

\section{Gabrail 2004}

Methods

Design: randomised, double-blind, cross-over trial.

Year: not reported.

Country: USA.
Participants: 58 participants screened, 47 participants titrated, 45 participants randomised, and 44 participants received $\geq 1$ dose of study medication and had $\geq 1$ pain intensity evaluation after treatment and were therefore analysed for safety ( $1 / 45$ never received any double-blind study medication and was excluded from all analyses). $37 / 45$ randomised participants completed the first double-blind phase and $\geq 5$ days of the second phase and were analysed for efficacy (2/45 participants had insufficient visits or assessments to be included in the efficacy population); 5/45 randomised participants discontinued the drug during the double-blind treatment periods: 2 participants withdrew due to adverse events unrelated to the study drug, 2 participants withdrew consent and 1 participant due to protocol violation. 0 participants discontinued the study due to insufficient analgesia or loss to follow-up.

21 safety and 18 efficacy participants received extended-release oxymorphone followed by controlled-release oxycodone and 23 safety and 19 efficacy participants received controlled-release oxycodone followed by extended-release oxymorphone

21 men, 23 women, mean age (range) 59.3 (26-81) years; 80\% had severe untreated pain and 20\% had moderate untreated pain. Previous anticancer therapy included surgery $(68 \%)$, chemotherapy (82\%), radiotherapy (50\%), and/or immunotherapy $(2.3 \%)$

Inclusion criteria: men and women aged $\geq 18$ years with moderate to severe pain secondary to cancer who required long-term outpatient treatment with an opioid analgesic. People hospitalised for reasons unrelated to cancer were also eligible.

Exclusion criteria: allergy or sensitivity to morphine, extended-release oxymorphone, controlled-release oxycodone or their components; requirement for a concurrent opioid analgesic other than the study medication; contraindication to opioid therapy; pregnancy; lactation; plan for pregnancy; uncontrolled emesis; inability to take adequate oral food and hydration; levels of hepatic enzymes (gam- 
Gabrail 2004 (Continued)

ma-glutamyl transpeptidase, alanine aminotransferase, and aspartate aminotransferase) $\geq 3$ times the upper limit of the normal range; receipt of radiotherapy or therapeutic radionuclides within the previous 2 weeks preceding study enrolment.

Interventions
Oxycodone arm

- Drug: oxycodone.

- Dose and dosing: mean daily dose $91.9 \mathrm{mg}$ (any dose adjustments were made during the first 3 days of the double-blind phase; dosage remained fixed thereafter).

- Formulation: Controlled-release (CR)

- Route of administration: oral.

- Length of treatment: 7-10 days, take medication at 8 a.m. and 8 p.m.

- Titration schedule: "During the open-label titration/stabilization phase, patients received either oxymorphone immediate-release (IR) or oxycodone CR to determine a stable dosage, defined as a fixed dosage that provided adequate analgesia for at least 2 consecutive days, required no more than 2 doses of rescue medication/day, and produced tolerable AEs [adverse events]."

- Rescue medication: tablets of $15 \mathrm{mg}$ oral morphine sulphate (IR) every 4-6 hours as needed. Participants requiring $>2$ doses/day after the first 3 days of double-blind treatment were discontinued. Mean daily dose (range) $=12.6(0-75) \mathrm{mg}$.

- Other medication: not reported.

\section{Comparison arm}

- Drug: oxymorphone.

- Dose and dosing: mean daily dose $45.9 \mathrm{mg}$ (any dose adjustments were made during the first 3 days of the double-blind phase; dosage remained fixed thereafter).

- Formulation: Extended-release, take medication at 8 am and $8 \mathrm{pm}$

- Route of administration: oral.

- Length of treatment: 7-10 days.

- Titration schedule: "During the open-label titration/stabilization phase, patients received either oxymorphone immediate-release (IR) or oxycodone CR to determine a stable dosage, defined as a fixed dosage that provided adequate analgesia for at least 2 consecutive days, required no more than 2 doses of rescue medication/day, and produced tolerable AEs [adverse events]."

- Rescue medication: tablets of $15 \mathrm{mg}$ oral morphine sulphate (IR) every 4-6 hours as needed. Participants requiring $>2$ doses/day after the first 3 days of double-blind treatment were discontinued. Mean daily dose (range) $16.6(0-90) \mathrm{mg}$.

- Other medication: not reported.

- For cross-over trials, cross-over schedule: "Following the first double-blind treatment period, patients crossed over to the alternative double-blind treatment (oxymorphone ER or oxycodone CR) for an additional 7-10 days."

Outcomes

- Pain intensity: Assessed by daily diary recording by the participants of all study drugs taken (including supplemental pain medication) and their 24 -hour pain intensity, using an 11-point numerical scale $(0=$ no pain to $10=$ worst possible pain) and the Brief Pain Inventory.

- Quality of life: assessed by the Brief Pain Inventory to assess the interference of pain with 7 domains of quality of life (general activity, mood, walking ability, normal work, relations with other people, sleep, and enjoyment of life). Appeared to be rated by the participants during the study visits that marked the end of each double-blind treatment phase. 
Gabrail 2004 (Continued)

- Global assessment of current pain medication, rated by participants and physicians independently following each double-blind phase. Physicians were asked "Please rate the subject's current pain medication used for treating their cancer pain"

- Karnofsky performance status: assessed by physicians at each visit

- Safety analysis: assessed by physical examination, vital signs, clinical laboratory tests (serum chemistry profile, complete blood count, urinalysis), electrocardiograms, and the monitoring of adverse events (which were rated by the investigators as mild, moderate, severe intensity, and as unlikely, possibly, probably related to study medication).

Notes

- Study free of commercial funding? No, the study was funded by Endo Pharmaceuticals Inc., Chadds Ford, PA and Penwest Pharmaceuticals Co., Danbury, CT.

- Groups comparable at baseline? The authors report that there were no significant differences in the demographic or baseline characteristics of the treatment groups, but did not report these characteristics split by treatment group.

- ITT analyses undertaken? No for efficacy and safety where the analyses were restricted to 37 and 41 to 43 of 45 randomised participants, respectively.

\section{Risk of bias}

\begin{tabular}{lll}
\hline Bias & Authors' judgement & Support for judgement \\
\hline $\begin{array}{l}\text { Random sequence genera- } \\
\text { tion (selection bias) }\end{array}$ & Unclear risk & Participants were randomised. No further information provided. \\
\hline $\begin{array}{l}\text { Allocation concealment } \\
\text { (selection bias) }\end{array}$ & Unclear risk & See cell above \\
\hline $\begin{array}{l}\text { Blinding of participants } \\
\text { and personnel (perfor- } \\
\text { mance bias) }\end{array}$ & Unclear risk & $\begin{array}{l}\text { The study is described as "double-blind". No further information reported, so it } \\
\text { Pain }\end{array}$ \\
$\begin{array}{l}\text { Blinding of participants } \\
\text { and personnel (perfor- } \\
\text { mance bias) }\end{array}$ & Unclear risk who was blinded and whether it was adequately executed \\
$\begin{array}{l}\text { Adverse events } \\
\end{array}$ & & \\
\hline
\end{tabular}

\begin{tabular}{ll}
\hline Blinding of outcome as- & Unclear risk cell above \\
sessment (detection bias) & \\
Pain & \\
\hline
\end{tabular}

$\begin{array}{ll}\text { Blinding of outcome as- } & \text { Unclear risk }\end{array}$

Adverse events

Incomplete outcome data High risk
(attrition bias)
Pain

Incomplete outcome data Unclear risk $\quad 41$ to 43 of 45 randomised participants were analysed for efficacy.
(attrition bias)

Adverse events

Selective reporting (re- Low risk The main expected outcomes are reported
porting bias)


Gabrail 2004 (Continued)

Other bias Low risk
The authors report that "There were no sequence effects observed during the study; comparable pain scores and other efficacy measures were obtained irrespective of the order in which patients received the study medication." No other potential biases were identified

\section{Were the participants ade- Low risk} quately titrated?
The participants were probably adequately titrated

$\begin{aligned} & \text { For cross-over trials: are } \\ & \text { data available for both }\end{aligned} \quad$ Low risk, data are available for both study periods for 40/45 participants
time

data available for both

time periods?

Hagen 1997

Methods Design: randomised, double-blind, cross-over trial.

Year: not reported.

Country: Canada.

Participants

Participants: 44 participants enrolled, 31 participants completed the study. Reasons for withdrawal included adverse events (8), inadequate pain control (3), intercurrent illness (1), and voluntary withdrawal (1). "Failure to complete both phases of the study did not appear to be related to toxicity of one of the study drugs over another." The analysis of all efficacy outcome variables, including VAS and categorical pain intensity, sedation VAS and nausea VAS were restricted to participants completing both study phases. Spontaneously reported safety variables were analysed for all enrolled participants.

13 men/18 women, mean age $( \pm S E)=56( \pm 3)$ years. Primary tumour: breast $(7)$, colorectal (5), lung (1), urological/prostate (5), CNS (4), unknown primary (2), other (7). Type of pain: bone (61\%), soft tissue $(29 \%)$, visceral $(23 \%)$, neuropathic (45\%). Pain described as "lancinating" (16\%): steady pain (61\%), incident pain with or without steady pain (52\%).

Inclusion criteria: Patients with chronic cancer pain and stable analgesic requirements

Exclusion criteria: Known hypersensitivity to opioid analgesics, intolerance of oxycodone or hydromorphone, presence of a medical or surgical condition likely to interfere with drug absorption in the gastrointestinal tract, concurrent use of other opioid analgesics during the study period, presence of intractable nausea and vomiting, and patients who had undergone or were expected to undergo therapeutic procedures likely to influence their pain during the study period

Interventions

\author{
Oxycodone arm \\ - Drug: oxycodone. \\ - Dose and dosing: mean daily initial dose $=120 \pm 22 \mathrm{mg}$, mean final dose $=124 \pm 22 \mathrm{mg}$ (blind-label \\ dose changes were permitted, and in case of a dose change, the rescue analgesic dose was modified \\ accordingly) \\ - Formulation: Controlled-release \\ - Route of administration: oral. \\ - Length of treatment: 7 days, 12-hourly. \\ - Titration schedule: "Patients with 3 days of stable analgesic requirements on a prestudy opioid were \\ randomized to controlled-release oxycodone or controlled-release hydromorphone. Stable analge- \\ sia was defined as 2 or fewer rescue doses of opioid analgesic per 24-hour period, calculated over 3 or \\ more days."
}


- Rescue medication: incident and non-incident breakthrough pain was treated with immediate-release oxycodone at a dosage of approximately $10 \%$ of the daily scheduled dose. Mean daily frequency of rescue use $(\mathrm{SD})=1.4 \pm 0.3 \mathrm{mg}$

- Other medication: no other opioids were permitted. Non-opioid analgesics, such as corticosteroids, antidepressants, anticonvulsants, bisphosphonates, and psychostimulants, that had been part of the participant's therapy were continued at the same dose level throughout the study.

\section{Comparison arm}

- Drug: hydromorphone.

- Dose/dosing: mean daily initial dose $24( \pm 4) \mathrm{mg}$, mean ( \pm SD) final dose $30( \pm 6) \mathrm{mg}$ (blind-label dose changes were permitted, and in case of a dose change, the rescue analgesic dose was modified accordingly).

\section{- Formulation: Controlled-release \\ - Route of administration: oral. \\ - Length of treatment: 7 days, 12-hourly.}

- Titration schedule: "Patients with 3 days of stable analgesic requirements on a prestudy opioid were randomized to controlled-release oxycodone or controlled-release hydromorphone. Stable analgesia was defined as 2 or fewer rescue doses of opioid analgesic per 24-hour period, calculated over 3 or more days."

- Rescue medication: Incident and nonincident breakthrough pain was treated with immediate-release hydromorphone at a dosage of approximately $10 \%$ of the daily scheduled dose. Mean daily frequency of rescue use $(\mathrm{SD})=1.6 \pm 0.3 \mathrm{mg}$

- Other medication: no other opioids were permitted. Non-opioid analgesics, such as corticosteroids, antidepressants, anticonvulsants, bisphosphonates, and psychostimulants, that had been part of the participant's therapy were continued at the same dose level throughout the study.

- For cross-over trials, cross-over schedule: "At the end of Phase I, patients were crossed over to the alternative treatment in Phase II without an intervening washout period."

Outcomes

- Pain intensity: Assessed by participants 4 times daily $(8.00,12.000,16.00$, and 20.00) on a $100 \mathrm{~mm}$ visual analogue scale (going from no pain to excruciating pain) and on a 5 -point categorical scale $(0=$ none, 1 = mild, 2 = moderate, 3 = severe, 4 = excruciating)

- Nausea and sedation: Assessed by participants 4 times daily $(8.00,12.000,16.00$, and 20.00) on a 100 $\mathrm{mm}$ visual analogue scale (going from no nausea or sedation to severe nausea or extreme sedation)

- Spontaneously reported, investigator-observed and elicited adverse events were recorded at the end of each phase

- Participant and investigator treatment preferences were recorded at the end of both phases

Notes

- Study free of commercial funding? No information reported, but the second author (Najib Babul) is an employee of Purdue Frederick, which is the manufacturer of the controlled-release oxycodone study drug used in the study.

- Groups comparable at baseline? No information provided about initial group allocation.

- ITT analyses undertaken? No for efficacy where the analyses were restricted to 31/44 participants.

\section{Risk of bias}


Hagen 1997 (Continued)
Random sequence genera- Unclear risk
No information reported. tion (selection bias)

Allocation concealment $\quad$ Unclear risk
(selection bias)

\begin{tabular}{ll}
\hline $\begin{array}{l}\text { Blinding of participants } \\
\text { and personnel (perfor- }\end{array}$ & "Blinding was maintained by the double-dummy technique, which involved \\
mance bias) & matching placebos. In the active treatment phases, patients received either \\
Pain & $\begin{array}{l}\text { active controlled-release oxycodone and placebos matching controlled-re- } \\
\text { lease hydromorphone or active controlled-release hydromorphone and place- } \\
\text { bos matching controlled-release oxycodone." }\end{array}$
\end{tabular}

Blinding of participants Low risk See cell above
and personnel (perfor-
mance bias)
Adverse events

\begin{tabular}{lll}
\hline $\begin{array}{l}\text { Blinding of outcome as- } \\
\text { sessment (detection bias) } \\
\text { Pain }\end{array}$ & Low risk & See cell above \\
\hline $\begin{array}{l}\text { Blinding of outcome as- } \\
\text { sessment (detection bias) }\end{array}$ & Low risk & See cell above \\
Adverse events & & \\
\hline
\end{tabular}

\begin{tabular}{lll}
\hline $\begin{array}{l}\text { Incomplete outcome data } \\
\text { (attrition bias) } \\
\text { Pain }\end{array}$ & High risk & The analyses were restricted to 31/44 participants \\
\hline $\begin{array}{l}\text { Incomplete outcome data } \\
\text { (attrition bias) } \\
\text { Adverse events }\end{array}$ & High risk & $\begin{array}{l}\text { The analyses were restricted to } 31 / 44 \text { participants, or not reported in a manner } \\
\text { that allowed them to be included in any meta-analysis }\end{array}$ \\
\hline $\begin{array}{l}\text { Selective reporting (re- } \\
\text { porting bias) }\end{array}$ & Unclear risk & $\begin{array}{l}\text { The adverse event reporting is restricted to } 4 \text { adverse events in a manner that } \\
\text { does not allow them to be included in the meta-analysis }\end{array}$ \\
\hline $\begin{array}{l}\text { Other bias } \\
\text { Low risk }\end{array}$ & $\begin{array}{l}\text { The authors reported that analysis of treatment sequence revealed no signifi- } \\
\text { cant carry-over effects }\end{array}$ \\
\hline
\end{tabular}

Were the participants ade- Low risk The participants were probably adequately titrated
quately titrated?
quately titrated?

For cross-over trials: are Low risk Yes, data are available for both study periods for $31 / 44$ participants
data available for both
time periods?

\section{Heiskanen 1997}

\begin{tabular}{ll}
\hline Methods & Design: randomised, double-blind, cross-over trial. \\
Year: not reported. \\
Country: Finland. \\
\hline Participants \\
$\begin{array}{l}\text { Participants: } 45 \text { participants enrolled, and } 27 / 45 \text { participants were evaluated for efficacy and safety. } \\
\text { the end of titration (5), non-compliance (3), sudden deterioration unrelated to the study (1), and a tech- }\end{array}$ \\
\hline
\end{tabular}


nical error (1); 1 participant was withdrawn due to suspected incomplete absorption of controlled-release oxycodone.

16 men/11 women, mean age (range) 60 (39-76) years. Primary tumour: breast (2), rectum (5), lung (4), prostate (6), kidney (1), pancreas (4), unknown primary (2), and other (3). Former analgesics: morphine alone or in combination with other analgesic (20), oxycodone alone or in combination with other analgesic (5). 12 participants were randomised to titration with CR oxycodone and 15 participants with CR morphine.

Inclusion criteria: Patients with chronic cancer pain requiring opioid analgesics, who were co-operative, and able to take oral medication and keep a simple diary

Exclusion criteria: Patients receiving radiation therapy or other cancer treatment that could affect their pain

Interventions
Oxycodone arm

- Drug: oxycodone + morphine-matched placebo.

- Dose and dosing: mean daily initial dose $123 \mathrm{mg}$ at the end of titration.

- Formulation: Controlled-release

- Route of administration: oral.

- Length of treatment: 3-6 days, unclear how many doses per day.

- Titration schedule: in opioid-naive participants, the open-label titration phase (of 21-day maximum duration) was started with a total daily dose of $40 \mathrm{mg}$ oxycodone. Dose titration was continued until effective pain relief with acceptable adverse effects was achieved for $\geq 48$ hours. The controlled-release dose was titrated upwards if pain continued at the moderate to severe level or if $>2$ dose of escape analgesic were used in a 24-hour period. The controlled-release dose was titrated downwards in case of unacceptable opioid adverse effects which were not manageable with appropriate treatment

- Rescue medication: oxycodone hydrochloride solution in a dose of approximately $1 / 6$ to $1 / 8$ of the daily dose of controlled-release oxycodone; mean total amount per participant during the last 3 days of the titration phase $=79 \mathrm{mg}$. Mean daily number of doses (SE) during double-blind phase $1.26( \pm 0.22)$ mg.

- Other medication: Non-steroidal anti-inflammatory analgesics, if used by the participant before the study, were continued at the same dose.

\section{Comparison arm}

- Drug: morphine + oxycodone-matched placebo.

- Dose and dosing: mean daily initial dose $180 \mathrm{mg}$ at the end of titration.

- Formulation: Controlled-release

- Route of administration: oral.

- Length of treatment: 3-6 days, unclear how many doses per day.

- Titration schedule: in opioid-naive participants the open-label titration phase (of 21-day maximum duration) was started with a total daily dose of $40 \mathrm{mg}$ oxycodone. Dose titration was continued until effective pain relief with acceptable adverse effects was achieved for $\geq 48$ hours. The controlled-release dose was titrated upwards if pain continued at the moderate to severe level or if $>2$ dose of escape analgesic were used in a 24-hour period. The controlled-release dose was titrated downwards in case of unacceptable opioid adverse effects which were not manageable with appropriate treatment

- Rescue medication: morphine hydrochloride solution in a dose of approximately $1 / 6$ to $1 / 8$ of the daily dose of controlled-release morphine; mean total amount per participant during the last 3 days of the titration phase $=74 \mathrm{mg}$. Mean daily number of doses $(\mathrm{SE})$ during double-blind phase $=0.79 \pm 0.18 \mathrm{mg}$ 
Heiskanen 1997 (Continued)

- Other medication: Non-steroidal anti-inflammatory analgesics, if used by the participant before the study, were continued at the same dose.

- For cross-over trials, cross-over schedule: after 3-6 days of dosing, the participant visited the Pain Relief Unit for an end of phase visit. A similar 3- to 6-day period was then completed in a cross-over fashion using the other opioid.

Outcomes
- Pain intensity: assessed by participants 4 times daily (morning, noon, evening, and bedtime) on a 4-
point verbal rating scale (none, slight, moderate, severe).
- Acceptability of therapy: assessed by participants twice daily, considering pain intensity and adverse
effects during the previous 12-hour period on a 5-point verbal rating scale (very poor, poor, fair, good,
excellent)
- Adverse experiences: recorded by participant in diary along with each dose of scheduled and escape
study medication, concomitant medications, and intercurrent illnesses
- At each double-blind phase ends, a Modified Specific Drug Effect Questionnaire was completed by the
participants and a trained research nurse or investigator
- Study free of commercial funding? No, the study was funded by Purdue Frederick, which is the manu-
facturer of the controlled-release oxycodone study drug used in the study, and the Academy of Finland.
- Groups comparable at baseline? No information provided about initial group allocation.
- ITT analyses undertaken? No, the analyses were restricted to $27 / 45$ participants.

\section{Risk of bias}

\begin{tabular}{|c|c|c|}
\hline Bias & Authors' judgement & Support for judgement \\
\hline $\begin{array}{l}\text { Random sequence genera- } \\
\text { tion (selection bias) }\end{array}$ & Low risk & $\begin{array}{l}\text { "Computer generated randomisation for the open-label titration phase and } \\
\text { again for the double-blind phase was performed by the Purdue Frederick Com- } \\
\text { pany and a list of randomisation codes was kept by the hospital pharmacist." }\end{array}$ \\
\hline $\begin{array}{l}\text { Allocation concealment } \\
\text { (selection bias) }\end{array}$ & Low risk & See cell above. No further details reported. Probably adequate \\
\hline $\begin{array}{l}\text { Blinding of participants } \\
\text { and personnel (perfor- } \\
\text { mance bias) } \\
\text { Pain }\end{array}$ & Low risk & $\begin{array}{l}\text { A double-blind placebo controlled design was used. It is unclear who was } \\
\text { blinded, but it appears that at least the participants were }\end{array}$ \\
\hline $\begin{array}{l}\text { Blinding of participants } \\
\text { and personnel (perfor- } \\
\text { mance bias) } \\
\text { Adverse events }\end{array}$ & Unclear risk & See cell above \\
\hline $\begin{array}{l}\text { Blinding of outcome as- } \\
\text { sessment (detection bias) } \\
\text { Pain }\end{array}$ & Low risk & Participant-reported. See also cell above \\
\hline $\begin{array}{l}\text { Blinding of outcome as- } \\
\text { sessment (detection bias) } \\
\text { Adverse events }\end{array}$ & Unclear risk & See cell above \\
\hline $\begin{array}{l}\text { Incomplete outcome data } \\
\text { (attrition bias) } \\
\text { Pain }\end{array}$ & High risk & The analyses were restricted to $27 / 45$ participants \\
\hline
\end{tabular}


Heiskanen 1997 (Continued)

Incomplete outcome data High risk The analyses were restricted to 27/45 participants (attrition bias)

Adverse events

Selective reporting (re- Low risk $\quad$ All expected main outcomes appear to be reported
porting bias)

\begin{tabular}{ll}
\hline Other bias $\quad$ Low risk & $\begin{array}{l}\text { It is unclear whether there were any carry-over effects, but there probably } \\
\text { were none }\end{array}$
\end{tabular}
were none

Were the participants ade- Low risk The participants were probably adequately titrated
quately titrated?

For cross-over trials: are data available for both

time periods?

\title{
Imanaka 2013
}

Methods
Design: randomised, double-blind, parallel-group multicentre, non-inferiority trial.
Year: 25 August 2010 to 16 August 2012.
Country: Japan, Korea.

\section{Participants}

\begin{abstract}
Participants: 343 participants enrolled, and 340/343 participants received $\geq 1$ dose of study drug (172 oxycodone, 168 tapentadol); 236/343 participants completed treatment (123 oxycodone, 113 tapentadol), and 231/343 participants completed the study (121 oxycodone, 110 tapentadol). Reasons for withdrawal included adverse events (14 oxycodone, 12 tapentadol), progressive disease (15 oxycodone, 11 tapentadol), withdrawal of consent (8 oxycodone, 8 tapentadol), physician decision (1 oxycodone, 8 tapentadol), protocol violation ( 5 oxycodone, 5 tapentadol), lack of efficacy ( 1 oxycodone, 4 tapentadol), non-compliance (4 oxycodone, 1 tapentadol), death (1 oxycodone, 0 tapentadol), other (0 oxycodone, 6 tapentadol).
\end{abstract}

Oxycodone: 172, 100 men, 72 women, mean age ( \pm SD) 64.9 ( \pm 11.41 ) years, 110 Japanese and 62 Korean. Primary tumour: gastrointestinal (65); respiratory or mediastinal (46); > 92\% participants had metastatic cancer. Former analgesics: not reported.

Tapentadol: 168, 90 men, 78 women, mean age ( \pm SD) 65.5 (11.21) years, 111 Japanese and 57 Korean. Primary tumour: gastrointestinal (70); respiratory or mediastinal (53); > 92\% participants had metastatic cancer. Former analgesics: not reported.

Inclusion criteria: Patients aged $\geq 20$ years with a diagnosis of any type of cancer, experiencing chronic malignant tumour-related pain, with an average pain intensity score over the past 24 hours $\geq 4$ on an 11-point numerical rating scale (NRS) ( 0 = 'no pain' to $10=$ 'pain as bad as you can imagine') on the day of randomisation, who "had not taken opioid analgesics (except for codeine phosphate ( $\leq 60 \mathrm{mg} /$ day), or dihydrocodeine phosphate ( $\leq 30 \mathrm{mg} /$ day) as antitussives) within 28 days before screening. Patients must have been dissatisfied with the pain relief achieved on their current analgesic treatment for cancer pain and must have had pain requiring treatment with an opioid analgesic (based on the investigator's assessment)."

Exclusion criteria: "an uncontrolled or clinically significant arrhythmia; a history of or current disease that could result in increased intracranial pressure, disturbance of consciousness, lethargy, or respiratory problems; any disease for which opioids are contraindicated; a history of surgery intended for the cure of the primary disease or for the treatment of cancer pain within 28 days before screening or during the study; radiation therapy within 7 days before screening; or a psychiatric disorder or concurrent symptoms with accompanying pain that could interfere with efficacy and safety evaluations. Patients were also excluded if they had any of the following laboratory values at screening: white blood 
cell count $\leq 3000 / \mathrm{mL}$, platelet count $\leq 10 \times 10^{4} / \mathrm{uL}$, haemoglobin $\leq 9.5 \mathrm{~g} / \mathrm{dL}$, corrected total serum calcium level $>12.5 \mathrm{mg} / \mathrm{dL}$, alanine aminotransferase or aspartate aminotransferase $\geq 3$ times the upper limit of normal, total bilirubin $\geq 1.5$ times the upper limit of normal, or creatinine $\geq 2 \mathrm{mg} / \mathrm{dL}$. The following medications were prohibited: opioid analgesics (including codeine phosphate and dihydrocodeine phosphate as antitussives), except morphine IR $5 \mathrm{mg}$ as rescue medication); opioid antagonists (e.g., naloxone, levallorphan), except for the treatment of respiratory depression; anti-parkinsonian drugs; neuroleptics (including antipsychotics, except for prochlorperazine); monoamine oxidase inhibitors; serotonin norepinephrine reuptake inhibitors; noradrenergic and specific serotonergic antidepressants; radiotherapy; nerve block; stimulation analgesia; other investigational drugs. The following drugs were prohibited on an as-needed basis as newly started treatment (but could be continued at the same and regimen if started before study entry): Selective serotonin reuptake inhibitors; tricyclic or tetracyclic antidepressants; anti-anxiety agents (e.g., benzodiazepines); hypnotics (e.g., benzodiazepines, non-benzodiazepine hypnotics, barbiturates); anticonvulsants; central muscle relaxants; bisphosphonates; corticosteroids; anti-arrhythmics; non-opioid analgesics (nonsteroidal anti-inflammatory drugs (e.g., cyclo-oxygenase II inhibitors)); pyrazolone antipyretic agents (e.g., sulpyrine) and analine antipyretic agents (e.g., acetaminophen); neurotropin; pregabalin. The following were permitted as needed during the study: topical corticosteroids; lidocaine (as a local anesthetic); acetaminophen ( $\leq 1.5 \mathrm{~g} /$ day (Japan) or $\leq 4 \mathrm{~g} /$ day (Korea) for fever reduction); supportive therapy for chemotherapy; stable doses of very short-acting, non-benzodiazepine hypnotic drugs (for insomnia); medications for nausea, vomiting, and constipation; and rescue medication (as described below). Chemotherapy could be continued at the same dose or chemotherapy doses could be reduced, discontinued, or restarted (if deemed necessary by the investigator); however, if a patient's chemotherapy was considered by the investigator to be interfering with efficacy or safety evaluations of the study drug, that patient was excluded from the study."

Interventions

Oxycodone arm

- Drug: Oxycodone $\mathrm{HCl}$

- Dose/dosing: 5 to $40 \mathrm{mg}$ bid. The median of the mean total daily dose $=13.8 \mathrm{mg}$. The median modal (or most frequently used) total daily dose $=10 \mathrm{mg}$

- Formulation: Controlled-release

- Route of administration: oral.

- Length of treatment: "4 week double-blind treatment period (including titration and maintenance periods), and a 1 week post-treatment period." Median duration of treatment 28 days.

- Titration schedule: "Study treatment was initiated with twice daily doses of oxycodone $\mathrm{HCl}$ [hydrochlorine] CR $5 \mathrm{mg}$. During the titration period, doses of study treatment could be increased if necessary to achieve adequate pain control to a maximum of oxycodone $\mathrm{HCl} \mathrm{CR} 40 \mathrm{mg}$ bid [twice daily] after a patient had received the same dose at least four consecutive times. Dose escalations could begin on Day 3 of the titration period. Although not required for dose escalation, the following criteria were evaluated in patients who needed a dose escalation (based on the investigators assessment): 24 hour pain intensity score (11-point NRS) of at least 4 on the previous evaluation and rescue medication used for breakthrough pain at least three times per day. Doses could be decreased during the study as needed for safety reasons to the minimum doses of oxycodone $\mathrm{HCl} \mathrm{CR} \mathrm{(5} \mathrm{mg} \mathrm{bid).} \mathrm{Study} \mathrm{drug} \mathrm{doses} \mathrm{were} \mathrm{titrat-}$ ed to each patient's optimal dose, balancing efficacy and tolerability, until sufficient analgesia was attained. Patients with a pain intensity score of no more than 3 who did not take rescue medication more than twice a day while taking stable doses of study drug (six consecutive identical doses) over a consecutive 3 day period were considered eligible to formally enter the maintenance period; patients who did not meet these criteria were permitted to continue in the double-blind treatment period while continuing to titrate their dose. During the maintenance period, patients continued taking the optimal dose of study drug determined during the titration period. Dose adjustments were permitted during the maintenance period except during the last 3 days. Dose levels during the last 3 days of the maintenance period were to be kept stable."

- Rescue medication: "Oral morphine IR 5 mg was permitted throughout the study (except during the screening period) as rescue medication for breakthrough pain, with no limit on the number and timing of doses per day." The mean (SD) of the average number of morphine IR doses taken per day $=1.4$ (0.43); mean (SD) of the average total daily dose $=6.7$ (2.15) $\mathrm{mg}$ morphine IR 


\section{Comparison arm \\ - Drug: tapentadol.}

- Dose and dosing: 25 to $200 \mathrm{mg}$ bid. The median of the mean total daily dose $=64.5 \mathrm{mg}$. The median modal (or most frequently used) total daily dose $=50 \mathrm{mg}$

- Formulation: Extended-release

- Route of administration: oral.

- Length of treatment: " 4 week double-blind treatment period (including titration and maintenance periods), and a 1 week post-treatment period." Median duration of treatment 28 days.

- Titration schedule: "Study treatment was initiated with twice daily doses of tapentadol ER 25 mg. During the titration period, doses of study treatment could be increased if necessary to achieve adequate pain control to a maximum of tapentadol ER $200 \mathrm{mg}$ bid [twice daily] after a patient had received the same dose at least four consecutive times. Dose escalations could begin on Day 3 of the titration period. Although not required for dose escalation, the following criteria were evaluated in patients who needed a dose escalation (based on the investigators assessment): 24 hour pain intensity score (11 point NRS) of at least 4 on the previous evaluation and rescue medication used for breakthrough pain at least three times per day. Doses could be decreased during the study as needed for safety reasons to the minimum doses of tapentadol ER ( $25 \mathrm{mg}$ bid). Study drug doses were titrated to each patient's optimal dose, balancing efficacy and tolerability, until sufficient analgesia was attained. Patients with a pain intensity score of no more than 3 who did not take rescue medication more than twice a day while taking stable doses of study drug (six consecutive identical doses) over a consecutive 3 day period were considered eligible to formally enter the maintenance period; patients who did not meet these criteria were permitted to continue in the double-blind treatment period while continuing to titrate their dose. During the maintenance period, patients continued taking the optimal dose of study drug determined during the titration period. Dose adjustments were permitted during the maintenance period except during the last 3 days. Dose levels during the last 3 days of the maintenance period were to be kept stable."

- Rescue medication: "Oral morphine IR $5 \mathrm{mg}$ was permitted throughout the study (except during the screening period) as rescue medication for breakthrough pain, with no limit on the number and timing of doses per day." The mean (SD) of the average number of morphine IR doses taken per day $=1.4$ (0.46); mean (SD) of the average total daily dose $=7$ (2.3) $\mathrm{mg}$ morphine IR

- Other medication: See the inclusion and exclusion criteria in cell above

Outcomes

- Pain intensity: Assessed by participants once daily (evening on an 11-point numerical rating scale from 0 (no pain) to 10 (= pain as bad as you can imagine). Primary efficacy endpoint was the mean change in average pain intensity from baseline to the last 3 days of study

- Patient global impression of change: questionnaire completed at weeks 1, 2, 3 of double-blind treatment and at the end of study or early withdrawal. Participants rated their overall condition on a scale from 1 (very much improved) to 7 (very much worse) by completing the following statement, "Since the start of this treatment, my cancer-related pain overall is..."

- Adverse events: monitored and coded using the Medical Dictionary for Regulatory Activities. Each instance of disease progression was considered an adverse event and included in the analysis of treatment-emergent adverse events.

- ITT analyses undertaken? No, the analyses were per protocol ("a subset of the full analysis population that excluded any patient with a major protocol deviation from a predefined list of deviations"). 
Imanaka 2013 (Continued)

Risk of bias

\begin{tabular}{lll}
\hline Bias & Authors' judgement & Support for judgement \\
\hline $\begin{array}{ll}\text { Random sequence genera- } \\
\text { tion (selection bias) }\end{array}$ & Low risk & $\begin{array}{l}\text { "Patient assignments to study treatment were based on a computer-generat- } \\
\text { ed randomization schedule prepared by the sponsor prior to the study; ran- } \\
\text { domization was balanced using randomly permuted blocks and stratified by } \\
\text { study site. An Interactive Voice Response System (IVRS) assigned each patient } \\
\text { a unique treatment code, which determined that patient's treatment assign- } \\
\text { ment." }\end{array}$ \\
\hline
\end{tabular}

\begin{tabular}{|c|c|c|}
\hline $\begin{array}{l}\text { Allocation concealment } \\
\text { (selection bias) }\end{array}$ & Low risk & See cell above \\
\hline $\begin{array}{l}\text { Blinding of participants } \\
\text { and personnel (perfor- } \\
\text { mance bias) } \\
\text { Pain }\end{array}$ & Low risk & $\begin{array}{l}\text { "The blind was not broken until all patients completed the study and the data- } \\
\text { base was finalized, except in case of emergency." }\end{array}$ \\
\hline $\begin{array}{l}\text { Blinding of participants } \\
\text { and personnel (perfor- } \\
\text { mance bias) } \\
\text { Adverse events }\end{array}$ & Low risk & See cell above \\
\hline
\end{tabular}

\begin{tabular}{|c|c|c|}
\hline $\begin{array}{l}\text { Blinding of outcome as- } \\
\text { sessment (detection bias) } \\
\text { Pain }\end{array}$ & Low risk & See cell above \\
\hline $\begin{array}{l}\text { Blinding of outcome as- } \\
\text { sessment (detection bias) } \\
\text { Adverse events }\end{array}$ & Low risk & See cell above \\
\hline $\begin{array}{l}\text { Incomplete outcome data } \\
\text { (attrition bias) } \\
\text { Pain }\end{array}$ & High risk & $\begin{array}{l}\text { Per protocol analyses including } 139 / 172 \text { oxycodone participants and } 126 / 168 \\
\text { tapentadol participants }\end{array}$ \\
\hline $\begin{array}{l}\text { Incomplete outcome data } \\
\text { (attrition bias) } \\
\text { Adverse events }\end{array}$ & Low risk & $\begin{array}{l}\text { The safety population included all randomised participants who received at } \\
\text { least one dose of study drug, that is } 340 / 343 \text { randomised participants ( } 172 \text { oxy- } \\
\text { codone participants and } 168 \text { tapentadol participants) }\end{array}$ \\
\hline $\begin{array}{l}\text { Selective reporting (re- } \\
\text { porting bias) }\end{array}$ & Low risk & All main expected outcomes are reported \\
\hline Other bias & Low risk & The study does not appear to be subject to high risk of other biases \\
\hline $\begin{array}{l}\text { Were the participants ade- } \\
\text { quately titrated? }\end{array}$ & Low risk & The participants were probably adequately titrated \\
\hline $\begin{array}{l}\text { For cross-over trials: are } \\
\text { data available for both } \\
\text { time periods? }\end{array}$ & Unclear risk & Not applicable \\
\hline
\end{tabular}

Kalso 1990

Methods

Design: randomised, double-blind, cross-over trial. 
Kalso 1990 (Continued)

Year: not reported.

Country: Finland.

Participants

Participants: 20 participants entered, 19 participants analysed (1 participant excluded as her morphine dose had to be considerably reduced due to adverse effects); 11 women, 9 men; median age (range): 56 (20-75) years; cancer type: pancreatic (3), breast (5), prostate (1), gastric (1), rectal (2), other (8): cancer stage: metastatic; type of pain: visceral (6), nerve (7), bone (5), bone-fracture (1), bonenerve (1), soft tissue (1); setting: not reported, tertiary ?; previous analgesic medication: buprenorphine (7), oxycodone (1), dextropropoxyphene (1), aspirin + codeine (1), ibuprofen + buprenorphine (2), indomethacin + buprenorphine (1), dextropropoxyphene + buprenorphine (1), diclofenac + buprenorphine (1), indomethacin + codeine (2), naproxen + dextropropoxyphene (1), noramidopyrin + pitofenone (1), ketoprofen + dextropropoxyphene (1).

Inclusion criteria: "Twenty patients, 11 women and nine men, who had metastasised cancer and severe pain and who required a change from weaker narcotic analgesic agents (codeine, dextropropoxyphene, buprenorphine) to morphine, participated in the study."

Exclusion criteria: none reported.

Interventions

\section{Oxycodone arm}

- Drug: oxycodone hydrochloride.

- Dose and dosing: previous opioid treatment was discontinued 12-24 hours before commencing the study, and during this time $1 \mathrm{mg} / \mathrm{kg}$ meperidine was given intramuscularly when requested. The participants titrated themselves free from pain in 48 hours using a patient-controlled analgesia (PCA) device. The concentration of both morphine hydrochloride and oxycodone hydrocloride was $10 \mathrm{mg} / \mathrm{ml} . \mathrm{This}$ treatment was continued for another 48 hours with the use of the same drug, which was now taken orally. The oral dose was calculated from the IV consumption during the previous 24 hours. The daily oral dose was calculated in $\mathrm{ml}$ by assuming that the bioavailability of morphine was either $44 \%$ (first 10 participants, group 1) or 33\% (last 10 participants, group 2) and that the bioavailability of oxycodone hydrocloride was $66 \%$ (group 1) and $50 \%$ (group 2). To overcome the differences in bioavailabilities of the two drugs, the concentrations of the oral solutions were $2.7 \mathrm{mg} / \mathrm{ml}$ for oxycodone hydrocloride and $4 \mathrm{mg} / \mathrm{ml}$ for morphine. The dosing interval was 4 hours and the dose was increased by $1 \mathrm{ml}$ at a time if the participant was not pain free during the 4-hour period. If the participant was pain-free, but too sedated, the dose was decreased by $1 \mathrm{ml}$. PCA device: The bolus dose was $3 \mathrm{mg}$, which was given over a period of 60 seconds, followed by a tail dose of $2 \mathrm{mg}$ over 1 hour. The lockout time, during which the participant was unable to initiate another dose, was 15 minutes. If the participant was not free from pain with this regimen, the tail dose was increased by $2 \mathrm{mg}$ at a time

- Formulation: Immediate-release (oral)

- Route of administration: IV ( 2 days) then oral (2 days).

- Length of treatment: 4 days.

- Titration schedule: see 'Dose and dosing.'

- Rescue medication: see 'Dose and dosing.' No further information was reported.

- Other medication: any pre-existing treatment with non-steroidal anti-inflammatory drugs was continued

\section{Comparison arm:}

Same as oxycodone arm, just replacing oxycodone with morphine.

- For cross-over trials, cross-over schedule: "The same protocol was then repeated with the other drug for another 96 hours."

Outcomes
- Pain severity: Assessed by participant at study start and every 4 hours from 8 am to 8 pm; VAS from 0 to 10 
- Adverse effects: determined by questioning (have you had nausea, constipation, drowsiness, sedation symptoms, hallucinations, or any other symptoms you would connect with the analgesic?) scored according to grade (moderate $=1$, severe $=2$ ); registered on the second day of each study period

- Sleep quality, registered on the second day of each study period

- Participant preference or acceptability with reason

The last 24 hours of each of the four study stages were considered as the steady state and the drug consumptions, and the ratings from the VAS during this period were used for the statistical calculations.

\section{Notes}

- Study free of commercial funding? Yes. Supported by the Paolo (non-profit) Foundation, Helsinki, Finland.

- Groups comparable at baseline? No participant details reported by initial treatment allocation.

- ITT analyses undertaken? No, data from 1 participant in regard to morphine consumption was excluded as her morphine dose had to be considerably reduced due to adverse effects. Her data was included in the participant preference analyses.

\section{Risk of bias}

\begin{tabular}{|c|c|c|}
\hline Bias & Authors' judgement & Support for judgement \\
\hline $\begin{array}{l}\text { Random sequence genera- } \\
\text { tion (selection bias) }\end{array}$ & Unclear risk & Participants were randomised. No further information provided. \\
\hline $\begin{array}{l}\text { Allocation concealment } \\
\text { (selection bias) }\end{array}$ & Unclear risk & See cell above \\
\hline $\begin{array}{l}\text { Blinding of participants } \\
\text { and personnel (perfor- } \\
\text { mance bias) } \\
\text { Pain }\end{array}$ & Unclear risk & $\begin{array}{l}\text { The study is described as "double-blind". No further information reported, so it } \\
\text { is unclear who was blinded and whether it was adequately executed }\end{array}$ \\
\hline $\begin{array}{l}\text { Blinding of participants } \\
\text { and personnel (perfor- } \\
\text { mance bias) } \\
\text { Adverse events }\end{array}$ & Unclear risk & See cell above: \\
\hline $\begin{array}{l}\text { Blinding of outcome as- } \\
\text { sessment (detection bias) } \\
\text { Pain }\end{array}$ & Unclear risk & See cell above \\
\hline $\begin{array}{l}\text { Blinding of outcome as- } \\
\text { sessment (detection bias) } \\
\text { Adverse events }\end{array}$ & Unclear risk & See cell above \\
\hline $\begin{array}{l}\text { Incomplete outcome data } \\
\text { (attrition bias) } \\
\text { Pain }\end{array}$ & Low risk & The data from $1 / 20$ participants were excluded \\
\hline $\begin{array}{l}\text { Incomplete outcome data } \\
\text { (attrition bias) } \\
\text { Adverse events }\end{array}$ & Low risk & Think the data from $1 / 20$ participants were excluded \\
\hline $\begin{array}{l}\text { Selective reporting (re- } \\
\text { porting bias) }\end{array}$ & Low risk & The main expected outcomes are reported \\
\hline
\end{tabular}


Kalso 1990 (Continued)

Other bias Low risk The authors report that "The order in which the drugs were given (either as the first or the second study drug) had no effect on the drug consumption." No other potential biases were identified
Were the participants ade- Low risk
The participants were probably adequately titrated quately titrated?

For cross-over trials: are Low risk Yes, data are available for both study periods for 19/20 participants

data available for both

time periods?

Kaplan 1998

Methods Design: randomised, double-blind, parallel-group trial.

Year: not reported.

Country: USA.

\section{Participants}

Participants: 180 participants enrolled (108 before protocol amendment allowing dose titration before randomisation and 72 after the amendment; 16/72 participants discontinued before randomisation due to lack of acceptable pain control (6), intercurrent illness (4), adverse event (2), death (1), withdrawal of consent (1), other (2). 164 participants were randomised (controlled-release oxycodone: $\mathrm{N}=$ 81; immediate-release oxycodone 83); 156 were included in efficacy analyses (4 participants did not receive the study medication, 3 participants did not complete the efficacy ratings, and 1 participant may have received unblinded treatment). All 160 participants who received at least 1 dose of study medication were included in the safety analyses (of adverse events). $74 \%$ of participants were white; mean (SE) age $=59$ (1) years; $58 \%$ were male; most participants were receiving oral morphine at study entry; cancer type: gastrointestinal (22\%), lung (21\%), prostate (17\%), breast $(10 \%)$, gynaecological (10\%): predominant pain sites were bone and viscera, with an additional 15 participants ( 9 in controlled-release oxycodone group and 6 in the immediate-release oxycodone group) reporting neuropathic pain

Inclusion criteria: "Male and female patients with cancer-related pain were enrolled at 17 centers. The study received institutional review board approval at each center and all patients gave written informed consent. At the time of enrollment, patients were being treated with a strong single-entity opioid or 10 or more tablets per day of a fixed-dose opioid/nonopioid analgesic; were receiving a stable opioid dose; and had stable coexistent disease. Under the original protocol, patients were excluded if they were receiving any other analgesics (opioid or nonopioid) or if they were to receive radiotherapy immediately before enrollment or during the study period. After the study had begun, these exclusion criteria were eliminated by an amendment to facilitate enrollment into the study, which had been slow."

Exclusion criteria: See above

Interventions $\quad$ Oxycodone arm

- Drug: oxycodone.

- Dose/dosing: Oxycodone tablets ( $10 \mathrm{mg}$ ) every 12 hours ( 8 am and $8 \mathrm{pm}$ ) and placebo tablets every 2 $\mathrm{pm}$ and bedtime. Mean daily dose (range) $=114$ (20 to 400) $\mathrm{mg}$

- Formulation: Controlled-release

- Route of administration: Oral

- Length of treatment: 6 days

- Titration schedule: The original study design did not allow dose titration or use of rescue medication for breakthrough/incident pain. Participants whose pain was not effectively controlled at the ini- 
tial oxycodone dose calculated from previous opioid use were discontinued from the study. However, an interim analysis conducted to determine whether dose adjustments were required showed that dropout rates were too high for relevant conclusions. This suggested that the initial conversion dose estimate was not adequate for a subgroup of participants, and the protocol was amended to include open-label titration with immediate-release oxycodone before the participants were randomised to double-blind treatment, as well as the use of immediate-release oxycodone $5 \mathrm{mg}$ tablets as rescue medication throughout the trial. Supplemental doses could be taken no more frequently than every 4 hours at no more than approximately $1 / 6$ of the daily dose of study medication. No further information was reported.

- Rescue medication: See 'Titration schedule' above. Mean number of rescue medication doses per day $=0.6$

- Other medication: See 'Inclusion criteria' above. No further information reported

\section{Comparison arm}

- Drug: Oxycodone

- Dose and dosing: Oxycodone tablets ( $5 \mathrm{mg}$ )every 6 hours ( $8 \mathrm{pm}$, bedtime ( $\geq 3$ hours after $8 \mathrm{pm}$, but not after $2 \mathrm{am}$ ), 8 am and $2 \mathrm{pm}$ ). Mean daily dose (range) $=127$ (40 to 640) $\mathrm{mg}$

- Formulation: Immediate-release

- Route of administration: oral.

- Length of treatment: 6 days.

- Titration schedule: The original study design did not allow dose titration or use of rescue medication for breakthrough/incident pain. Participants whose pain was not effectively controlled at the initial oxycodone dose calculated from previous opioid use were discontinued from the study. However, an interim analysis conducted to determine whether dose adjustments were required showed that dropout rates were too high for relevant conclusions. This suggested that the initial conversion dose estimate was not adequate for a subgroup of participants, and the protocol was amended to include openlabel titration with immediate-release oxycodone before the participants were randomised to double-blind treatment, as well as the use of immediate-release oxycodone $5 \mathrm{mg}$ tablets as rescue medication throughout the trial. Supplemental doses could be taken no more frequently than every 4 hours at no more than approximately $1 / 6$ of the daily dose of study medication. No further information was reported.

- Rescue medication: see 'Titration schedule.' Mean number of rescue medication doses per day 1.

- Other medication: see 'Inclusion criteria.' No further information reported.

Outcomes

- Pain intensity: Assessed by participant at study start and 4 times daily at 8 am, 2 pm, 8 pm and bedtime; categorical verbal scale from 0 (= none, 1 = slight, 2 = moderate) to 3 (= severe)

- Acceptability of treatment: Assessed by participant at study start and twice daily at 8am and $8 \mathrm{pm}$; categorical verbal scale from 1 (= very poor; 2 = poor, 3 = fair, 4 = good) to 5 (= excellent)

- Adverse events: Those spontaneously reported by participants or observed by investigators were recorded, and their severity and relationship to study drug (none, possible, probable, definite) were assessed by each investigator

- Groups comparable at baseline? The authors reported, "There were no significant differences in the primary pain site, prestudy opioid, or cancer diagnosis between the two treatment groups." No other information reported.

- ITT analyses undertaken? No, 156 and 160/164 participants, respectively, were included in the safety and efficacy analyses 
Kaplan 1998 (Continued)

Risk of bias

\begin{tabular}{|c|c|c|}
\hline Bias & Authors' judgement & Support for judgement \\
\hline $\begin{array}{l}\text { Random sequence genera- } \\
\text { tion (selection bias) }\end{array}$ & Unclear risk & $\begin{array}{l}\text { The authors state that the participants were randomised, but give no further } \\
\text { details }\end{array}$ \\
\hline $\begin{array}{l}\text { Allocation concealment } \\
\text { (selection bias) }\end{array}$ & Unclear risk & $\begin{array}{l}\text { The authors state that the participants were randomised, but give no further } \\
\text { details }\end{array}$ \\
\hline $\begin{array}{l}\text { Blinding of participants } \\
\text { and personnel (perfor- } \\
\text { mance bias) } \\
\text { Pain }\end{array}$ & Low risk & $\begin{array}{l}\text { Double-blind placebo-controlled study. To maintain the blind, all doses of the } \\
\text { study medication were encapsulated in green size \#00 lactose-filled capsules }\end{array}$ \\
\hline $\begin{array}{l}\text { Blinding of participants } \\
\text { and personnel (perfor- } \\
\text { mance bias) } \\
\text { Adverse events }\end{array}$ & Low risk & See cell above \\
\hline $\begin{array}{l}\text { Blinding of outcome as- } \\
\text { sessment (detection bias) } \\
\text { Pain }\end{array}$ & Low risk & See cell above \\
\hline $\begin{array}{l}\text { Blinding of outcome as- } \\
\text { sessment (detection bias) } \\
\text { Adverse events }\end{array}$ & Low risk & See cell above \\
\hline $\begin{array}{l}\text { Incomplete outcome data } \\
\text { (attrition bias) } \\
\text { Pain }\end{array}$ & Low risk & A total of $156 / 164$ participants were included in the efficacy analyses \\
\hline $\begin{array}{l}\text { Incomplete outcome data } \\
\text { (attrition bias) } \\
\text { Adverse events }\end{array}$ & Low risk & A total of $160 / 164$ participants were included in the safety analyses \\
\hline $\begin{array}{l}\text { Selective reporting (re- } \\
\text { porting bias) }\end{array}$ & Low risk & All obvious outcomes are reported \\
\hline Other bias & Low risk & The study does not appear to be subject to high risk of other biases \\
\hline $\begin{array}{l}\text { Were the participants ade- } \\
\text { quately titrated? }\end{array}$ & High risk & No before amendment, unclear after amendment \\
\hline $\begin{array}{l}\text { For cross-over trials: are } \\
\text { data available for both } \\
\text { time periods? }\end{array}$ & Unclear risk & Not applicable \\
\hline
\end{tabular}

\section{Lauretti 2003}

$\begin{array}{ll}\text { Methods } & \text { Design: randomised, double-blind, cross-over trial. } \\ & \text { Year: not reported. } \\ & \text { Country: Brazil. }\end{array}$


Lauretti 2003 (Continued)

Participants
Participants: 22/26 enrolled participants evaluated (withdrawals due to death (unrelated to the study 1), uncontrollable nausea/vomiting (1), and unstable pain control requiring spinal drugs (2)); mean/median (?) (SD/interquartile range?) age 59 (19) years; 15 men, 7 women; cancer type: oropharynx (9), lung (3), prostate gland (2), colon (4), gastric (2), ovary (2); pain types were somatic and visceral; adjuvant therapy: radiation (1), chemotherapy (6), radiation/chemotherapy (4), none (11).

Inclusion criteria: "26 patients with chronic cancer pain of the visceral and somatic type..... Before enrolling in this actual study, patients received $3-4 \mathrm{mg} / \mathrm{kg}^{-1}$ tramadol, plus nonsteroidal anti-inflammatory drugs: however they still complained of pain VAS $\geq 4 \mathrm{~cm}$."

Exclusion criteria: none listed.
Interventions

\section{Oxycodone arm}

- Drug: oxycodone

- Dose/dosing: The optimum dosage was calculated on a daily basis, and the consumption ratio of oxycodone to morphine was set at 1:1.8

- Formulation: Controlled-release

- Route of administration: oral.

- Length of treatment: 14 days.

- Titration schedule: The study started with an open-label, randomised titration phase to achieve stable pain control for 7 days. Participants only used immediate-release morphine and had free access to it to keep pain $\mathrm{VAS}<4$

- Rescue medication: At any point, participants were allowed to use immediate-release morphine (10 $\mathrm{mg}$ tablets) as needed to keep pain VAS $\leq 4$

- Other medication: as part of the protocol, all participants were taking oral $25 \mathrm{mg}$ amitriptyline at bedtime

\section{Comparison arm}

- Drug: morphine

- Dose/dosing: The optimum dosage was calculated on a daily basis, and the consumption ratio of oxycodone to morphine was set at 1:1.8

- Formulation: Controlled-release

- Route of administration: oral.

- Length of treatment: 14 days.

- Titration schedule: The study started with an open-label, randomised titration phase to achieve stable pain control for 7 days. Participants only used immediate-release morphine and had free access to it to keep pain VAS $<4$

- Rescue medication: at any point, participants were allowed to use immediate-release morphine (10 $\mathrm{mg}$ tablets) as needed to keep pain VAS $\leq 4$.

- Other medication: as part of the protocol, all participants were taking oral $25 \mathrm{mg}$ amitriptyline at bedtime

- For cross-over trials, cross-over schedule: "After stable pain relief was achieved [during titration phase], this was followed by a double-blind, cross-over phase in two periods, 14 days each...... and no period of washout was was allowed for ethical reasons"
- Pain intensity: assessed by participants; $10 \mathrm{~cm}$ VAS from 0 (= no pain at all) to 10 (= worst possible pain) 
Lauretti 2003 (Continued)

- Participant satisfaction: assessed by participant

- Adverse events: assessed by participant (possibly using a $10 \mathrm{~cm}$ VAS similar to pain intensity, but data not reported that way)

- Number of rescue morphine tablets: Assessed by participant

It also appears that an investigator recorded these data on a weekly basis

Notes

- Study free of commercial funding? No information reported.

- Groups comparable at baseline? Unclear, no information reported.

- ITT analyses undertaken? No, 22/26 participants were included in the analyses.

\section{Risk of bias}

\begin{tabular}{|c|c|c|}
\hline Bias & Authors' judgement & Support for judgement \\
\hline $\begin{array}{l}\text { Random sequence genera- } \\
\text { tion (selection bias) }\end{array}$ & Unclear risk & No information reported. \\
\hline $\begin{array}{l}\text { Allocation concealment } \\
\text { (selection bias) }\end{array}$ & Unclear risk & No information reported. \\
\hline $\begin{array}{l}\text { Blinding of participants } \\
\text { and personnel (perfor- } \\
\text { mance bias) } \\
\text { Pain }\end{array}$ & Low risk & $\begin{array}{l}\text { The participants were blinded, but it is unclear whether the investigator ad- } \\
\text { ministering the drugs was }\end{array}$ \\
\hline $\begin{array}{l}\text { Blinding of participants } \\
\text { and personnel (perfor- } \\
\text { mance bias) } \\
\text { Adverse events }\end{array}$ & Low risk & $\begin{array}{l}\text { The participants were blinded, but it is unclear whether the investigator ad- } \\
\text { ministering the drugs was }\end{array}$ \\
\hline $\begin{array}{l}\text { Blinding of outcome as- } \\
\text { sessment (detection bias) } \\
\text { Pain }\end{array}$ & Low risk & The participants and outcome assessor were blinded \\
\hline $\begin{array}{l}\text { Blinding of outcome as- } \\
\text { sessment (detection bias) } \\
\text { Adverse events }\end{array}$ & Low risk & The participants and outcome assessor were blinded \\
\hline $\begin{array}{l}\text { Incomplete outcome data } \\
\text { (attrition bias) } \\
\text { Pain }\end{array}$ & Unclear risk & Data from $22 / 26$ participants included. \\
\hline $\begin{array}{l}\text { Incomplete outcome data } \\
\text { (attrition bias) } \\
\text { Adverse events }\end{array}$ & Unclear risk & Data from $22 / 26$ participants included. \\
\hline $\begin{array}{l}\text { Selective reporting (re- } \\
\text { porting bias) }\end{array}$ & High risk & $\begin{array}{l}\text { All obvious outcomes are reported, although not in the most useful manner } \\
\text { (e.g., no collapsing across study phase weeks, that is, mean final weekly dose } \\
\text { of CR oxycodone and morphine are reported for } 4 \text { weeks, not } 2 \text { weeks) }\end{array}$ \\
\hline Other bias & Low risk & $\begin{array}{l}\text { It is unclear whether there were any carry-over effects, but there probably } \\
\text { were none }\end{array}$ \\
\hline
\end{tabular}


Lauretti 2003 (Continued)

Were the participants ade- Low risk The participants were probably adequately titrated quately titrated?

For cross-over trials: are Low risk data available for both time periods?
Yes, data are available from both time periods, although not reported by arm (see two cells above)

\section{Leow 1995}

Methods

Design: randomised, open-label, single-dose, cross-over trial.

Year: not reported.

Country: Australia.

Participants

Participants: 12 participants entered; 5 women, 7 men; mean age $( \pm$ SD): 68.8 ( \pm 12.6$)$ years; cancer type: cervical (2), breast (1), prostate (1), bowel (1), anal (1), endometrial (1), renal (1), lung/bronchial (2), skeletal or thoracic-vertebral metastases (2); all inpatients; all receiving oral nutrition; none hypovolaemic; all opioid-naive apart from 1 participant who was receiving paracetamol + dextropropoxyphene. 2 participants had compromised renal function, and 5 participants had impaired liver function to varying degree.

Inclusion criteria: inpatients with moderate to severe cancer pain.

Exclusion criteria: known hypersensitivity to oxycodone or other opioid analgesics or a history of drug dependence, or both.

Interventions

\section{Oxycodone arm}

- Drug: oxycodone hydrochloride.

- Dose and dosing: single dose of IV oxycodone hydrochloride in a concentration of $5 \mathrm{mg} / \mathrm{ml}$, equivalent to $4.5 \mathrm{mg} / \mathrm{ml}$ oxycodone base. The mean (SD) IV oxycodone dose administered was $0.11(0.02) \mathrm{mg} / \mathrm{kg}$ (range 5.4 to $9 \mathrm{mg}$ ), which a previous study by the authors had shown to produce satisfactory analgesia in participants with moderate to severe cancer. Participants with impaired liver function received the lower doses of IV oxycodone. The IV oxycodone dose was administered into a forearm vein. The rate of injection ( 0.5 to $5 \mathrm{~min}$ ) was titrated by the anaesthetist.

- Formulation: IV

- Route of administration: IV

- Length of treatment: 24 hours, 1 dose

- Titration schedule: See 'Dose and dosing' section.

- Rescue medication: oral paracetamol (up to $1 \mathrm{~g}$ every 4 hours) or Di-Gesic (up to 2 tablets every 4 hours) were available as rescue medication on participant request. 9 participants asked for supplementary analgesics after 4 hours postdosing.

- Other medication: "Medications that had been taken routinely by patients before the study, were permitted."

\section{Comparison arm}

- Drug: oxycodone.

- Dose and dosing: single dose of $30 \mathrm{mg}$ oxycodone base in a rectal suppository.

- Formulation: suppository. 
Leow 1995 (Continued)
- Route of administration: rectal.
- Length of treatment: 24 hours, 1 dose.
- Titration schedule: see 'Dose and dosing' section.

- Rescue medication: oral paracetamol (up to 1 g every 4 hours) or digesic (up to 2 tablets every 4 hours) were available as rescue medication on participant request. 9 participants asked for supplementary analgesics after 6-8 hours postdosing.

- Other medication: "Medications that had been taken routinely by patients before the study, were permitted."

- For cross-over trials, cross-over schedule: "Patients were randomly assigned to begin treatment with either a single dose of... The second treatment was administered $24 \mathrm{~h}$ [hours] after the first dose."

\begin{tabular}{l} 
- Pain intensity: Assessed by participant at study start at $0.5,1,2,4,8,12$ and 24 hours post-dosing; 10 \\
cm VAS with delimiters 'no pain' and 'worst pain imaginable.' \\
- Adverse effects: assessed by questioning the participant at study start at $0.5,1,2,4,8,12$, and 24 \\
hours postdosing; participants were asked to report any adverse effects, but were specifically asked \\
whether they experienced nausea, vomiting, pruritus, lightheadedness, or drowsiness, using a 4-point \\
verbal rating scale going from 0 to 3 (none = 0, mild = 1, moderate = 3, severe = 3) \\
\hline - Study free of commercial funding? No. Supported by the Boots Company (Australia; manufacturer of \\
the rectal suppository study drug), Pty Ltd, the University of Queensland Cancer Research Fund, and \\
the Queensland Cancer Fund \\
- Groups comparable at baseline? No participant details reported by initial treatment allocation. \\
- ITT analyses undertaken? Appears so. It was not possible to confirm it based on the presented date, \\
but no information to the contrary was reported.
\end{tabular}

\section{Risk of bias}

\begin{tabular}{lll}
\hline Bias & Authors' judgement & Support for judgement \\
\hline $\begin{array}{l}\text { Random sequence genera- } \\
\text { tion (selection bias) }\end{array}$ & Unclear risk & $\begin{array}{l}\text { "Patients were randomly assigned to begin treatment with..." No further infor- } \\
\text { mation reported. }\end{array}$ \\
\hline $\begin{array}{l}\text { Allocation concealment } \\
\text { (selection bias) }\end{array}$ & Unclear risk & $\begin{array}{l}\text { "Patients were randomly assigned to begin treatment with..." No further infor- } \\
\text { mation reported. }\end{array}$ \\
\hline $\begin{array}{l}\text { Blinding of participants } \\
\begin{array}{l}\text { and personnel (perfor- } \\
\text { mance bias) }\end{array}\end{array}$ & High risk & The study was open-label \\
\hline \begin{tabular}{l} 
Pain \\
\hline
\end{tabular} & & \\
\hline
\end{tabular}

$\begin{array}{lll}\begin{array}{l}\text { Blinding of participants } \\ \text { and personnel (perfor- }\end{array} & \text { High risk } & \\ \text { mance bias) } \\ \text { Adverse events }\end{array}$

Blinding of outcome as- High risk The study was open-label sessment (detection bias)

Adverse events 
Leow 1995 (Continued)

Incomplete outcome data Low risk All data appear to be included. It is not possible to confirm it based on the pre(attrition bias) sented data, but no information to the contrary is reported

Pain
All data appear to be included. It is not possible to confirm it based on the presented data, but no information to the contrary is reported
Incomplete outcome data Low risk (attrition bias)

Adverse events
All expected outcomes seem to be reported

Selective reporting (re- Low risk porting bias)
Low risk
"An absence of carryover effects $(P>0.05)$ between Treatments 1 and 2 was confirmed using the Grizzle analysis for cross-over designs"

Were the participants ade- Unclear risk Not enough information reported
quately titrated?

For cross-over trials: are Low risk Yes, data are available from both time periods

data available for both

time periods?

Lux 2014

Methods
Design: randomised, double-blind, non-inferiority cross-over trial.
Year: 2010-2012. (www.clinicaltrialsregister.eu/ctr-search/trial/2010-020402-15/results).
Country: Germany, Poland, Switzerland.

Participants

Participants: 85 participants entered into titration/stabilisation phase, 71 participants randomised and 68 took at least 1 dose of the study drug and comprised the safety data set. The full analysis set comprised the 60 participants with at least 1 measurement of the primary efficacy parameter. 56 participants completed the trial of whom 46 qualified for the per protocol data set ( 23 in each sequence), of the 60 participants in the full analysis set, 40 had malignant pain of the following type: lung (7), breast (6), cervix (5), prostate (5), colon/rectum/anus (4), oropharynx (3), skin (2), lymphoma (2), and other (6). 32 women, 36 men. Mean age (SD) of the 68 participants in the safety data set were 60.8 (10) years.

Inclusion criteria: white men and women, $\geq 18$ years of age with chronic cancer pain (in the protocol) or non-cancer pain (not in the protocol) and predominantly non-neuropathic pain, requiring at least 40 mg oxycodone per day (or equivalent), ECOG (Eastern Cooperative Oncology Group) performance status $<3$, life expectancy of at least 3 months, adequate analgesia (mean 'current' pain intensity per day $\leq 40 \mathrm{~mm}$ on VAS) prior to randomisation for at least 3 consecutive days and stable analgesic requirements prior to randomisation for at least 3 days (stable maintenance dose of oxycodone; requirement of $\geq 40 \mathrm{mg}$ oxycodone per day; $\leq 2$ doses of rescue medication per day).

Exclusion criteria: hypersensitivity to oxycodone or any of the excipients of the study drugs, requirement of $>120 \mathrm{mg}$ oxycodone per day (or equivalent), surgery within 1 month prior to study start and/or anticipated or scheduled surgical intervention during the study, intravenous chemotherapy and/or radiotherapy for pain alleviation and/or neural blockade within 2 weeks prior to study start, significant hepatic impairment or severe renal impairment (creatinine clearance $<30 \mathrm{ml} / \mathrm{min}$ ), and pregnancy or lactation.

However, only outcome data pertaining to the participants with malignant pain alone were included in this review.

Interventions

Oxycodone arm

- Drug: oxycodone (Oxygesic/OxyContin). 
- Dose and dosing: twice-daily administration of oxycodone at 8.00 and 20.00 hours. No dose adjustment of oxycodone was allowed during the double-blind treatment phase after the titration/stabilisation phase. The total daily dose was determined during the titration/stabilization phase and fixed throughout the study. The mean daily dose was not reported.

- Formulation: Controlled-release

- Route of administration: oral.

- Length of treatment: 10 days per cross-over phase (data only analysed for days 6-10).

- Titration schedule: after a screening phase (maximum 14 days), a titration/ stabilisation period followed (maximum 14 days) where the participants were switched to oxycodone and the dose was adjusted for sufficient pain relief, i.e. daily mean current pain $\leq 40 \mathrm{~mm}$ on VAS.

- Rescue medication: $10 \mathrm{mg}$ immediate-release morphine sulfate ( $\leq 2$ doses of rescue medication per day).

- Other medication: not reported

Comparison arm

- Drug: oxycodone + placebo.

- Dose and dosing: once-daily administration of oxycodone at 8.00 hours and placebo at 20.00 hours. No dose adjustment of oxycodone was allowed during the double-blind treatment phase after the titration/stabilisation phase. Total daily dose was determined during the titration/stabilisation phase and fixed throughout the study. Mean daily dose was not reported.

- Formulation: Extended-release

- Route of administration: oral.

- Length of treatment: 10 days per cross-over phase (data only analysed for days 6-10).

- Titration schedule: after a screening phase (maximum 14 days), a titration/ stabilisation period followed (maximum 14 days) where the participants were switched to oxycodone and the dose was adjusted for sufficient pain relief, i.e. daily mean current pain $\leq 40 \mathrm{~mm}$ on VAS.

- Rescue medication: $10 \mathrm{mg}$ immediate-release morphine sulfate ( $\leq 2$ doses of rescue medication per day).

- Other medication: not reported

- For cross-over trials, cross-over schedule: "After 10 days of treatment with the first study medication of the respective sequence, patients were directly switched to the second medication without washout." "During the double-blind phase of the study, for each study medication the current pain and recalled pain scores obtained from days 6 to 10 were employed for statistical evaluations. Days 1 to 5 of each period were regarded as an active 5 day run-in phase in order to avoid any potential carry-over effects between the different study periods."

Primary outcome measures:

- Overall 'current' pain intensity (PI) on 0 to $100 \mathrm{~mm}$ VAS (mean 'current' PI of the last 5 days of each treatment period). Pain intensity (PI) was assessed five times daily, i.e., at 08:00 $\mathrm{h}$ (before study drug intake), 11:00 h, 14:00 h, 17:00 h, and 20:00 h (before study drug intake; allowed deviation $\pm 20 \mathrm{~min}$ for all assessments) on a 0 to $100 \mathrm{~mm}$ VAS ('current' pain). PI assessment at 08:00 $\mathrm{h}$ and 20:00 $\mathrm{h}$ also comprised ratings of PI over the past 12 hours ('recalled' pain during day- and night-time). From the PI scores the mean 'current' PI over all time points of the last 5 treatment days of period 1 and period 2 (= overall mean 'current' PI) will be calculated for each participant as the primary efficacy endpoint

Secondary outcome measures:

- mean 'current' pain intensity (PI) per day 
Lux 2014 (Continued)

$$
\begin{aligned}
& \text { - mean 'current' PI per time point } \\
& \text { - mean 'recalled' PI over the past } 12 \text { hours at 08:00 h } \\
& \text { - mean 'recalled' PI over the past } 12 \text { hours at 20:00 h }
\end{aligned}
$$

- overall effectiveness on 4-point categorical scale (CAT; 0 = not effective, $3=$ highly effective) by participant and investigator (assessed at the end of each treatment period)

- daily dose of rescue medication for each of the last 5 days of period 1 and 2

- mean daily dose of rescue medication over the last 5 treatment days of period 1 and 2

- total amount of rescue medication over the last 5 treatment days of period 1 and 2

- Adverse events and serious adverse events recorded using the Medical Dictionary for Regulatory Activities (MedDRA).

- Nausea and sedation assessed on 0 to $100 \mathrm{~mm}$ VAS at 08:00 $\mathrm{h}$ and 20:00 $\mathrm{h}$ by participants.

However, only the primary outcome data was reported on a per protocol basis for participants with malignant pain alone. These are therefore the only study results included in this review.

- Study free of commercial funding? No. Study was funded by study sponsor Develco Pharma Schweiz AG.

- Groups comparable at baseline? Unclear. The groups comprising the safety data set were comparable at baseline in terms of age, sex, weight, height, and body mass index, but this was not the analysis set used for the present review (i.e. included both benign and malignant pain).

- ITT analyses undertaken? The only data available for the participants with malignant pain only is per

\begin{tabular}{|c|c|c|}
\hline Bias & Authors' judgement & Support for judgement \\
\hline $\begin{array}{l}\text { Random sequence genera- } \\
\text { tion (selection bias) }\end{array}$ & Low risk & $\begin{array}{l}\text { "The treatment sequence (test-reference; reference- test) was assigned by } \\
\text { randomization code and central randomization procedure." }\end{array}$ \\
\hline $\begin{array}{l}\text { Allocation concealment } \\
\text { (selection bias) }\end{array}$ & Low risk & See cell above \\
\hline $\begin{array}{l}\text { Blinding of participants } \\
\text { and personnel (perfor- } \\
\text { mance bias) } \\
\text { Pain }\end{array}$ & Low risk & $\begin{array}{l}\text { "OTD, OOD and a dummy were blinded using the same type of over-encapsula- } \\
\text { tion. The patients received the same number of encapsulated tablets in both } \\
\text { periods of the double-blind treatment phase in the morning (OTD or OOD) and } \\
\text { in the evening (OTD or dummy)." }\end{array}$ \\
\hline $\begin{array}{l}\text { Blinding of participants } \\
\text { and personnel (perfor- } \\
\text { mance bias) } \\
\text { Adverse events }\end{array}$ & Low risk & See cell above: \\
\hline $\begin{array}{l}\text { Blinding of outcome as- } \\
\text { sessment (detection bias) } \\
\text { Pain }\end{array}$ & Low risk & See cell above \\
\hline $\begin{array}{l}\text { Blinding of outcome as- } \\
\text { sessment (detection bias) } \\
\text { Adverse events }\end{array}$ & Low risk & See cell above \\
\hline
\end{tabular}
protocol.

\section{Risk of bias}


Lux 2014 (Continued)

Incomplete outcome data High risk Outcome data only available for $31 / 40$ participants.
(attrition bias)

Pain
Adverse events only reported for the 68 participants in the safety data set of whom 40 had malignant pain. These data are therefore not included in this review.

\begin{tabular}{lll}
\hline $\begin{array}{l}\text { Selective reporting (re- } \\
\text { porting bias) }\end{array}$ & High risk & $\begin{array}{l}\text { Adverse events were not reported separately for the participants with malig- } \\
\text { nant pain and could therefore not be extracted for the purposes of this review. }\end{array}$ \\
\hline Other bias & Low risk & The study appears to be free of other bias. \\
\hline $\begin{array}{l}\text { Were the participants ade- } \\
\text { quately titrated? }\end{array}$ & Low risk & Adequate titration was an inclusion criterion. \\
\hline $\begin{array}{l}\text { For cross-over trials: are } \\
\text { data available for both } \\
\text { time periods? }\end{array}$ & Low risk & $\begin{array}{l}\text { Yes, data were available for both time periods collapsed across the time peri- } \\
\text { ods. }\end{array}$ \\
\hline
\end{tabular}

\section{Mercadante 2010}

\begin{tabular}{ll}
\hline Methods & Design: randomised, parallel group trial. \\
& Year: not reported. \\
& Country: Italy.
\end{tabular}

\section{Participants}

Participants: 60 participants randomised; $46 / 60$ participants completed baseline evaluation (21 participants in group oxycodone and 25 participants in group morphine, 14/60 participants did not complete baseline evaluation as they were lost to follow up); 27 females, 19 males; mean age (SD): 63.2 (9.48) years. 19 oxycodone and 20 morphine participants completed 4 weeks of study participation and 7 and 10 participants, respectively, completed 8 weeks of study participation

Inclusion criteria: Patients with pancreatic cancer with local disease, presenting abdominal pain with an intensity $\geq 4 / 10$ numerical rating scale from 0 to 10 , and no longer responsive no nonopioid analgesics

Exclusion criteria: Distant and bone metastases, or prevalent somatic pain due to evident peritoneal involvement, changes in chemotherapy regimen, hepatic or renal failure, cognitive failure, lack of cooperation, aged $<18$ or $>80$ years, and a Karnofsky performance status $<50$

Interventions

$$
\begin{aligned}
& \text { Oxycodone arm } \\
& \text { - Drug: oxycodone. } \\
& \text { - Dose and dosing: starting dose of } 20 \mathrm{mg} / \text { day, according to an approximate morphine to oxycodone } \\
& \text { ratio of } 1.5: 1 . \text { For participants requiring an increase in the dose for increasing pain (> } 4 / 10 \text { or }>3 \text { break- } \\
& \text { through pain medications per day) during the study period, opioid doses were increased according to } \\
& \text { clinical needs. Mean dose (SD) at week } 1: 23.8(8) \mathrm{mg} / \text { day; mean dose (SD) at week 2: } 25.5 \text { (8) mg/day; } \\
& \text { mean dose (SD) at week 3: } 27.9 \text { (9) mg/day; Mean dose (SD) at week 4: } 33.1 \text { (14) mg/day; mean dose } \\
& \text { (SD) at week } 8: 45.7(24) \mathrm{mg} / \mathrm{day} \\
& \text { - Formulation: Sustained-release } \\
& \text { - Route of administration: oral. } \\
& \text { - Length of treatment: } 4 \text { weeks (with a study extension up to } 8 \text { weeks). }
\end{aligned}
$$
ratio of 1.5:1. For participants requiring an increase in the dose for increasing pain $(>4 / 10$ or $>3$ breakthrough pain medications per day) during the study period, opioid doses were increased according to clinical needs. Mean dose (SD) at week 1: 23.8 (8) mg/day; mean dose (SD) at week 2: 25.5 (8) mg/day; mean dose (SD) at week 3: 27.9 (9) $\mathrm{mg}$ /day; Mean dose (SD) at week 4: 33.1 (14) mg/day; mean dose 
- Titration schedule: "Patients were recruited and followed during admission to the palliative care unit, as outpatients and at home. Physicians provided frequent call contacts to adjust the opioid dose at any time." See also 'Dose and dosing' section. No further information provided.

- Rescue medication: oral morphine in doses of $1 / 6$ of the daily dose was provided (starting at $5 \mathrm{mg}$ ).

- Other medication: "Adjuvants and symptomatic drugs were prescribed as indicated by the clinical situation."

\section{Comparison arm}

- Drug: morphine.

- Dose and dosing: starting dose of $30 \mathrm{mg} /$ day, according to an approximate morphine:oxycodone ratio of 1.5:1. For participants requiring an increase in the dose for increasing pain $>4 / 10$ or $>3$ breakthrough pain medications per day) during the study period, opioid doses were increased according to the clinical needs. Mean dose (SD) at week 1: 35 (9) mg/day; mean dose (SD) at week 2: 36.2 (14) mg/ day; mean dose (SD) at week 3: 41 (19) $\mathrm{mg} /$ day; mean dose (SD) at week 4: 42.6 (21) $\mathrm{mg} /$ day; mean dose (SD) at week 8: 60 (46) $\mathrm{mg} /$ day

- Formulation: Sustained-release

- Route of administration: oral.

- Length of treatment: 4 weeks (with study extension up to 8 weeks).

- Titration schedule: "Patients were recruited and followed during admission to the palliative care unit, as outpatients and at home. Physicians provided frequent call contacts to adjust the opioid dose at any time." See also 'Dose and dosing' section. No further information provided.

- Rescue medication: oral morphine in doses of $1 / 6$ of the daily dose was provided (starting at $5 \mathrm{mg}$ ).

- Other medication: "Adjuvants and symptomatic drugs were prescribed as indicated by the clinical situation."

Outcomes
- Pain intensity (average in the last 24 hours): Assessed by participant, using a numerical rating scale
- Opioid-related symptoms (including nausea and vomiting, drowsiness and confusion): Assessed by
participant, using a categorical scale from 0 (= absent, $1=$ slight, $2=$ moderate) to 3 (= severe)
- Constipation: Assessed by participant, using a categorical scale from 0 (= 1 passage, 1 to 2 days; $1=1$
passage, 3 to 4 days; 2 = 1 passage, 4 days) to 3 (= only by enema)
- Study free of commercial funding? Unclear. No details reported.
- Groups comparable at baseline? No participant details reported by initial treatment allocation.
- ITT analyses undertaken? No, did not appear so. From baseline to study end at 4 weeks, $11 / 30$ oxy-
codone participants and $10 / 30$ morphine participants dropped out of study and only data from partici-
pants who completed study phases were reported/analysed by week (0, $1,2,3,4$, and 8$).$

\section{Risk of bias}

\begin{tabular}{lll}
\hline Bias & Authors' judgement & Support for judgement \\
\hline $\begin{array}{l}\text { Random sequence genera- } \\
\text { tion (selection bias) }\end{array}$ & Unclear risk & $\begin{array}{l}\text { "Patients were randomized by a computer system in 2 groups." No further in- } \\
\text { formation reported }\end{array}$ \\
\hline $\begin{array}{l}\text { Allocation concealment } \\
\text { (selection bias) }\end{array}$ & Unclear risk & See cell above \\
\hline
\end{tabular}


Mercadante 2010 (Continued)

\begin{tabular}{lll} 
Blinding of participants & High risk & Unblinded study \\
and personnel (perfor- & & \\
mance bias) & & \\
Pain & & \\
\hline $\begin{array}{l}\text { Blinding of participants } \\
\text { and personnel (perfor- }\end{array}$ & High risk & Unblinded study \\
mance bias) & & \\
Adverse events &
\end{tabular}

\begin{tabular}{|c|c|c|}
\hline $\begin{array}{l}\text { Blinding of outcome as- } \\
\text { sessment (detection bias) } \\
\text { Pain }\end{array}$ & High risk & Unblinded study \\
\hline $\begin{array}{l}\text { Blinding of outcome as- } \\
\text { sessment (detection bias) } \\
\text { Adverse events }\end{array}$ & High risk & Unblinded study \\
\hline $\begin{array}{l}\text { Incomplete outcome data } \\
\text { (attrition bias) } \\
\text { Pain }\end{array}$ & High risk & $\begin{array}{l}\text { From baseline to study end at } 4 \text { weeks } 11 / 30 \text { oxycodone participants and } 10 / 30 \\
\text { morphine participants dropped out of the study and only the data from partic- } \\
\text { ipants who completed the study phases are reported/analysed by week }(0,1 \text {, } \\
2,3,4 \text {, and } 8)\end{array}$ \\
\hline
\end{tabular}

\begin{tabular}{|c|c|c|}
\hline $\begin{array}{l}\text { Incomplete outcome data } \\
\text { (attrition bias) } \\
\text { Adverse events }\end{array}$ & High risk & $\begin{array}{l}\text { From baseline to study end at } 4 \text { weeks } 11 / 30 \text { oxycodone participants and } 10 / 30 \\
\text { morphine participants dropped out of the study and only the data from partic- } \\
\text { ipants who completed the study phases are reported/analysed by week }(0,1 \text {, } \\
2,3,4 \text {, and } 8 \text { ) }\end{array}$ \\
\hline
\end{tabular}

\begin{tabular}{lll}
\hline $\begin{array}{l}\text { Selective reporting (re- } \\
\text { porting bias) }\end{array}$ & Low risk & All obvious outcomes appear to be reported \\
\hline Other bias & Low risk & The study does not appear to be subject to high risk of other biases \\
\hline $\begin{array}{l}\text { Were the participants ade- } \\
\text { quately titrated? }\end{array}$ & Unclear risk & Not enough information reported \\
\hline $\begin{array}{l}\text { For cross-over trials: are } \\
\text { data available for both } \\
\text { time periods? }\end{array}$ & Unclear risk & Not applicable \\
\hline
\end{tabular}

\section{Mucci-LoRusso 1998}

\begin{tabular}{ll}
\hline Methods & Design: randomised, parallel group trial. \\
& Year: not reported. \\
Country: USA. & \\
\hline Participants & $\begin{array}{l}\text { Paticipants: } 101 \text { participants randomised; } 100 / 101 \text { participants received } \geq \text { one dose of study med- } \\
\text { (range) age }=58 \text { in oxycodone group and } 52 \text { in the morphine group, } 55 \% \text { participants were male, mean } \\
\text { primary pain type in } 10 / 48 \text { oxycodone and } 9 / 52 \text { morphine participants; most common pre-study pain } \\
\text { medication was fixed-dose oxycodone-acetaminophen combination (22 participants in each group), } \\
\text { followed by single-entity morphine (13 oxycodone and } 17 \text { morphine participants). Most participants } \\
\text { were receiving > 1 pain medication pre-study and all but } 3 \text { participants (all in the oxycodone group) } \\
\text { were receiving opioids prior to enrolment, the mean (range) oral oxycodone equivalent of the pre-study } \\
\text { dose }=64 \text { (14 to } 280) \text { mg in the oxycodone group and } 70 \text { (14-235) mg in the morphine group. } 7 \text { oxy- }\end{array}$ \\
\hline
\end{tabular}


Mucci-LoRusso 1998 (Continued)

codone and 9 morphine participants discontinued the study before achieving stable pain control due to adverse experiences ( 2 oxycodone and 6 morphine participants), intercurrent illness ( 3 oxycodone participants), ineffective treatment (1 oxycodone and 1 morphine participants), participant request ( 1 oxycodone and 1 morphine participants), and protocol violation (1 morphine participant). An additional 4 participants dropped out of the study after achieving stable pain control due to adverse experience ( 1 oxycodone participant), protocol violation ( 1 oxycodone participant), intercurrent illness (1 morphine participant) and worsening of pre-existing condition (1 morphine participant)

Inclusion criteria: Patients who required around-the-clock treatment with opioid analgesics for chronic cancer-related pain with the equivalent of 30 to $340 \mathrm{mg}$ of oral oxycodone daily. Patients whose pain was not controlled by maximum recommended doses of nonopioid analgesics were also eligible if they would require $\geq 30 \mathrm{mg}$

Exclusion criteria: "a history of sensitivity to oxycodone or morphine, any contra-indication for opioid therapy (such as paralytic ileus or severe pulmonary disease) or severely compromised organ function that could obscure efficacy or or adversely affect safety. Patients whose pain control was so fragile they could not switch opioids were also excluded."

Interventions

\section{Oxycodone arm \\ - Drug: oxycodone hydrochloride. 12 hour (range): 101 (40-360) mg. \\ - Formulation: Controlled-release \\ - Route of administration: oral. \\ - Length of treatment: up to 12 days. \\ - Titration schedule: see 'Dose and dosing' section.}

- Dose and dosing: multiples of $20 \mathrm{mg}$ tablets, every 12 hours ( 8 a.m. and 8 p.m.). Starting dose calculated from participants' prestudy daily opioid dose and could be adjusted based on the investigator's judgement. Dose was titrated until stable pain control was achieved. Pain control was considered stable when, over a 48-hour period, the 'every 12 hours' dose was unchanged, $\leq 2$ supplemental analgesic doses were taken per day, the dosing regimen for any non-opioids or adjuvants was unchanged, and the participant reported that pain control was acceptable and any adverse effects were tolerable. Participants who could not be stabilised within 10 days were discontinued. Mean final daily doses of every

- Rescue medication: Immediate-release oxycodone in multiples of $2 \times 5 \mathrm{mg}$ tablets. Each supplemental medication dose was $1 / 4$ to $1 / 3$ of every 12 hours scheduled dose. Participants were instructed to take a supplemental dose as needed for breakthrough pain, but not more frequently than once every 2-4 hours or 1 hour before activity associated with incident pain. Median dose use on the next to last study day (during stable pain control) 1 (range $0-4$ ) and median dose use on last study day (during stable pain control) 1 (range $0-3$ ).

- Other medication: "Non-opioid analgesics and adjuvant medications were allowed during the study provided they had been given on a regular basis (not as needed) before the study."

\section{Comparison arm}

- Drug: morphine sulfate

- Dose and dosing: multiples of $30 \mathrm{mg}$ tablets, every 12 hours (8 a.m. and 8 p.m.). Starting dose was calculated from the participants' prestudy daily opioid dose and could be adjusted based on the investigator's judgement. Dose was titrated until stable pain control was achieved. Pain control was considered stable when, over a 48-hour period, the q12h dose ( = dose every 12 hours) was unchanged, $\leq 2$ supplemental analgesic doses were taken per day, the dosing regimen for any non-opioids or adjuvants was unchanged, and the participant reported that pain control was acceptable and any adverse effects were tolerable. Participants who could not be stabilised within 10 days were discontinued. Mean final daily doses every 12 hours (range) 140 (60-300) mg.

- Formulation: Controlled-release 
Mucci-LoRusso 1998 (Continued)

- Route of administration: oral.

- Length of treatment: $\leq 12$ days.

- Titration schedule: see 'Dose and dosing' section.

- Rescue medication: Immediate-release morphine in multiples of $15 \mathrm{mg}$ tablets. Each supplemental medication dose was $1 / 4$ to $1 / 3$ of every $12 \mathrm{~h}$ scheduled dose. Participants were instructed to take a supplemental dose as needed for breakthrough pain, but not more frequently than once every 2 to 4 hours or 1 hour before activity associated with incident pain. Median dose use on the next to last study day (during stable pain control) $=1$ (range 0 to 3 ) and median dose use on last study day (during stable pain control $)=1($ range 0 to 3$)$

- Other medication: "Non-opioid analgesics and adjuvant medications were allowed during the study provided they had been given on a regular basis (not as needed) before the study."

Outcomes

- Pain intensity (average since previous evaluation): Assessed by participant at baseline and before every $q 12 \mathrm{~h}$ dose, using a categorical scale from 0 (= none) ( 1 = slight, $2=$ moderate) to 3 (= severe). Also assessed after $\geq 48$ hours of stable pain control using the categorical scale and a $100 \mathrm{~mm}$ VAS scale from 0 (= no pain) to 100 (worst possible pain)

- Adverse experiences and drug effects: Assessed by participant in a daily diary, and after $\geq 48$ hours of stable pain control by using the Specific Drug Effect Questionnaire $100 \mathrm{~mm}$ VAS scale (?) from 0 (= not at all) to 100 (an awful lot); also assessed by observers after $\geq 48$ hours of stable pain control by using the Specific Drug Effect Questionnaire $100 \mathrm{~mm}$ VAS scale (?) from 0 (= not at all) to 100 (extremely)

- Drowsiness and nausea: Assessed by participant after $\geq 48$ hours of stable pain control (?), using a categorical scale from 0 (= none, 1 = slight, 2 = moderate) to 3 (= severe) and a 100-mm VAS scale from 0 (= none) to 100 (worst possible)

- Acceptability of therapy: Assessed by participant at baseline and study end, using a categorical scale from 1 (= very poor, 2 = poor, 3 = fair, 4 = good) to 5 (= excellent)

- Quality of life: Assessed by participant at baseline and study end, using the Functional Assessment of Cancer Therapy-General (FACT-G), a 28-item questionnaire consisting of 5 subscales measuring different aspects of quality of life: Physical, social/family, relationship with physician, emotional and functional

Notes - Study free of commercial funding? No. The authors were either "financially compensated for their efforts" or employees of the study drug manufacturer.

- Groups comparable at baseline? Unclear. No participant details reported by initial treatment allocation.

- ITT analyses undertaken? No, 100/101 participants were analysed for safety; 79/101 participants who achieved stable pain control and had simultaneous pharmacokinetic-pharmacodynamic assessments were analysed for efficacy (39 oxycodone, 40 morphine).

\section{Risk of bias}

\begin{tabular}{lll}
\hline Bias & Authors' judgement & Support for judgement \\
\hline $\begin{array}{l}\text { Random sequence genera- } \\
\text { tion (selection bias) }\end{array}$ & Unclear risk & $\begin{array}{l}\text { "Block randomization was used to ensure that all centers had a comparable } \\
\text { number of patients in each treatment group." No further information reported }\end{array}$ \\
\hline $\begin{array}{l}\text { Allocation concealment } \\
\text { (selection bias) }\end{array}$ & Unclear risk & No further information reported than that in the cell above \\
\hline $\begin{array}{l}\text { Blinding of participants } \\
\text { and personnel (perfor- } \\
\text { mance bias) }\end{array}$ & Low risk & "The double-dummy technique was used to blind the study medications." \\
\end{tabular}


Mucci-LoRusso 1998 (Continued)

Pain

Blinding of participants Low risk "The double-dummy technique was used to blind the study medications."
and personnel (perfor-
mance bias)
Adverse events

\begin{tabular}{|c|c|c|}
\hline $\begin{array}{l}\text { Blinding of outcome as- } \\
\text { sessment (detection bias) } \\
\text { Pain }\end{array}$ & Low risk & Participant recorded. See cell above \\
\hline $\begin{array}{l}\text { Blinding of outcome as- } \\
\text { sessment (detection bias) } \\
\text { Adverse events }\end{array}$ & Low risk & See cell above \\
\hline $\begin{array}{l}\text { Incomplete outcome data } \\
\text { (attrition bias) } \\
\text { Pain }\end{array}$ & High risk & $\begin{array}{l}\text { A total of } 79 / 101 \text { participants who achieved stable pain control and had simul- } \\
\text { taneous pharmacokinetic-pharmacodynamic assessments were analysed for } \\
\text { efficacy }\end{array}$ \\
\hline $\begin{array}{l}\text { Incomplete outcome data } \\
\text { (attrition bias) } \\
\text { Adverse events }\end{array}$ & Low risk & A total of $100 / 101$ participants were analysed for safety \\
\hline
\end{tabular}

\begin{tabular}{ll}
\hline $\begin{array}{l}\text { Selective reporting (re- } \\
\text { porting bias) }\end{array}$ Low risk obvious outcomes are reported
\end{tabular}

\begin{tabular}{lll}
\hline Other bias & Low risk & The study does not appear to be subject to high risk of other biases \\
\hline $\begin{array}{l}\text { Were the participants ade- } \\
\text { quately titrated? }\end{array}$ & Low risk & The participants were adequately titrated \\
\hline $\begin{array}{l}\text { For cross-over trials: are } \\
\text { data available for both } \\
\text { time periods? }\end{array}$ & Unclear risk & Not applicable \\
\hline
\end{tabular}

\section{Parris 1998}

\begin{tabular}{|c|c|}
\hline Methods & $\begin{array}{l}\text { Design: randomised, double-blind, parallel group trial. } \\
\text { Year: not reported. } \\
\text { Country: USA. }\end{array}$ \\
\hline Participants & $\begin{array}{l}\text { Participants: } 111 \text { participants randomised; } 103 / 111 \text { participants received } \geq \text { one dose of study medica- } \\
\text { tion; } \mathrm{N}=52 \text { in controlled-release group and } 51 \text { in the immediate-release group, } 50 \% \text { participants were } \\
\text { female, average (mean?) (range) age = } 57 \text { ( } 31 \text { to } 80 \text { ) years; bone ( } 45 \%) \text { and viscera ( } 28 \% \text { ) were most } \\
\text { common pain sites; most common cancer diagnoses were breast, gastrointestinal, lung, and gynaeco- } \\
\text { logical. } 66 / 111 \text { participants completed the } 5 \text {-day study period ( } 33 \text { in each group). Pre-study analgesics: } \\
\text { Oxycodone and acetaminophen ( } 71 \%) \text {, most lower-dose participants received a total daily pre-study } \\
\text { oxycodone dosage of } 30 \text { to } 45 \mathrm{mg} \text { with } 2.0 \text { to } 2.9 \mathrm{~g} \text { of acetaminophen; higher-dose participants received } \\
\text { a daily oxycodone dosage of } 50 \text { to } 60 \mathrm{mg} \text { with } 3.2 \text { to } 3.9 \mathrm{~g} \text { of acetaminophen; other prior opioids includ- } \\
\text { ed codeine and acetaminophen (17\%), hydrocodone and acetaminophen (10\%), propoxyphene nap- } \\
\text { sylate and acetaminophen ( } 2 \%) \text {, and transdermal fentanyl ( } 1 \% \text { ) (protocol violation). A total of } 19 \text { con- } \\
\text { trolled-release and } 18 \text { immediate-release participants discontinued the study due to adverse events ( } 4 \\
\text { controlled-release and } 7 \text { immediate-release participants), unrelated illness ( } 1 \text { in each group), ineffec- } \\
\text { tive treatment (10 controlled-release and } 4 \text { immediate-release participants), protocol violation ( } 4 \text { con- } \\
\text { trolled-release and } 5 \text { immediate-release participants), and other ( } 1 \text { immediate-release participant) }\end{array}$ \\
\hline
\end{tabular}


Parris 1998 (Continued)

Inclusion criteria: "The study included adult patients recruited from 15 centers in the United States who were receiving 6 to 12 tablets or capsules per day of fixed-combination analgesics for cancer-related pain. Patients were of either gender and had stable coexistent disease."

Exclusion criteria: "Patients were excluded if their pain was not already acceptably controlled; if they had surgery or radiotherapy within 10 days of prior to study or anticipated these procedures during study; of they had compromised function of a major organ system; or of they were receiving nonopioid analgesics (before the protocol was amended). Of course, concomitant nonanalgesic therapies were allowed during the study. To encourage participation and to lower the discontinuation rate, the protocol was modified during the study to include patients undergoing or recently given radiotherapy and those receiving stable doses of nonopioid analgesics or analgesic adjuvants. In addition, patients receiving ten to more tablets or capsules of fixed-combination analgesics were no longer permitted to enter the study, but could be enrolled in a companion study intended for patients with greater opioid requirements."

- Drug: oxycodone.

- Dose and dosing: $30 \mathrm{mg}$, every 12 hours, total daily dosage $60 \mathrm{mg}$. Mean daily dosage $60 \mathrm{mg}$ (see 'Titration schedule').

- Formulation: Controlled-release

- Route of administration: oral.

- Length of treatment: 5 days.

- Titration schedule: participants needing titration of analgesic or supplemental medication were required to discontinue from the study.

- Rescue medication: see 'Titration schedule.'

- Other medication: see 'Titration schedule.' "Of course, concomitant nonanalgesic therapies were allowed during the study."

\section{Comparison arm}

- Drug: oxycodone.

- Dose and dosing: $15 \mathrm{mg}$, 4 times daily, total daily dose $60 \mathrm{mg}$, mean daily dose $60 \mathrm{mg}$. See 'Titration schedule.'

- Formulation: Immediate-release

- Route of administration: oral.

- Length of treatment: 5 days.

- Titration schedule: participants needing titration of analgesic or supplemental medication were required to discontinue from the study.

- Rescue medication: see 'Titration schedule.'

- Other medication: see 'Titration schedule.' "Of course, concomitant nonanalgesic therapies were allowed during the study."

Outcomes - Pain intensity: Assessed by participant at baseline and 4 times daily, that is, morning (overnight pain
rating), midday (morning pain rating), evening (afternoon pain rating), and bedtime (evening pain rat-
ing), using a categorical scale from 0 (= none) ( $1=$ slight, $2=$ moderate) to 3 (= severe)

- Acceptability of current therapy: Assessed by participant at baseline and 2 times daily, that is, for both day and night, using a categorical scale from 1 (= very poor) $(2=$ poor, $3=$ fair, $4=$ moderate) to 5 (= excellent) 
Parris 1998 (Continued)

- Adverse experiences: "Observers contacted patients by telephone daily throughout the 5-day study period and recorded information about adverse events and changes in the patients' condition."

Notes

- Study free of commercial funding? No. The study was sponsored by the drug manufacturers (The Purdue Frederick Company and Purdue Pharma L.P.) and some of the authors were employees of the study drug manufacturer

- Groups comparable at baseline? No participant details reported by initial treatment allocation

- ITT analyses undertaken? Yes, it seems so. 103/111 participants who took $\geq 1$ study drug dose constituted the ITT population (52 controlled-release, 51 immediate-release), 8/111 participants were excluded for administrative reasons, which are not further specified; 109/111 participants were analysed for safety

\section{Risk of bias}

\begin{tabular}{|c|c|c|}
\hline Bias & Authors' judgement & Support for judgement \\
\hline $\begin{array}{l}\text { Random sequence genera- } \\
\text { tion (selection bias) }\end{array}$ & Unclear risk & $\begin{array}{l}\text { No information reported beyond that "This was a randomized, double-blind, } \\
\text { parallel-group study" }\end{array}$ \\
\hline $\begin{array}{l}\text { Allocation concealment } \\
\text { (selection bias) }\end{array}$ & Unclear risk & See cell above \\
\hline $\begin{array}{l}\text { Blinding of participants } \\
\text { and personnel (perfor- } \\
\text { mance bias) } \\
\text { Pain }\end{array}$ & Low risk & $\begin{array}{l}\text { "This was a randomized, double-blind, parallel-group study".... "using a dou- } \\
\text { ble-dummy technique". No further information reported }\end{array}$ \\
\hline $\begin{array}{l}\text { Blinding of participants } \\
\text { and personnel (perfor- } \\
\text { mance bias) } \\
\text { Adverse events }\end{array}$ & Unclear risk & $\begin{array}{l}\text { See cell above. We here assume that the participants were blinded, but it is un- } \\
\text { clear whether the personnel administering the study medication or the per- } \\
\text { sonnel assessing some of the outcomes, or both, were also blinded }\end{array}$ \\
\hline
\end{tabular}

\begin{tabular}{|c|c|c|}
\hline $\begin{array}{l}\text { Blinding of outcome as- } \\
\text { sessment (detection bias) } \\
\text { Pain }\end{array}$ & Low risk & This outcome was participant-assessed. See cell above \\
\hline $\begin{array}{l}\text { Blinding of outcome as- } \\
\text { sessment (detection bias) } \\
\text { Adverse events }\end{array}$ & Unclear risk & $\begin{array}{l}\text { See cell above. We here assume that the participants were blinded, but it is un- } \\
\text { clear whether the personnel administering the study medication and/or the } \\
\text { personnel assessing some of the outcomes were also blinded }\end{array}$ \\
\hline $\begin{array}{l}\text { Incomplete outcome data } \\
\text { (attrition bias) } \\
\text { Pain }\end{array}$ & Low risk & $\begin{array}{l}\text { A total of } 103 / 111 \text { participants who took } \geq 1 \text { study drug dose constituted the } \\
\text { ITT population ( } 52 \text { controlled-release, } 51 \text { immediate-release), } 8 / 111 \text { partici- } \\
\text { pants were excluded for administrative reasons, which are not further speci- } \\
\text { fied. The pain data appear to include these } 103 \text { participants }\end{array}$ \\
\hline $\begin{array}{l}\text { Incomplete outcome data } \\
\text { (attrition bias) } \\
\text { Adverse events }\end{array}$ & Low risk & A total of $109 / 111$ participants were analysed for safety \\
\hline $\begin{array}{l}\text { Selective reporting (re- } \\
\text { porting bias) }\end{array}$ & Low risk & All obvious outcomes appear to be reported \\
\hline Other bias & Low risk & The study does not appear to be subject to high risk of other biases \\
\hline $\begin{array}{l}\text { Were the participants ade- } \\
\text { quately titrated? }\end{array}$ & Low risk & $\begin{array}{l}\text { The participants were probably adequately titrated because otherwise they } \\
\text { were discontinued }\end{array}$ \\
\hline
\end{tabular}


Parris 1998 (Continued)

For cross-over trials: are data available for both

Unclear risk Not applicable time periods? to first line opioid).

Year: 2006-2011.

Country: UK.

Participants

Participants: 200 participants randomised; $198 / 200$ participants received $\geq 1$ dose of study medication; $\mathrm{N}=100$ in the oxycodone group and 98 in the morphine group; 198 were included in the intention-totreat analyses:

- Oxycodone: $\mathrm{N}=100 ; 38$ males and 62 females, mean (SD) age $=58.9$ (13.2) years; cancer diagnosis: breast (18), lower gastrointestinal (16), upper gastrointestinal (2), pancreas and hepatobiliary (4), sarcoma (8), lung (13), gynaecological (9), urinary tract (3), prostate (8), haematological (7), malignant melanoma (6), head and neck (3), other (3); concomitant opioid medications before randomisation: As required morphine (40), as required oxycodone (3), codeine (45), tramadol (45), dihydrocodeine (5), dextropropoxyphene (1), buprenorphine (3). A total of 20/100 participants who received first line oxycodone withdrew from the trial for drug (16) or trial (4) reasons

- Morphine: $\mathrm{N}=100 ; 50$ males and 50 females, mean (SD) age $=59.2$ (11.6) years; cancer diagnosis: breast (14), lower gastrointestinal (11), upper gastrointestinal (10), pancreas and hepatobiliary (10), sarcoma (11), lung (5), gynaecological (7), urinary tract (12), prostate (2), haematological (6), malignant melanoma (4), head and neck (2), other (6); concomitant opioid medications before randomisation: as required morphine (51), as required oxycodone (1), codeine (47), tramadol (47), dihydrocodeine (3), dextropropoxyphene (0), buprenorphine (0). 13/98 participants who received first-line oxycodone withdrew from the trial for drug (10) or trial (3) reasons.

Inclusion criteria: "Inpatients and outpatients were identified and recruited at a tertiary referral cancer center by the specialist palliative care team. Patients were eligible if they needed to begin a regular oral strong opioid for cancer-related pain and were strong opioid naive, that is, had not taken a regular strong opioid within the previous month. The use of an "as required" strong opioid was permitted (less than six doses in 24 hours). Patients were recruited before, or within 24 hours, of starting a regular strong opioid."

Exclusion criteria: renal impairment (serum creatinine $\geq 1.5$ times the upper limit of normal), requirement of parenteral opioids, previous poor response to either morphine or oxycodone, and pregnancy.

Interventions

\author{
Oxycodone arm \\ - Drug: oxycodone. \\ - Dose and dosing: see 'Titration schedule.' No further information reported. \\ - Formulation: Controlled-release \\ - Route of administration: oral. \\ - Length of treatment: 1 year.
}

- Titration schedule: "Patients were initially titrated on immediate-release preparations, administered at four-hourly intervals with additional as required doses available for breakthrough pain .... the starting dose was determined by the treating physician on an individual patient basis and titrated accordingly.... until adequate pain control was achieved or intolerable side effects were reported by the patient. At this stage, patients were converted to the comparable modified-release preparations. 
Riley 2015 (Continued)

Nonresponders to the first opioid were switched to the alternative opioid. As this was not a stable analgesic setting, the ratio of oral morphine:oxycodone $(2: 1)$.... Doses were retitrated according to response."

- Rescue medication: see 'Titration schedule.'

- Other medication: "adjuvant medications (laxatives, antiemetics, coanalgesics) were either started or continued where indicated."

\section{Comparison arm}

- Drug: morphine.

- Dose and dosing: see 'Titration schedule.' No further information reported.

- Formulation: Controlled-release

- Route of administration: oral.

- Length of treatment: 1 year.

- Titration schedule: "Patients were initially titrated on immediate-release preparations, administered at four-hourly intervals with additional as required doses available for breakthrough pain .... the starting dose was determined by the treating physician on an individual patient basis and titrated accordingly.... until adequate pain control was achieved or intolerable side effects were reported by the patient. At this stage, patients were converted to the comparable modified-release preparations. Nonresponders to the first opioid were switched to the alternative opioid. As this was not a stable analgesic setting, the ratio of oral morphine:oxycodone $(2: 1) \ldots$. Doses were retitrated according to response."

- Rescue medication: see 'Titration schedule.'

- Other medication: "Adjuvant medications (laxatives, antiemetics, coanalgesics) were either started or continued where indicated."

- Pain intensity: Assessed by participant at baseline and daily during titration in addition to the following times: (1) when the participant is clinically stabilised on first line opioid, (2) if the participant does not respond to first-line opioid and requires switching to alternative opioid, (3) when participant is clinically stabilised on second line opioid, (4) if the participant's analgesic requirement have increase by $200 \%$ of their initial stable opioid dose, and (5) if the participant does not respond to second line opioid or fits the criteria to exit the study, using an 11-point numerical rating scale (the Brief Pain Inventory) with five pain modalities from 0 (= no pain) to 10 (= worst pain imaginable)

- Adverse experiences: Assessed by participant at baseline and daily during titration in addition to the following times: (1) when the participant is clinically stabilised on first line opioid, (2) if the participant does not respond to first-line opioid and requires switching to alternative opioid, (3) when participant is clinically stabilised on second line opioid, (4) if the participant's analgesic requirement have increase by $200 \%$ of their initial stable opioid dose, and (5) if the participant does not respond to second line opioid or fits the criteria to exit the study, using an 11-point numerical rating scale from 0 (= no symptom) to 10 (= worst symptom severity imaginable) for nausea, vomiting, constipation, diarrhoea, drowsiness, confusion or disorientation or hallucinations, bad dreams and other notable symptoms. During assessments participants were also asked to report any new adverse events

- Responding participants (primary outcome): Defined as participants who responded clinically to morphine and oxycodone when used as the first line strong opioid in cancer-related pain, that is, opioid non-response was classified as inadequate analgesia despite dose escalation or intolerable adverse effects, or both, and adequacy of pain control and tolerability of adverse effects were defined by participants' subjective assessment, regardless of score.

Notes

- Study free of commercial funding? "This study was funded by the Palliative Care Research Fund from the Royal Marsden Hospital, St. Joseph's Hospice, the Asmarley Trust, and an unrestricted educational grant from Napp Pharmaceuticals. None of the funding bodies had any role in the design and conduct of the study, the collection, management, analysis, or interpretation of the data, and the preparation, 
Riley 2015 (Continued)

review, and approval of the manuscript, or in the decision to submit for publication. The authors report no conflicts of interest. The study also was supported by the National Institute for Health Research Respiratory Disease Biomedical Research Unit at the Royal Brompton and Harefield National Health Service Foundation Trust and Imperial College London."

- Groups comparable at baseline? Yes, the groups seem to be comparable at baseline.

- ITT analyses undertaken? Yes for efficacy, but data only included for 153/198 participants for safety.

\section{Risk of bias}

\begin{tabular}{|c|c|c|}
\hline Bias & Authors' judgement & Support for judgement \\
\hline $\begin{array}{l}\text { Random sequence genera- } \\
\text { tion (selection bias) }\end{array}$ & Low risk & $\begin{array}{l}\text { "Patients were randomized to either morphine or oxycodone in a 1:1 ratio via } \\
\text { computer-generated random permuted blocks." }\end{array}$ \\
\hline $\begin{array}{l}\text { Allocation concealment } \\
\text { (selection bias) }\end{array}$ & Unclear risk & No information reported. \\
\hline $\begin{array}{l}\text { Blinding of participants } \\
\text { and personnel (perfor- } \\
\text { mance bias) } \\
\text { Pain }\end{array}$ & High risk & $\begin{array}{l}\text { "This independent study was an open-label one because of safety, logistical, } \\
\text { and financial considerations." }\end{array}$ \\
\hline $\begin{array}{l}\text { Blinding of participants } \\
\text { and personnel (perfor- } \\
\text { mance bias) } \\
\text { Adverse events }\end{array}$ & High risk & See cell above \\
\hline $\begin{array}{l}\text { Blinding of outcome as- } \\
\text { sessment (detection bias) } \\
\text { Pain }\end{array}$ & High risk & Participant-assessed. See cell above \\
\hline $\begin{array}{l}\text { Blinding of outcome as- } \\
\text { sessment (detection bias) } \\
\text { Adverse events }\end{array}$ & High risk & See cell above \\
\hline $\begin{array}{l}\text { Incomplete outcome data } \\
\text { (attrition bias) } \\
\text { Pain }\end{array}$ & High risk & $\begin{array}{l}\text { Data only available for } 80 / 100 \text { participants in the oxycodone group and } 85 / 100 \\
\text { in the morphine group for the meta-analyses }\end{array}$ \\
\hline $\begin{array}{l}\text { Incomplete outcome data } \\
\text { (attrition bias) } \\
\text { Adverse events }\end{array}$ & High risk & Adverse events reported for $153 / 198$ participants. \\
\hline $\begin{array}{l}\text { Selective reporting (re- } \\
\text { porting bias) }\end{array}$ & Low risk & All obvious outcomes are reported \\
\hline Other bias & Low risk & The study does not appear to be subject to high risk of other biases \\
\hline $\begin{array}{l}\text { Were the participants ade- } \\
\text { quately titrated? }\end{array}$ & Low risk & Yes, the participants appear to be adequately titrated \\
\hline $\begin{array}{l}\text { For cross-over trials: are } \\
\text { data available for both } \\
\text { time periods? }\end{array}$ & Unclear risk & Not applicable \\
\hline
\end{tabular}


Salzman 1999

Methods
Design: randomised, double-blind, parallel group trial.
Year: not reported.
Country: USA.

Participants

Participants: 50 participants randomised; $48 / 50$ participants received $\geq 1$ dose of study medication; $N$ $=24$ in each group. $35 / 50$ participants completed the titration period, 3 participants discontinued the study due to adverse events, 8 due to ineffective treatment or intercurrent illnesses, and 2 due to other reasons

Controlled-release group: 8 males and 16 females, mean (range) age $=60$ (25 to 77) years; participants taking pre-study opioids: Yes: $\mathrm{N}=23, \mathrm{No}: \mathrm{N}=1$

Immediate-release group:13 males and 11 females, mean (range) age $=61$ (39 to 91) years; participants taking pre-study opioids: Yes: $\mathrm{N}=22, \mathrm{No}: \mathrm{N}=2$

Inclusion criteria: Patients aged $\geq 18$ years with stable cancer pain not adequately controlled by prior analgesic therapy with or without opioids. Among patients who were receiving nonopioid analgesic therapy, the dosing regimen was stabilised $\geq 1$ week before the initiation of study medication and remained stable for the duration of the studies.

Exclusion criteria: "Patients excluded from the studies included individuals with an allergy or contraindication to opioid therapy; patients with a history of substance abuse; patients receiving an opioid analgesic that could not be discontinued; cancer patients prescribed oral oxycodone at a total dose of more than $400 \mathrm{mg} /$ day."

- Drug: oxycodone.

- Dose and dosing: starting dose for opioid-naive participants $20 \mathrm{mg} /$ day, and for non-opioid-naive participants starting dose was based on prior 3 days of analgesic therapy; every 12 hours at 8 a.m. and 8 p.m. ( \pm 1 hour each time). Mean final daily dose $(S E)=104(20) \mathrm{mg}$

- Formulation: Controlled-release

- Route of administration: oral

- Length of treatment: Up to 21 days

- Titration schedule: "The starting dose was titrated upward in each study to a limit of $400 \mathrm{mg} /$ day..... Among those who required titration, the dose was increased until the patients rated their level of pain at an intensity of no greater than "slight" (1.5) on the CAT scale. The dose could be adjusted every 24 to 48 hours if necessary. Criteria for stable pain control were said to be met if pain was stabilized at 1.5 or below for 48 hours while patients were taking no more than two doses per day of supplemental analgesic."

- Rescue medication: "Supplemental analgesic was permitted as needed for control of breakthrough or incident pain and was provided in doses of $5 \mathrm{mg} I \mathrm{R}$ oxycodone ( 1 tablet) for patients titrated to 20 to $40 \mathrm{mg} /$ day and $10 \mathrm{mg}$ IR oxycodone ( 2 X $5 \mathrm{mg}$ tablets) for patients titrated to 60 to $80 \mathrm{mg} /$ day. For patients receiving doses greater than $80 \mathrm{mg} /$ day, the supplemental analgesic dose was approximately $1 / 6$ of the patient's total daily oxycodone dose rounded to the nearest $5 \mathrm{mg}$. Rescue medication was taken no more than once every 4 hours."

- Other medication: "All other opioid analgesics were prohibited. Besides nonopioid analgesic medications (discussed above), other medications necessary for patients' welfare were administered under the supervision of the investigator/physician."

\section{Comparison arm}

- Drug: oxycodone. 
- Dose and dosing: starting dose for opioid-naive participants $20 \mathrm{mg} /$ day, and for non-opioid-naive participants starting dose was based on prior 3 days of analgesic therapy; 4 times daily at 8 a.m., 2 p.m., 8 p.m., and bedtime ( \pm 1 hour each time). Bedtime dose was to be taken $\geq 3$ hours after the 8 p.m. dose. Mean final daily dose (SE) $=113(24) \mathrm{mg}$

- Formulation: Immediate-release

- Route of administration: oral.

- Length of treatment: Up to 21 days

- Titration schedule: "The starting dose was titrated upward in each study to a limit of $400 \mathrm{mg} /$ day..... Among those who required titration, the dose was increased until the patients rated their level of pain at an intensity of no greater than "slight" (1.5) on the CAT scale. The dose could be adjusted every 24 to 48 hours if necessary. Criteria for stable pain control were said to be met if pain was stabilized at 1.5 or below for 48 hours while patients were taking no more than two doses per day of supplemental analgesic."

- Rescue medication: "Supplemental analgesic was permitted as needed for control of breakthrough or incident pain and was provided in doses of $5 \mathrm{mg} \mathrm{IR}$ oxycodone ( 1 tablet) for patients titrated to 20 to $40 \mathrm{mg} /$ day and $10 \mathrm{mg}$ IR oxycodone $(2 \times 5 \mathrm{mg}$ tablets) for patients titrated to 60 to $80 \mathrm{mg} / \mathrm{day}$. For patients receiving doses greater than $80 \mathrm{mg} /$ day, the supplemental analgesic dose was approximately $1 / 6$ of the patient's total daily oxycodone dose rounded to the nearest $5 \mathrm{mg}$. Rescue medication was taken no more than once every 4 hours."

- Other medication: "All other opioid analgesics were prohibited. Besides nonopioid analgesic medications... other medications necessary for patients' welfare were administered under the supervision of the investigator/physician."

Outcomes

- Pain intensity: Assessed by participant in daily diary, using a categorical scale from 0 (= none) $(1=$ slight, 2 = moderate) to 3 (= severe). Also assessed at the clinic visit at the end of the titration period

- Adverse events: Assessed by participant in daily diary, using a categorical scale from 0 (= none) $(1=$ slight, 2 = moderate) to 3 (= severe). Also assessed at the clinic visit at the end of the titration period

- Time to stable pain control was recorded as zero for participants meeting the criteria for success in the first 48 hours (i.e., no titration was needed)."

Notes

- Study free of commercial funding? No. The study was sponsored by the drug manufacturer (Purdue Pharma L.P.) and some of the authors were employees of the study drug manufacturer

- Groups comparable at baseline? The groups appear to be comparable at baseline

- ITT analyses undertaken? Yes, it seems so for adverse events where the data from 48/50 participants are analysed, but only the data from $35 / 50$ are analysed for pain intensity as only $35 / 50$ participants completed the titration phase

\section{Risk of bias}

\begin{tabular}{lll}
\hline Bias & Authors' judgement & Support for judgement \\
\hline $\begin{array}{l}\text { Random sequence genera- } \\
\text { tion (selection bias) }\end{array}$ & Unclear risk & No information reported. \\
\hline $\begin{array}{l}\text { Allocation concealment } \\
\text { (selection bias) }\end{array}$ & Unclear risk & No information reported. \\
\hline $\begin{array}{l}\text { Blinding of participants } \\
\text { and personnel (perfor- } \\
\text { mance bias) }\end{array}$ & High risk & \\
Pain & & The study was open-label \\
\hline
\end{tabular}


Salzman 1999 (Continued)

Blinding of participants and personnel (perfor-

mance bias)

Adverse events
High risk The study was open-label

\begin{tabular}{|c|c|c|}
\hline $\begin{array}{l}\text { Blinding of outcome as- } \\
\text { sessment (detection bias) } \\
\text { Pain }\end{array}$ & High risk & The study was open-label \\
\hline $\begin{array}{l}\text { Blinding of outcome as- } \\
\text { sessment (detection bias) } \\
\text { Adverse events }\end{array}$ & High risk & The study was open-label \\
\hline $\begin{array}{l}\text { Incomplete outcome data } \\
\text { (attrition bias) } \\
\text { Pain }\end{array}$ & High risk & Data reported for $35 / 50$ participants. \\
\hline $\begin{array}{l}\text { Incomplete outcome data } \\
\text { (attrition bias) } \\
\text { Adverse events }\end{array}$ & Low risk & Data reported for $48 / 50$ participants \\
\hline $\begin{array}{l}\text { Selective reporting (re- } \\
\text { porting bias) }\end{array}$ & Low risk & All obvious outcomes appear to be reported \\
\hline Other bias & Low risk & The study does not appear to be subject to high risk of other biases \\
\hline $\begin{array}{l}\text { Were the participants ade- } \\
\text { quately titrated? }\end{array}$ & Unclear risk & Not applicable. This study was a titration study \\
\hline $\begin{array}{l}\text { For cross-over trials: are } \\
\text { data available for both } \\
\text { time periods? }\end{array}$ & Unclear risk & Not applicable \\
\hline
\end{tabular}

Stambaugh 2001

\begin{tabular}{|c|c|}
\hline Methods & $\begin{array}{l}\text { Design: randomised, double-blind, cross-over trial. } \\
\text { Year: not reported. } \\
\text { Country: USA. }\end{array}$ \\
\hline Participants & $\begin{array}{l}\text { Participants: } 40 \text { participants entered; } 30 / 40 \text { participants completed both of the double-blind periods } \\
\text { with } 100 \% \text { compliance; } 9 \text { participants discontinued the study during the titration phase due to adverse } \\
\text { events ( } 2 \text { ), lack of efficacy (4), intercurrent illness (1), and 'other' reasons ( } 2 \text { ), and } 1 \text { participant discon- } \\
\text { tinued the study during the double-blind phase due to weakness secondary to progressive disease } \\
10 \text { males and } 20 \text { females, mean (range) age = } 60 \text { ( } 34 \text { to } 83 \text { ) years; primary pain site was bone (27), vis- } \\
\text { cera (1), and other (2). All participants were receiving therapy that included opioids pre-study } \\
\text { Inclusion criteria: Patients aged > } 18 \text { years with moderate or severe cancer-related pain who did not re- } \\
\text { quire > } 240 \mathrm{mg} / \text { day oral oxycodone equivalent for pain relief who were able to take oral medication and } \\
\text { and practiced a medically acceptable method of birth control if female with childbearing potential } \\
\text { Exclusion criteria: Primary tumour or metastatic disease in the brain, received chemotherapy within } 3 \\
\text { days of study entry, drug abuse, severe cognitive impairment, compromised hepatic or renal function, } \\
\text { radiotherapy to the pain site, or hypersensitivity to oxycodone }\end{array}$ \\
\hline
\end{tabular}


Stambaugh 2001 (Continued)

Interventions

\section{Oxycodone arm}

- Drug: oxycodone + placebo.

- Dose and dosing: The total 24-hour oxycodone dose was equal to the stable daily dose obtained at the end of the titration phase. Drug administration 4 times daily consisting of oxycodone interspersed with placebo, resulting in q12h dosing of oxycodone. Mean final daily dose is not reported

- Formulation: Controlled-release

- Route of administration: oral.

- Length of treatment: Up to 35 days, consisting of a titration period of 2-21 days, followed by 2 double-blind cross-over periods each lasting 3-7 days.

- Titration schedule: open-label with immediate-release oxycodone, starting dose was comparable to that calculated, based on the past 3 days of analgesia therapy. "The subjects completed the titration phase at home while monitored on a daily basis by telephone by the research monitor. Recommendations regarding changes in in medication were used to minimize oxycodone use while providing adequate analgesia. More than 2 rescue medication doses per 24-hour period or a moderate or severe global pain score indicated inadequate pain control. Participants whose pain was inadequately controlled after 21 days or who required more than $240 \mathrm{mg}$ or less than 20 of oxycodone daily were discontinued from the study"

- Rescue medication: Immediate-release oxycodone in $5 \mathrm{mg}$ tablets

- Other medication: "Concurrent, stable therapy with acetaminophen, NSAIDs, or analgesic adjuvants and coanalgesics were allowed. Opioids other than the study medication were prohibited. All medically necessary but noninvestigational medications were permitted."

\section{Comparison arm}

- Drug: oxycodone.

- Dose and dosing: The total 24-hour oxycodone dose was equal to the stable daily dose obtained at the end of the titration phase. Drug administration 4 times daily, qid dosing of oxycodone. Mean final daily dose is not reported

- Formulation: Immediate-release

- Route of administration: oral.

- Length of treatment: Up to 35 days, consisting of a titration period of 2-21 days, followed by 2 double-blind cross-over periods each lasting 3-7 days.

- Titration schedule: open-label with immediate-release oxycodone, starting dose was comparable to that calculated, based on the past 3 days of analgesia therapy. "The subjects completed the titration phase at home while monitored on a daily basis by telephone by the research monitor. Recommendations regarding changes in in medication were used to minimize oxycodone use while providing adequate analgesia. More than 2 rescue medication doses per 24-hour period or a moderate or severe global pain score indicated inadequate pain control. Participants whose pain was inadequately controlled after 21 days or who required more than $240 \mathrm{mg}$ or less than 20 of oxycodone daily were discontinued from the study". Stable pain control for 48 hours to 10 days was required before entry into the double-blind phase

- Rescue medication: Immediate-release oxycodone in $5 \mathrm{mg}$ tablets

- Other medication: "Concurrent, stable therapy with acetaminophen, NSAIDs, or analgesic adjuvants and coanalgesics were allowed. Opioids other than the study medication were prohibited. All medically necessary but noninvestigational medications were permitted." 
Stambaugh 2001 (Continued)

- For cross-over trials, cross-over schedule: "After successful completion of period 1, patients were crossed over into the double-blind period 2 without a washout." The procedures for this period were identical to those in period 1

\begin{tabular}{ll}
\hline Outcomes & - Pain intensity or pain relief: Assessed by participant in daily diary, using an 11-point scale from 0 (= no \\
pain or no relief) to 10 (= severe pain or complete relief) \\
- Acceptability of treatment: Assessed by participant in daily diary, using a 5-point scale from 1 (= very \\
poor) ( 2 = poor, $3=$ fair, $4=$ good) to 5 (= excellent) \\
- Adverse events: Spontaneously reported by participant in daily telephone contact \\
\hline - Study free of commercial funding? No. The study was sponsored by the drug manufacturer (Purdue \\
Frederick Company) and one of the authors was employed by the study drug manufacturer \\
- Groups comparable at baseline? No details reported about initial group allocation \\
- ITT analyses undertaken? Yes, although only data from $30 / 40$ participants are analysed
\end{tabular}

\section{Risk of bias}

\begin{tabular}{lll}
\hline Bias & Authors' judgement & Support for judgement \\
\hline $\begin{array}{l}\text { Random sequence genera- } \\
\text { tion (selection bias) }\end{array}$ & Unclear risk & No information reported. \\
\hline $\begin{array}{l}\text { Allocation concealment } \\
\text { (selection bias) }\end{array}$ & Unclear risk & No information reported. \\
\hline $\begin{array}{l}\text { Blinding of participants } \\
\text { and personnel (perfor- } \\
\text { mance bias) }\end{array}$ & Low risk & "The double-blind periods were blinded by using three tablets identical in ap- \\
$\begin{array}{l}\text { Pain } \\
\text { Blinding of participants } \\
\text { and personnel (perfor- } \\
\text { mance bias) }\end{array}$ & Low risk & pearance: 5 mg IR oxycodone, 10 mg CR oxycodone, and placebo." \\
Adverse events & & \\
\hline
\end{tabular}

\begin{tabular}{|c|c|c|}
\hline $\begin{array}{l}\text { Blinding of outcome as- } \\
\text { sessment (detection bias) } \\
\text { Pain }\end{array}$ & Low risk & Participant reported outcome. See also cell above \\
\hline $\begin{array}{l}\text { Blinding of outcome as- } \\
\text { sessment (detection bias) } \\
\text { Adverse events }\end{array}$ & Low risk & See cell above \\
\hline $\begin{array}{l}\text { Incomplete outcome data } \\
\text { (attrition bias) } \\
\text { Pain }\end{array}$ & High risk & Data from $30 / 40$ participants analysed. \\
\hline $\begin{array}{l}\text { Incomplete outcome data } \\
\text { (attrition bias) } \\
\text { Adverse events }\end{array}$ & High risk & See cell above \\
\hline $\begin{array}{l}\text { Selective reporting (re- } \\
\text { porting bias) }\end{array}$ & Low risk & All obvious outcomes appear to be reported \\
\hline Other bias & Low risk & The study does not appear to be subject to high risk of other biases \\
\hline
\end{tabular}


Stambaugh 2001 (Continued)

Were the participants ade- Low risk The participants were probably adequately titrated. Pain intensity dropped quately titrated? from $6(\mathrm{SD}=2.2)$ at the beginning of titration to 2.7 at the completion of the titration phase

For cross-over trials: are Low risk Yes, data are available for both study periods for 30/40 participants data available for both time periods?

Su 2015

Methods Design: randomised, parallel-group trial.

Year: 2011-2014.

Country: China.

Participants

Participants: 80 participants selected; cancer types were lung $(N=22)$, breast $(N=20)$, gastric $(N=18)$, colon $(N=9)$, prostate $(N=6)$ and oesophageal $(N=5)$. Pain was assessed on a numerical rating scale (NRS) going from 0 (no pain), 1-3 (mild pain), 4-6 (moderate pain), 7-9 (severe pain), to 10 (very severe pain). All participants enrolled were NRS $\geq 4$ points.

The participants were randomly allocated to 2 treatment groups:

-Oxycodone: $\mathrm{N}=42 ; 25$ males $/ 17$ females; mean age $=55.48(\mathrm{SD}=11.54$; range $=29$-76) years; mean Karnofsky score $(\mathrm{KPS})=55.14(\mathrm{SD}=5.25)$; mean NRS $=6.93(\mathrm{SD}=1.73), \mathrm{N}=16$ with NRS of 4-6 points, and $N=26$ with NRS of 7-9 points. Pain types were chest pain $(N=18)$, abdominal pain $(N=7)$, ostealgia $(\mathrm{N}=11)$, and shoulder and back pain $(\mathrm{N}=6)$.

-Fentanyl: $\mathrm{N}=38 ; 22$ males $/ 16$ females; mean age $=54.89(\mathrm{SD}=11.07$; range 32-83) years, mean $\mathrm{KPS}$ score $=56.05(\mathrm{SD}=5.77)$; mean NRS $=7.16(\mathrm{SD}=1.64), \mathrm{N}=14$ with NRS of 4-6 points, and $\mathrm{N}=24$ with NRS of 7-9 points. Pain types were chest pain $(N=16)$, abdominal pain $(N=8)$, ostealgia $(N=10)$, and shoulder and back pain ( $N=4)$.

Inclusion criteria: Patients with a diagnosis of malignant tumours with moderate-severe pain, and no radiotherapy for the pain; no respiratory, cardiovascular and cerebrovascular dysfunction, and no obstruction and serious liver and kidney dysfunction; and no history of psychosis and opioids drug abuse history.

Exclusion criteria: not reported.

Interventions

Oxycodone arm

- Drug: oxycodone.

- Dose and dosing: $10 \mathrm{mg}$ every 12 hours as initial dose for morphine-naive participants, while participants who had previously received morphine were given Oxycontin according to used dosage (total daily dose of morphine $\times 0.5$ and then divided into 2 equal doses for 12 hourly treatment). The drug should be taken as whole tablets, but not grinded pieces. Mean final daily dose was not reported.

- Formulation: Controlled-release (Oxycontin)

- Route of administration: oral.

- Length of treatment: 2 weeks.

- Titration schedule: effectiveness and adverse events were evaluated 15 minutes after the drugs were administered. If NRS increased or did not change, dose increased by $50-100 \%$. If NRS decreased to 4-6, administered the same dose after $15 \mathrm{~min}$. If NRS decreased to $0-3$, the basic treatment for alleviating pain was continued, and administered the same dose if needed. On the second day, the needed dose 
was calculated according to the total amount of analgesics used during the first day, in an attempt to maintain the NRS at 0-3.

- Rescue medication: IV short-acting morphine was used as rescue medication for breakthrough pain. The initial dose for those who had not used morphine before was $2-5 \mathrm{mg}$. For those who had used morphine before, the total amount of analgesics needed in the first 24 hours was calculated and converted to the equivalent dose of morphine for injection, of which $10-20 \%$ was the initial dose.

- Other medication: not reported.

\section{Comparison arm}

- Drug: fentanyl.

- Dose and dosing: $25 \mu \mathrm{g} /$ hour replaced after 72 hours as initial dose for morphine-naive participants, while participants who had previously received morphine, received a dose $0.5 \times$ morphine dose. Mean final daily dose was not reported.

- Formulation: patch (Durogesic).

- Route of administration: Transdermal

- Length of treatment: 2 weeks.

- Titration schedule: effectiveness and adverse events were evaluated 15 minutes after the drugs were administered. If NRS increased or did not change, the dose increased by $50-100 \%$. If NRS decreased to 4-6, administered same dose after 15 minutes. If NRS decreased to 0-3, the basic treatment for alleviating pain was continued, and administered the same dose if needed. On the second day, the needed dose was calculated according to the total amount of analgesics used during the first day, in an attempt to maintain the NRS at 0-3.

- Rescue medication: IV short-acting morphine was used as rescue medication for breakthrough pain. The initial dose for those who had not used morphine before was 2-5 mg. For those who had used morphine before, the total amount of analgesics needed in the first 24 hours was calculated and converted to the equivalent dose of morphine for injection, of which $10-20 \%$ was the initial dose.

- Other medication: not reported.

Outcomes

- Pain relief: Categorised as complete remission (CR; pain disappeared), partial remission (PR; medication significantly reduced pain), mild remission (MR, pain after treatment reduced, but sleep still affected?), and invalid (NR; no pain relief after medication). Pain relief rate $(\%)=(C R+P R+M R) /$ total number of cases $\times 100 \%$.

- Quality of life: Assessed using Karnofsky (KPS) score, with participants' daily life, mental status, and appetite evaluated before and after treatment. "Interpersonal communication and other aspects of the situation" were also assessed before and after treatment.

- Adverse events: "Sleep, dizziness, nausea and vomiting, constipation, dysuria and other adverse reactions" observed using WHO standards

Notes

- Study free of commercial funding? Unclear, no information appeared to be reported.

- Groups comparable at baseline? The treatment groups did not differ statistically significantly in terms of sex, age, KPS, type of pain, and degree of pain ( $P>0.05)$.

- ITT analyses undertaken? Unclear.

\section{Risk of bias}

Bias Authors' judgement Support for judgement

Random sequence genera- Unclear risk No information reported. tion (selection bias) 


\section{Su 2015 (Continued)}

\begin{tabular}{lll}
$\begin{array}{l}\text { Allocation concealment } \\
\text { (selection bias) }\end{array}$ & Unclear risk & No information reported. \\
\hline $\begin{array}{l}\text { Blinding of participants } \\
\text { and personnel (perfor- } \\
\text { mance bias) }\end{array}$ & Unclear risk & No information reported. \\
Pain & &
\end{tabular}

Blinding of participants Unclear risk No information reported.
and personnel (perfor-
mance bias)
Adverse events

Blinding of outcome as- Unclear risk No information reported.
sessment (detection bias)
Pain

\begin{tabular}{|c|c|c|}
\hline $\begin{array}{l}\text { Blinding of outcome as- } \\
\text { sessment (detection bias) } \\
\text { Adverse events }\end{array}$ & Unclear risk & No information reported. \\
\hline $\begin{array}{l}\text { Incomplete outcome data } \\
\text { (attrition bias) } \\
\text { Pain }\end{array}$ & Low risk & The data from all the participants are reported \\
\hline $\begin{array}{l}\text { Incomplete outcome data } \\
\text { (attrition bias) } \\
\text { Adverse events }\end{array}$ & Low risk & The data from all the participants are reported \\
\hline $\begin{array}{l}\text { Selective reporting (re- } \\
\text { porting bias) }\end{array}$ & Low risk & All obvious outcomes appear to have been reported \\
\hline Other bias & Unclear risk & No information reported \\
\hline $\begin{array}{l}\text { Were the participants ade- } \\
\text { quately titrated? }\end{array}$ & Low risk & The participants appear to be adequately titrated \\
\hline $\begin{array}{l}\text { For cross-over trials: are } \\
\text { data available for both } \\
\text { time periods? }\end{array}$ & Unclear risk & Not applicable \\
\hline
\end{tabular}

Yu 2014

\begin{tabular}{ll} 
Methods & Design: randomised, double-blind, non-inferiority parallel-group trial. \\
Year: 2009-2011 (from ClinicalTrials.gov). \\
Country: China. \\
\hline Participants: Of 260 randomised participants, 137 completed the maintenance (active treatment) \\
phase of the study (70 in the hydromorphone group and 67 in the oxycodone group), and these 137 par- \\
ticipants presumably comprised the per protocol data set, although the criteria for the per-protocol \\
set were also that they needed to have completed all efficacy evaluations with good compliance. The \\
full analysis set comprised all randomised participants with at least one dose of medication adminis- \\
tered during the titration phase and one measurement of efficacy. The safety data set comprised all \\
randomised participants with at least one dose of medication administered during the titration phase \\
and one measurement of safety.
\end{tabular}


Yu 2014 (Continued)

- Hydromorphone: $\mathrm{N}=125,82$ males / 43 females; mean/median (SD, range) age $=53.5$ / 54 (10.86; 22-70) years; cancer type: Breast $(N=8)$, lung $(N=38)$, bone $(N=0)$, oral cavity $(N=1)$, gastrointestinal $(N=46)$, genitourinary $(N=13)$, lymphoma $(N=0)$, leukaemia $(N=0)$, other $(N=17)$, not known $(N=2)$; tumour metastatic: Yes $(\mathrm{N}=118)$, no $(\mathrm{N}=7)$; concomitant cancer therapy $(\mathrm{N}=75)$; administration of strong opioids $(\mathrm{N}=104)$, weak opioids $(\mathrm{N}=21)$.

- Oxycodone: $\mathrm{N}=123,80$ males / 43 females; mean/median (SD, range) age $=52.7$ / 55 (10.75; 18-68) years; cancer type: Breast $(N=7)$, lung $(N=34)$, bone $(N=0)$, oral cavity $(N=0)$, gastrointestinal $(N=46)$, genitourinary $(N=17)$, lymphoma $(N=0)$, leukaemia $(N=0)$, other $(N=16)$, not known $(N=3)$; tumour metastatic: Yes $(N=112)$, no $(N=11)$; concomitant cancer therapy $(N=72)$; administration of strong opioids $(N=105)$, weak opioids $(N=18)$.

Inclusion criteria: Patients aged 18 to 70 years; currently receiving strong oral or transdermal (through the skin) opioid analgesics with inadequate control of moderate to severe cancer pain or currently receiving weak opioids for cancer pain and are eligible according to the study protocol to receive treatment with a strong opioid analgesic; who require or are expected to require between $40 \mathrm{mg}$ and $184 \mathrm{mg}$ of oral morphine or morphine equivalents every 24 hours and who are reasonably expected to achieve a stable dose of opioid study medication during the study; with a life expectancy of 12 weeks or longer

Exclusion criteria: Patients with pure neuropathic pain, pain of unknown origin, acute pain, or only pain on movement; requiring other opioid analgesics (apart from immediate-release morphine hydrochloride as rescue medication for breakthrough pain), with any significant central nervous system (CNS) disorder or any disorder that predisposes the patient to respiratory depression or any condition wherein the risks of treatment with study drug may outweigh the potential benefits; and women of childbearing potential who were pregnant or lactating.

Interventions

\section{Oxycodone arm \\ - Drug: oxycodone.}

- Dose and dosing: twice daily administration of oxycodone morning and evening at 12-hourly intervals. The mean (SD) (daily?) dose of study medication in the overall maintenance phase 38.5 (20.94) mg oxycodone CR.

- Formulation: Controlled-release provided in 10, 20 and 40 mg over-encapsulated tablets,

- Route of administration: oral.

- Length of treatment: 28 days

- Titration schedule: Up to 8 days during which participants were converted from their prior opioids to their morphine equivalents (morphine to oxycodone CR, 2:1) and titrated to adequate effect (as determined by pain assessments and supplementary analgesic requirements). Dosage adjustments were made no more frequently than every 2 days, both upwards and downwards. Maximum total daily dose allowed was $80 \mathrm{mg}$ oxycodone. For breakthrough pain episodes observed within a 2-day period, rescue medication (IR morphine hydrochloride tablets, $5 \mathrm{mg}$ or $10 \mathrm{mg}$ ) was administered once every 4 hours as needed. The participants had to achieve a stable dose providing pain control (maximum use of rescue medication allowed was 3 times per day on average) at least in the last 2 days the titration phase (2-8 days) and this does was continued for 28 consecutive days. In the 28-day active treatment phase "upward and downward dose titrations were not to exceed a total daily dose of " $80 \mathrm{mg}$ oxycodone CR.

- Rescue medication: see "'Titration schedule.' "A single dose of rescue medication was approximately $15 \%$ of the corresponding total daily dose of study medication."

- Other medication: other opioids (than study drugs and rescue medication) not allowed during the study. The following therapies were not allowed during the study or within 2 weeks before study entry: monoamine oxidase inhibitors, neuroablative procedures, therapy with isotopes, anaesthetic procedures including acupuncture, or surgical procedures relevant to cancer pain. Fentanyl patches were not allowed during the study or within 5 days of study entry. Adjuvant medications (e.g. paracetamol, NSAIDs, anxiolytics, antidepressants, antiarrhythmic drugs, hormone therapy, anticonvulsants, corticosteroids, and neuroleptics were allowed if the participant, at study start, was on a stable dose, which was to be maintained. 
Yu 2014 (Continued)

\author{
Comparison arm \\ - Drug: hydromorphone + placebo. \\ - Dose and dosing: twice-daily administration of hydromorphone and placebo morning and evening at \\ 12-hourly intervals. The mean (SD) (daily?) dose of study medication in the overall maintenance phase \\ 16 (8.51) mg hydromorphone ER. \\ - Formulation: Extended-release provided in 8 and $16 \mathrm{mg}$ over-encapsulated tablets \\ - Route of administration: oral \\ - Length of treatment: 28 days
}

- Titration schedule: Up to 8 days during which participants were converted from their prior opioids to their morphine equivalents (morphine to hydromorphone ER, 5:1) and titrated to adequate effect (as determined by pain assessments and supplementary analgesic requirements). Dosage adjustments were made no more frequently than every 2 days, both upwards and downwards. Maximum total daily dose allowed was $32 \mathrm{mg}$ hydromorphone. For breakthrough pain episodes observed within a 2-day period, rescue medication (IR morphine hydrochloride tablets, $5 \mathrm{mg}$ or $10 \mathrm{mg}$ ) was administered once every 4 hours as needed. The participants had to achieve a stable dose providing pain control (maximum use of rescue medication allowed was 3 times per day on average) at least in the last 2 days the titration phase (2-8 days) and this does was continued for 28 consecutive days. In the 28-day active treatment phase "upward and downward dose titrations were not to exceed a total daily dose of " 32 mg oxycodone CR.

- Rescue medication: see 'Titration schedule.' "A single dose of rescue medication was approximately $15 \%$ of the corresponding total daily dose of study medication."

- Other medication: other opioids (than study drugs and rescue medication) not allowed during the study. The following therapies were not allowed during the study or within 2 weeks before study entry: monoamine oxidase inhibitors, neuroablative procedures, therapy with isotopes, anaesthetic procedures including acupuncture, or surgical procedures relevant to cancer pain. Fentanyl patches were not allowed during the study or within 5 days of study entry. Adjuvant medications (e.g. paracetamol, nonsteroidal anti-inflammatory drugs, anxiolytics, antidepressants, antiarrhythmic drugs, hormone therapy, anticonvulsants, corticosteroids, and neuroleptics were allowed if the participant, at study start, was on a stable dose, which was to be maintained.

- Participant assessment of "pain at its worst in the last 24 hours," included as an item in the Brief Pain Inventory (BPI) Short Form ( $0=$ no pain and $10=$ pain as bad as you can imagine). "Endpoint was defined as the last recorded BPI score of worst pain, just before taking the morning dose of study drug.

- "Pain at its least in the past 24 hours", "average pain," "pain right now;" all assessed in the same way as "pain at its worst in the past 24 hours."

- Number of breakthrough pain medication doses taken, recorded by participants in dairies.

- Number of participants with treatment emergent adverse events, serious adverse events, and adverse events leading to discontinuation from the study.

Notes

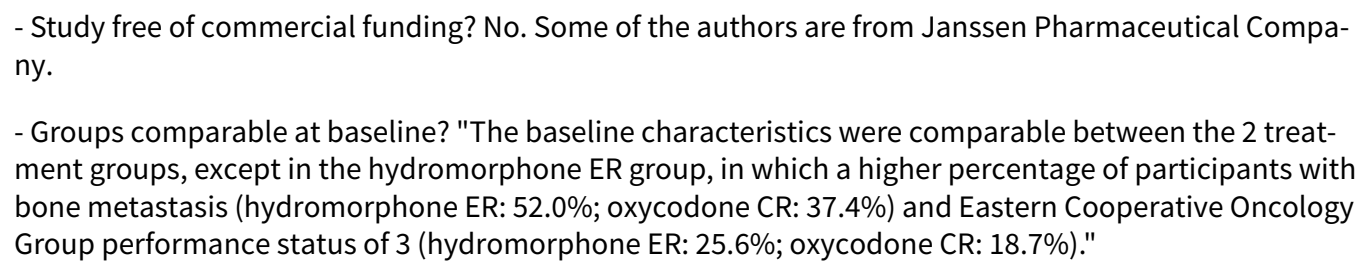

- Groups comparable at baseline? "The baseline characteristics were comparable between the 2 treatment groups, except in the hydromorphone ER group, in which a higher percentage of participants with bone metastasis (hydromorphone ER: 52.0\%; oxycodone CR: 37.4\%) and Eastern Cooperative Oncology Group performance status of 3 (hydromorphone ER: 25.6\%; oxycodone CR: 18.7\%)."

- ITT analyses undertaken? No, the analyses are per protocol.

\title{
Risk of bias
}


Yu 2014 (Continued)

\section{Bias Authors' judgement Support for judgement}

Random sequence genera- Low risk tion (selection bias)

Central randomisation by an online dynamic minimisation allocation programme with stratification for centre, concomitant cancer therapy, and administration of opioids during the last 14 days before study entry.

\begin{tabular}{|c|c|c|}
\hline $\begin{array}{l}\text { Allocation concealment } \\
\text { (selection bias) }\end{array}$ & Low risk & See cell above. \\
\hline $\begin{array}{l}\text { Blinding of participants } \\
\text { and personnel (perfor- } \\
\text { mance bias) } \\
\text { Pain }\end{array}$ & Low risk & $\begin{array}{l}\text { "The interactive web based response system designated a unique patient } \\
\text { number and treatment code, which dictated the treatment assignment for } \\
\text { each patient. The blind was broken only if specific emergency treatment dic- } \\
\text { tated knowing the treatment status." }\end{array}$ \\
\hline & & All study drugs, including placebo, provided in over-encapsulated tablets. \\
\hline $\begin{array}{l}\text { Blinding of participants } \\
\text { and personnel (perfor- } \\
\text { mance bias) } \\
\text { Adverse events }\end{array}$ & Low risk & See cell above. \\
\hline $\begin{array}{l}\text { Blinding of outcome as- } \\
\text { sessment (detection bias) } \\
\text { Pain }\end{array}$ & Low risk & See cell above. \\
\hline $\begin{array}{l}\text { Blinding of outcome as- } \\
\text { sessment (detection bias) } \\
\text { Adverse events }\end{array}$ & Low risk & See cell above. \\
\hline
\end{tabular}

\begin{tabular}{|c|c|c|}
\hline $\begin{array}{l}\text { Incomplete outcome data } \\
\text { (attrition bias) } \\
\text { Pain }\end{array}$ & High risk & Only data from $81 / 260$ randomised participants are analysed \\
\hline $\begin{array}{l}\text { Incomplete outcome data } \\
\text { (attrition bias) } \\
\text { Adverse events }\end{array}$ & Low risk & The data from $254 / 260$ randomised participants are analysed \\
\hline $\begin{array}{l}\text { Selective reporting (re- } \\
\text { porting bias) }\end{array}$ & Low risk & All obvious outcomes appear to have been reported \\
\hline Other bias & Low risk & The results do not appear to be subject to other bias \\
\hline $\begin{array}{l}\text { Were the participants ade- } \\
\text { quately titrated? }\end{array}$ & Low risk & The participants appear to be adequately titrated. \\
\hline $\begin{array}{l}\text { For cross-over trials: are } \\
\text { data available for both } \\
\text { time periods? }\end{array}$ & Unclear risk & Not applicable. \\
\hline
\end{tabular}

\section{Zecca 2016}

Methods

Design: randomised, open-label, superiority parallel-group trial.

Year: 2006-2007.

Country: Italy. 
Zecca 2016 (Continued)

Participants
Participants: 187 participants randomised to oxycodone or morphine:

- Oxycodone: $\mathrm{N}=92,60$ males and 32 females, mean (SD) age $=62.1(12.5)$ years; cancer types were $\mathrm{GI}$ tract (digestive tract, liver, pancreas; $N=23)$, urogenital system $(N=16)$, breast $(N=10)$, lung $(N=20)$, sarcoma $(N=9)$, head and neck $(N=3)$, other $(N=10)$ and unknown $(N=1)$; anatomical pain site(s) were lower back $(N=25)$, abdomen $(N=21)$, lower $\operatorname{limb}(N=3)$, thorax $(N=11) ; 81$ participants had metastatic disease and 11 had localised disease; and 36 participants were receiving ongoing chemotherapy while 56 participants were not.

- Morphine: $\mathrm{N}=95,56$ males and 39 females, mean (SD) age $=61.8$ (11.5) years; cancer types were GI tract (digestive tract, liver, pancreas; $N=23)$, urogenital system $(N=15)$, breast $(N=16)$, lung $(N=16)$, sarcoma $(N=1)$, head and neck $(N=5)$, other $(N=17)$ and unknown $(N=2)$; anatomical pain site $(\mathrm{s})$ were lower back $(N=11)$, abdomen $(N=20)$, lower limb $(N=7)$, thorax $(N=25) ; 80$ participants had metastatic disease and 15 had localised disease; and 39 participants were receiving ongoing chemotherapy while 56 participants were not.

Inclusion criteria:Patients aged 18 years or above; previous 24 hours average pain intensity score of at least 5 on a 0-10 numerical rating scale; Karnofsky performance status score of at least 40; $>1$ month expected survival; and minimum expectedfollow-up of two weeks at the study center.

Exclusion criteria: treatment with WHO step-III opioids within 30 days of study entry; severe renal impairment; severe hepatic failure; dyspnoea or severe chronic obstructive pulmonary disease; inability to take oral medications; history of psychiatric illness; cerebral metastasis; cognitive impairment; medical history of intolerance to morphine or oxycodone; pregnancy; or breastfeeding.

Interventions

Oxycodone arm

- Drug: oxycodone.

- Dose and dosing: every 12 hours. "The initial daily dose of the study medication was decided by the treating physician, based on patient characteristics, pain intensity, and previous analgesic dosage, according to usual clinical practice." "and the dose was titrated to effect. Dose adjustments during follow-up were encouraged if patients required more than two rescue analgesic doses over 24 hours." Mean(?; $95 \% \mathrm{Cl}$ ) oral morphine equivalent daily dose at baseline $=36.6$ (33.6 to 39.6 ) mg; mean(?; 95\% $\mathrm{Cl}$ ) oral morphine equivalent daily dose at study end $=69.8(58.3$ to 81.4$) \mathrm{mg}$.

- Formulation: Controlled-release

- Route of administration: oral.

- Length of treatment: 14 days.

- Titration schedule: see "Dose and dosing."

- Rescue medication: "Oral immediate release or parenteral morphine could be prescribed as supplemental analgesics for breakthrough pain."

- Other medication: "Administration of hormonotherapy, chemotherapy, analgesic adjuvants (steroids, anticonvulsants, and antidepressants) was permitted only if started before study entry and had to be kept unchanged during the study period." "Use of antiemetics and laxatives was permitted for treatment of adverse effects as required."

\section{Comparison arm}

- Drug: morphine.

- Dose and dosing: every 12 hours. "The initial daily dose of the study medication was decided by the treating physician, based on patient characteristics, pain intensity, and previous analgesic dosage, according to usual clinical practice." "and the dose was titrated to effect. Dose adjustments during follow-up were encouraged if patients required more than two rescue analgesic doses over 24 hours." Mean(?; $95 \% \mathrm{Cl}$ ) oral morphine equivalent daily dose at baseline $=30.9$ (27.7 to 34.1) mg; mean(?; $95 \%$ $\mathrm{Cl}$ ) oral morphine equivalent daily dose at study end $=53.9(44.4$ to 63.4$) \mathrm{mg}$. 
Zecca 2016 (Continued)
- Formulation: Controlled-release
- Route of administration: oral.
- Length of treatment: 14 days.
- Titration schedule: see 'Dose and dosing.'
- Rescue medication: "Oral immediate release or parenteral morphine could be prescribed as supple- mental analgesics for breakthrough pain."
- Other medication: "Administration of hormonotherapy, chemotherapy, analgesic adjuvants (steroids, anticonvulsants, and antidepressants) was permitted only if started before study entry and had to be kept unchanged during the study period." "Use of antiemetics and laxatives was permitted for treat- ment of adverse effects as required."

- Participant assessment of "average pain intensity in the previous 24 hours" on 0 (no pain) to 10 (worst
possible pain) numerical rating scale at baseline, 7 days and 14 days.
- Participant assessment of "average intensity of adverse events in the previous week" on 0 (no symp-
tom) to 10 (worst possible symptom) numerical rating scale at baseline, 7 days and 14 days of the fol-
lowing adverse events: Nausea, vomiting, confusion, constipation, somnolence, dry mouth, itching,
and hallucinations (rated as present/absent). Other than hallucinations, an adverse event was consid-
ered to occur when there was a worsening, relative to baseline of $\geq 2$ points.

Notes - Study free of commercial funding? No. Study supported by Mundipharma Pharmaceuticals; Floriani Foundation, Milan (del.CDA 22/11/12) and by Associazione Italiana per la Ricerca sul Cancro (IG15314). The authors stated that the funders had no part in study design, data analysis and interpretation, nor in writing the report.

- Groups comparable at baseline? Yes apart from Kanofsky Performance Status: Higher number of participants in the oxycodone group ( $N=46 / 52 \%)$ with a performance status of 70 or below compared to morphine ( $N=36 / 39 \%)$.

- ITT analyses undertaken? No, the analyses were based on available data.

Study terminated early due to slow accrual

\section{Risk of bias}

\begin{tabular}{lll}
\hline Bias & Authors' judgement & Support for judgement \\
\hline $\begin{array}{l}\text { Random sequence genera- } \\
\text { tion (selection bias) }\end{array}$ & Low risk & $\begin{array}{l}\text { Randomisation to treatment group in a 1:1 ratio via a computer-generated } \\
\text { block randomisation with a block size of } 4 \text { and stratification by age (<70 } v 70 \\
\text { years or above) and ongoing (administered from } 15 \text { days before to } 15 \text { days af- } \\
\text { ter randomisation) v not ongoing chemotherapy. }\end{array}$ \\
\hline $\begin{array}{l}\text { Allocation concealment } \\
\text { (selection bias) }\end{array}$ & Low risk & $\begin{array}{l}\text { Centralised randomisation by a trial office. Randomisation sequence con- } \\
\text { cealed until interventions assignment. }\end{array}$ \\
\hline $\begin{array}{l}\text { Blinding of participants } \\
\text { and personnel (perfor- } \\
\text { mance bias) }\end{array}$ & High risk & Open-label study. \\
\hline \begin{tabular}{l} 
Pain \\
\hline
\end{tabular} & & \\
\hline
\end{tabular}

Blinding of participants High risk Open-label study. and personnel (performance bias)

Adverse events 
Zecca 2016 (Continued)

\begin{tabular}{lll}
$\begin{array}{l}\text { Blinding of outcome as- } \\
\text { sessment (detection bias) } \\
\text { Pain }\end{array}$ & High risk & Open-label study. \\
\hline $\begin{array}{l}\text { Blinding of outcome as- } \\
\text { sessment (detection bias) } \\
\text { Adverse events }\end{array}$ & High risk & Open-label study. \\
\hline
\end{tabular}

\begin{tabular}{|c|c|c|}
\hline $\begin{array}{l}\text { Incomplete outcome data } \\
\text { (attrition bias) } \\
\text { Pain }\end{array}$ & Low risk & $\begin{array}{l}\text { Data included from } 85 / 92 \text { participants in the oxycodone arm and } 88 / 95 \text { partici- } \\
\text { pants in the morphine arm }\end{array}$ \\
\hline $\begin{array}{l}\text { Incomplete outcome data } \\
\text { (attrition bias) } \\
\text { Adverse events }\end{array}$ & Low risk & Data from 185 of 187 randomised participants analysed \\
\hline $\begin{array}{l}\text { Selective reporting (re- } \\
\text { porting bias) }\end{array}$ & Low risk & The obvious outcomes are reported \\
\hline Other bias & Low risk & The study does not appear to be subject to other bias \\
\hline $\begin{array}{l}\text { Were the participants ade- } \\
\text { quately titrated? }\end{array}$ & Low risk & The participants appear to be adequately titrated \\
\hline $\begin{array}{l}\text { For cross-over trials: are } \\
\text { data available for both } \\
\text { time periods? }\end{array}$ & Unclear risk & Not applicable \\
\hline
\end{tabular}

\section{Zhang 2014}

\begin{tabular}{ll}
\hline Methods & Design: randomised, double-blind, parallel-group trial. \\
Year: 2013-2014. & Country: China. \\
\hline Participants & $\begin{array}{l}\text { Participants: } 171 \text { participants selected; } 94 \text { males and } 77 \text { females, median (range) age }=62(39 \text { to } 74) \\
\text { (N }=21) \text {, colorectal }(\mathrm{N}=25) \text { and bone metastases }(\mathrm{N}=19) ; 49 \text { participants had moderate pain and } 122 \\
\text { had severe pain. The participants were randomly allocated to } 3 \text { treatment groups with } \mathrm{N}=57 \text { in each. }\end{array}$ \\
& $\begin{array}{l}\text { Inclusion criteria: Not explicitly given, but "All patients had moderate or severe stable pain, the KPS } \\
\text { score }>50, \text { Expected survival }>3 \text { months, no obvious respiratory depression or airway obstruction, nor- } \\
\text { mal liver function and blood routine examination, no drug allergy history, no use of other analgesics at } \\
\text { 5 h before treatment." } \\
\text { Exclusion criteria: Not reported }\end{array}$ \\
\hline
\end{tabular}

\section{Oxycodone arm}

- Drug: oxycodone (supplied by Mundipharma (China) Pharmaceutical Co. Ltd.).

- Dose and dosing: 10 mg every 12 hours as initial dose. Mean final daily dose was not reported.

- Formulation: Controlled-release

- Route of administration: oral. 
- Length of treatment: not reported.

- Titration schedule: "The above-mentioned drugs must be swallowed wholly, not partially or trituration. If the patients cannot take the drugs, the same dose of rectal administration was considered. The dose was evaluated once every $48 \mathrm{~h}$ and regulated according to the degrees of pain relief. The dose was added and each dose was increased by $50 \%$ $100 \%$ due to poor control of disease but the administration frequency was not changed until the cancer pain was relived satisfactorily."

- Rescue medication: "During the treatment, if the unsound short-term effect or sudden aggravated pain, a short-acting morphine injection was given."

- Other medication: not reported.

\section{Comparison arm 1}

- Drug: morphine (supplied by Taiji Group, Southwest Pharmaceutical Co Ltd)

- Dose and dosing: 30 mg every 12 hours as initial dose. Mean final daily dose is not reported

- Formulation: Controlled-release

- Route of administration: oral.

- Length of treatment: not reported.

- Titration schedule: "The above-mentioned drugs must be swallowed wholly, not partially or trituration. If the patients cannot take the drugs, the same dose of rectal administration was considered. The dose was evaluated once every $48 \mathrm{~h}$ and regulated according to the degrees of pain relief. The dose was added and each dose was increased by $50 \%$ $100 \%$ due to poor control of disease but the administration frequency was not changed until the cancer pain was relived satisfactorily."

- Rescue medication: "During the treatment, if the unsound short-term effect or sudden aggravated pain, a short-acting morphine injection was given."

- Other medication: not reported.

\section{Comparison arm 2}

- Drug: MS Contin (supplied by Mundipharma (China) Pharmaceutical Co Ltd)

- Dose and dosing: $30 \mathrm{mg}$ every 12 hours as initial dose. Mean final daily dose is not reported

- Formulation: Controlled-release

- Route of administration: oral.

- Length of treatment: not reported.

- Titration schedule: "The above-mentioned drugs must be swallowed wholly, not partially or trituration. If the patients cannot take the drugs, the same dose of rectal administration was considered. The dose was evaluated once every $48 \mathrm{~h}$ and regulated according to the degrees of pain relief. The dose was added and each dose was increased by $50 \%$ $100 \%$ due to poor control of disease but the administration frequency was not changed until the cancer pain was relived satisfactorily."

- Rescue medication: "During the treatment, if the unsound short-term effect or sudden aggravated pain, a short-acting morphine injection was given."

- Other medication: not reported.

Outcomes

\begin{abstract}
- Pain: Classified according to World Health Organisation (WHO) from level 0 (painless), through level 1 (mild pain, no need to use drugs), level 2 moderate pain, influences sleep, analgesics needed) to level 3 (severe pain, strong impact on sleep, analgesics needed).
\end{abstract}

- Pain relief: Measured on degree scale from 0 (non-remission pain), through I degree (mild pain relief, pain which is reduced by $1 / 4$ ), II degree (moderate pain relief, pain reduced by $1 / 2$ ), II degree (obvious 
pain relief, pain reduced by $3 / 4$ ), and $\mathbb{N}$ degree (complete pain relief, pain disappears). "The pain relief rate refers to the rate of moderate or above pain, that is, The pain relief rate =patients of TheIldegree and the above/the total selected patients." (p. 8798)

- Adverse events: Nausea, vomiting, constipation, dizziness, dysuria and somnolence. No further details reported.

Notes

- Study free of commercial funding? Unclear, the study drugs were provided by Taili Group Southwest Pharmaceuticals Co. Ltd. (morphine) and Mundipharma (China) Pharmaceuticals Co. Ltd.

- Groups comparable at baseline? No differences were found between the 3 groups in mean age, gender, disease categories, KPS score, pain types, and degrees $(p>0.05)$.

- ITT analyses undertaken? Yes, data from 57 participants in each group are analysed

\section{Risk of bias}

\begin{tabular}{lll}
\hline Bias & Authors' judgement & Support for judgement \\
\hline $\begin{array}{l}\text { Random sequence genera- } \\
\text { tion (selection bias) }\end{array}$ & Unclear risk & No information reported \\
\hline $\begin{array}{l}\text { Allocation concealment } \\
\text { (selection bias) }\end{array}$ & Unclear risk & No information reported \\
\hline $\begin{array}{l}\text { Blinding of participants } \\
\text { and personnel (perfor- } \\
\text { mance bias) }\end{array}$ & Unclear risk & No information reported \\
Pain & \\
\hline
\end{tabular}

Blinding of participants Unclear risk No information reported
and personnel (perfor-
mance bias)
Adverse events

\begin{tabular}{lll}
\hline $\begin{array}{l}\text { Blinding of outcome as- } \\
\text { sessment (detection bias) } \\
\text { Pain }\end{array}$ & Unclear risk & No information reported \\
\hline $\begin{array}{l}\text { Blinding of outcome as- } \\
\text { sessment (detection bias) } \\
\text { Adverse events }\end{array}$ & Unclear risk & No information reported \\
\hline $\begin{array}{l}\text { Incomplete outcome data } \\
\text { (attrition bias) } \\
\text { Pain }\end{array}$ & Unclear risk & Unclear how many were entered into the trial \\
\hline $\begin{array}{l}\text { Incomplete outcome data } \\
\text { (attrition bias) }\end{array}$ & Unclear risk & Unclear how many were entered into the trial \\
$\begin{array}{l}\text { Adverse events } \\
\begin{array}{l}\text { Selective reporting (re- } \\
\text { porting bias) }\end{array}\end{array}$ & Low risk & All obvious outcomes appear to be reported \\
\hline $\begin{array}{l}\text { Other bias } \\
\text { quately titrated? }\end{array}$ & Unclear risk & $\begin{array}{l}\text { It cannot be evaluated whether this study is at risk of other bias due to the } \\
\text { sparse reporting of study details. }\end{array}$ \\
\hline $\begin{array}{l}\text { Were the participants ade- } \\
\text { Low risk }\end{array}$ & $\begin{array}{l}\text { The participants were probably adequately titrated. About 90\% of patients in } \\
\text { each of the three groups achieved at least moderate pain relief. }\end{array}$ \\
\hline
\end{tabular}


Zhang 2014 (Continued)

For cross-over trials: ar data available for both

Not applicable

time periods?

cm: centimeters; CNS: central nervous system; CR: controlled release; ER: extended-release; g: grams; g/dL: grams per decilitre; h or hr: hour(s); IM: intramuscular; IR: Immediate-release; ITT: intention to treat; IV: intravenous; kg: kilograms;KPS: Karnofsky Performance Status; max: maximum; mg: milligrams; mg/dL: milligrams per decilitre; min: minute(s); ml: millilitres; mm: millimetres; N: number of participants; NRS: numerical rating scale; NSAID: non-steroidal anti-inflammatory drug; OOD: oxycodone once daily; OTD: oxycodone twice daily; PCA: patient-controlled analgesia; PI: pain intensity; SD: standard deviation; SE: standard error; SR: sustained-release; TD: transdermal; uL: microlitres; v: versus; VAS: visual analogue scale; WHO: World Health Organization.

Characteristics of excluded studies [ordered by study ID]

\begin{tabular}{|c|c|}
\hline Study & Reason for exclusion \\
\hline Ahmedzai 2012 & Comparison not in PICO: Oxycodone-naloxone versus oxycodone \\
\hline Awerbuch 2011 & Not cancer pain \\
\hline Bekkering 2011 & Systematic review. Checked for relevant, previously unidentified studies for current review \\
\hline Bell 2006 & Systematic review. Checked for relevant, previously unidentified studies for current review \\
\hline Borchgrevink 2004 & Narrative review \\
\hline Caraceni 2011 & Systematic review. Checked for relevant, previously unidentified studies for current review \\
\hline Carroll 2011 & $\begin{array}{l}\text { Comparison not in PICO: Patients received a variety of sustained-release opioids }+ \text { immediate-re- } \\
\text { lease morphine or oxycodone versus placebo }\end{array}$ \\
\hline Chary 1994 & Intervention not in PICO \\
\hline Chen 2009 & Comparison not in PICO: Oxycodone-acetominophen versus morphine \\
\hline De Conno 1991 & Not RCT \\
\hline Dunlop 2013 & Comparison not in PICO: Oxycodone-naloxone versus oxycodone \\
\hline Fallon 2011 & Systematic review. Checked for relevant, previously unidentified studies for current review \\
\hline Garassino 2010 & $\begin{array}{l}\text { Comparison not in PICO: Fixed-dose oxycodone and increasing dose of pregabalin versus increas- } \\
\text { ing dose of oxycodone and fixed-dose pregabalin }\end{array}$ \\
\hline Garassino 2011 & $\begin{array}{l}\text { Comparison not in PICO: Fixed-dose oxycodone and increasing dose of pregabalin versus increas- } \\
\text { ing dose of oxycodone and fixed-dose pregabalin }\end{array}$ \\
\hline Garassino 2013 & $\begin{array}{l}\text { Comparison not in PICO: Fixed-dose oxycodone and increasing dose of pregabalin versus increas- } \\
\text { ing dose of oxycodone and fixed-dose pregabalin }\end{array}$ \\
\hline George 2003 & Narrative review \\
\hline Hanks 2002 & Narrative review \\
\hline Hongmei 2013 & Not RCT \\
\hline
\end{tabular}




\begin{tabular}{|c|c|}
\hline Study & Reason for exclusion \\
\hline Igarashi 2015 & Letter to the editor \\
\hline Katz 2008 & Letter to the editor \\
\hline Kim 2015 & Comparion not in PICO: Transdermal fentanyl versus transdermal fentanyl + oral oxycodone \\
\hline King 2011 & Systematic review. Checked for relevant, previously unidentified studies for current review \\
\hline Koyyalagunta 2012 & Systematic review.Checked for relevant, previously unidentified studies for current review \\
\hline Kummer 2011 & Particpants were healthy individuals, not people with cancer \\
\hline LeBon 2009 & Systematic review.Checked for relevant, previously unidentified studies for current review \\
\hline Leppert 2011 & Comparison not in PICO: Oxycodone-naxolone versus oxycodone \\
\hline Li 2008 & Comparison not in PICO: Oxycodone-acetominophen versus oxycodone \\
\hline Li 2010 & Comparison not in PICO: Oxycodone + gabapentin versus oxycodone \\
\hline Ma 2016 & Systematic review. Checked for relevant, previously unidentified studies for current review \\
\hline Marineo 2012 & Not randomised enrolment \\
\hline Meng 2008 & $\begin{array}{l}\text { Published completely in Chinese. Translator confirmed that the study is not an RCT, but rather a } \\
\text { retrospective review of cancer patient charts }\end{array}$ \\
\hline Moertel 1974 & $\begin{array}{l}\text { Comparison not in PICO: Aspirin versus aspirin+codeine versus aspirin+oxycodone versus as- } \\
\text { pirin+pentazocine hydrochloride }\end{array}$ \\
\hline Moksnes 2012 & $\begin{array}{l}\text { Comparison not in PICO: Study compared two switching strategies from morphine/oxycodone to } \\
\text { methadone }\end{array}$ \\
\hline Nadstawek 2008 & Comparison not in PICO: Comparing different doses of naloxone in patients on oxycodone \\
\hline Nalamachu 2013 & Not RCT \\
\hline NCT01859715 & $\begin{array}{l}\text { Population not in PICO: "Patients with pain and/or nausea are enrolled in the Emergency Depart- } \\
\text { ment (ED). They are given either oxycodone, hydrocodone, or ondansetron at the discretion of the } \\
\text { Emergency Department (ED) provider or the triage nurse by triage protocol. Detailed prescription, } \\
\text { over the counter, herbal, supplement, and illicit drug ingestion histories are taken from the patient } \\
\text { or their health care proxy. Serial visual analogue scales are captured prior to study drug administra- } \\
\text { tion then between } 30 \text { and } 90 \text { minutes following drug administration." "Subjects given either oxy- } \\
\text { codone } 5 \mathrm{mg} \text { or hydrocodone/acetaminophen } 5 \mathrm{mg} / 500 \mathrm{mg} \text { by ED provider decision or by triage } \\
\text { nurse randomization." Unclear whether it is a RCT }\end{array}$ \\
\hline
\end{tabular}

\begin{tabular}{ll}
\hline NCT01885182 & Comparison not in PICO: Oxycodone-naxolone versus oxycodone \\
\hline Nunez Olarte 2008 & Narrative review \\
\hline Oosten 2015 & Systematic review. Checked for relevant, previously unidentified studies for current review \\
\hline Pang 2009 & $\begin{array}{l}\text { Comparison not in PICO: fixed doses of oxycodone-acetominophen versus background doses of } \\
\text { oxycodone-acetominophen plus additional dose for breakout pain versus controlled-release oxy- } \\
\text { codone plus oxycodone-acetominophen for breakout pain }\end{array}$ \\
\hline
\end{tabular}




\begin{tabular}{|c|c|}
\hline Study & Reason for exclusion \\
\hline Passik 2014 & Comparison/population not in PICO ( $\mathrm{N}=2$ with cancer) \\
\hline Reid 2006 & Systematic review. Checked for relevant, previously unidentified studies for current review \\
\hline Rentz 2009 & Not RCT-based analyses \\
\hline Shi 2008 & Comparison not in PICO: Oxycodone-acetominophen versus morphine \\
\hline Sima 2010a & Comparison not in PICO: Oxycodone + aceteminophen versus placebo \\
\hline Sima 2010b & Comparison not in PICO: Oxycodone + aceteminophen versus placebo \\
\hline Sima 2012 & Comparison not in PICO: Oxycodone + paracetamol versus placebo \\
\hline Stambaugh 1980a & $\begin{array}{l}\text { Comparison not in PICO: Oxycodone + aspirin + caffiene + phenaticin (Percodan) versus zomepirac } \\
\text { versus placebo }\end{array}$ \\
\hline Stambaugh $1980 \mathrm{~b}$ & Comparison not in PICO: Oxycodone-acetominophen (tylox) versus oxycodone-aspirin (Percodan) \\
\hline Stambaugh 1981 & $\begin{array}{l}\text { Comparison not in PICO: Oxycodone + aspirin + caffiene + phenaticin (Percodan) versus zomepirac } \\
\text { versus placebo }\end{array}$ \\
\hline Stambaugh 1985 & Comparison not in PICO: Ibuprofen vs. placebo \\
\hline Stambaugh 1987 & Comparison not in PICO: Xorphanol versus oxycodone-acetominophen versus placebo \\
\hline Stambaugh 1990 & Comparison not in PICO: Flurbiprofen versus oxycodone-acetominophen versus placebo \\
\hline Stambaugh 1991 & Narrative review \\
\hline Taeron 2002 & Narrative review \\
\hline Wallace 2013 & Case report \\
\hline Wang 2012 & Systematic review. Checked for relevant, previously unidentified studies for current review \\
\hline Watanabe 2008 & $\mathrm{~N}=1$ received oxycodone \\
\hline Wu 2009 & Comparison not in PICO: Oxycodone-acetominophen versus tramadol \\
\hline Wu 2015 & Comparison not in PICO: Morphine versus oxycodone + morphine \\
\hline Xiong 2008 & Comparison not in PICO: Oxycodone-acetominophen versus morphine \\
\hline Xu 2008 & Not RCT \\
\hline Zou 2009 & $\begin{array}{l}\text { Comparison not in PICO: Oxycodone + acetaminophen versus increased dose of existing opioid } \\
\text { treatment }\end{array}$ \\
\hline
\end{tabular}

PICO: $\mathrm{P}=$ participant, problem, or population; I = intervention; $\mathrm{C}=$ comparison, control, or comparator; $\mathrm{O}=$ outcome; $\mathrm{RCT}$ : randomised controlled trial.

Characteristics of studies awaiting assessment [ordered by study ID] 


\section{Methods}

Randomised, parallel-group, open-label controlled trial:

An International, Multicentre, Open Randomised Parallel Group Trial Comparing a Two Step Approach for Cancer Pain Relief With the Standard Three Step Approach of the WHO Analgesic Ladder in Patients With Cancer Pain Requiring Step 2 Analgesia
Inclusion Criteria:

- A18 years of age and over.

- Patient has a cancer diagnosis (based on radiological, histological, cytological, or operative evidence). Those with haematological malignancies are eligible

- Cancer related pain - which in the opinion of the clinician is caused by the presence of tumour or metastases

- Average pain score $>4$, on a numerical rating scale from 0 to 10 , requiring step 2 analgesia (weak opioid)

- Patient is able to comply with trial procedures

\section{Exclusion criteria:}

- Patients who have received radiotherapy in the previous 6 weeks or are planned to receive radiotherapy during the trial period where in either case, it is expected to affect pain during the trial period

- Pain due to surgery in the preceding 4 weeks

- Life expectancy less than two months (based on clinical impression)

- Patients with psychotic disorders or cognitive impairment

- Patients who have received regular doses (scheduled doses - not as required dosing) of weak or strong opioids in the preceding two weeks

- Patients using immediate-release opioids $>2$ doses/24 hours, in the previous 24 hours
Standard 3 Step approach (participants will be managed according to the standard 3 Step approach of the WHO analgesic ladder (Step 1 - Step 2 - Step 3))

versus

2 Step approach (participants managed according to the WHO analgesic ladder bypassing Step 2, i.e. participants will move from Step 1 of the WHO analgesic ladder to Step 3)

Drugs to be used: oral morphine, oral oxycodone, oral tramadol, codeine.

\section{Primary outcome measures:}

- Time to achieving stable pain control, where stable pain control is defined as the first day of three consecutive days with average pain score less than or equal to 3 using scores from the Patient Diary and participant assessments. (Time frame: Up to 20 days)

\section{Secondary outcome measures:}

- Mean of daily average pain scores from the Patient Diary

- Mean of daily worst pain scores from the Patient Diary

- Percentage of days with average pain score $\geq 6$ from the Patient Diary

- Percentage of days with worst pain score $\geq 6$ from the Patient Diary 
- Patient distress score at day 10 and 20 from the NCCN Distress Thermometer

Notes Location: UK, Norway, Australia, Italy, Germany, Uganda, Spain

Sponsors and collaborators: University of Edinburgh, NHS Lothian, Mundipharma (UK), St Olavs Hospital (Norway)

Principal investigators: Marie Fallon, University of Edinburgh

Target enrolment: $\mathrm{N}=450$

Study dates: March 2012 to December 2014

Other study ID numbers: NCT01493635, 11/SS/0079

Aurilio 2009

Pester Presentations
Session title: Chronic pain
Presentation date: Sunday, 15 March 2009
Evaluation of efficacy and safety of prolonged-release oxycodone at different dosages for the
treatment of severe chronic pain

Aurilio C, Sansone P, Pace MC, Passavanti MB, Romano SV, Pota V

Second University of Naples, Department of Anaesthesiological, Surgical and Emergency Sciences, Napoli, Italy

Background and aims: It's important to arrange a correct and flexible therapy for the treatment of chronic malignant and non-malignant pain especially in fragile patients. The aim of this study is to evaluate the efficacy and safety of prolonged-release (PR) oxycodone $10 \mathrm{mg} / \mathrm{morning}$ and $20 \mathrm{mg} /$ evening versus PR oxycodone $20 \mathrm{mg}$ twice a day

Methods: After local ethical committee approval and written informed consent 40 patients (13 men and 27 women), affected by severe chronic pain (mean NRS 8 ) were randomised in two groups: OD group: 20 patients receiving PR oxycodone 10 /morning and 20 /evening; OS Group: 20 patients who receiving PR oxycodone $20 \mathrm{mg}$ every 12 hours. The observation period was 28 days with 5 visits, once a week (T0 to T5). NRS was the parameter of efficacy while the incidence and intensity of nausea, vomiting, somnolence, stipsis and itching were the parameters of safety. Any assumption of rescue medication (immediate-release oral morphine $10 \mathrm{mg}$ ) was registered Results: Both the groups presented a $50 \%$ reduction of pain T1, and kept a very good analgesia for all the observation period. In OD group there was a lower incidence of adverse events than in OS Group. In OS group there was a lower assumption of rescue medication than in OD Group Conclusion: Therapy using PR oxycodone at different dosages allows a pain reduction similar to therapy with PR oxycodone at same dosage. Moreover with this therapeutic scheme it's possible to reduce the incidence of adverse events

Interventions

Outcomes

Notes 


\begin{tabular}{ll}
\hline Methods & $\begin{array}{l}\text { JapicCTI-090789: An open-label study of intravenous (i.v.) S-811717 (oxycodone hydrochloride so- } \\
\text { lution for injection) in patients with cancer pain } \\
\text { JapicCTI-090790: An extension study of S-811717 (oxycodone hydrochloride solution for injection) } \\
\text { in patients with cancer pain } \\
\text { JapicCTI-090791: An open-label study of subcutaneous injection (s.c.) S-811717 (oxycodone hy- } \\
\text { drochloride solution for injection) in patients with cancer pain }\end{array}$ \\
\hline Participants & Inpatients with pain associated with various cancers aged $\geq 20$ years \\
\hline Interventions & S-811717 \\
\hline Outcomes & $\begin{array}{l}\text { - To evaluate the efficacy and safety of S-811717 in patients with pain caused by various cancers } \\
\text { - To determine the pharmacokinetics of S-811717 and its metabolites. No other information avail- }\end{array}$ \\
able & $\begin{array}{l}\text { Location: Japan } \\
\text { Sponsors, collaborators, investigators: Shionogi \& Co, Ltd., Research and Development } \\
\text { No other information available }\end{array}$ \\
\hline
\end{tabular}
Analgesic Ladder (Non-Opioid to Oxycodone) With Conventional Management Using A Three-Step Approach

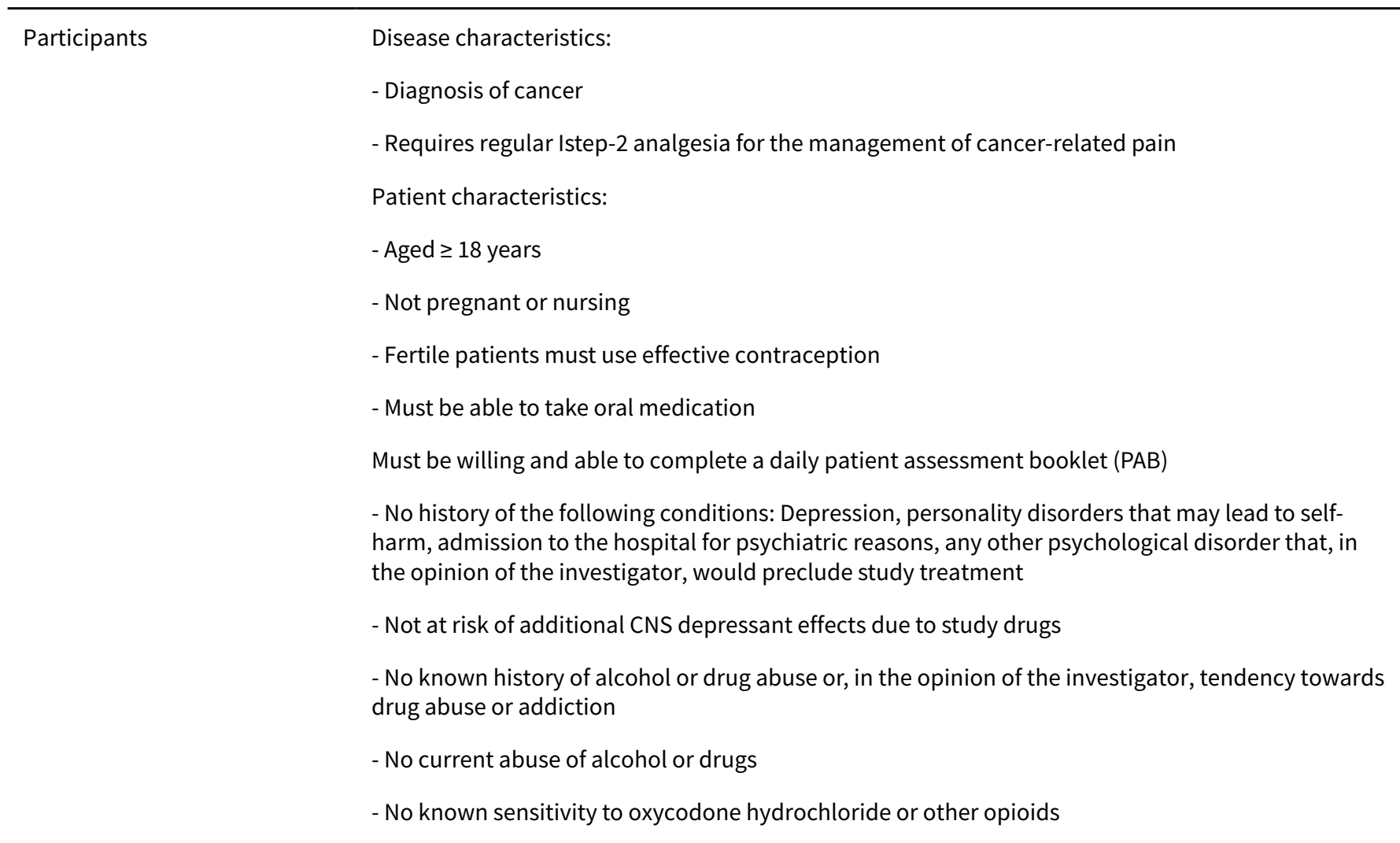


- No history of a specific or allergic reaction to study drugs

- No contraindications as a result of adverse drug reaction or drug interactions of oxycodone or other opioid drugs

- No other condition that, in the opinion of the investigator, would make the patient unsuitable for study participation

Prior concurrent therapy:

- More than 30 days since prior and no concurrent chemotherapy or radiotherapy

- At least 2 weeks since prior regular (i.e., 4 times per day) step-2 analgesics

- More than 3 months since prior regular use of opioids, defined as having a regular prescription of an opioid medication

- Not planning to undergo cancer-related surgery

- No other concurrent opioid-based medication other than oxycodone hydrochloride capsules as escape medication (arm II)

- No concurrent participation in another clinical trial involving a new chemical entity

Participants receive an analgesic regimen, according to their level of pain, for up to 18 weeks

- Step 1: Participants in mild pain receive oral acetaminophen 4 times daily

- Step 2: Participants in mild-to-moderate pain receive oral codeine or oral dextropropoxyphene hydrochloride 4 times daily and oral acetaminophen 4 times daily.

- Step 3: Participants in moderate-to-severe pain receive oral morphine or oral oxycodone hydrochloride 6 times daily (every 4 hours) with or without a non-opioid analgesic

Participants may also receive an adjuvant drug (i.e., for side effects or for primary indication other than pain management that is analgesic in selected circumstances)

versus

Arm 2:

Participants receive oral oxycodone hydrochloride twice daily for up to 18 weeks. Participants may receive a different opioid analgesic or analgesia or adjuvant medication as in arm I, if needed

Participants in both arms may also receive additional medication for breakthrough pain. Participants complete a participant-assessment booklet (PAB) daily which includes a Box-Scale (BS)-11 rating for average pain; questions regarding contact (e.g., telephone or visit) with healthcare professionals on that day; and information regarding the number of times escape medication is used. Quality of life and levels of cancer pain are assessed using the short form of the Brief Pain Inventory (BPI). After completion of study treatment, participants are followed at 4 weeks

\section{Outcomes}

\section{Primary Outcome Measures:}

- Percentage of time in assessment periods 1 and 2 (i.e., first 4 weeks) with a BS-11 pain score of $\leq 4$ (i.e., mild pain) Secondary Outcome Measures:

- Percentage of time in assessment periods 3 and 4 with a BS-11 pain score of $\leq 4$

- Mean BS-11 pain scores

- Time to reach stable pain control

- Mean escape medication use

- Quality of sleep

- Global assessment of pain relief with study drugs 
NCT00378937 (Continued)

- Mean pain intensity, pain interference, and pain relief scores as measured by the BPI

- Overall number of phone calls, home visits by a nurse, home visits by a doctor, and unscheduled visits to a healthcare provider, related to pain control or analgesic medication during study treatment

\section{Notes}

Location: US

Sponsors and collaborators: University Hospitals Bristol NHS Trust

Study chair: Geoff Hanks, University Hospitals Bristol NHS Trust

Target enrolment: $\mathrm{N}=30$

Study dates: ?

Other study ID numbers: CDR0000507650, CRUK-ON/2003/1772, EU-20640, EU-

DRACT-2004-004235-66, NAPP-CRUK-ON/2003/1772

A Randomized Comparison of Oral Methadone as a "First-Switch" Opioid Versus Opioid Switching Between Sustained-Release Morphine and Oxycodone for Oncology-Hematology Outpatients With Pain Management Problems: The "Simply Rotate" Study

\section{Participants}

Disease characteristics:

- Receiving ongoing care in the outpatient medical oncology setting

- Self-reported pain (of any cause) for which long-acting strong opioids (morphine or oxycodone) have been prescribed or administered oral morphine-equivalent daily dose (MEDD) of existing opioid regimen (long-acting or immediate-release) 40 to $300 \mathrm{mg} /$ day

- Worst pain score on a scale of 0 (no pain) to 10 (worst pain) of $\geq 5$ for $\geq 1$ week duration based on verbal self-report or $\geq 1$ persistently bothersome symptom attributed to an opioid side effect (e.g., fatigue, confusion, depressed level of consciousness, memory loss, personality change, anorexia, constipation, dehydration, nausea, vomiting, weight loss, pruritus, urticaria, impotence, reduced libido, and urinary retention or hesitancy), or both

Patient characteristics:

- Aged $\geq 18$ years

- None of the following conditions that could predispose the patient to prolonged QT interval-associated tachycardia: serum potassium $<3.0 \mathrm{mg} / \mathrm{dL}$; cocaine abuse within the past 3 months; family history of sudden death; advanced heart failure (ejection fraction $<40 \%$ or New York Heart Association (NYHA) class III or IV heart disease, or both

- No known or suspected cognitive impairment that could interfere with adherence to the medication plan or self-report of symptoms and side effects

- Not pregnant or nursing

- Fertile patients must use effective contraception

Prior concurrent therapy:

- See 'Disease characteristics'

- More than 4 weeks since prior radiotherapy or surgery for local control of cancer or pain palliation 
- More than 60 days since prior use of the same long-acting opioid (i.e., the new long-acting opioid) that patient is switching to on the study

- More than 12 weeks since prior methadone therapy

- More than 3 days since prior and no concurrent transdermal fentanyl, oxymorphone, or buprenorphine

- Concurrent systemic anticancer therapy or bisphosphonates allowed provided therapy was initiated $\geq 4$ weeks ago

- Concurrent tricyclic antidepressants, non-steroidal anti-inflammatory drugs (NSAIDs), anticonvulsants, or other adjuvant analgesics or psychostimulants allowed provided therapy was initiated $\geq 2$ weeks ago; dose expected to remain stable until after the first week of opioid rotation on study

- No concurrent methadone maintenance therapy for opioid addiction

- No concurrent intrathecal infusion of analgesics

- No concurrent antiarrhythmic medications (e.g., amiodarone or quinidine) (oxycodone or morphine) to methadone. Participants receive oral methadone 2 to 3 times daily for 4 weeks) versus

Opioid rotation to another long-acting strong opioid (participants currently receiving oxycodone are switched to sustained-release (SR) morphine. Participants currently receiving morphine are switched to SR oxycodone. Participants receive either oral SR morphine or oxycodone 2 to 3 times daily for 4 weeks)

\section{Outcomes}

\section{Primary outcome measures:}

- Number of participants with at least a 3-point reduction in pain score on the M.D. Anderson Symptom Inventory (MDASI) (time frame: 28 days)

- MDASI questionnaire completed on days 8, 15, and 22 after enrollment. The 'primary success' is defined as a 3-point reduction in pain score on the MDASI. Scores from baseline and from four weeks later compared using the MDASI average pain intensity on a scale of 0 (no pain) to 10 (worst pain)

\section{Secondary outcome measures:}

- Number of participants with 30\% reduction in total summary score for the Individual Composite Drug Toxicity Score (CDTS) Items (time frame: 28 days) (Designated as safety issue)

Sponsors and collaborators: M.D. Anderson Cancer Institute, National Cancer Institute

Principal investigators: Michael J Fisch, MD, Anderson Cancer Center; James D Bearden, CCOP - Upstate Carolina

Target enrolment: $\mathrm{N}=$ ?

Study dates: March 2009 to October 2010

Other study ID numbers: 2007-0791, MDA-2007-0791, CDR0000598283 


\section{Methods}

It is unclear whether this is a retrospective study or a randomised controlled trial. Authors e-mailed on 14 January 2014 for clarification

Design: 'Randomized', parallel-group

Year: 2006 to 2008

Country: China

\section{Participants:}

- Oxycodone (commercial name Tai Lening): $\mathrm{N}=42,42$ analysed, $\mathrm{M} / \mathrm{F}=$ unclear, median (range) age $=55$ (28 to 83) years. Primary tumours were: lung cancer (12), breast cancer (5), liver cancer (6), gastric cancer (4), nasopharyngeal carcinoma (3), colorectal cancer (3), oesophageal cancer (3), lymphoma (2), osteosarcoma (2), chordoma (1), pancreatic cancer (1)

- Morphine sulfate controlled-release (MS Contin): N = 45, 45 analysed, 27 males and 18 females; median (range) age = 53 (30 to 76) years. Primary tumours were: Lung cancer (14), breast cancer (6), liver cancer (6); gastric cancer (6), oesophageal cancer (3), pancreatic cancer (2), nasopharyngeal (2), colorectal cancer (2), non-Hodgkin's lymphoma (2), ovarian cancer (2).

Inclusion criteria: "87 patients who were diagnosed with malignant tumour based on histopathology and cytology, with moderate to severe cancer pain and who did not respond to non-steroidal anti-inflammatory drugs and weak opioid analgesics".

Exclusion criteria: Not reported

\section{Oxycodone arm}

- Drug: Oxycodone +1 tablet (each containing oxycodone $5 \mathrm{mg}$, acetaminophen $325 \mathrm{mg}$ ),

- Dose and dosing: every $6 \mathrm{~h}$ ( 2 oxycodone tables has equal titration dose with oral morphine 30 to $40 \mathrm{mg}$ )

- Formulation: Controlled-release

- Route of administration: Oral

- Length of treatment: 5 days

- Titration schedule: Not clear but seems they have same dose increased as the contin group.

- Rescue medication: During the treatment, if participants have short term unsatisfactory treatment efficacy or have sudden intensified pain, then short-acting morphine injection was administrated. The participants were considered treatment failure if the pain relief was not relieved until the observation period had ended or the limit dose was reached

- Other medication: Unclear

\section{Comparison arm}

- Drug: Morphine sulfate (MS Contin)

- Dose and dosing: $20 \mathrm{mg} /$ day as the first dose

- Formulation: Controlled-release

- Route of administration: Oral

- Length of treatment: 5 days

- Titration schedule: MS Contin group with $20 \mathrm{mg} /$ day as the first dose, if the pain could be relieved, then continued using the same dose as maintenance treatment. If the pain was not relieved after $24 \mathrm{hr}$, then increased the dose until a satisfactory pain relief, or till reach the maximum dose (the maximumdose $=270 \mathrm{mg} /$ day) 
Song 2009 (Continued)

- Rescue medication: During the treatment, if participants have short-term unsatisfactory treatment efficacy or have sudden intensified pain, then short-acting morphine injection was administrated. The participants were considered treatment failure if the pain relief was not relieved until the observation period had ended or the limit dose was reached

- Other medication: Unclear

For both groups, if the participants had intolerable adverse reactions when increasing the dose, the drugs could be discontinued at any time, then the participants were observed 30 days and then evaluated the treatment efficacy

The participant was also considered as treatment failure if the treatment has to be stopped due to intolerable adverse events

\section{Outcomes}

- Pain Intensity (PI) and pain relief: the WHO linear Visual Analog Scale VAS was used, the degree of pain was graded using by dividing a line into 10 segments: $0=$ no pain, 1 to 3 as mild, 4 to 7 as moderate, severe pain as 8 to $9,10=$ extreme pain

Complete remission (CR): completely no pain after treatment, with a pain score of 0 on a 0 to 10 VAS. Partial remission (PR): pain reduced significantly, there was no sleep disturbance, have normal daily life, the pain reduced 4 or more grades in the segments.(YY's note: they did not say scores lower than 4 , they said reduced 4 or more, $C R$ can be translated as complete relief). Mild remission (NC): certain degree of pain relief, but require enhanced pain control, participants had sleep disturbances, VAS score reduced 1 to 3 grades in the 0 to 10 VAS line. (YY note, NC normally means no changes). Treatment failure (PD): no pain relief compared to baseline. (YY note - PD normally means progression of disease). The authors considered participants who were CR or PR as "treatment was effective"

- Adverse reactions. Participants were observed for all kinds of adverse reactions: constipation, nausea, vomiting, dizziness, drowsiness, skin rash or itching, abdominal discomfort etc

Were the participants adequately titrated? Unclear, possibly?

Groups comparable at baseline? Unclear, probably if properly randomised

ITT analyses undertaken? Yes

BPI: Brief Pain Inventory; MDASI: M.D. Anderson Symptom Inventory; NCCN: National Comprehensive Cancer Network; NHS: National Health Service; NRS: numerical rating scale; PR: prolonged-release; SR: sustained-release; VAS: visual analogue scale; WHO: World Health Organization.

Characteristics of ongoing studies [ordered by study ID]

2008-002273-12

Trial name or title $\quad \begin{aligned} & \text { Long term opioid administration in oncologic chronic pain: open label, prospective study on effica- } \\ & \text { cy, safety and pharmacogenetic factors }\end{aligned}$

\begin{tabular}{ll}
\hline Methods & Randomised, parallel-group, open controlled trial \\
\hline Participants & Inclusion criteria: \\
& - age $>18$ years \\
& - oncologic, chronic, neurophatic or nociceptive peripheral pain \\
& Exclusion criteria: \\
- abuse history
\end{tabular}




$$
\text { - opioid analgesic use history }
$$

- opioid allergies

\begin{tabular}{|c|c|}
\hline Interventions & $\begin{array}{l}\text { Morphine (oral solution) } \\
\text { versus } \\
\text { morphine (oral tablet) } \\
\text { versus } \\
\text { oxycodone (oral tablet) } \\
\text { versus } \\
\text { fentanyl (transdermal patch) } \\
\text { versus } \\
\text { buprenorphine (transdermal patch) } \\
\text { versus } \\
\text { hydromorphone (prolonged-release oral tablet) }\end{array}$ \\
\hline Outcomes & Pain reduction at least $40 \%$ in VAS scale \\
\hline Starting date & Not reported \\
\hline Contact information & $\begin{array}{l}\text { Location: Italy } \\
\text { Sponsors: Ospedale Policlinico S. Matteo } \\
\text { Principal investigators: Not reported }\end{array}$ \\
\hline Notes & $\begin{array}{l}\text { Target enrolment: } \mathrm{N}=320 \\
\text { Study completion date: ? but of 3-year duration } \\
\text { Other study ID numbers: None reported, but is it the same as NCT00916890NCT00916890 below? }\end{array}$ \\
\hline
\end{tabular}

\section{9-013118-28}

\section{Trial name or title}

Bukkaalinen fentanyyli syöpäpotilaiden toimenpidekivun hoidossa ("The buccal fentanyl in cancer pain management measure")

\begin{tabular}{ll}
\hline Methods & Randomised, cross-over (open or blind?) controlled trial \\
\hline Participants & Inclusion criteria: \\
& - Cancer metastatic to the bone \\
& - beginning radiotherapy to bone metastases (?) \\
& Exclusion criteria: \\
& - Severe hepatic, renal or cardiac dysfunction \\
& - uncontrolled or rapidly increasing pain \\
- dry mouth
\end{tabular}


2009-013118-28 (Continued)

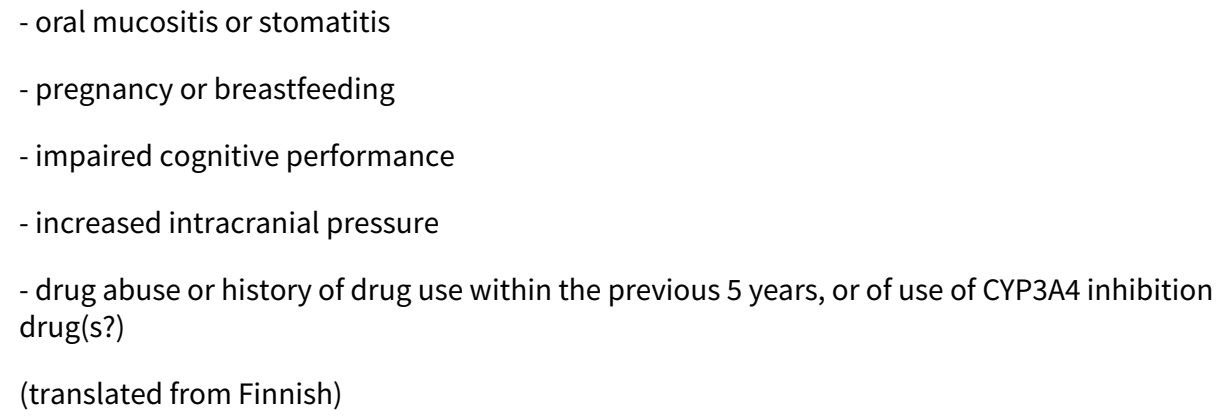

Outcomes

Pain relief and speed of effect for fentanyl compared to oxycodone, radiation therapy-related acute, short-term pain relief (translated from Finnish), side effects

\begin{tabular}{ll}
\hline Starting date & Not reported \\
\hline Contact information & Location: Finland \\
& Sponsors: Tarja Heiskanen \\
& Principal investigators: Not reported \\
\hline Notes & Target enrolment: $\mathrm{N}=?$ \\
& Study completion date: ? \\
& Other study ID numbers: None reported \\
\hline
\end{tabular}

\section{Elsayem 2010}

Trial name or title
Abstract (this is all the information in the record)

TPS324

Background: Methadone is an opioid with many unique pharmacologic properties and it is much less expensive than other opioids commonly used in cancer pain management. It is a particularly attractive analgesic to use for opioid switching, with the goal of improving analgesia and/or decreasing opioid-related side effects. Prospective trials involving methadone for opioid switching are uncommon in publicly-funded, clinical cooperative groups. This trial in progress will help determine the feasibility, safety, and efficacy of two approaches to opioid switching. It will also provide useful information regarding the feasibility of opioid-related research conducted by oncologists in the outpatient community setting.

Methods: This $\mathrm{NCl}$-funded, randomized, prospective, open-label trial intends to enroll 300 cancer patients in the outpatient community setting. Eligible patients have inadequate pain control and/ or intolerable opioid-related side effects and are prescribed either sustained-release morphine or oxycodone, with an oral morphine equivalent daily dose between $40 \mathrm{mg}$ and $300 \mathrm{mg}$. Patients are randomly assigned to be rotated to either oral methadone or oral sustained-release morphine or oxycodone, and the new opioid dose is determined using study-specific equianalgesic tables. $\mathrm{Pa}$ tients receive immediate-release opioids for breakthrough pain and supportive measures for side effects, and patients have their opioids titrated according to study protocol Evaluation occurs at enrollment and then weekly for a total of 4 weeks using validated tools that include: M. D. Anderson Symptom Inventory (MDASI), Composite Drug Toxicity Score (CDTS), and Revised Edmonton Staging System (rESS) for Cancer Pain. We hypothesize that $60 \%$ of patients rotated to methadone 
will achieve a $30 \%$ reduction in pain and/or opioid-related side effects; whereas $40 \%$ of patients rotated to either sustained-release morphine or oxycodone will achieve this response. We define primary success as a 3-point reduction in pain score-measured by MDASI-from baseline to completion of the study.

No significant financial relationships to disclose

\section{Methods}

Participants

Interventions

\section{Outcomes}

\begin{tabular}{ll}
\hline Starting date $2010 ?$ \\
\hline Contact information \\
\hline Notes \\
\hline
\end{tabular}

\section{JapicCTI-132338}

Trial name or title

DS-7113b phase III study

A randomized double-blind comparison study with immediate release (IR) oxycodone in opioid-naive patients with cancer pain

\begin{tabular}{ll}
\hline Methods & A multicentre, active controlled, randomised, double-blind, parallel-group study \\
\hline Participants & Inclusion criteria: \\
& - Both genders, aged $\geq 20$ years \\
& - Patients receiving non-opioid analgesics for cancer pain, who have not been receiving opioid \\
analgesics & - Patients whose VAS is $\geq 35$ mm and judged necessary to be treated with strong opioid analgesics \\
- Patients with an ECOG Performance Status (PS) $\leq 3$, etc \\
Exclusion criteria: \\
- Patients with symptom(s) or finding(s) falling under the contraindications or relative contraindi- \\
cations stated in the package insert for oxycodone hydrochloride powder and morphine hy- \\
drochloride preparations, etc
\end{tabular}

Interventions

\section{DS-7113b:}

Each participant will be administered 4 doses a day orally for 5 days, versus

Oxycodone hydrochloride powder:

Each participant will be administered 4 doses a day orally for 5 days

$\begin{array}{ll}\text { Outcomes } & \text { Primary outcome measures: } \\ \text { Change of VAS between pre-treatment and end of treatment } \\ \text { Secondary outcome measures: }\end{array}$


JapicCTI-132338 (Continued)

Response rate at end of treatment (analgesia improvement rate), efficacy and safety

\begin{tabular}{ll}
\hline Starting date & October 2013. \\
\hline Contact information & Location: Japan \\
& Sponsors, collaborators, investigators: Daiichi Sankyo Company, Limited \\
& Principal investigator: Not reported \\
\hline Notes & Target enrolment: Not reported \\
& Study completion date: 31 March 2015 \\
& Other study ID numbers: None reported \\
\hline
\end{tabular}

\section{NCT00916890}

Trial name or title

Chronic Administration of Opioids in Cancer Chronic Pain:an Open Prospective Study on Efficacy, Safety and Pharmacogenetic Factors Influence

\section{Methods}

Randomised (parallel group), single-blind (outcome assessor) controlled trial

$\begin{array}{ll}\text { Participants } & \text { Inclusion criteria: } \\ \text { - Adult oncologic patients ( } \geq 18 \text { years old) } \\ \text { - Chronic peripheral neuropathic or nociceptive pain, or both } \\ \text { - Written informed consent } \\ \text { Exclusion criteria: } \\ \text { - Pediatric patients } \\ \text { - Mental impaired patients } \\ \text { - Substance abuse disorder } \\ \text { - Opioid allergy } \\ \text { - History of opioids use or addiction } \\ \text { - Severe immunodeficiency, severe renal impairment, severe liver disease } \\ \text { - Cachectic state } \\ \text { - HIV positive patients }\end{array}$

Interventions

Morphine (after a titration phase with fast-release oral morphine, once the optimal dosage (no side effects and less than two rescue doses per day) is reached, an equipotent dose of oral sustained-release morphine will be randomly assigned to a participant) versus

oxycodone (after a titration phase with fast-release oral morphine, once the optimal dosage (no side effects and less than two rescue doses per day) is reached, an equipotent dose of oral extended-release oxycodone will be randomly assigned to a participant) versus

fentanyl (after a titration phase with fast-release oral morphine, once the optimal dosage (no side effects and less than two rescue doses per day) is reached, an equipotent dosage of transdermal fentanyl will be randomly assigned to a participant) versus 
NCT00916890 (Continued)

buprenorphine (after a titration phase with fast-release oral morphine, once the optimal dosage (no side effects and less than two rescue doses per day) is reached, an equipotent dosage of transdermal buprenorphine will be randomly assigned to a participant)

\section{Outcomes}

\section{Primary outcome measures:}

- To identify the drug with the best clinical-pharmacological safety-efficacy profile among the four opioids: oral extended-release morphine, oral extended-release oxycodone, transdermal fentanyl and transdermal buprenorphine. (Time frame: 15 days after randomisation (Reduction of at least $40 \%$ of median daily pain, on a NRS))

"We will define a treatment effective if it will produce a mean reduction of NRS values at least of $40 \%$ than basal values. Among all effective treatments, we will identify the best as the one that will have a reduction of NRS to a value of 4 or less in $90 \%$ of participants compared to the $70 \%$ of the others treatments. To evaluate pharmacological safety the plasma concentrations of the drugs and their metabolites will be measured. We will branch participants population in 3 groups to evaluate the correlation between clinical-pharmacological response and genetics (responder,partially and not responder)."

\section{Secondary outcome measures:}

- Pharmacokinetic of opioids and of their metabolites during long-term administration; correlation between specific genotypes and clinical response or the clinical/pharmacological susceptibility to side-effects on administration of a specific opioid. (Time frame: 6 months (each participant will be followed for 6 month after enrolment with clinical and pharmacological evaluations once a month and if inefficacy, tolerance or side effects))

- Comparison of plasma levels of opioids and of their metabolites in 'responder' participants (clinical effectiveness without side effects), 'partial responder' participants (clinical effectiveness without side effects but taking not more than 2 rescue doses per day), and in 'non-responder' participants ( 3 groups: clinical inefficacy, side effects, tolerance or opioid induced hyperalgesia). Evaluation of the correlation between the polymorphisms studied and clinical response; the frequency of allelic variants of interest will be compared in 'responder', 'partial responder' and 'non-responder'

Starting date $\quad$ February 2009

Contact information

Location: Italy

Sponsors, collaborators, investigators: IRCCS Policlinico S. Matteo, University of Pavia, Italy

Principal investigator: Massimo Allegri, IRCCS Foundation Policlinico "San Matteo", Pavia, Italy; email: m.allegri@smatteo.pv.it, Tel: 00390382502627

Notes

Target enrolment: $\mathrm{N}=320$

Study completion date: December 2015

Other study ID numbers: PT-SM-1-Op-Cancer

\section{NCT01165281}

Trial name or title
A Randomized, Double-Blind, Active Controlled, Optimal Dose Titration, Multicenter Study to Evaluate the Safety and Efficacy of Oral JNS024 Extended Release (ER) in Japanese and Korean Subjects With Moderate to Severe Chronic Malignant Tumor Related Cancer Pain

\section{Methods}

Participants
Randomised (parallel-group), double-blind (participant, caregiver, investigator) controlled trial

Inclusion criteria:

- Aged $\geq 20$ years 
- Diagnosis of chronic malignant tumour-related cancer pain with an average score for pain intensity in the past 24 hours of $\geq 4$ on the 11-point numerical rating scale (NRS) on the day of randomisation (Day -1)

- Have not received treatment with opioid analgesics within 28 days before screening (note: codeine phosphate $(\leq 60 \mathrm{mg} / \mathrm{d})$ or dihydrocodeine phosphate $(\leq 30 \mathrm{mg} / \mathrm{d})$ for antitussive use are allowed)

- Dissatisfied with pain relief by the current treatment and for whom the investigator or designee judges that treatment with opioid analgesics is required

\section{Exclusion criteria:}

- Have complicated with uncontrolled or clinically significant arrhythmia

- Have previous or concurrent presence of any disease which may develop increased intracranial pressure, disturbance of consciousness, lethargy, or respiratory problems such as traumatic encephalopathy with cerebral contusion, intracranial hematoma, disturbance of consciousness, brain tumour, cerebral infarction, transient ischemic attack, epilepsy or convulsive diseases

- Have history of alcohol or drug abuse

- Have any disease for which opioids are contraindicated such as serious respiratory depression of serious chronic obstructive pulmonary disease, bronchial asthma attack, cardiac failure secondary to chronic pulmonary disease, paralytic ileus, status epileptics, tetanus, strychnine poisoning, acute alcohol poisoning, hypersensitivity to opium alkaloid, haemorrhagic colitis, or bacterial diarrhoea

Interventions R331333 ((referred to as JNS024 ER or CG5503) one $25 \mathrm{mg}$ to $200 \mathrm{mg}$ capsule twice daily for 4 weeks) versus

Oxycodone CR (one $5 \mathrm{mg}$ to $40 \mathrm{mg}$ capsule twice daily for 4 weeks)

Primary outcome measures:

- The average pain intensity score using an 11-point numerical rating scale (NRS) (timeframe: change from baseline to the last 3 days of study drug administration) Secondary outcome measures:

- The Patient Global Impression of Change (PGIC) (time frame: at the end of the 4-week double-blind treatment phase)

- The duration of rescue medication (time frame: during the 4-week double-blind treatment phase)

- The concentration of JNS024 in blood samples from participants (time frame: protocol-specified time points during Weeks 1,2 , and 4 )

- The proportion of participants responding to treatment, including at least $30 \%$ and $50 \%$, based on the per cent change from baseline using an 11-point numerical rating score (NRS) (timeframe: at Week 4 of the double-blind treatment phase on an 11-point NRS)

- Adverse events and findings from clinical laboratory tests, physical examinations, vital signs measurements, and ECG measurements reported (time frame: from time of screening (Days -7 to -1 ) to post-treatment (Week 5) or time of early termination from study)

\begin{tabular}{ll}
\hline Starting date & August 2012 \\
\hline Contact information & Location: Japan, Republic of Korea \\
& Sponsors, collaborators, investigators, study director: Janssen Research \& Development, L.L.C. \\
& Clinical Trial (no other contact information reported) \\
\hline Notes & Target enrolment: $\mathrm{N}=343$ \\
& Study completion date: August 2012 \\
\hline
\end{tabular}


NCT01675622

Trial name or title
A Comparative Study of Immediate-Release Oxycodone Capsules Versus Immediate-Release Morphine Tablets for the Treatment of Chinese Patients With Cancer Pain.
Randomised, parallel-group, double (triple?)-blind (participant, care-giver, investigator, outcome-assessor) controlled trial

Participants

Inclusion criteria:

- Patients of either sex aged 18 to 80 years inclusive, with cancers of all types

- Patients with moderate to severe cancer pain, whose pain intensity NRS $\geq 4$

- Patients who can understand and are able to complete NRS and BPI assessment

- Patients who have given written informed consent to participate in the study

Exclusion criteria:

- Patients who are pregnant, or lactating

- Patients who are unable to manage their pain effectively with opioids

- Patient who need $\geq 120 \mathrm{mg}$ morphine or equivalent for treatment of pain at time of study entry

- Patients who are receiving chemotherapy, or still under the responsive period of chemotherapy (patients who are at the interval period of chemotherapy can be enrolled into study. That is to say, patients who completed chemotherapy for more than 2 weeks can enrolled, or patients has completed chemotherapy for at least one week could be enrolled at the discretion of the investigator)

- Patients who have received radiotherapy for bony metastasis, patients receiving radiotherapy within the 4-week period before study entry (patient receiving radiotherapy for area other than pain area can be enrolled), or patients who were scheduled to receive radiotherapy for pain area during study period

- Patients are receiving or should receive anticonvulsive drugs or antidepressant drugs considered by investigator for the treatment of neuropathy pain

- Patients are receiving or should receive any analgesic other than study medicine, including NSAIDS

- Patients with other unstable disease, or with dysfunction of important organ

- Patients with an ongoing infection, abscess or fever

- Patient with serious abnormal liver or renal function (ALT, AST, creatinine, urea nitrogen) which is higher than 3 times upper limit

- Paralytic or mechanical ileus

- Persistent asthma, chronic obstructive diseases, and cor pulmonary

- Intracranial neoplasms, and intracranial hypertension with central respiratory depression risk

- Monoamine oxidase inhibitors (MAOIs) or same type drugs have been administered in last 2 weeks

- Patients who are currently taking active treatment for epilepsy or arrhythmias

- Patients with known sensitivity or record of specific or allergic reaction to oxycodone or morphine 
- Patients excluded by the contra-indications, adverse drug reaction (ADRs) and drug interactions of oxycodone or morphine as detailed in the data sheet, summary of product characteristics or investigator's brochure

- Patients with a history of drug or alcohol abuse

- Patients who participated in another clinical research study involving a new chemical entity within one month prior to study entry

- Patients whose concomitant medication is likely to be changed within the study period, with the exception of treatment for opioid side effects

- Patients who, in the opinion of the investigator, are unsuitable to participate in the study for any other reason not mentioned in the inclusion and exclusion criteria

Interventions

Oxycodone ( $5 \mathrm{mg}, 10 \mathrm{mg}$ and $20 \mathrm{mg}$ capsules every $6 \mathrm{~h}, 5$ to 8 days) versus

morphine (tablets $10 \mathrm{mg}$ and $20 \mathrm{mg}$, oral every 4 to 6 hours)

\section{Outcomes}

\section{Primary outcome measures:}

- NRS (Numerical Rating Scale) score (time frame: 5 to 8 days). To compare the average for decrease of NRS score after double-blind treatment between the two treatment groups

- The average dose of study medicine used during double blind treatment period (time frame: 5 to 8 days). To compare the average dose of study medicine used during double-blind treatment period between the two treatment groups Secondary outcome measures:

- BPI (Brief pain inventory) (time frame: 19 to 22 days). To compare BPI score at baseline, after completion of double-blind treatment and open-label treatment to baseline between the two treatment groups

- Times and frequency of breakthrough pain and the total dose of rescue medicine for breakthrough pain (time frame: 19 to 22 days). To compare the times and frequency of breakthrough pain and the total dose of rescue medicine for breakthrough pain during double-blind phase between the two treatment groups

- Participant assessments of satisfaction for pain management (time frame: 19 to 22 days). To compare participant assessments of satisfaction for pain management between the two treatment groups at the end of double-blind treatment and the open-label treatment period

- Average time for titration (time frame: 1 to 3 days). To compare the average time for titration between the two treatment groups

Starting date December 2010

Contact information Location: China

Sponsors, collaborators: Mundipharma

Principal investigator: Shiying Yu, Wuhan Tong Ji Hospital

Notes Target enrolment: $\mathrm{N}=240$

Study completion date: July 2012

Other study ID numbers: OXYC10-CN-303

\section{NCT02084355}

Trial name or title

Efficacy and Safety of Opioid Rotation Compared With Opioid Dose Escalation in Patients With Moderate to Severe Cancer Pain - Open Label, Randomized, Prospective Study 
NCT02084355 (Continued)

Methods Open-label, randomised, prospective study

Participants

Inclusion criteria:

- age $>18$ years

- patients who are being treated with one of strong opioids including oral oxycodone, oral hydromorphone, or fentanyl patch with range from $60 \mathrm{mg}$ to $200 \mathrm{mg}$ of oral morphine equivalent daily dose (MEDD)

- moderate to severe cancer pain (numeric rating scale more than 3 ) at screening

- patients without uncontrolled adverse effects associated with currently applied opioid

\section{Exclusion criteria:}

- previous opioid rotation

- unable to take oral medication

- life expectancy less than a month

- newly started chemotherapy or radiotherapy within past 2 weeks of screening

- serum aspartate aminotransferase, alanine aminotransferase, or alkaline phosphatase $>2.5$ times upper normal limit

- serum total bilirubin or creatinine $>1.5$ times of upper normal limit

\section{Opioid rotation:}

Participants who are randomised to opioid rotation are treated with strong opioid other than currently used strong opioid (reduce the dose by $25 \%$ to $50 \%$ to allow for incomplete cross-tolerance between different opioids):

Oral oxycodone: convert to oral hydromorphone or fentanyl patch

Oral hydromorphone: convert to oral oxycodone or fentanyl patch

Fentanyl patch: convert to oral oxycodone or oral hydromorphone versus

opioid dose escalation:

Participants who are randomised to opioid dose escalation will be treated cancer pain by escalation dose of same strong opioid:

Oral oxycodone: maintain oral oxycodone and titrate the dose

Oral hydromorphone: maintain oral hydromorphone and titrate the dose

Fentanyl patch: maintain fentanyl patch and titrate the dose

Outcomes

Primary outcome measures:

The rate of successful pain control defined as a 30\% or 2-point reduction in the numeric rating scale (time frame: 18 months). (Designated as safety issue: Yes)

$$
\text { Starting date }
$$

Contact information
April 2014

Location: Republic of Korea

Sponsors, collaborators: Gyeongsang National University Hospital 
NCT02084355 (Continued)

Principal investigator/contact: Se-Il Go, M.D., tel@ +82 557509454 ext 9454, e-mail: gose1@hanmail.net

\begin{tabular}{ll}
\hline Notes & Target enrolment: $\mathrm{N}=136$ \\
& Study completion date: January 2016 \\
& Other study ID numbers: GNUH-2013-07-014
\end{tabular}

UMIN000011756

\begin{tabular}{ll}
\hline Trial name or title & $\begin{array}{l}\text { Randomized study of fentanyl citrate versus Oxycodone Hydrochloride Hydrate in patients with un- } \\
\text { resectable advanced pancreatic cancer (FRONTIER) }\end{array}$ \\
\hline Methods & Randomised, single arm (?), phase III, open trial \\
\hline Participants & Inclusion criteria: \\
& - Aged 20 to $<100$ years \\
& - unresectable advanced pancreatic cancer \\
& $-\geq 15$ to 25 mg oxycodone hydrochloride hydrate per day required for cancer pain \\
& Exclusion criteria: \\
& - Serious liver, kidney, cardiac disorders \\
& - pulmonary impairment \\
& - nervous system and psychic disorders
\end{tabular}

Interventions

Oxycodone hydrochloride hydrate: $10 \mathrm{mg}$ every 12 hours, versus

Transdermal fentanyl citrate: $1 \mathrm{mg}$ once a day

\begin{tabular}{|c|c|}
\hline \multirow[t]{4}{*}{ Outcomes } & Primary outcome measures: \\
\hline & The rates of gastrointestinal disorders events in four weeks \\
\hline & Secondary outcome measures: \\
\hline & $\begin{array}{l}\text { Quality of life, rates of opioid rotation, pain score, time until stable pain control, overall survival } \\
\text { time, adverse events }\end{array}$ \\
\hline Starting date & 27 March 2014 \\
\hline \multirow[t]{3}{*}{ Contact information } & Location: Japan \\
\hline & $\begin{array}{l}\text { Sponsors, collaborators: National Cancer Center Hospital East; Welfare labor science research cost } \\
\text { (MHLW(Japan)) }\end{array}$ \\
\hline & $\begin{array}{l}\text { Principal investigator/contact: Minori Odanaka, Clinical Trial Support Office, National Cancer } \\
\text { Center Hospital, Tsukiji 5-1-1, Chuo-ku, Tokyo 104-0045, Japan Tel: +81-3-3547-5201, e-mails: } \\
\text { minochant23@yahoo.co.jp; modanaka@ncc.go.jp }\end{array}$ \\
\hline \multirow[t]{3}{*}{ Notes } & Target enrolment: $\mathrm{N}=80$ \\
\hline & Study completion date: Not reported \\
\hline & Other study ID numbers: None reported \\
\hline
\end{tabular}


ALT: alanine transaminase; AST: aspartate aminotransferase; BPI: Brief Pain Inventory; CR: controlled-release; ECG: electrocardiogram; ECOG: Eastern Cooperative Oncology Group; NRS: numerical rating scale; VAS: visual analogue scale.

\section{DATA AND ANALYSES}

\section{Comparison 1. Pain}

\begin{tabular}{|c|c|c|c|c|}
\hline Outcome or subgroup title & No. of studies & $\begin{array}{l}\text { No. of partici- } \\
\text { pants }\end{array}$ & Statistical method & Effect size \\
\hline 1 Pain intensity and pain relief & 17 & & $\begin{array}{l}\text { Std. Mean Difference (IV, Fixed, } \\
95 \% \mathrm{Cl})\end{array}$ & Subtotals only \\
\hline $\begin{array}{l}\text { 1.1 Controlled-release (CR) oxy- } \\
\text { codone vs immediate-release (IR) } \\
\text { oxycodone }\end{array}$ & 3 & 578 & $\begin{array}{l}\text { Std. Mean Difference (IV, Fixed, } \\
95 \% \mathrm{Cl} \text { ) }\end{array}$ & $0.10[-0.06,0.26]$ \\
\hline $\begin{array}{l}1.2 \text { CR oxycodone vs extended-re- } \\
\text { lease (ER) oxycodone }\end{array}$ & 1 & 62 & $\begin{array}{l}\text { Std. Mean Difference (IV, Fixed, } \\
95 \% \mathrm{Cl})\end{array}$ & $0.08[-0.42,0.57]$ \\
\hline 1.3 CR oxycodone vs CR morphine & 7 & 882 & $\begin{array}{l}\text { Std. Mean Difference (IV, Fixed, } \\
95 \% \mathrm{CI} \text { ) }\end{array}$ & $0.14[0.01,0.27]$ \\
\hline $\begin{array}{l}1.4 \text { CR oxycodone vs CR hydromor- } \\
\text { phone }\end{array}$ & 1 & 62 & $\begin{array}{l}\text { Std. Mean Difference (IV, Fixed, } \\
95 \% \mathrm{CI} \text { ) }\end{array}$ & $-0.13[-0.63,0.37]$ \\
\hline $\begin{array}{l}1.5 \text { CR oxycodone vs ER hydromor- } \\
\text { phone }\end{array}$ & 1 & 81 & $\begin{array}{l}\text { Std. Mean Difference (IV, Fixed, } \\
95 \% \mathrm{Cl} \text { ) }\end{array}$ & $0.10[-0.34,0.54]$ \\
\hline $\begin{array}{l}1.6 \text { CR oxycodone vs ER oxymor- } \\
\text { phone }\end{array}$ & 1 & 74 & $\begin{array}{l}\text { Std. Mean Difference (IV, Fixed, } \\
95 \% \mathrm{CI})\end{array}$ & $0.23[-0.23,0.69]$ \\
\hline 1.7 CR oxycodone vs ER tapentadol & 1 & 265 & $\begin{array}{l}\text { Std. Mean Difference (IV, Fixed, } \\
95 \% \mathrm{CI} \text { ) }\end{array}$ & $-0.06[-0.30,0.18]$ \\
\hline $\begin{array}{l}\text { 1.8 CR oxycodone vs transdermal } \\
\text { (TD) fentanyl }\end{array}$ & 2 & 329 & $\begin{array}{l}\text { Std. Mean Difference (IV, Fixed, } \\
95 \% \mathrm{CI} \text { ) }\end{array}$ & $0.02[-0.19,0.24]$ \\
\hline $\begin{array}{l}1.9 \text { CR oxycodone vs TD buprenor- } \\
\text { phine }\end{array}$ & 1 & 252 & $\begin{array}{l}\text { Std. Mean Difference (IV, Fixed, } \\
95 \% \mathrm{CI} \text { ) }\end{array}$ & $0.10[-0.15,0.35]$ \\
\hline 1.10 IR oxycodone vs IR morphine & 1 & 38 & $\begin{array}{l}\text { Std. Mean Difference (IV, Fixed, } \\
95 \% \mathrm{CI})\end{array}$ & $-0.15[-0.79,0.49]$ \\
\hline
\end{tabular}

Analysis 1.1. Comparison 1 Pain, Outcome 1 Pain intensity and pain relief.

\begin{tabular}{|c|c|c|c|c|c|c|c|}
\hline \multirow[t]{2}{*}{ Study or subgroup } & \multicolumn{2}{|c|}{ Oxycodone } & \multicolumn{2}{|c|}{ Comparison } & \multirow{2}{*}{$\begin{array}{c}\text { Std. Mean Difference } \\
\text { Fixed, } 95 \% \mathrm{Cl}\end{array}$} & \multirow[t]{2}{*}{ Weight } & \multirow{2}{*}{$\begin{array}{c}\text { Std. Mean Difference } \\
\text { Fixed, } 95 \% \mathrm{Cl}\end{array}$} \\
\hline & $\mathbf{N}$ & $\operatorname{Mean}(S D)$ & $\mathbf{N}$ & $\operatorname{Mean}(S D)$ & & & \\
\hline \multicolumn{8}{|c|}{ 1.1.1 Controlled-release (CR) oxycodone vs immediate-release (IR) oxycodone } \\
\hline Kaplan 1998 & 156 & $1.3(1.3)$ & 156 & $1.3(1.3)$ & - & $54.19 \%$ & $0[-0.22,0.22]$ \\
\hline Parris 1998 & 103 & $1.4(1)$ & 103 & $1.1(1)$ & 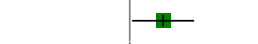 & $35.39 \%$ & $0.3[0.02,0.57]$ \\
\hline Stambaugh 2001 & 30 & $2.7(1.9)$ & 30 & $2.8(1.9)$ & - & $10.42 \%$ & $-0.05[-0.56,0.45]$ \\
\hline
\end{tabular}




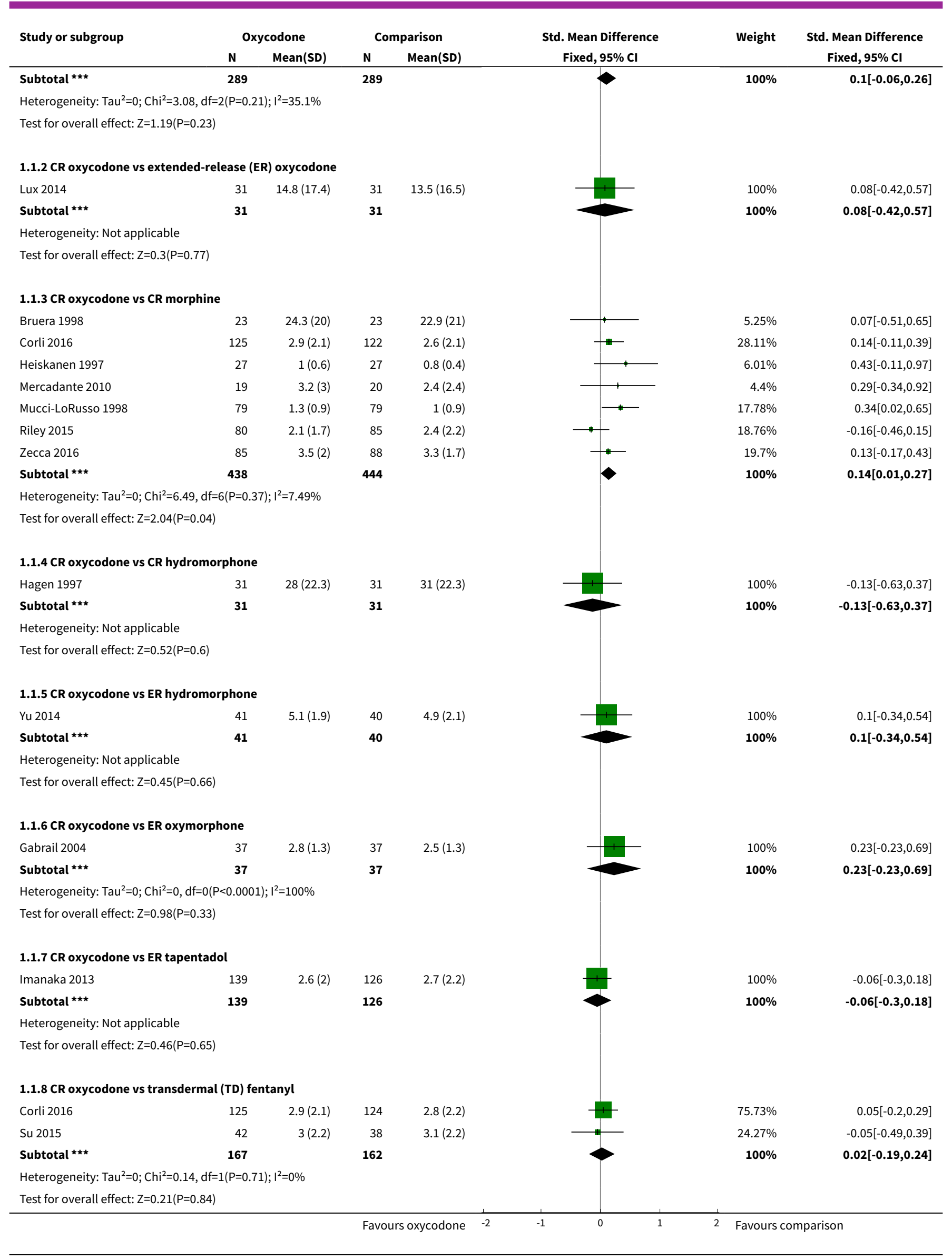

Oxycodone for cancer-related pain (Review) 


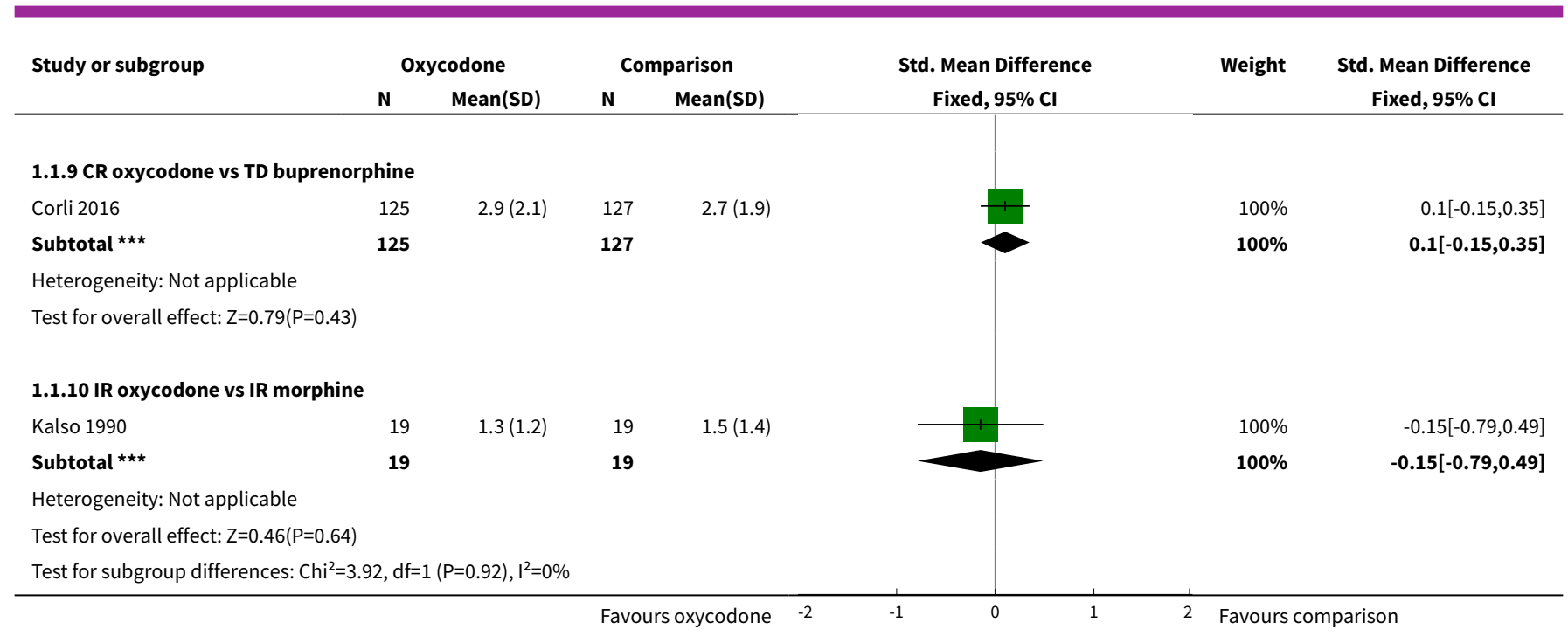

\section{Comparison 2. Adverse events}

\begin{tabular}{|c|c|c|c|c|}
\hline Outcome or subgroup title & No. of studies & $\begin{array}{l}\text { No. of partici- } \\
\text { pants }\end{array}$ & Statistical method & Effect size \\
\hline 1 Any adverse events & 3 & & Risk Ratio (M-H, Fixed, 95\% Cl) & Subtotals only \\
\hline $\begin{array}{l}1.1 \text { Controlled-release (CR) } \\
\text { oxycodone vs CR morphine }\end{array}$ & 3 & 399 & Risk Ratio (M-H, Fixed, 95\% Cl) & $0.97[0.87,1.09]$ \\
\hline 2 Asthenia & 2 & & Risk Ratio (M-H, Fixed, 95\% Cl) & Subtotals only \\
\hline $\begin{array}{l}2.1 \mathrm{CR} \text { oxycodone vs immedi- } \\
\text { ate-release (IR) oxycodone }\end{array}$ & 2 & 208 & Risk Ratio (M-H, Fixed, 95\% Cl) & $0.58[0.20,1.68]$ \\
\hline 3 Confusion & 5 & & Risk Ratio (M-H, Fixed, 95\% Cl) & Subtotals only \\
\hline $\begin{array}{l}\text { 3.1 CR oxycodone vs IR oxy- } \\
\text { codone }\end{array}$ & 2 & 157 & Risk Ratio (M-H, Fixed, 95\% Cl) & $0.78[0.20,3.02]$ \\
\hline $\begin{array}{l}3.2 \text { CR oxycodone vs CR mor- } \\
\text { phine }\end{array}$ & 3 & 584 & Risk Ratio (M-H, Fixed, 95\% Cl) & $1.01[0.78,1.31]$ \\
\hline 4 Constipation & 9 & & Risk Ratio (M-H, Fixed, 95\% Cl) & Subtotals only \\
\hline $\begin{array}{l}4.1 \text { CR oxycodone vs IR oxy- } \\
\text { codone }\end{array}$ & 3 & 317 & Risk Ratio (M-H, Fixed, 95\% Cl) & $0.71[0.45,1.13]$ \\
\hline $\begin{array}{l}4.2 \mathrm{CR} \text { oxycodone vs CR mor- } \\
\text { phine }\end{array}$ & 5 & 797 & Risk Ratio (M-H, Fixed, 95\% Cl) & $0.98[0.82,1.16]$ \\
\hline $\begin{array}{l}\text { 4.3 CR oxycodone vs transder- } \\
\text { mal (TD) fentanyl }\end{array}$ & 2 & 336 & Risk Ratio (M-H, Fixed, 95\% Cl) & $1.07[0.88,1.32]$ \\
\hline 5 Dizziness/lightheadedness & 6 & & Risk Ratio (M-H, Fixed, 95\% Cl) & Subtotals only \\
\hline
\end{tabular}




\begin{tabular}{|c|c|c|c|c|}
\hline Outcome or subgroup title & No. of studies & $\begin{array}{l}\text { No. of partici- } \\
\text { pants }\end{array}$ & Statistical method & Effect size \\
\hline $\begin{array}{l}\text { 5.1 CR oxycodone vs IR oxy- } \\
\text { codone }\end{array}$ & 3 & 317 & Risk Ratio (M-H, Fixed, 95\% CI) & $0.74[0.40,1.37]$ \\
\hline $\begin{array}{l}5.2 \text { CR oxycodone vs CR mor- } \\
\text { phine }\end{array}$ & 3 & 367 & Risk Ratio (M-H, Fixed, 95\% Cl) & $0.76[0.33,1.76]$ \\
\hline 6 Drowsiness/somnolence & 8 & & Risk Ratio (M-H, Fixed, 95\% CI) & Subtotals only \\
\hline $\begin{array}{l}\text { 6.1 CR oxycodone vs IR oxy- } \\
\text { codone }\end{array}$ & 3 & 317 & Risk Ratio (M-H, Fixed, 95\% Cl) & $1.03[0.69,1.54]$ \\
\hline $\begin{array}{l}6.2 \text { CR oxycodone vs CR mor- } \\
\text { phine }\end{array}$ & 5 & 798 & Risk Ratio (M-H, Fixed, 95\% Cl) & $0.90[0.75,1.08]$ \\
\hline 7 Dry mouth & 7 & & Risk Ratio (M-H, Fixed, 95\% Cl) & Subtotals only \\
\hline $\begin{array}{l}\text { 7.1 CR oxycodone vs IR oxy- } \\
\text { codone }\end{array}$ & 3 & 317 & Risk Ratio (M-H, Fixed, 95\% Cl) & $1.14[0.48,2.75]$ \\
\hline $\begin{array}{l}7.2 \text { CR oxycodone vs CR mor- } \\
\text { phine }\end{array}$ & 4 & 684 & Risk Ratio (M-H, Fixed, 95\% Cl) & $1.01[0.80,1.26]$ \\
\hline 8 Dysuria & 3 & & Risk Ratio (M-H, Fixed, 95\% CI) & Subtotals only \\
\hline $\begin{array}{l}\text { 8.1 CR oxycodone vs CR mor- } \\
\text { phine }\end{array}$ & 2 & 372 & Risk Ratio (M-H, Fixed, 95\% Cl) & $0.71[0.40,1.26]$ \\
\hline $\begin{array}{l}\text { 8.2 CR oxycodone vs TD fen- } \\
\text { tanyl }\end{array}$ & 2 & 336 & Risk Ratio (M-H, Fixed, 95\% Cl) & $1.15[0.62,2.16]$ \\
\hline 9 Hallucinations & 4 & & Risk Ratio (M-H, Fixed, 95\% CI) & Subtotals only \\
\hline $\begin{array}{l}\text { 9.1 CR oxycodone vs CR mor- } \\
\text { phine }\end{array}$ & 4 & 696 & Risk Ratio (M-H, Fixed, 95\% Cl) & $0.52[0.28,0.97]$ \\
\hline 10 Headache & 3 & & Risk Ratio (M-H, Fixed, 95\% CI) & Subtotals only \\
\hline $\begin{array}{l}\text { 10.1 CR oxycodone vs IR oxy- } \\
\text { codone }\end{array}$ & 3 & 317 & Risk Ratio (M-H, Fixed, 95\% Cl) & $0.83[0.34,2.02]$ \\
\hline 11 Insomnia & 2 & & Risk Ratio (M-H, Fixed, 95\% Cl) & Subtotals only \\
\hline $\begin{array}{l}11.1 \text { CR oxycodone vs IR oxy- } \\
\text { codone }\end{array}$ & 2 & 269 & Risk Ratio (M-H, Fixed, 95\% Cl) & $1.04[0.31,3.53]$ \\
\hline 12 Nausea & 8 & & Risk Ratio (M-H, Fixed, 95\% CI) & Subtotals only \\
\hline $\begin{array}{l}\text { 12.1 CR oxycodone vs IR oxy- } \\
\text { codone }\end{array}$ & 3 & 317 & Risk Ratio (M-H, Fixed, 95\% Cl) & $0.85[0.56,1.28]$ \\
\hline $\begin{array}{l}12.2 \text { CR oxycodone vs CR mor- } \\
\text { phine }\end{array}$ & 5 & 798 & Risk Ratio (M-H, Fixed, 95\% Cl) & $1.02[0.82,1.26]$ \\
\hline 13 Nervousness & 2 & & Risk Ratio (M-H, Fixed, 95\% Cl) & Subtotals only \\
\hline
\end{tabular}




\begin{tabular}{|c|c|c|c|c|}
\hline Outcome or subgroup title & No. of studies & $\begin{array}{l}\text { No. of partici- } \\
\text { pants }\end{array}$ & Statistical method & Effect size \\
\hline $\begin{array}{l}\text { 13.1 CR oxycodone vs IR oxy- } \\
\text { codone }\end{array}$ & 2 & 208 & Risk Ratio (M-H, Fixed, 95\% Cl) & $0.57[0.20,1.64]$ \\
\hline 14 Pruritus & 7 & & Risk Ratio (M-H, Fixed, 95\% Cl) & Subtotals only \\
\hline $\begin{array}{l}\text { 14.1 CR oxycodone vs IR oxy- } \\
\text { codone }\end{array}$ & 3 & 317 & Risk Ratio (M-H, Fixed, 95\% Cl) & $1.46[0.65,3.25]$ \\
\hline $\begin{array}{l}\text { 14.2 CR oxycodone vs CR mor- } \\
\text { phine }\end{array}$ & 4 & 684 & Risk Ratio (M-H, Fixed, 95\% Cl) & $0.81[0.51,1.29]$ \\
\hline 15 Sweating & 2 & & Risk Ratio (M-H, Fixed, 95\% Cl) & Subtotals only \\
\hline $\begin{array}{l}\text { 15.1 CR oxycodone vs IR oxy- } \\
\text { codone }\end{array}$ & 2 & 269 & Risk Ratio (M-H, Fixed, 95\% Cl) & $0.65[0.22,1.93]$ \\
\hline 16 Vomiting & 8 & & Risk Ratio (M-H, Fixed, 95\% Cl) & Subtotals only \\
\hline $\begin{array}{l}\text { 16.1 CR oxycodone vs IR oxy- } \\
\text { codone }\end{array}$ & 3 & 317 & Risk Ratio (M-H, Fixed, 95\% Cl) & $0.66[0.38,1.15]$ \\
\hline $\begin{array}{l}\text { 16.2 CR oxycodone vs CR mor- } \\
\text { phine }\end{array}$ & 5 & 798 & Risk Ratio (M-H, Fixed, 95\% Cl) & $0.94[0.68,1.29]$ \\
\hline $\begin{array}{l}17 \text { Discontinuation due to ad- } \\
\text { verse events }\end{array}$ & 6 & & Risk Ratio (M-H, Fixed, 95\% Cl) & Subtotals only \\
\hline $\begin{array}{l}\text { 17.1 CR oxycodone vs IR oxy- } \\
\text { codone }\end{array}$ & 3 & 317 & Risk Ratio (M-H, Fixed, 95\% Cl) & $0.60[0.29,1.22]$ \\
\hline $\begin{array}{l}17.2 \text { CR oxycodone vs CR mor- } \\
\text { phine }\end{array}$ & 3 & 399 & Risk Ratio (M-H, Fixed, 95\% Cl) & $1.06[0.43,2.60]$ \\
\hline
\end{tabular}

Analysis 2.1. Comparison 2 Adverse events, Outcome 1 Any adverse events.

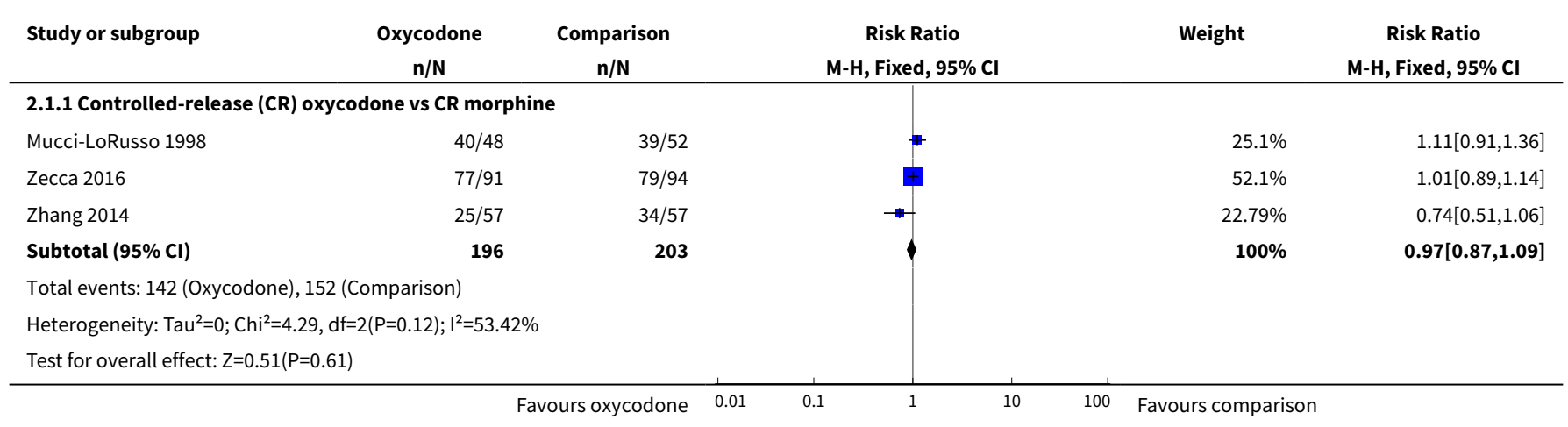


Analysis 2.2. Comparison 2 Adverse events, Outcome 2 Asthenia.

\begin{tabular}{|c|c|c|c|c|c|}
\hline Study or subgroup & $\begin{array}{c}\text { Oxycodone } \\
n / N\end{array}$ & $\begin{array}{c}\text { Comparison } \\
n / N\end{array}$ & $\begin{array}{c}\text { Risk Ratio } \\
\text { M-H, Fixed, 95\% Cl }\end{array}$ & Weight & \multirow[t]{2}{*}{$\begin{array}{c}\text { Risk Ratio } \\
\text { M-H, Fixed, 95\% Cl }\end{array}$} \\
\hline \multicolumn{3}{|c|}{ 2.2.1 CR oxycodone vs immediate-release (IR) oxycodone } & & & \\
\hline Kaplan 1998 & $3 / 78$ & $8 / 82$ & - & $88.64 \%$ & $0.39[0.11,1.43]$ \\
\hline Salzman 1999 & $2 / 24$ & $1 / 24$ & $\longrightarrow$ & $11.36 \%$ & $2[0.19,20.61]$ \\
\hline Subtotal $(95 \% \mathrm{Cl})$ & 102 & 106 & 一 & $100 \%$ & $0.58[0.2,1.68]$ \\
\hline \multicolumn{6}{|c|}{ Total events: 5 (Oxycodone), 9 (Comparison) } \\
\hline \multicolumn{2}{|c|}{ Test for overall effect: $Z=1.01(P=0.31)$} & & & & \\
\hline
\end{tabular}

Analysis 2.3. Comparison 2 Adverse events, Outcome 3 Confusion.

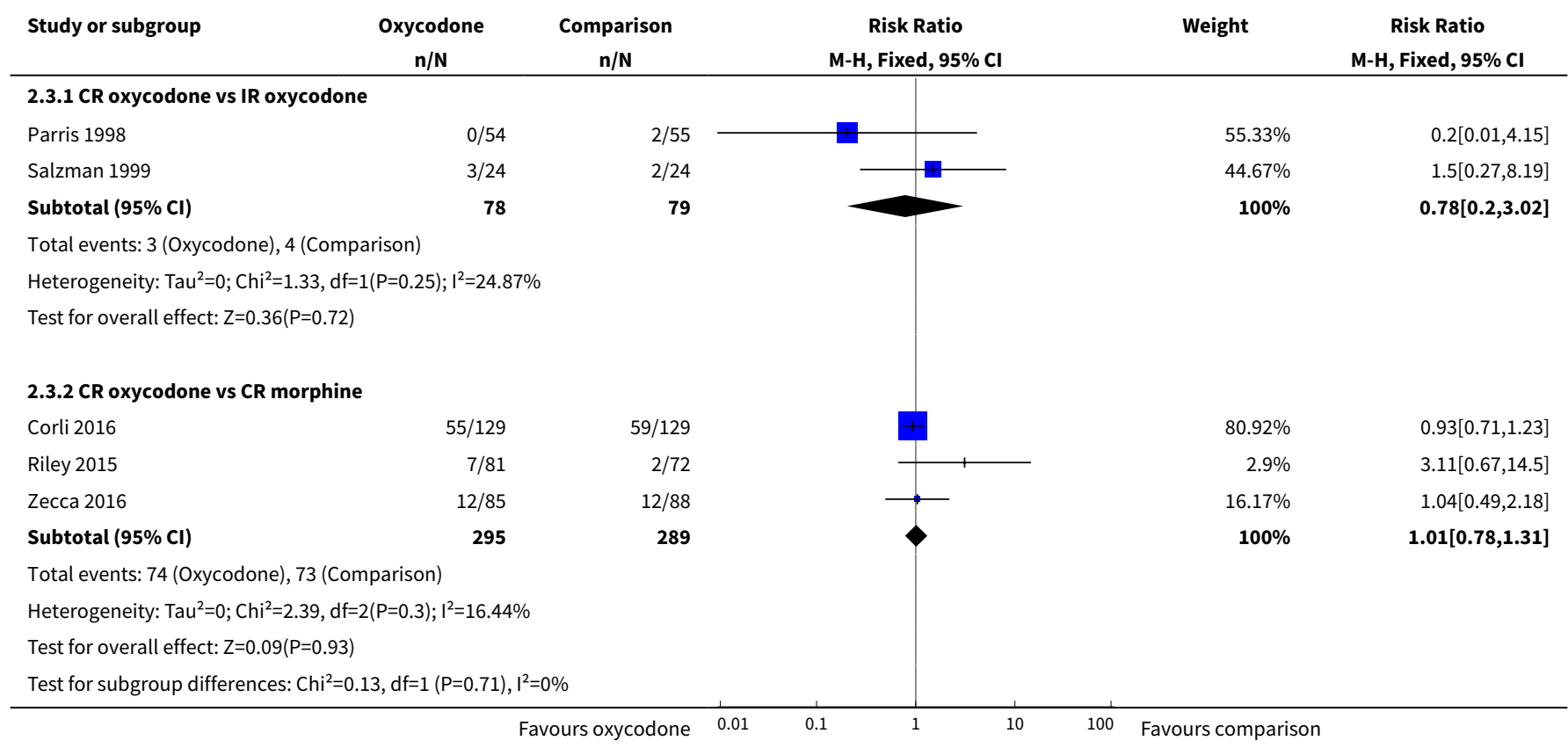

Analysis 2.4. Comparison 2 Adverse events, Outcome 4 Constipation.

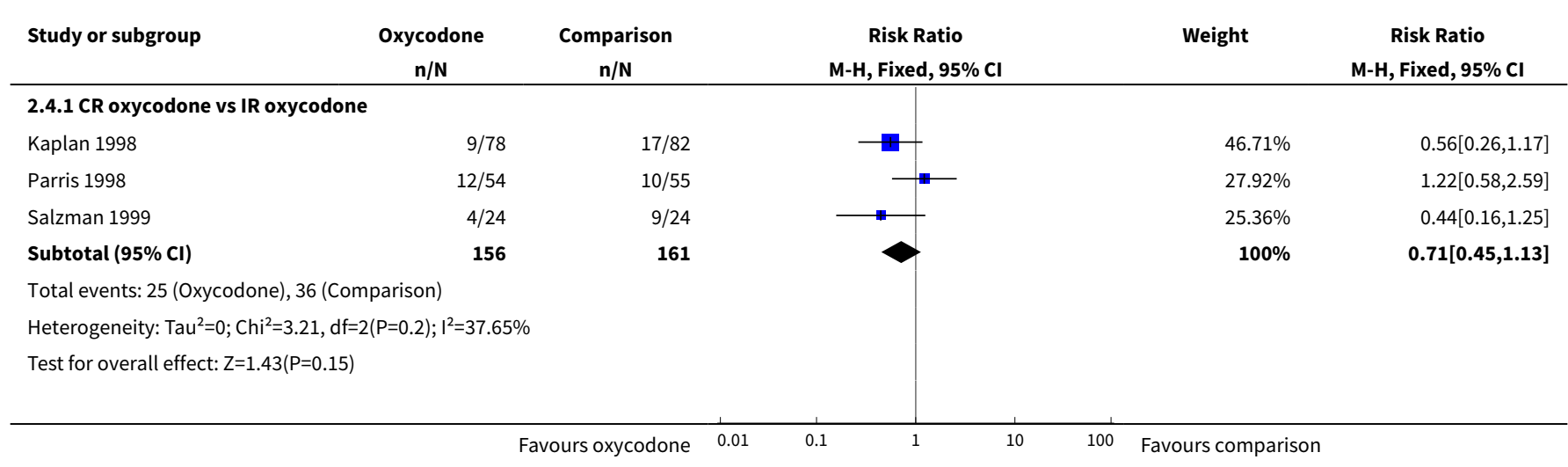




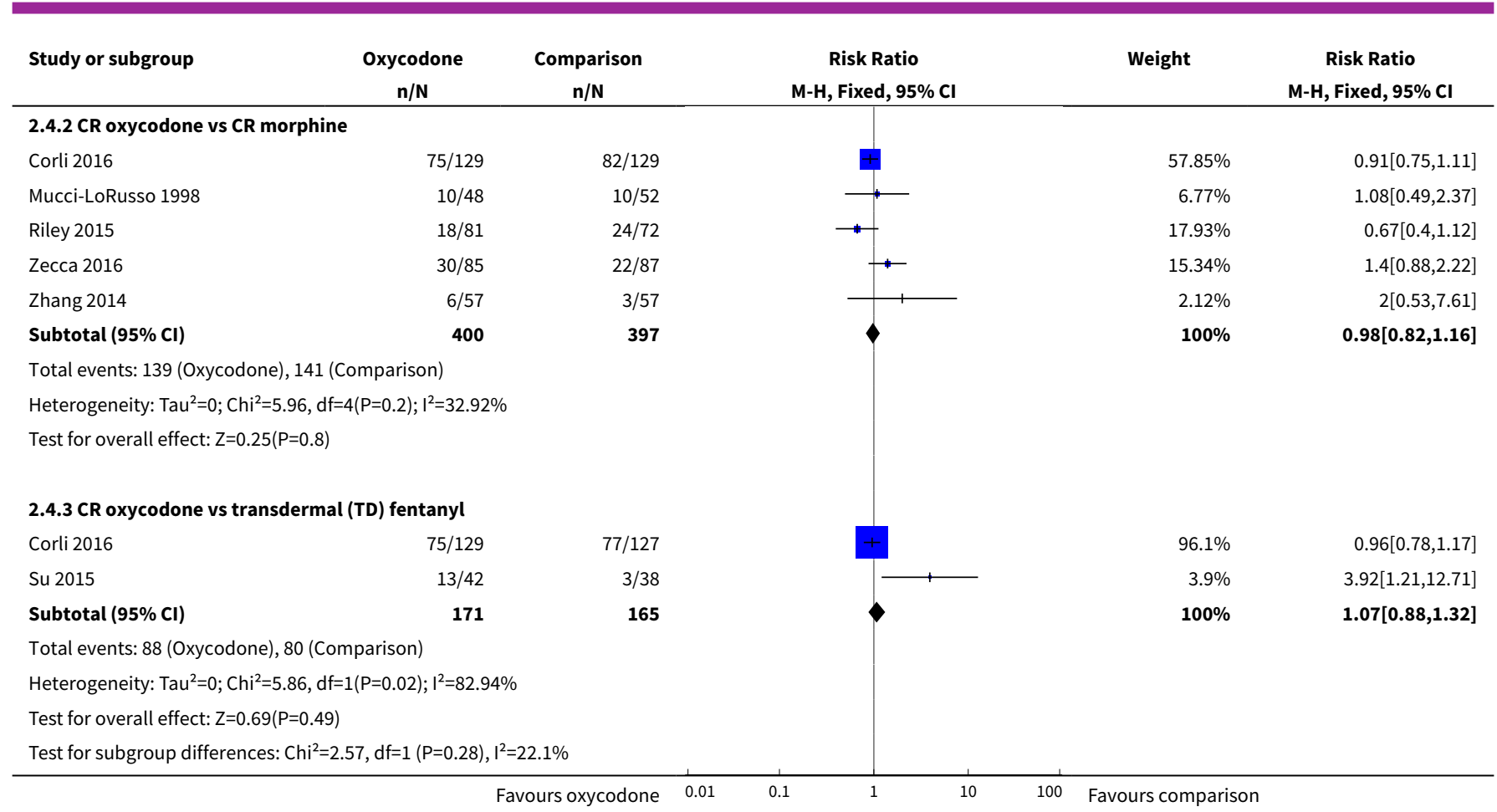

Analysis 2.5. Comparison 2 Adverse events, Outcome 5 Dizziness/lightheadedness.

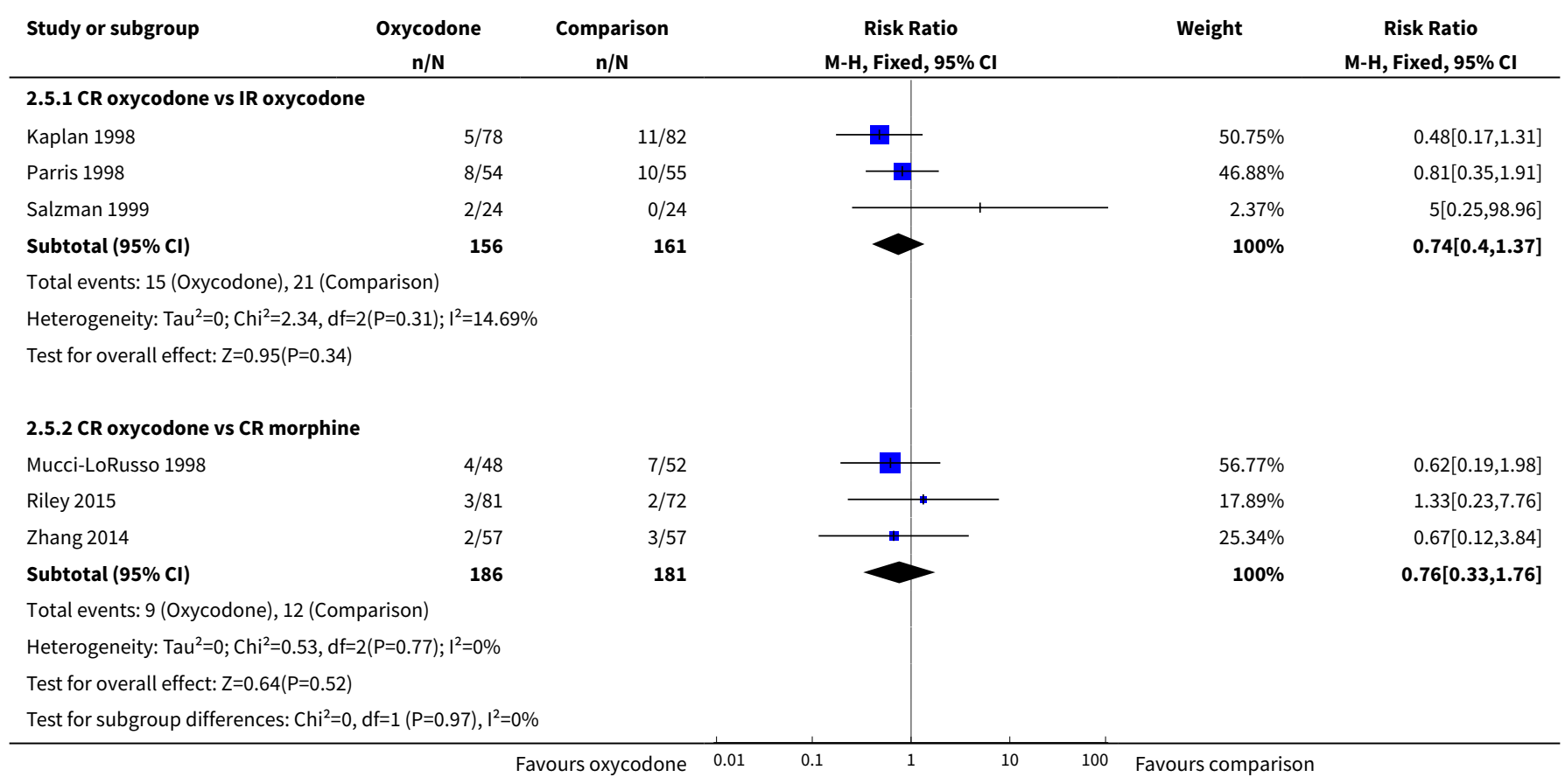


Analysis 2.6. Comparison 2 Adverse events, Outcome 6 Drowsiness/somnolence.

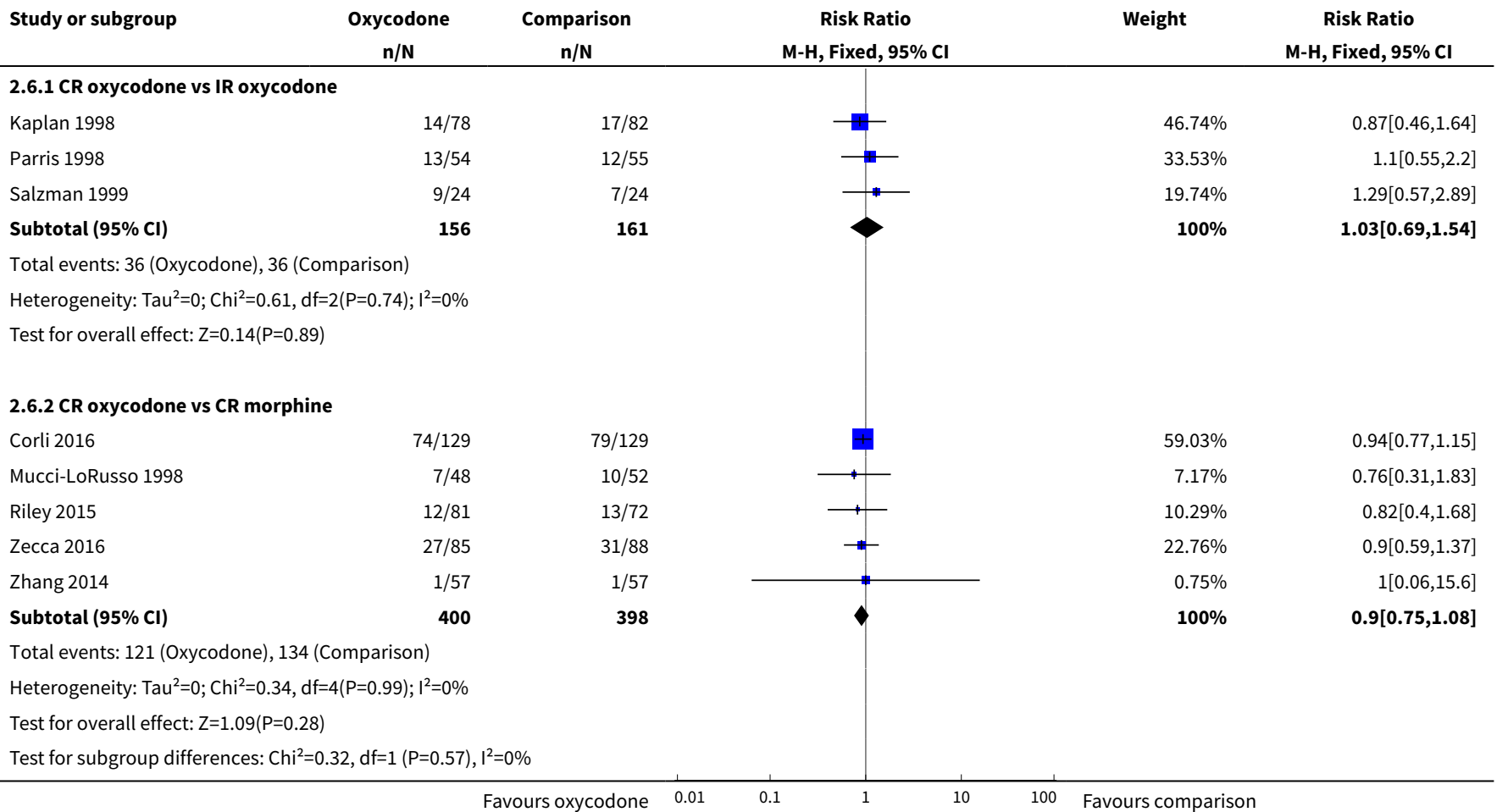

Analysis 2.7. Comparison 2 Adverse events, Outcome 7 Dry mouth.

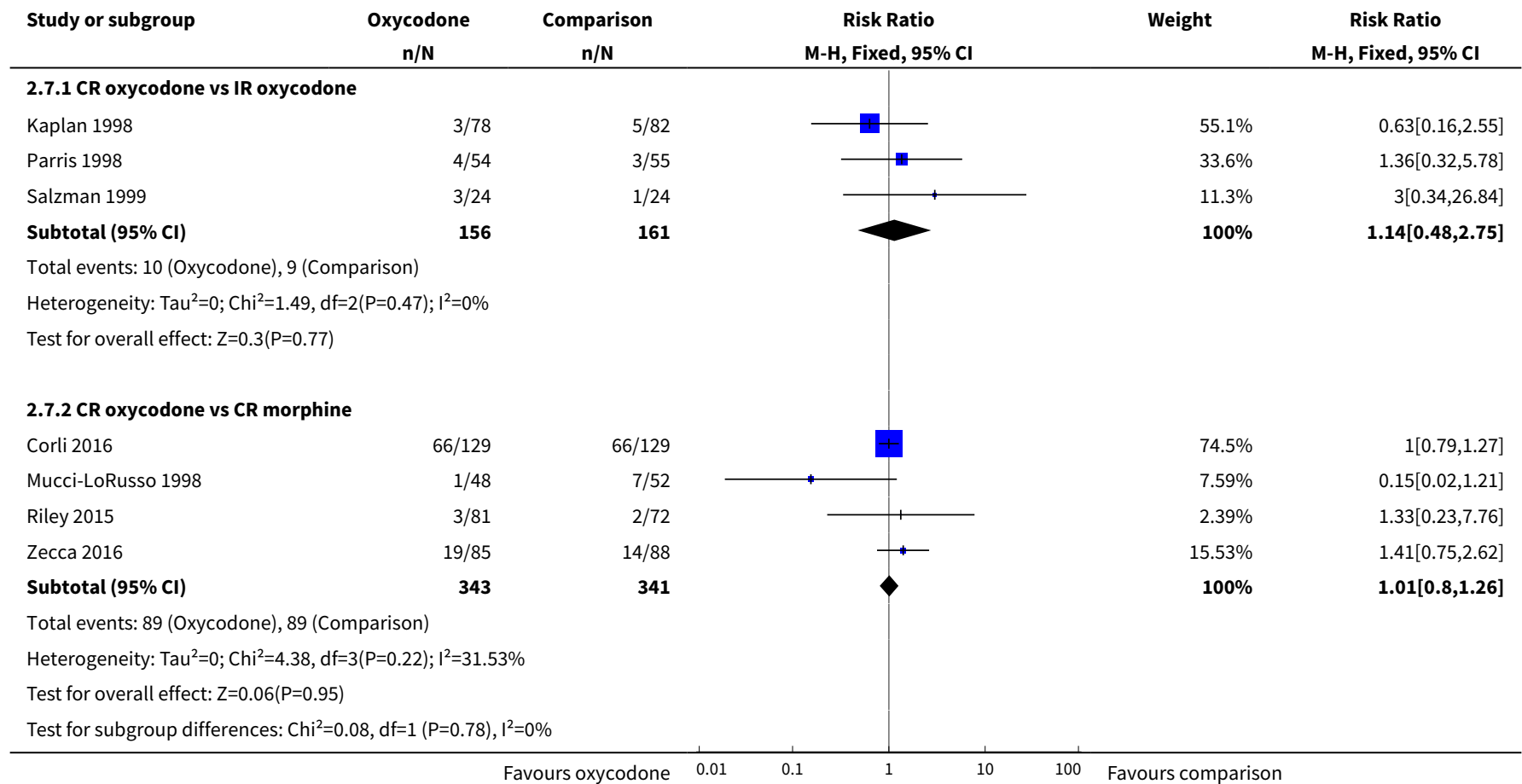




\section{Analysis 2.8. Comparison 2 Adverse events, Outcome 8 Dysuria.}

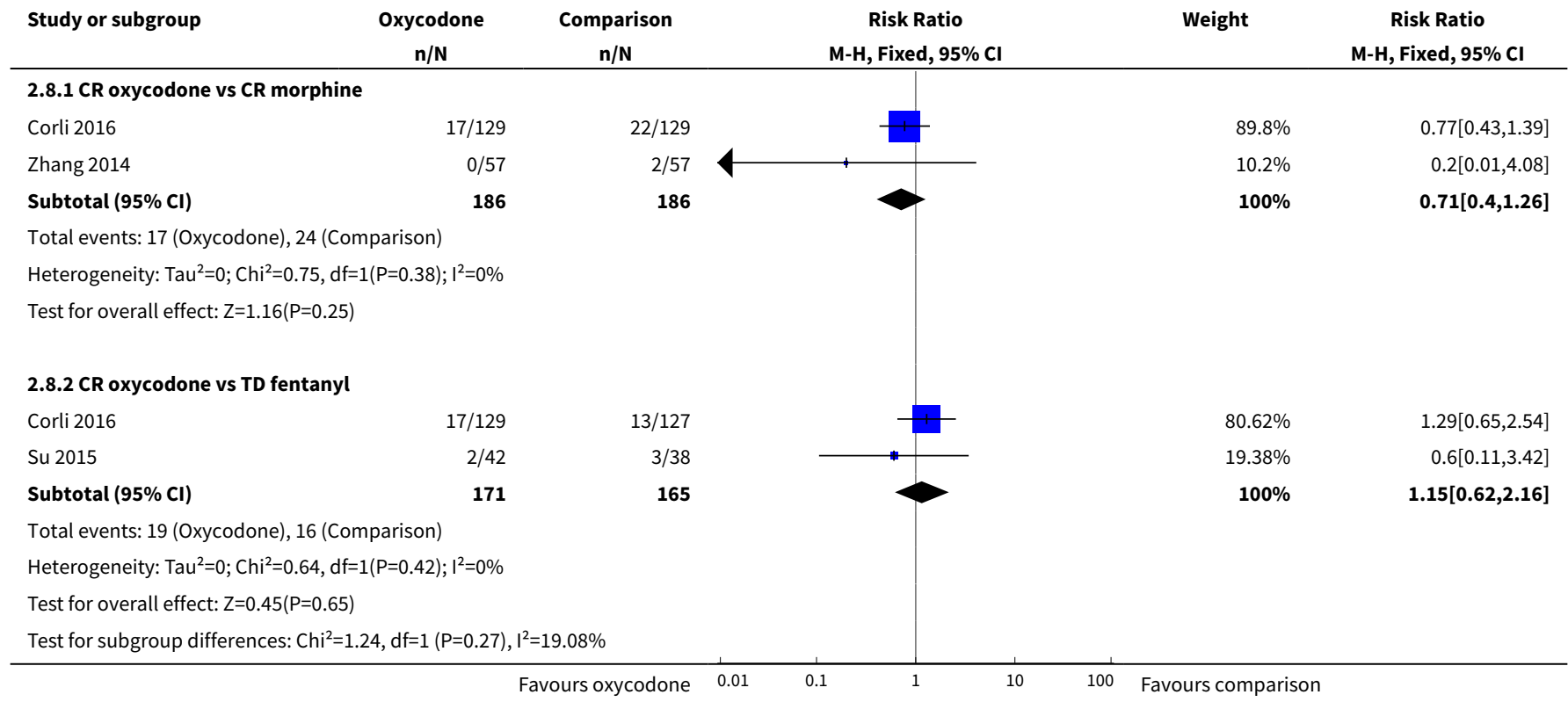

Analysis 2.9. Comparison 2 Adverse events, Outcome 9 Hallucinations.

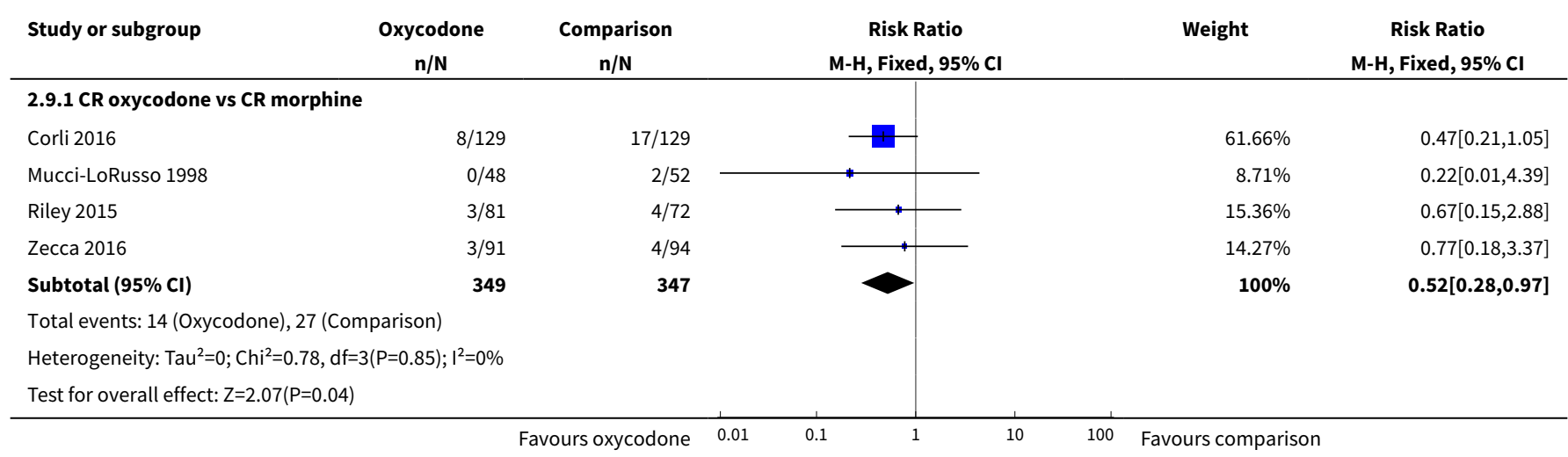

Analysis 2.10. Comparison 2 Adverse events, Outcome 10 Headache.

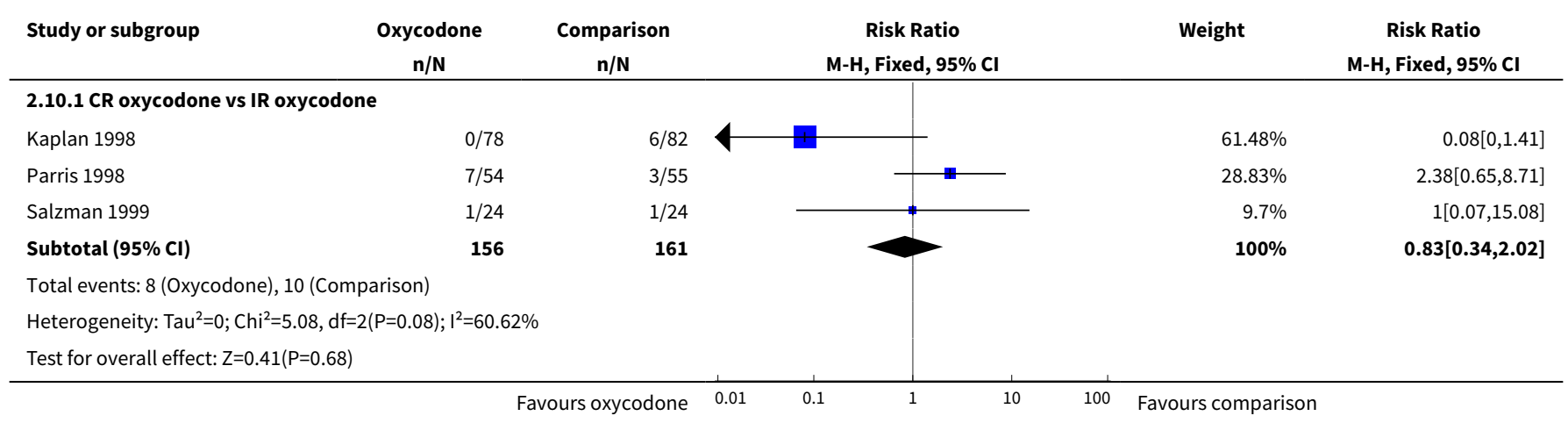


Analysis 2.11. Comparison 2 Adverse events, Outcome 11 Insomnia.

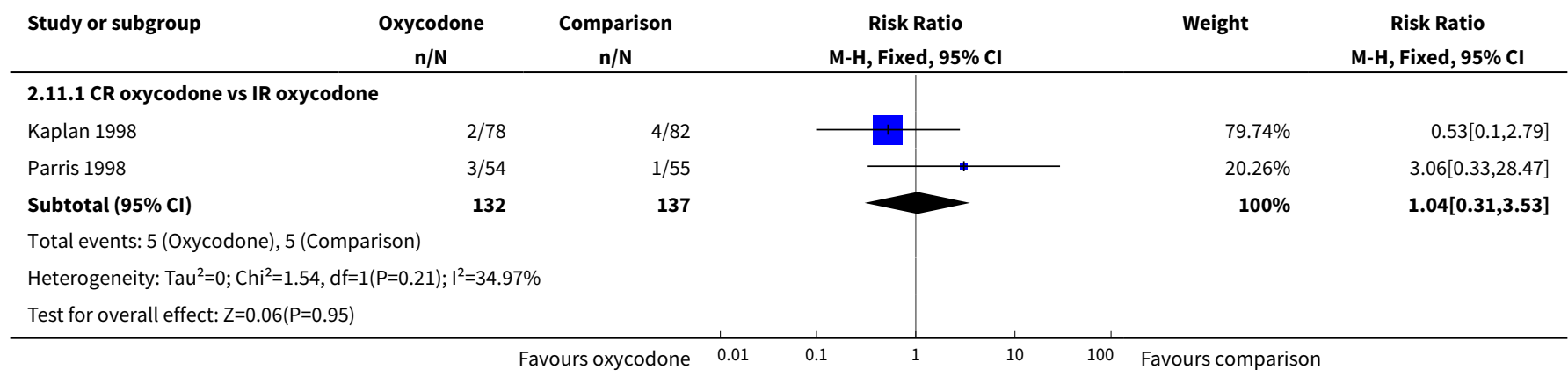

Analysis 2.12. Comparison 2 Adverse events, Outcome 12 Nausea.

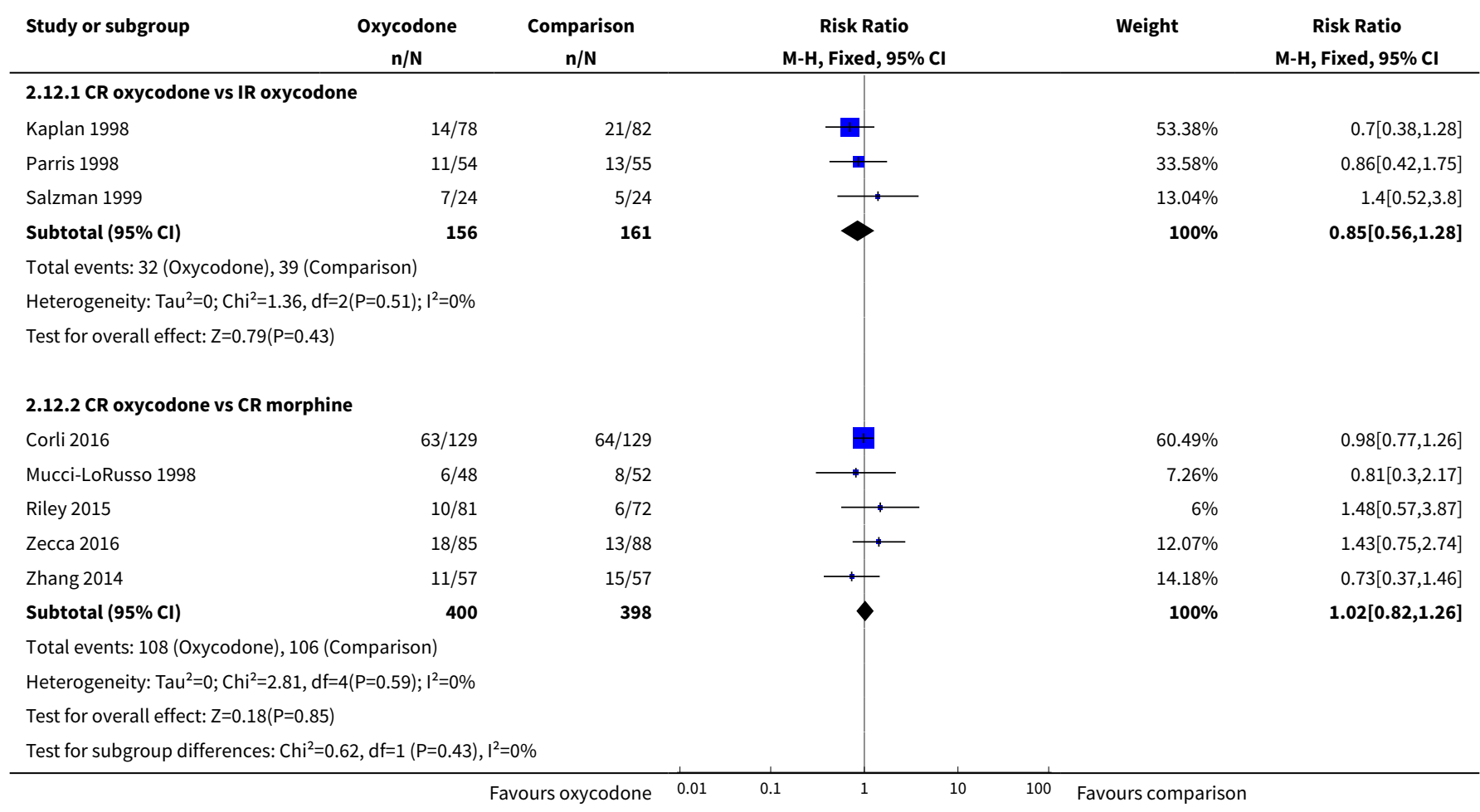

Analysis 2.13. Comparison 2 Adverse events, Outcome 13 Nervousness.

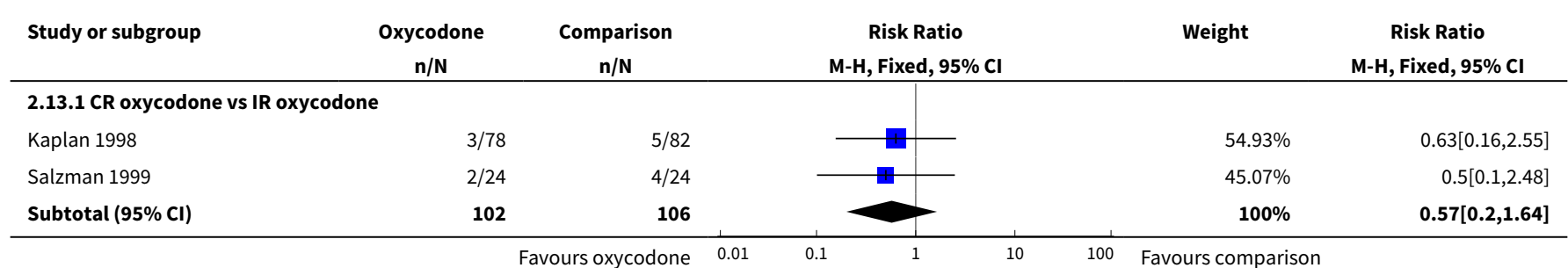




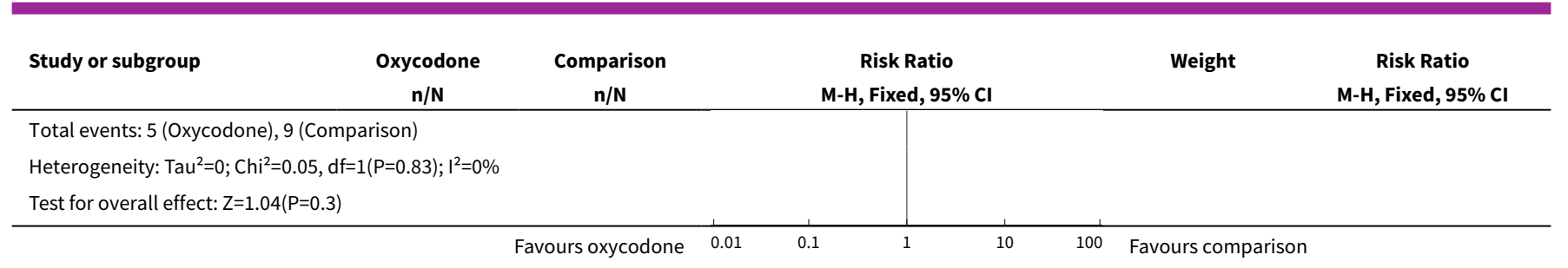

Analysis 2.14. Comparison 2 Adverse events, Outcome 14 Pruritus.

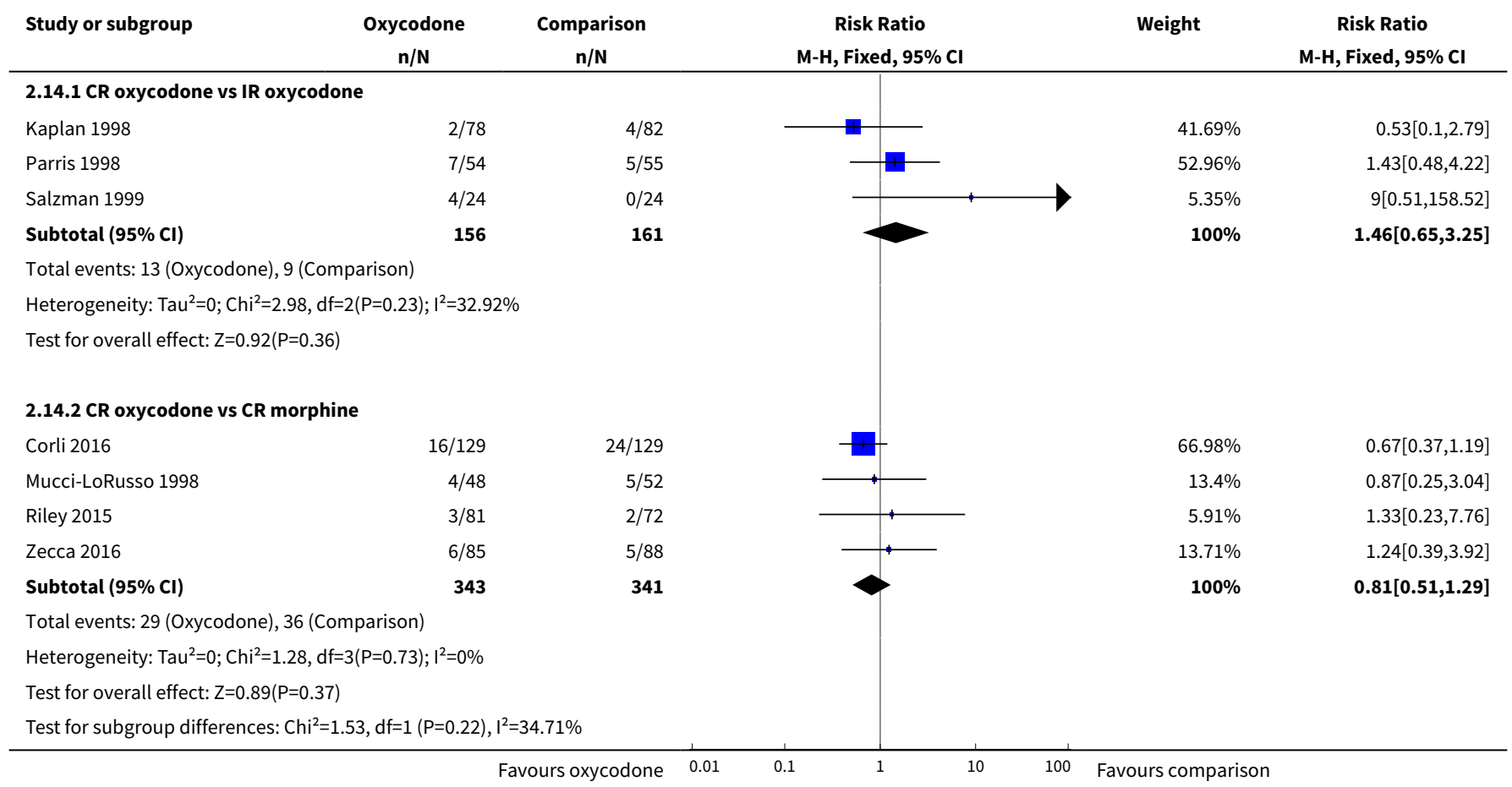

Analysis 2.15. Comparison 2 Adverse events, Outcome 15 Sweating.

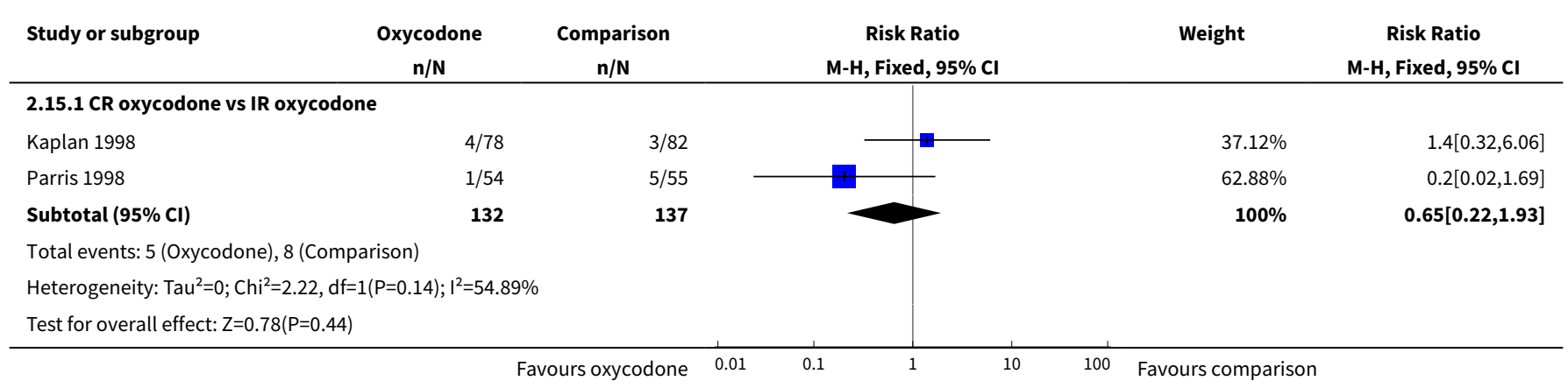


Analysis 2.16. Comparison 2 Adverse events, Outcome 16 Vomiting.

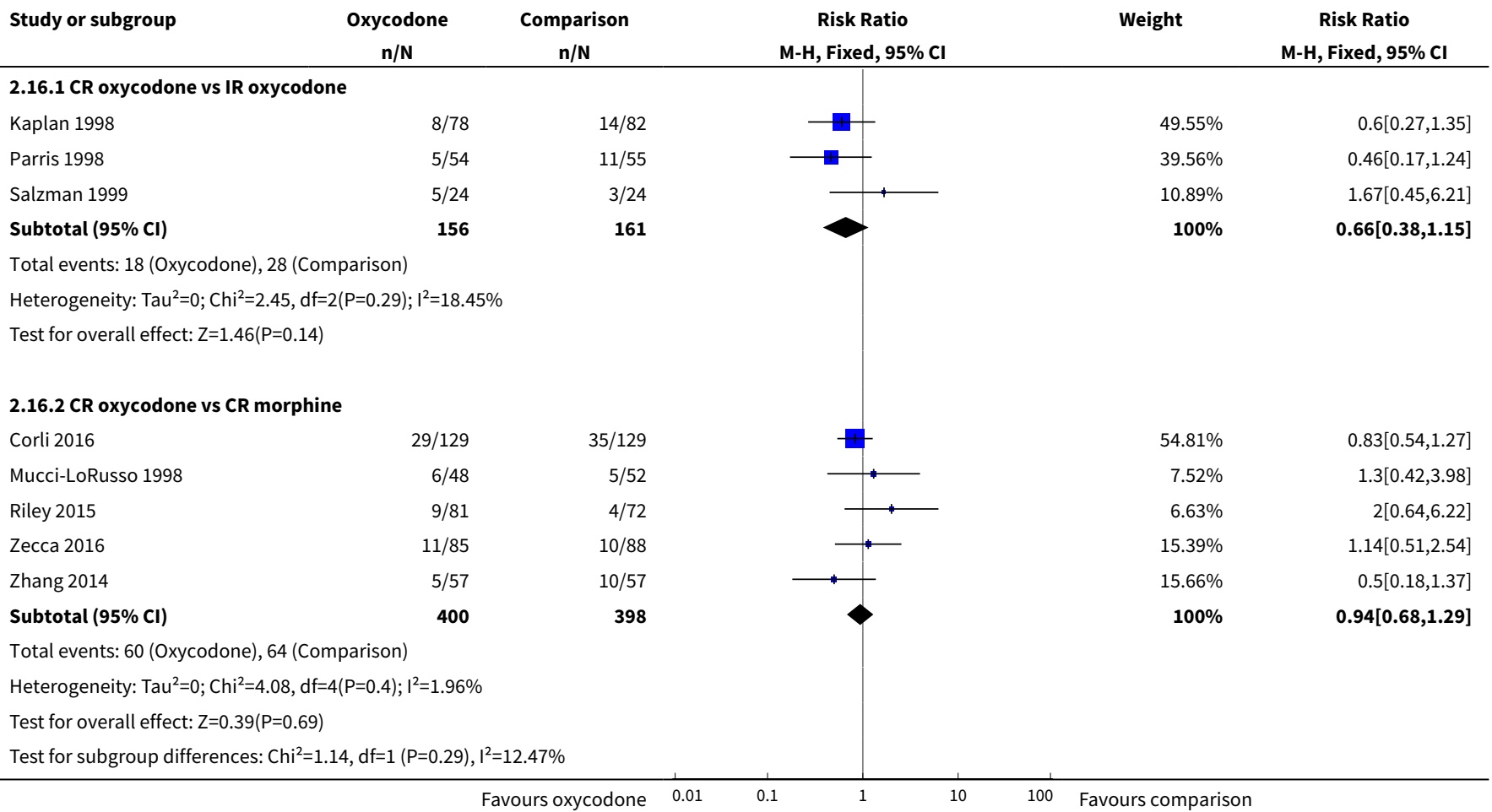

Analysis 2.17. Comparison 2 Adverse events, Outcome 17 Discontinuation due to adverse events.

\begin{tabular}{|c|c|c|c|c|c|}
\hline Study or subgroup & $\begin{array}{c}\text { Oxycodone } \\
n / N\end{array}$ & $\begin{array}{c}\text { Comparison } \\
n / N\end{array}$ & $\begin{array}{c}\text { Risk Ratio } \\
\text { M-H, Fixed, } 95 \% \mathrm{Cl}\end{array}$ & Weight & $\begin{array}{c}\text { Risk Ratio } \\
\text { M-H, Fixed, 95\% Cl }\end{array}$ \\
\hline \multicolumn{6}{|c|}{ 2.17.1 CR oxycodone vs IR oxycodone } \\
\hline Kaplan 1998 & $6 / 78$ & $10 / 82$ & & $52.18 \%$ & $0.63[0.24,1.65]$ \\
\hline Parris 1998 & $4 / 54$ & $7 / 55$ & $\longrightarrow$ & $37.12 \%$ & $0.58[0.18,1.87]$ \\
\hline Salzman 1999 & $1 / 24$ & $2 / 24$ & & $10.7 \%$ & $0.5[0.05,5.15]$ \\
\hline Subtotal $(95 \% \mathrm{Cl})$ & 156 & 161 & & $100 \%$ & $0.6[0.29,1.22]$ \\
\hline \multicolumn{6}{|c|}{ Heterogeneity: $\mathrm{Tau}^{2}=0 ; \mathrm{Chi}^{2}=0.04, \mathrm{df}=2(\mathrm{P}=0.98) ; \mathrm{I}^{2}=0 \%$} \\
\hline \multicolumn{6}{|c|}{ Test for overall effect: $Z=1.42(P=0.16)$} \\
\hline \multicolumn{6}{|c|}{ 2.17.2 CR oxycodone vs CR morphine } \\
\hline Mucci-LoRusso 1998 & $3 / 48$ & $6 / 52$ & 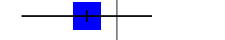 & $66.12 \%$ & $0.54[0.14,2.05]$ \\
\hline Zecca 2016 & $6 / 91$ & $3 / 94$ & - & $33.88 \%$ & $2.07[0.53,8.01]$ \\
\hline Subtotal $(95 \% \mathrm{Cl})$ & 196 & 203 & & $100 \%$ & $1.06[0.43,2.6]$ \\
\hline \multicolumn{6}{|c|}{ Total events: 9 (Oxycodone), 9 (Comparison) } \\
\hline \multicolumn{6}{|c|}{ Heterogeneity: $\operatorname{Tau}^{2}=0 ; \mathrm{Chi}^{2}=1.91, \mathrm{df}=1(\mathrm{P}=0.17) ; \mathrm{I}^{2}=47.66 \%$} \\
\hline \multicolumn{6}{|c|}{ Test for overall effect: $Z=0.12(P=0.9)$} \\
\hline Test for subgroup diff & , df=1 $(P=0.33)$, & & & & \\
\hline
\end{tabular}




\begin{tabular}{|c|c|c|c|c|c|c|c|c|}
\hline \multirow{3}{*}{$\begin{array}{l}\text { Comparison } \\
\text { Study } \\
\text { Treatment }\end{array}$} & \multicolumn{8}{|c|}{ CR oxycodone versus IR oxycodone } \\
\hline & \multicolumn{2}{|c|}{ Kaplan 1998} & \multicolumn{2}{|c|}{ Parris 1998a } & \multicolumn{2}{|c|}{ Salzman 1999} & \multicolumn{2}{|c|}{ Stambaugh 2001} \\
\hline & CR & IR & CR & IR & CR & IR & CR & IR \\
\hline Any adverse events & - & - & $38 / 54-55$ & $38 / 54-55$ & - & - & $10 / 30$ & $10 / 30$ \\
\hline Total adverse events & 109 & 186 & 138 & 142 & - & - & - & - \\
\hline Abdominal pain & - & - & $3 / 54-55$ & $1 / 54-55$ & - & - & - & - \\
\hline Anxiety & $0 / 78$ & $4 / 82$ & - & - & - & - & - & - \\
\hline Asthenia & $3 / 78$ & $8 / 82$ & - & - & $2 / 24$ & $1 / 24$ & $2 / 30$ & $2 / 30$ \\
\hline Confusion & - & - & $0 / 54-55$ & $2 / 54-55$ & $3 / 24$ & $2 / 24$ & - & - \\
\hline Constipation & $9 / 78$ & $17 / 82$ & $12 / 54-55$ & $10 / 54-55$ & $4 / 24$ & $9 / 24$ & $1 / 30$ & $1 / 30$ \\
\hline Dizziness, lightheadedness & $5 / 78$ & $11 / 82$ & $8 / 54-55$ & $10 / 54-55$ & $2 / 24$ & $0 / 24$ & $3 / 30$ & $3 / 30$ \\
\hline Drowsiness, somnolence & $14 / 78$ & $17 / 82$ & $13 / 54-55$ & $12 / 54-55$ & $9 / 24$ & $7 / 24$ & $3 / 30$ & $2 / 30$ \\
\hline Dry mouth & $3 / 78$ & $5 / 82$ & $4 / 54-55$ & $3 / 54-55$ & $3 / 24$ & $1 / 24$ & $1 / 30$ & $1 / 30$ \\
\hline Headache & $0 / 78$ & $6 / 82$ & $7 / 54-55$ & $3 / 54-55$ & $1 / 24$ & $1 / 24$ & - & - \\
\hline Insomnia & $2 / 78$ & $4 / 82$ & $3 / 54-55$ & $1 / 54-55$ & - & - & - & - \\
\hline Nausea & $14 / 78$ & $21 / 82$ & $11 / 54-55$ & $13 / 54-55$ & $7 / 24$ & $5 / 24$ & $4 / 30$ & $3 / 30$ \\
\hline Nervousness & $3 / 78$ & $5 / 82$ & - & - & $2 / 24$ & $4 / 24$ & $0 / 30$ & $1 / 30$ \\
\hline Postural hypotension & - & - & - & - & $5 / 24$ & $4 / 24$ & - & - \\
\hline Pruritus & $2 / 78$ & $4 / 82$ & $7 / 54-55$ & $5 / 54-55$ & $4 / 24$ & $0 / 24$ & $1 / 30$ & $2 / 30$ \\
\hline Sweating & $4 / 78$ & $3 / 82$ & $1 / 54-55$ & $5 / 54-55$ & - & - & $2 / 30$ & $1 / 30$ \\
\hline Vomiting & $8 / 78$ & $14 / 82$ & $5 / 54-55$ & $11 / 54-55$ & $5 / 24$ & $3 / 24$ & $2 / 30$ & $0 / 30$ \\
\hline
\end{tabular}




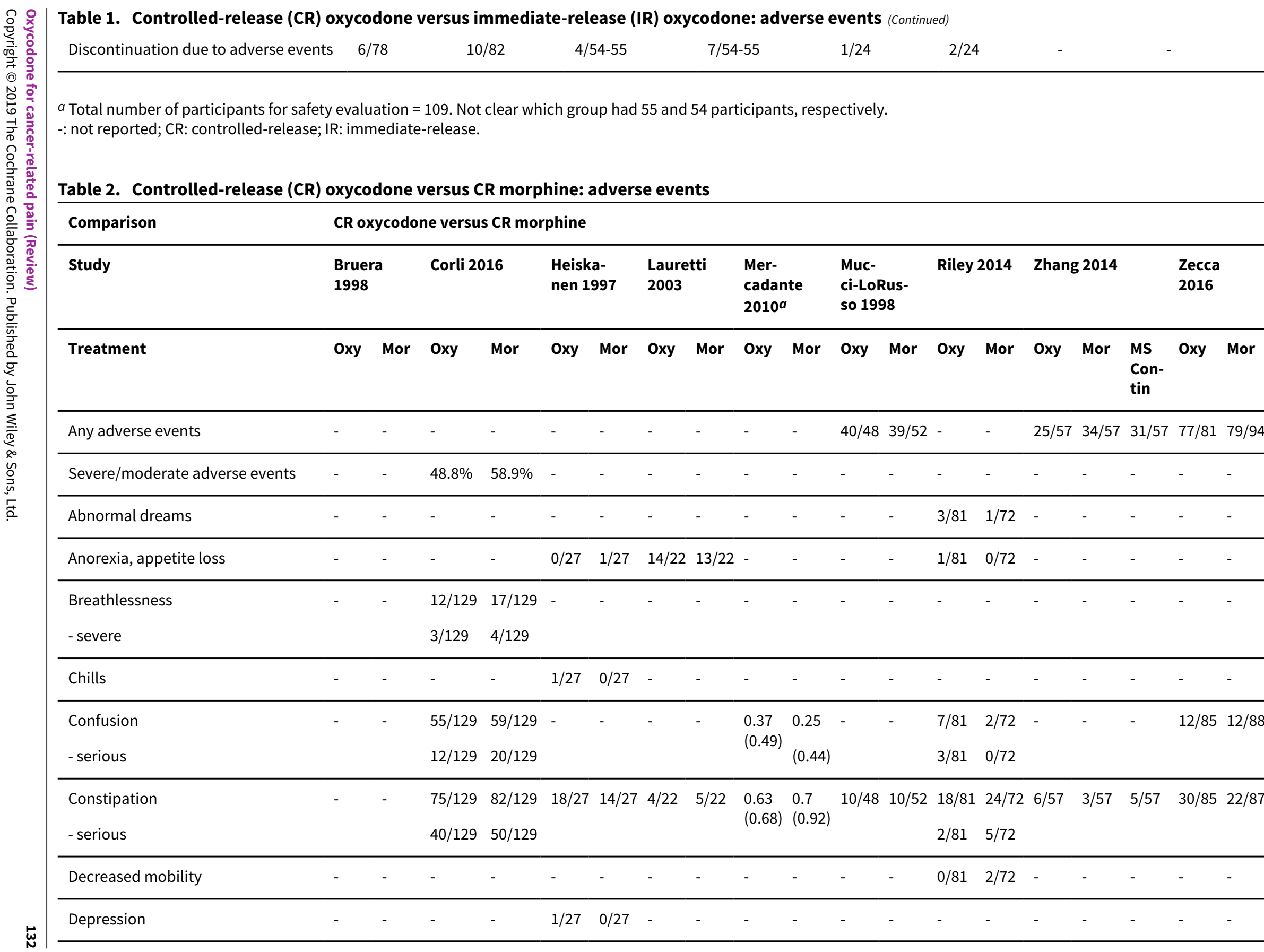

Table 2. Controlled-release (CR) oxycodone versus CR morphine: adverse events 


\begin{tabular}{|c|c|c|c|c|c|c|c|c|c|c|c|c|c|c|c|c|c|c|c|}
\hline Diarrhoea & - & - & - & - & $2 / 27$ & $2 / 27$ & - & - & - & - & - & - & - & - & - & - & - & - & - \\
\hline Dizziness, lightheadedness & - & - & - & - & $6 / 27$ & $6 / 27$ & - & - & - & - & $4 / 48$ & $7 / 52$ & $3 / 81$ & $2 / 72$ & $2 / 57$ & $3 / 57$ & $4 / 57$ & - & - \\
\hline Double vision & - & - & - & - & - & - & - & - & - & - & - & - & $0 / 81$ & $1 / 72$ & - & - & - & - & - \\
\hline Drowsiness, somnolence & - & - & $74 / 129$ & $79 / 129$ & - & - & $7 / 22$ & $11 / 22$ & 0.37 & 0.35 & $7 / 48$ & $10 / 52$ & $12 / 81$ & $13 / 72$ & $1 / 57$ & $1 / 57$ & $1 / 57$ & $27 / 85$ & $31 / 88$ \\
\hline $\begin{array}{l}\text { - serious (with/without hallucina- } \\
\text { tions) }\end{array}$ & & & $34 / 129$ & $38 / 129$ & & & & & & & & & $1 / 81$ & $0 / 72$ & & & & & \\
\hline Drunken feeling & - & - & - & - & $1 / 27$ & $1 / 27$ & - & - & - & - & - & - & - & - & - & - & - & - & - \\
\hline Dry mouth & - & - & $66 / 129$ & $66 / 129$ & $12 / 27$ & $15 / 27$ & $3 / 22$ & $2 / 22$ & 0.63 & 0.6 & $1 / 48$ & $7 / 52$ & $3 / 81$ & $2 / 72$ & - & - & - & $19 / 85$ & $14 / 88$ \\
\hline - severe & & & $27 / 129$ & $31 / 129$ & & & & & & & & & & & & & & & \\
\hline Dyspnoea & - & - & - & - & $2 / 27$ & $2 / 27$ & $0 / 22$ & $0 / 22$ & - & - & - & - & - & - & - & - & - & - & - \\
\hline Dysuria & - & - & $17 / 129$ & $22 / 129$ & - & - & - & - & - & - & - & - & - & - & $0 / 57$ & $2 / 57$ & $1 / 57$ & - & - \\
\hline - severe & & & $4 / 129$ & $2 / 129$ & & & & & & & & & & & & & & & \\
\hline Extrasystoles & - & - & - & - & $1 / 27$ & $0 / 27$ & - & - & - & - & - & - & - & - & - & - & - & - & - \\
\hline Faecal incontinence & - & - & - & - & $1 / 27$ & $1 / 27$ & - & - & - & - & - & - & - & - & - & - & - & - & - \\
\hline Fall & - & - & - & - & - & - & - & - & - & - & - & - & $0 / 81$ & $3 / 72$ & - & - & - & - & - \\
\hline Feeling abnormal & - & - & - & - & - & - & - & - & - & - & - & - & $0 / 81$ & $1 / 72$ & - & - & - & - & - \\
\hline Flatus & - & - & - & - & $0 / 27$ & $1 / 27$ & - & - & - & - & - & - & - & - & - & - & - & - & - \\
\hline Gastralgia & - & - & $21 / 129$ & $24 / 129$ & - & - & - & - & - & - & - & - & - & - & - & - & - & - & - \\
\hline - severe & & & $6 / 129$ & $3 / 129$ & & & & & & & & & & & & & & & \\
\hline Hallucinations & - & - & $8 / 129$ & $17 / 129$ & - & - & $0 / 22$ & $0 / 22$ & - & - & $0 / 48$ & $2 / 52$ & $3 / 81$ & $4 / 72$ & - & - & - & $3 / 91$ & $4 / 94$ \\
\hline - severe & & & $1 / 129$ & $6 / 129$ & & & & & & & & & & & & & & & \\
\hline Hollow feeling & - & - & - & - & $1 / 27$ & $0 / 27$ & - & - & - & - & - & - & - & - & - & - & - & - & - \\
\hline Lethargy & - & - & - & - & - & - & - & - & - & - & - & - & $1 / 81$ & $0 / 72$ & - & - & - & - & - \\
\hline
\end{tabular}




\begin{tabular}{|c|c|c|c|c|c|c|c|c|c|c|c|c|c|c|c|c|c|c|c|}
\hline Memory impairment & - & - & - & - & - & - & - & - & - & - & - & - & $1 / 81$ & $1 / 72$ & - & - & - & - & - \\
\hline Muscle twitches & - & - & - & - & $1 / 27$ & $1 / 27$ & - & - & - & - & - & - & $0 / 81$ & $2 / 72$ & - & - & - & - & - \\
\hline Muscle spasm myoclonus & - & - & $23 / 129$ & $14 / 129$ & - & - & - & - & - & - & - & - & - & - & - & - & - & - & - \\
\hline - severe & & & $0 / 129$ & $6 / 129$ & & & & & & & & & & & & & & & \\
\hline Nausea & 12.3 & 13.9 & $63 / 129$ & $64 / 129$ & $14 / 27$ & $16 / 27$ & $1 / 22$ & $8 / 22$ & 0.84 & 0.6 & $6 / 48$ & $8 / 52$ & $10 / 81$ & $6 / 72$ & $11 / 57$ & $15 / 57$ & $14 / 57$ & $18 / 85$ & $13 / 88$ \\
\hline - serious (with vomiting)/severe & & & $22 / 129$ & $19 / 129$ & & & & & & & & & $1 / 81$ & $0 / 72$ & & & & & \\
\hline Nightmares & - & - & - & - & $0 / 27$ & $3 / 27$ & - & - & - & - & - & - & $2 / 81$ & $0 / 72$ & - & - & - & - & \\
\hline Pain & - & - & - & - & - & - & - & - & - & - & - & - & $0 / 81$ & $1 / 72$ & - & - & - & - & - \\
\hline Paresthesia & - & - & - & - & - & - & - & - & - & - & - & - & $1 / 81$ & $0 / 72$ & - & - & - & - & - \\
\hline Pruritus & - & - & $16 / 129$ & $24 / 129$ & $10 / 27$ & $7 / 27$ & $1 / 22$ & $1 / 22$ & - & - & $4 / 48$ & $5 / 52$ & $3 / 81$ & $2 / 72$ & - & - & - & $6 / 85$ & $5 / 88$ \\
\hline - severe & & & $2 / 129$ & $3 / 129$ & & & & & & & & & & & & & & & \\
\hline Sedation & 21.4 & 25 & - & - & $16 / 27$ & $18 / 27$ & - & - & - & - & - & - & - & - & - & - & - & - & - \\
\hline Sensation of empty head & - & - & - & - & - & - & $1 / 22$ & $0 / 11$ & - & - & - & - & - & - & - & - & - & - & - \\
\hline Slow speech & - & - & - & - & - & - & - & - & - & - & - & - & $1 / 81$ & $0 / 72$ & - & - & - & - & - \\
\hline Sweating, hyperhidrosis & - & - & - & - & $12 / 27$ & $9 / 27$ & - & - & - & - & - & - & $2 / 81$ & $0 / 72$ & - & - & - & - & - \\
\hline $\begin{array}{l}\text { Serious toxicity secondary to infec- } \\
\text { tion }\end{array}$ & - & - & - & - & - & - & - & - & - & - & - & - & $1 / 81$ & $0 / 72$ & - & - & - & - & - \\
\hline Urinary hesitation & - & - & - & - & - & - & - & - & - & - & - & - & $0 / 81$ & $1 / 72$ & - & - & - & - & - \\
\hline Visual impairment & - & - & - & - & - & - & - & - & - & - & - & - & $1 / 81$ & $0 / 72$ & - & - & - & - & - \\
\hline Vomiting & - & - & $29 / 129$ & $35 / 129$ & $5 / 27$ & $10 / 27$ & $0 / 22$ & $7 / 22$ & - & - & $6 / 48$ & $5 / 52$ & $9 / 81$ & $4 / 72$ & $5 / 57$ & $10 / 57$ & $6 / 57$ & $11 / 85$ & $10 / 8 \varepsilon$ \\
\hline - severe & & & $12 / 129$ & $12 / 129$ & & & & & & & & & & & & & & & \\
\hline $\begin{array}{l}\text { Discontinuation due to adverse } \\
\text { events }\end{array}$ & - & - & - & - & - & - & - & - & - & - & $3 / 48$ & $6 / 52$ & - & - & $0 / 57$ & $0 / 57$ & $0 / 57$ & $6 / 91$ & $3 / 94$ \\
\hline
\end{tabular}




\begin{tabular}{|c|c|c|c|c|c|c|c|c|c|c|c|c|c|c|}
\hline \multicolumn{2}{|c|}{ Unexpected serious adverse events } & - & - & - & - & - & - & - & - & $2 / 81$ & $7 / 72$ & - & - & - \\
\hline \multicolumn{15}{|c|}{$\begin{array}{l}\text { a Mean (SD) ratings (out of 3) experienced during week } 4 . \\
\text {-: not reported; CR: controlled release; Oxy: oxycodone; Mor: morphine. }\end{array}$} \\
\hline Comparison & \multicolumn{2}{|c|}{$\begin{array}{l}\text { CR oxycodone } \\
\text { versus CR hydro- } \\
\text { morphone }\end{array}$} & \multicolumn{2}{|c|}{$\begin{array}{l}\text { CR oxycodone } \\
\text { versus ER hydro- } \\
\text { morphone }\end{array}$} & \multicolumn{2}{|c|}{$\begin{array}{l}\text { CR oxycodone } \\
\text { versus ER oxy- } \\
\text { morphone }\end{array}$} & \multicolumn{2}{|c|}{$\begin{array}{l}\text { CR oxycodone } \\
\text { versus ER tapen- } \\
\text { tadol }\end{array}$} & \multicolumn{2}{|c|}{$\begin{array}{l}\text { IV oxycodone } \\
\text { versus rectal } \\
\text { oxycodone }\end{array}$} & \multicolumn{4}{|c|}{$\begin{array}{l}\text { IV oxycodone followed by IR oxy- } \\
\text { codone versus IV morphine followed } \\
\text { by IR morphine }\end{array}$} \\
\hline Study & \multicolumn{2}{|c|}{ Hagen 1997} & \multicolumn{2}{|l|}{ Yu 2014} & \multicolumn{2}{|c|}{ Gabrail 2004} & \multicolumn{2}{|c|}{ Imanaka 2013} & \multicolumn{2}{|c|}{ Leow 1995b } & \multicolumn{4}{|c|}{ Kalso $1990 c$} \\
\hline Treatment & Oxy & Hyd & Oxy & Hyd & Oxy & $\begin{array}{l}\text { Oxy- } \\
\text { mo }\end{array}$ & Oxy & Tap & IV & Rectal & IV oxy & IR oxy & IV mor & IR mor \\
\hline Any adverse events & - & - & $117 / 126$ & $111 / 128$ & - & - & $155 / 172$ & $147 / 168$ & - & - & - & - & - & - \\
\hline Total adverse events & - & - & - & - & - & - & - & - & 82 & 94 & - & - & - & - \\
\hline Severe adverse events & - & - & $30 / 126$ & $30 / 128$ & - & - & - & - & - & - & - & - & - & - \\
\hline Serious adverse events & - & - & $18 / 126$ & $11 / 128$ & - & - & - & - & - & - & - & - & - & - \\
\hline Abdominal discomfort & - & - & $7 / 126$ & $4 / 128$ & - & - & - & - & - & - & - & - & - & - \\
\hline Abdominal distension & - & - & $7 / 126$ & $7 / 128$ & - & - & - & - & - & - & - & - & - & - \\
\hline Anaemia & - & - & $14 / 126$ & $14 / 128$ & - & - & - & - & - & - & - & - & - & - \\
\hline Anorexia, appetite loss & - & - & $21 / 126$ & $20 / 128$ & - & - & $24 / 172$ & $23 / 168$ & - & - & - & - & - & - \\
\hline Asthenia & - & - & $9 / 126$ & $11 / 128$ & - & - & - & - & - & - & - & - & - & - \\
\hline Bone marrow failure & - & - & $9 / 126$ & $9 / 128$ & - & - & - & - & - & - & - & - & - & - \\
\hline Chest discomfort & - & - & $6 / 126$ & $9 / 128$ & - & - & - & - & - & - & - & - & - & - \\
\hline Confusion & - & - & - & - & - & - & - & - & - & - & $0 / 19$ & $1 / 19$ & $0 / 19$ & $1 / 19$ \\
\hline Constipation & - & - & $45 / 126$ & $43 / 128$ & $19 / 41$ & $21 / 43$ & $64 / 172$ & $51 / 168$ & - & - & $6 / 19$ & $6 / 19$ & $8 / 19$ & $8 / 19$ \\
\hline
\end{tabular}




\begin{tabular}{|c|c|c|c|c|c|c|c|c|c|c|c|c|c|c|}
\hline Delirium & - & - & - & - & - & - & $6 / 172$ & $10 / 168$ & - & - & - & - & - & - \\
\hline Diarrhoea & - & - & $9 / 126$ & $12 / 128$ & - & - & $19 / 172$ & $11 / 168$ & - & - & - & - & - & - \\
\hline $\begin{array}{l}\text { Dizziness or lighthead- } \\
\text { edness }\end{array}$ & - & - & $22 / 126$ & $21 / 128$ & $9 / 41$ & $7 / 43$ & - & - & $\begin{array}{l}0.54 \\
(0.74)\end{array}$ & $\begin{array}{l}0.71 \\
(0.9)\end{array}$ & - & - & - & - \\
\hline Drowsiness, somnolence & $28 / 31$ & $19 / 31$ & - & - & - & - & $36 / 172$ & $29 / 168$ & $\begin{array}{l}0.68 \\
(0.81)\end{array}$ & $\begin{array}{l}0.79 \\
(0.93)\end{array}$ & $7 / 19$ & $4 / 19$ & $4 / 19$ & $5 / 19$ \\
\hline Hallucinations & $0 / 31$ & $2 / 31$ & - & - & - & - & - & - & - & - & $0 / 19$ & $0 / 19$ & $2 / 19$ & $3 / 19$ \\
\hline Hypoproteinaemia & - & - & $5 / 126$ & $9 / 128$ & - & - & - & - & - & - & - & - & - & - \\
\hline Insomnia & - & - & - & - & - & - & $11 / 172$ & $9 / 168$ & - & - & - & - & - & - \\
\hline Nausea & $15(3)^{a}$ & $13(3)^{a}$ & $45 / 126$ & $43 / 128$ & $15 / 41$ & $17 / 43$ & $61 / 172$ & $48 / 168$ & $\begin{array}{l}0.02 \\
(0.15)\end{array}$ & $\begin{array}{l}0.12 \\
(0.45)\end{array}$ & $7 / 19$ & $7 / 19$ & $7 / 19$ & $12 / 19$ \\
\hline $\begin{array}{l}\text { Neutrophil count de- } \\
\text { creased }\end{array}$ & - & - & $5 / 126$ & $7 / 128$ & - & - & - & - & - & - & - & - & - & - \\
\hline Oedema, peripheral & - & - & $6 / 126$ & $11 / 128$ & - & - & - & - & - & - & - & - & - & - \\
\hline Platelet count decreased & - & - & $7 / 126$ & $8 / 128$ & - & - & - & - & - & - & - & - & - & - \\
\hline Pruritus & - & - & - & - & $8 / 41$ & $13 / 43$ & - & - & $\begin{array}{l}0.05 \\
(0.21)\end{array}$ & $\begin{array}{l}0.05 \\
(0.21)\end{array}$ & $3 / 19$ & $1 / 19$ & $3 / 19$ & $2 / 19$ \\
\hline Pyrexia & - & - & $27 / 126$ & $24 / 128$ & - & - & - & - & - & - & - & - & - & - \\
\hline Rash & - & - & $4 / 126$ & $7 / 128$ & - & & - & - & - & - & - & - & - & - \\
\hline Sedation & $24(4)^{a}$ & $18(3)^{a}$ & - & - & $13 / 41$ & $18 / 43$ & - & - & - & - & $12 / 19$ & $13 / 19$ & $12 / 19$ & $14 / 19$ \\
\hline $\begin{array}{l}\text { Sweating or hyperhidro- } \\
\text { sis }\end{array}$ & - & - & $8 / 126$ & $3 / 128$ & $9 / 41$ & $12 / 43$ & - & - & $\begin{array}{l}0.04 \\
(0.19)\end{array}$ & $\begin{array}{l}0.07 \\
(0.3)\end{array}$ & $4 / 19$ & $2 / 19$ & $1 / 19$ & $1 / 19$ \\
\hline Urinary retention & - & - & - & - & - & - & - & - & - & - & $1 / 19$ & $1 / 19$ & $2 / 19$ & $0 / 19$ \\
\hline Urinary tract infection & - & - & $7 / 126$ & $4 / 128$ & - & - & - & - & - & - & - & - & - & - \\
\hline
\end{tabular}




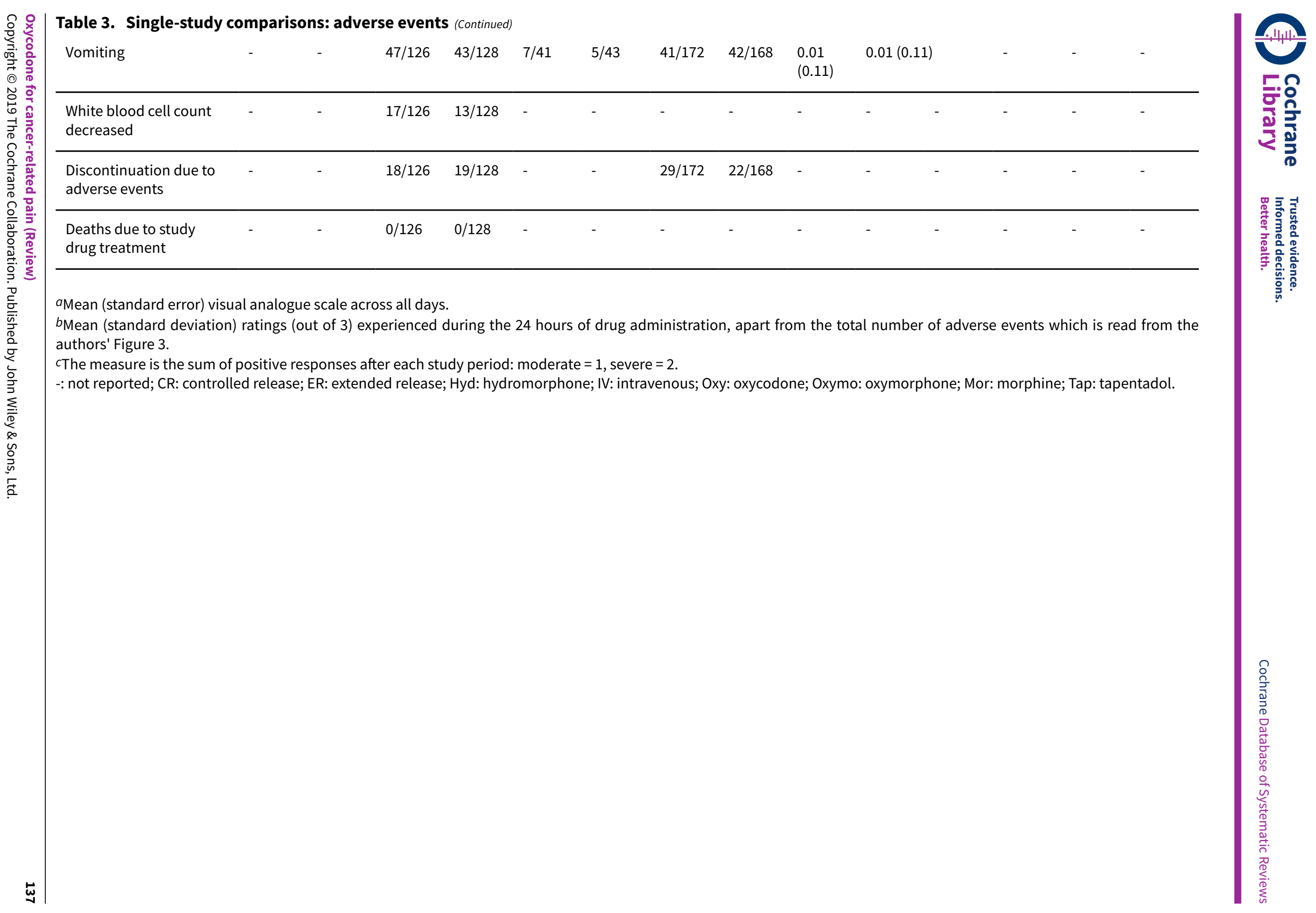


Table 4. Controlled-release (CR) oxycodone versus transdermal fentanyl or buprenorphine

\begin{tabular}{|c|c|c|c|c|c|c|}
\hline \multirow{3}{*}{$\begin{array}{l}\text { Comparison } \\
\text { Study } \\
\text { Treatment }\end{array}$} & \multicolumn{4}{|c|}{ CR oxycodone versus TD fentanyl } & \multicolumn{2}{|c|}{$\begin{array}{l}\text { CR oxycodone versus TD } \\
\text { buprenorphine }\end{array}$} \\
\hline & \multicolumn{2}{|c|}{ Corli 2016} & \multicolumn{2}{|c|}{ Su 2015} & \multicolumn{2}{|c|}{ Corli 2016} \\
\hline & Oxy & Fen & Oxy & Fen & Oxy & Bup \\
\hline Severe/moderate adverse events & $48.8 \%$ & $50.4 \%$ & - & - & $48.8 \%$ & $60 \%$ \\
\hline Breathlessness & $12 / 129$ & $22 / 127$ & - & - & $12 / 129$ & $30 / 130$ \\
\hline Breathlessness, severe & $3 / 129$ & $5 / 127$ & - & - & $3 / 129$ & $6 / 130$ \\
\hline Confusion & $55 / 129$ & $46 / 127$ & - & - & $55 / 129$ & $61 / 130$ \\
\hline Confusion, severe & $12 / 129$ & $8 / 127$ & - & - & $12 / 129$ & $12 / 130$ \\
\hline Constipation & $75 / 129$ & $77 / 127$ & $13 / 42$ & $3 / 38$ & $75 / 129$ & $87 / 130$ \\
\hline Constipation, severe & $40 / 129$ & $36 / 127$ & - & - & $40 / 129$ & $39 / 130$ \\
\hline Dizziness & - & - & $4 / 42$ & $3 / 38$ & - & - \\
\hline Drowsiness & $74 / 129$ & $70 / 127$ & - & - & $74 / 129$ & $81 / 130$ \\
\hline Drowsiness, severe & $34 / 129$ & $26 / 127$ & - & - & $34 / 129$ & $40 / 130$ \\
\hline Dry mouth & $66 / 129$ & $67 / 127$ & - & - & $66 / 129$ & $73 / 130$ \\
\hline Dry mouth, severe & $27 / 129$ & $29 / 127$ & - & - & $27 / 129$ & $30 / 130$ \\
\hline Dysuria & $17 / 129$ & $13 / 127$ & $2 / 42$ & $3 / 38$ & $17 / 129$ & $16 / 130$ \\
\hline Dysuria, severe & $4 / 129$ & $4 / 127$ & - & - & $4 / 129$ & $4 / 130$ \\
\hline Gastralgia & $21 / 129$ & $26 / 127$ & - & - & $21 / 129$ & $21 / 130$ \\
\hline Gastralgia, severe & $6 / 129$ & $4 / 127$ & - & - & $6 / 129$ & $1 / 130$ \\
\hline Hallucinations & $8 / 129$ & $3 / 127$ & - & - & $8 / 129$ & $8 / 130$ \\
\hline Hallucinations, severe & $1 / 129$ & $0 / 127$ & - & - & $1 / 129$ & $2 / 130$ \\
\hline Itching & $16 / 129$ & $14 / 127$ & - & - & $16 / 129$ & $21 / 130$ \\
\hline Itching, severe & $2 / 129$ & $3 / 127$ & - & - & $2 / 129$ & $1 / 130$ \\
\hline Lethargy & - & - & $3 / 42$ & $2 / 38$ & - & - \\
\hline Muscle spasm myoclonus & $23 / 129$ & $15 / 127$ & - & - & $23 / 129$ & $24 / 130$ \\
\hline Muscle spasm myoclonus, severe & $0 / 129$ & $3 / 127$ & - & - & $0 / 129$ & $1 / 130$ \\
\hline Nausea and vomiting & - & - & $11 / 42$ & $2 / 38$ & - & - \\
\hline
\end{tabular}


Table 4. Controlled-release (CR) oxycodone versus transdermal fentanyl or buprenorphine (Continued)

\begin{tabular}{|c|c|c|c|c|c|c|}
\hline Nausea & $63 / 129$ & $57 / 127$ & - & - & $63 / 129$ & $59 / 130$ \\
\hline Nausea, severe & $22 / 129$ & $16 / 127$ & - & - & $22 / 129$ & $18 / 130$ \\
\hline Vomiting & $29 / 129$ & $29 / 127$ & - & - & $29 / 129$ & $30 / 130$ \\
\hline Vomiting, severe & $12 / 129$ & $10 / 127$ & - & - & $12 / 129$ & $5 / 130$ \\
\hline
\end{tabular}

-: not reported; Bup: buprenorphine; CR: controlled release; Fen: fentanyl; Oxy: oxycodone; TD: transdermal.

\section{AP P E N D I CES}

\section{Appendix 1. Search strategies}

Original search run in March 2014

\section{CENTRAL (the Cochrane Library)}

\#1 MeSH descriptor: [Oxycodone] explode all trees

\#2 (ox?codon* or oxycontin or oxycodeinon or oxycone or oxycdn or ox?conum or oxydose or oxyfast or oxygesic or oxynorm or oxynormoro or oxyrapid):ti,ab,kw (Word variations have been searched)

\#3 (dazidox or dihydrohydroxycodeinone or dihydrone or dinarkon):ti,ab,kw (Word variations have been searched)

\#4 (endocet or endocodone or endone or eu?odal or eubine):ti,ab,kw (Word variations have been searched)

\#5 ("m oxy" or oxecta or oxydihydrocodeinonum or pancodine or pavinal or percocet or percolone or proladone):ti,ab,kw (Word variations have been searched)

\#6 (remoxy or roxicet or rox?codone or roxilox):ti,ab,kw (Word variations have been searched)

\#7 (supeudol or thecodinum or theocodin or tylox):ti,ab,kw (Word variations have been searched)

\#8 \#1 or \#2 or \#3 or \#4 or \#5 or \#6 or \#7

\#9 MeSH descriptor: [Neoplasms] explode all trees

\#10 (cancer* or neoplas* or tumo* or carcinoma* or hodgkin* or nonhodgkin* or adenocarcinoma* or leuk? emia* or metasta* or malignan* or lymphoma* or sarcoma* or melanoma* or myeloma* or oncolog*):ti,ab,kw (Word variations have been searched)

$\# 11 \# 9$ or \#10

$\# 12 \# 8$ and \#11

\section{MEDLINE and MEDLINE In-Process (Ovid)}

1 Oxycodone/

2 (ox?codon\$ or oxycontin or oxycodeinon or oxycone or oxycdn or ox?conum or oxydose or oxyfast or oxygesic or oxynorm or oxynormoro or oxyrapid).tw.

3 (dazidox or dihydrohydroxycodeinone or dihydrone or dinarkon).tw.

4 (endocet or endocodone or endone or eu?odal or eubine).tw.

5 ("m oxy" or oxecta or oxydihydrocodeinonum or pancodine or pavinal or percocet or percolone or proladone).tw.

6 (remoxy or roxicet or rox?codone or roxilox).tw.

7 (supeudol or thecodinum or theocodin or tylox).tw. 
8 or $1-7$

$9 \exp$ Neoplasms/

10 (cancer\$ or neoplas\$ or tumo\$ or carcinoma\$ or hodgkin\$ or nonhodgkin\$ or adenocarcinoma\$ or leuk? emia\$1 or metasta\$ or malignan $\$$ or lymphoma\$ or sarcoma\$ or melanoma\$ or myeloma\$ or oncolog\$).tw.
11 or $/ 9-10$
128 and 11
13 randomized controlled trial.pt.
14 controlled clinical trial.pt.
15 randomized.ab.
16 placebo.ab.
17 drug therapy.fs.
18 randomly.ab.
19 trial.ab.
20 or/13-19
21 exp animals/ not humans.sh.
$22 \quad 20 \operatorname{not} 21$
$23 \quad 12$ and 22

\section{Embase (Ovid)}

1 Oxycodone/

2 (ox?codon\$ or oxycontin or oxycodeinon or oxycone or oxycdn or ox?conum or oxydose or oxyfast or oxygesic or oxynorm or oxynormoro or oxyrapid).tw.

3 (dazidox or dihydrohydroxycodeinone or dihydrone or dinarkon).tw.

4 (endocet or endocodone or endone or eu?odal or eubine).tw.

5 ("m oxy" or oxecta or oxydihydrocodeinonum or pancodine or pavinal or percocet or percolone or proladone).tw.

6 (remoxy or roxicet or rox?codone or roxilox).tw.

7 (supeudol or thecodinum or theocodin or tylox).tw.

8 or $1-7$

$9 \exp$ Neoplasms/

10 (cancer\$ or neoplas\$ or tumo\$ or carcinoma\$ or hodgkin\$ or nonhodgkin\$ or adenocarcinoma\$ or leuk?emia\$1 or metasta\$ or malignan\$ or lymphoma\$ or sarcoma\$ or melanoma\$ or myeloma\$ or oncolog\$).tw.
11 or $/ 9-10$
$12 \quad 8$ and 11
13 random\$.tw.
14 factorial\$.tw.
15 crossover\$.tw.
16 cross over\$.tw.

Oxycodone for cancer-related pain (Review) 
17 cross-over\$.tw.

18 placebo\$.tw.

19 (doubl\$ adj blind\$).tw.

20 (singl\$ adj blind\$).tw.

21 assign\$.tw.

22 allocat\$.tw.

23 volunteer\$.tw.

24 Crossover Procedure/

25 double-blind procedure.tw.

26 Randomized Controlled Trial/

27 Single Blind Procedure/

28 or $/ 13-27$

29 (animal/ or nonhuman/) not human/

$30 \quad 28$ not 29

$31 \quad 12$ and 30

\section{Web of Science (ISI) SSCI and SCI}

\#22 \#21 AND \#9

\#21 \#20 OR \#17 OR \#16 OR \#15 OR \#14 OR \#11 OR \#10

\#20 \#19 AND \#18

\#19 TS=random* OR TI=random*

\#18 TS=(allocate* OR assign $\left.{ }^{\star}\right)$ OR TI=(allocate ${ }^{\star}$ OR assign $\left.{ }^{\star}\right)$

\#17 TS=crossover ${ }^{\star}$ OR TI=crossover ${ }^{*}$

\#16 TS=(mask* OR blind $\left.{ }^{\star}\right)$ OR TI=(mask* OR blind $\left.{ }^{\star}\right)$

\#15 TS=(singl ${ }^{\star}$ OR Doubl* OR Tripl* OR Trebl*) OR TI=(singl* OR Doubl* OR Tripl* OR Trebl*)

\#14 \#13 AND \#12

\#13 TS=trial* OR TI=trial*

$\# 12 \mathrm{TI}=\mathrm{clin}^{\star}$ OR TS=clin*

\#11 TI=randomi* OR TS=randomi *

\#10 TS=Randomized clinical trial ${ }^{\star}$ OR TI=Randomized clinical trial ${ }^{\star}$

\#9 \#8 AND \#7

\#8 Topic=((cancer ${ }^{\star}$ or neoplas* or tumo* or carcinoma* or hodgkin* or nonhodgkin* or adenocarcinoma* or leuk?emia* or metasta* or malignan* or lymphoma* or sarcoma* or melanoma* or myeloma* or oncolog*))

\#7 \#6 OR \#5 OR \#4 OR \#3 OR \#2 OR \#1

\#6 Topic=((supeudol or thecodinum or theocodin or tylox $))$

\#5 Topic=((remoxy or roxicet or rox?codone or roxilox $))$ 
\#4 Topic=(("m oxy" or oxecta or oxydihydrocodeinonum or pancodine or pavinal or percocet or percolone or proladone))

\#3 Topic=((endocet or endocodone or endone or eu?odal or eubine))

\#2 Topic=((dazidox or dihydrohydroxycodeinone or dihydrone or dinarkon))

\#1 Topic=((ox?codon* or oxycontin or oxycodeinon or oxycone or oxycdn or ox?conum or oxydose or oxyfast or oxygesic or oxynorm or oxynormoro or oxyrapid))

\section{BIOSIS (ISI)}

\#21 \#20 AND \#19 AND \#12

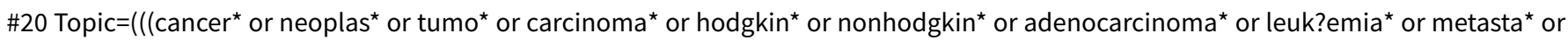
malignan $^{\star}$ or lymphoma* or sarcoma* or melanoma* or myeloma* or oncolog*)))

\section{\#19 \#18 OR \#17 OR \#16 OR \#15 OR \#14 OR \#13}

\#18 Topic=(((supeudol or thecodinum or theocodin or tylox $)))$

\#17 Topic=(((remoxy or roxicet or rox?codone or roxilox $)))$

\#16 Topic=((("m oxy" or oxecta or oxydihydrocodeinonum or pancodine or pavinal or percocet or percolone or proladone $)))$

\#15 Topic=(((endocet or endocodone or endone or eu?odal or eubine $)))$

\#14 Topic=(((dazidox or dihydrohydroxycodeinone or dihydrone or dinarkon)))

\#13 Topic=l((ox?codon* or oxycontin or oxycodeinon or oxycone or oxycdn or ox?conum or oxydose or oxyfast or oxygesic or oxynorm or oxynormoro or oxyrapid)))

\#12 \#11 OR \#8 OR \#7 OR \#6 OR \#5 OR \#2 OR \#1

\#11 \#10 AND \#9

\#10 DS=random* OR TS=random* OR TI=random*

\#9 DS=(allocate ${ }^{\star}$ OR assign $)$ OR TS=(allocate* OR assign*) OR TI=(allocate* OR assign $\left.{ }^{\star}\right)$

\#8 DS=crossover ${ }^{\star}$ OR TS=crossover ${ }^{\star}$ OR TI=crossover ${ }^{\star}$

\#7 DS=(mask* OR blind $\left.{ }^{\star}\right)$ OR TS=(mask* OR blind $\left.{ }^{\star}\right)$ OR TI=(mask* OR blind $\left.{ }^{\star}\right)$

\#6 DS=(singl* OR Doubl* OR Tripl* OR Trebl*) OR TS=(singl* OR Doubl* OR Tripl* OR Trebl*) OR TI=(singl* OR Doubl* OR Tripl* OR Trebl*) \#5 \#4 AND \#3

\#4 DS=trial* OR TS=trial* OR TI=trial ${ }^{*}$

\#3 DS=clin* OR TI=clin* OR TS=clin*

\#2 DS=randomi* OR TI=randomi* OR TS=randomi*

\#1 MQ=Randomized clinical trial* OR DS=Randomized clinical trial ${ }^{\star}$ OR TS=Randomized clinical trial ${ }^{*}$ OR TI=Randomized clinical trial ${ }^{*}$

\section{Psycinfo (Ovid)}

1 (ox?codon\$ or oxycontin or oxycodeinon or oxycone or oxycdn or ox?conum or oxydose or oxyfast or oxygesic or oxynorm or oxynormoro or oxyrapid).tw.

2 (dazidox or dihydrohydroxycodeinone or dihydrone or dinarkon).tw.

3 (endocet or endocodone or endone or eu?odal or eubine).tw.

4 ("m oxy" or oxecta or oxydihydrocodeinonum or pancodine or pavinal or percocet or percolone or proladone).tw.

5 (remoxy or roxicet or rox?codone or roxilox).tw.

6 (supeudol or thecodinum or theocodin or tylox).tw. 
7 exp Neoplasms/

8 (cancer\$ or neoplas\$ or tumo\$ or carcinoma\$ or hodgkin\$ or nonhodgkin\$ or adenocarcinoma\$ or leuk?emia\$1 or metasta\$ or malignan\$ or lymphoma or sarcoma\$ or melanoma\$ or myeloma\$ or oncolog\$).tw.

9 or/7-8

10 or/1-6

119 and 10

12 clinical trials/

13 (randomis* or randomiz*).tw.

14 (random\$ adj3 (allocat\$ or assign\$)).tw.

15 ((clinic\$ or control\$) adj trial\$).tw.

16 ((singl\$ or doubl\$ or trebl\$ or tripl\$) adj3 (blind\$ or mask\$)).tw.

17 (crossover\$ or "cross over\$").tw.

18 random sampling/

19 Experiment Controls/

20 Placebo/

21 placebo\$.tw.

22 exp program evaluation/

23 treatment effectiveness evaluation/

24 ((effectiveness or evaluat\$) adj3 (stud\$ or research\$)).tw.

25 or $/ 12-24$

$26 \quad 11$ and 25

\section{PubMed}

(((Oxycodone[MeSH Terms]) OR ((ox?codon* OR oxycontin OR oxycodeinon OR oxycone OR oxycdn OR ox?conum OR oxydose OR oxyfast OR oxygesic OR oxynorm OR oxynormoro OR oxyrapid)) OR ((dazidox OR dihydrohydroxycodeinone OR dihydrone OR dinarkon)) OR ((endocet OR endocodone OR endone OR eu?odal OR eubine)) OR (("m oxy" OR oxecta OR oxydihydrocodeinonum OR pancodine OR pavinal OR percocet OR percolone OR proladone)) OR ((remoxy OR roxicet OR rox?codone OR roxilox)) OR ((supeudol OR thecodinum OR theocodin OR tylox))) AND and AND ((Neoplasms[MeSH Terms]) OR ((cancer* OR neoplas* OR tumo* OR carcinoma* OR hodgkin* OR nonhodgkin ${ }^{\star}$ OR adenocarcinoma* OR leuk?emia*1 OR metasta* OR malignan ${ }^{\star}$ OR lymphoma* OR sarcoma* OR melanoma* OR myeloma* OR oncolog* $))))$ AND and AND (((randomized controlled trial[Publication Type]) OR (controlled clinical trial[Publication Type]) OR (randomized[Title/Abstract]) OR (placebo[Title/Abstract]) OR (drug therapy[Title/Abstract]) OR (randomly[Title/Abstract]) OR (trial[Title/ Abstract]) OR (groups[Title/Abstract])) NOT ((animals[MeSH Terms]) NOT humans[MeSH Terms]))

\section{Update search run in November 2016}

\section{CENTRAL (the Cochrane Library)}

\#1 MeSH descriptor: [Oxycodone] explode all trees

\#2 (ox?codon* or oxycontin or oxycodeinon or oxycone or oxycdn or ox?conum or oxydose or oxyfast or oxygesic or oxynorm or oxynormoro or oxyrapid):ti,ab,kw (Word variations have been searched)

\#3 (dazidox or dihydrohydroxycodeinone or dihydrone or dinarkon):ti,ab,kw (Word variations have been searched)

\#4 (endocet or endocodone or endone or eu?odal or eubine):ti,ab,kw (Word variations have been searched)

\#5 ("m oxy" or oxecta or oxydihydrocodeinonum or pancodine or pavinal or percocet or percolone or proladone):ti,ab,kw (Word variations have been searched)

Oxycodone for cancer-related pain (Review) 
\#6 (remoxy or roxicet or rox?codone or roxilox):ti,ab,kw (Word variations have been searched)

\#7 (supeudol or thecodinum or theocodin or tylox):ti,ab,kw (Word variations have been searched)

\#8 \#1 or \#2 or \#3 or \#4 or \#5 or \#6 or \#7

\#9 MeSH descriptor: [Neoplasms] explode all trees

\#10 (cancer ${ }^{\star}$ or neoplas* or tumo* or carcinoma* or hodgkin* or nonhodgkin* or adenocarcinoma* or leuk? emia* or metasta* or malignan or lymphoma* or sarcoma* or melanoma* or myeloma* or oncolog*):ti,ab,kw (Word variations have been searched)

$\# 11 \# 9$ or \#10

$\# 12$ \#8 and \#11

\section{MEDLINE and MEDLINE In-Process (Ovid)}

\section{Oxycodone/}

2 (ox?codon\$ or oxycontin or oxycodeinon or oxycone or oxycdn or ox?conum or oxydose or oxyfast or oxygesic or oxynorm or oxynormoro or oxyrapid).tw.

3 (dazidox or dihydrohydroxycodeinone or dihydrone or dinarkon).tw.

4 (endocet or endocodone or endone or eu?odal or eubine).tw.

5 ("m oxy" or oxecta or oxydihydrocodeinonum or pancodine or pavinal or percocet or percolone or proladone).tw.

6 (remoxy or roxicet or rox?codone or roxilox).tw.

7 (supeudol or thecodinum or theocodin or tylox).tw.

8 or/1-7

9 exp Neoplasms/

10 (cancer\$ or neoplas\$ or tumo or carcinoma or hodgkin $\$$ or nonhodgkin $\$$ or adenocarcinoma or leuk? emia 1 or metasta\$ or malignan $\$$ or lymphoma\$ or sarcoma or melanoma\$ or myeloma\$ or oncolog\$).tw.

11 or/9-10

128 and 11

13 randomized controlled trial.pt.

14 controlled clinical trial.pt.

15 randomized.ab.

16 placebo.ab.

17 drug therapy.fs.

18 randomly.ab.

19 trial.ab.

20 or/13-19

21 exp animals/ not humans.sh.

2220 not 21

2312 and 22

$24\left(201403^{\star}\right.$ or $201404^{\star}$ or $201405^{\star}$ or $201406^{\star}$ or $201407^{\star}$ or $201408^{\star}$ or $201409^{\star}$ or $201410^{\star}$ or $201411^{\star}$ or $201412^{\star}$ or $2015^{\star}$ or $\left.2016^{\star}\right) . e d$.

2523 and 24

Oxycodone for cancer-related pain (Review) 


\section{Embase (Ovid)}

\section{Oxycodone/}

2. (ox?codon\$ or oxycontin or oxycodeinon or oxycone or oxycdn or ox?conum or oxydose or oxyfast or oxygesic or oxynorm or oxynormoro or oxyrapid).tw.

3. (dazidox or dihydrohydroxycodeinone or dihydrone or dinarkon).tw.

4. (endocet or endocodone or endone or eu?odal or eubine).tw.

5. ("m oxy" or oxecta or oxydihydrocodeinonum or pancodine or pavinal or percocet or percolone or proladone).tw.

6. (remoxy or roxicet or rox?codone or roxilox).tw.

7. (supeudol or thecodinum or theocodin or tylox).tw.

8. or/1-7

9. $\exp$ Neoplasms/

10. (cancer\$ or neoplas\$ or tumo\$ or carcinoma\$ or hodgkin\$ or nonhodgkin\$ or adenocarcinoma\$ or leuk?emia\$1 or metasta\$ or malignan\$ or lymphoma or sarcoma\$ or melanoma or myeloma\$ or oncolog\$).tw.

11. or/9-10

12. 8 and 11

13. random\$.tw.

14. factorial\$.tw.

15. crossover\$.tw.

16. cross over\$.tw.

17. cross-over\$.tw.

18. placebo\$.tw.

19. (doubl\$ adj blind\$).tw.

20. (singl\$ adj blind\$).tw.

21. assign\$.tw.

22. allocat\$.tw.

23. volunteer\$.tw.

24. Crossover Procedure/

25. double-blind procedure.tw.

26. Randomized Controlled Trial/

27. Single Blind Procedure/

28. or/13-27

29. (animal/ or nonhuman/) not human/

30.28 not 29

31.12 and 30

$32\left(201403^{\star}\right.$ or $201404^{\star}$ or $201405^{\star}$ or $201406^{\star}$ or $201407^{\star}$ or $201408^{\star}$ or $201409^{\star}$ or $201410^{\star}$ or $201411^{\star}$ or $201412^{\star}$ or $2015^{\star}$ or $\left.2016^{\star}\right) . d d$.

3331 and 32

Oxycodone for cancer-related pain (Review) 


\section{Web of Science (ISI) SSCI \& SCI}

\#22 \#21 AND \#9

\#21 \#20 OR \#17 OR\#16 OR \#15 OR \#14 OR \#11 OR\#10

\#20 \#19 AND \#18

\#19 TS=random* OR TI=random*

\#18 TS=(allocate* OR assign $\left.{ }^{\star}\right)$ OR TI=(allocate* OR assign $\left.{ }^{\star}\right)$

\#17 TS=crossover ${ }^{\star}$ OR TI=crossover ${ }^{*}$

\#16 TS=(mask* OR blind $\left.{ }^{\star}\right)$ OR TI=(mask* OR blind $\left.{ }^{\star}\right)$

\#15 TS=(singl ${ }^{\star}$ OR Doubl* OR Tripl* OR Trebl*) OR TI=(singl* OR Doubl* OR Tripl* OR Trebl*)

\#14 \#13 AND \#12

\#13 TS=trial* OR TI=trial*

$\# 12 \mathrm{TI}=$ clin* OR TS=clin*

\#11 TI=randomi* OR TS=randomi*

\#10 TS=Randomized clinical trial ${ }^{\star}$ OR TI=Randomized clinical trial ${ }^{\star}$

\#9 \#8 AND \#7

\#8 Topic=((cancer* or neoplas* or tumo* or carcinoma* or hodgkin* or nonhodgkin* or adenocarcinoma* or leuk?emia* or metasta* or malignan ${ }^{\star}$ or lymphoma* or sarcoma* or melanoma* or myeloma* or oncolog*))

\#7 \#6 OR \#5 OR \#4 OR \#3 OR \#2 OR \#1

\#6 Topic=((supeudol or thecodinum or theocodin or tylox $))$

\#5 Topic=((remoxy or roxicet or rox?codone or roxilox $))$

\#4 Topic=(("m oxy" or oxecta or oxydihydrocodeinonum or pancodine or pavinal or percocet or percolone or proladone))

\#3 Topic=((endocet or endocodone or endone or eu?odal or eubine) $)$

\#2 Topic=((dazidox or dihydrohydroxycodeinone or dihydrone or dinarkon))

\#1 Topic=((ox?codon* or oxycontin or oxycodeinon or oxycone or oxycdn or ox?conum or oxydose or oxyfast or oxygesic or oxynorm or oxynormoro or oxyrapid))

\section{BIOSIS (ISI)}

\#21 \#20 AND \#19 AND \#12

\#20 Topic=(((cancer ${ }^{\star}$ or neoplas* or tumo* or carcinoma* or hodgkin* or nonhodgkin* or adenocarcinoma* or leuk?emia* or metasta* or malignan* or lymphoma* or sarcoma* or melanoma* or myeloma* or oncolog*)))

\section{\#19 \#18 OR \#17 OR \#16 OR \#15 OR \#14 OR \#13}

\#18 Topic=(((supeudol or thecodinum or theocodin or tylox $)))$

\#17 Topic=(((remoxy or roxicet or rox?codone or roxilox $)))$

\#16 Topic=((("m oxy" or oxecta or oxydihydrocodeinonum or pancodine or pavinal or percocet or percolone or proladone $)))$

\#15 Topic=(((endocet or endocodone or endone or eu?odal or eubine $)))$

\#14 Topic=(((dazidox or dihydrohydroxycodeinone or dihydrone or dinarkon)))

\#13 Topic=(((ox?codon* or oxycontin or oxycodeinon or oxycone or oxycdn or ox?conum or oxydose or oxyfast or oxygesic or oxynorm or oxynormoro or oxyrapid)))

Oxycodone for cancer-related pain (Review) 
\#12 \#11 OR \#8 OR \#7 OR \#6 OR \#5 OR \#2 OR \#1

\#11 \#10 AND \#9

\#10 DS=random* OR TS=random* OR TI=random*

\#9 DS=(allocate* OR assign ${ }^{\star}$ OR TS=(allocate* OR assign*) OR TI=(allocate* OR assign^)

\#8 DS=crossover ${ }^{\star}$ OR TS=crossover ${ }^{\star}$ OR TI=crossover ${ }^{\star}$

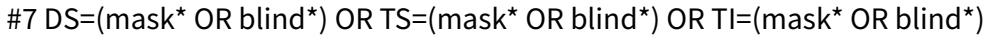

\#6 DS=(singl* OR Doubl* OR Tripl* OR Trebl*) OR TS=(singl* OR Doubl* OR Tripl* OR Trebl $\left.{ }^{\star}\right)$ OR TI=(singl* OR Doubl* OR Tripl* OR Trebl*) \#5 \#4 AND \#3

\#4 DS=trial ${ }^{*}$ OR TS=trial* OR TI=trial ${ }^{*}$

\#3 DS=clin* OR TI=clin* OR TS=clin*

\#2 DS=randomi ${ }^{\star}$ OR TI=randomi* OR TS=randomi *

\#1 MQ=Randomized clinical trial* OR DS=Randomized clinical trial ${ }^{\star}$ OR TS=Randomized clinical trial* OR TI=Randomized clinical trial ${ }^{\star}$

\section{PsycINFO (Ovid)}

1. (ox?codon\$ or oxycontin or oxycodeinon or oxycone or oxycdn or ox?conum or oxydose or oxyfast or oxygesic or oxynorm or oxynormoro or oxyrapid).tw.

2. (dazidox or dihydrohydroxycodeinone or dihydrone or dinarkon).tw.

3. (endocet or endocodone or endone or eu?odal or eubine).tw.

4. ("m oxy" or oxecta or oxydihydrocodeinonum or pancodine or pavinal or percocet or percolone or proladone).tw.

5. (remoxy or roxicet or rox?codone or roxilox).tw.

6. (supeudol or thecodinum or theocodin or tylox).tw.

7. exp Neoplasms/

8. (cancer\$ or neoplas\$ or tumo\$ or carcinoma\$ or hodgkin\$ or nonhodgkin\$ or adenocarcinoma\$ or leuk?emia\$1 or metasta\$ or malignan \$ or lymphoma\$ or sarcoma\$ or melanoma\$ or myeloma\$ or oncolog\$).tw.

9. or $/ 7-8$

10. or/1-6

11.9 and 10

12. clinical trials/

13. (randomis ${ }^{\star}$ or randomiz*).tw.

14. (random\$ adj3 (allocat\$ or assign\$)).tw.

15. ((clinic\$ or control\$) adj trial\$).tw.

16. ((singl\$ or doubl\$ or trebl\$ or tripl\$) adj3 (blind\$ or mask\$)).tw.

17. (crossover\$ or "cross over\$").tw.

18. random sampling/

19. Experiment Controls/

20. Placebo/

21. placebo\$.tw.

Oxycodone for cancer-related pain (Review) 
22. exp program evaluation/

23. treatment effectiveness evaluation/

24. ((effectiveness or evaluat\$) adj3 (stud\$ or research\$)).tw.

25. or $/ 12-24$

26. 11 and 25

WHAT'S NEW

\begin{tabular}{lll}
\hline Date & Event & Description \\
\hline 12 March 2019 & Review declared as stable & See Published notes. \\
\hline
\end{tabular}

\section{H ISTORY}

Protocol first published: Issue 4, 2002

Review first published: Issue 2, 2015

\begin{tabular}{|c|c|c|}
\hline Date & Event & Description \\
\hline 25 June 2018 & Amended & Updated Other published versions of this review \\
\hline 25 October 2017 & Amended & Minor correction to Discussion \\
\hline 30 January 2017 & $\begin{array}{l}\text { New citation required but conclusions } \\
\text { have not changed }\end{array}$ & $\begin{array}{l}\text { An update search run on } 29 \text { November } 2016 \text { identified } 267 \text { new } \\
\text { records of which } 6 \text { new eligible studies (Corli 2016; Lux 2014; Su } \\
2015 \text {; Yu 2014; Zecca 2016; Zhang 2014), have been included in } \\
\text { this review. The studies added a further } 1258 \text { participants to the } \\
\text { review and examined four new comparisons with oxycodone, } \\
\text { namely transdermal (TD) fentanyl ( } 2 \text { studies), TD buprenorphine, } \\
\text { extended-release (ER) oxycodone, and ER hydromorphone, and } \\
\text { also contained data to include in the original controlled-release } \\
\text { (CR) oxycodone versus CR morphine comparison. The addition- } \\
\text { al studies allowed us to meta-analyse the adverse event data } \\
\text { (which were summarised narratively and in tables in the original } \\
\text { review), to examine the robustness of our primary outcome pain } \\
\text { intensity meta-analyses in sensitivity analyses, and to include } \\
\text { an additional meta-analysis of pain intensity for the comparison } \\
\text { of CR oxycodone and TD fentanyl. None of the meta-analyses of } \\
\text { pain intensity and adverse events were significant with two ex- } \\
\text { ceptions: } 1 \text { ) Pain intensity was statistically significantly, but not } \\
\text { clinically significantly, higher after treatment with CR oxycodone } \\
\text { compared to CR morphine. Sensitivity analysis of this result how- } \\
\text { ever did not find a statistically significant difference in pain in- } \\
\text { tensity between the two treatments, and 2) the risk ratio of expe- } \\
\text { riencing hallucinations was significantly higher after treatment } \\
\text { with CR morphine than CR oxycodone. Otherwise, the conclu- } \\
\text { sions of the updated review remain the same as that of the origi- } \\
\text { nal review. Previous readers of the review may enjoy re-reading } \\
\text { this update. }\end{array}$ \\
\hline
\end{tabular}

18 January $2017 \quad$ New search has been performed

An update search run on 29 November 2016 revealed 6 new eligible studies. These have now been added. 


\begin{tabular}{lll}
\hline Date & Event & Description \\
\hline 22 February 2013 & $\begin{array}{l}\text { New citation required and major } \\
\text { changes }\end{array}$ & $\begin{array}{l}\text { This protocol has been significantly updated by new authors. } \\
\text { See Published notes. }\end{array}$ \\
\hline 11 February 2010 & $\begin{array}{l}\text { New citation required and major } \\
\text { changes }\end{array}$ & $\begin{array}{l}\text { This protocol was originally published in Issue 4, 2002. As the au- } \\
\text { thors were unable to commit time to the completion of the full } \\
\text { review it was then withdrawn in January 2009. The original au- } \\
\text { thors are now able to work on completing the full review and } \\
\text { plan to do so by the end of 2010. }\end{array}$ \\
\hline 13 January 2009 & $\begin{array}{l}\text { New citation required and major } \\
\text { changes }\end{array}$ & $\begin{array}{l}\text { Withdrawn: the review group was unable to maintain contact } \\
\text { with the contact author. New authors are being sought to take } \\
\text { over this protocol, please contact the PaPaS Review Group if you } \\
\text { are interested in working on this review title. }\end{array}$ \\
\hline 22 September 2008 & Amended & \begin{tabular}{l} 
Converted to new review format. \\
\hline
\end{tabular}
\end{tabular}

\section{CONTRIBUTIONS OF AUTHORS}

MSH and MIB conceived and designed the review and wrote the protocol.

SA devised and undertook the search strategy.

MSH, NB, and JSH screened the search results and performed the data extraction and 'risk of bias' assessment of the included studies.

MSH devised and performed the analysis strategy, and wrote the first draft of the full review.

MIB interpreted the results and wrote the 'Authors conclusions' section.

All the authors approved the final version of the review.

\section{For the update}

SA undertook the search strategy.

MSH and NB screened the search results and performed the data extraction and 'risk of bias' assessment of the included studies.

MSH devised and performed the analysis strategy, and wrote the first draft of the updated review.

MIB interpreted the results and wrote the 'Authors conclusions' section.

All the authors approved the final version of the review

\section{DECLARATIONS OF INTEREST}

MSH: none known.

MIB is a specialist palliative medicine physician and manages people with cancer pain. MIB received lecture fees from Pfizer in 2016.

SA: none known.

NB: none known.

JSH: none known.

\section{DIFFERENCES BETWEEN PROTOCOL AND REVIEW}

2015: In the 'risk of bias' assessments, we also included an item that captured whether data were available for both time periods in crossover trials, in order to make explicit this potential source of bias. We reported treatment acceptability as a proxy for quality of life as this outcome was rarely reported. 


\section{NOTES}

Following an updated search in February 2019, the authors identified a number of potentially relevant new studies, some of which were published, some ongoing, and some awaiting classification [see references below]. However, the authors and editors judged that the new information is unlikely to change the review findings at present. The conclusions of this Cochrane Review are therefore still considered up to date. The review will be reassessed for updating within 12 months.

\section{References for potentially relevant studies}

\section{Published studies}

\section{Inoue 2017}

Inoue, S., et al. (2017). "A randomized, double-blind study of hydromorphone hydrochloride extended-release tablets versus oxycodone hydrochloride extended-release tablets for cancer pain: efficacy and safety in Japanese cancer patients (EXHEAL: a Phase III study of EXtended-release HydromorphonE for cAncer pain reLief)." Journal of Pain Research 10: 1953-1961.

Inoue, S., et al. (2018). "A randomized, double-blind, non-inferiority study of hydromorphone hydrochloride immediate-release tablets versus oxycodone hydrochloride immediate-release powder for cancer pain: efficacy and safety in Japanese cancer patients." Japanese journal of clinical oncology 48(6): 542-547.

\section{Lee 2017}

Lee, K. H., et al. (2017). "Intravenous Oxycodone versus Intravenous Morphine in Cancer Pain: A Randomized, Open-Label, Parallel-Group, Active-Control Study." Pain research \& management: 11.

Oh, H. S., et al. (2017). "Efficacy and safety of oxynorm compared to morphine sulfate administering through iv continuous infusion in moderate-severe cancer-related pain." Supportive Care in Cancer 25 (2 Supplement 1): S90.

\section{Nosek 2017}

Nosek, K., et al. (2017). "A comparison of oral controlled-release morphine and oxycodone with transdermal formulations of buprenorphine and fentanyl in the treatment of severe pain in cancer patients." Drug Design Development and Therapy 11: 2409-2419.

\section{Shi 2018}

Shi, Z. Y., et al. (2018). "Efficacy and safety of titration with controlled-release oxycodone versus immediate-release morphine in patients with moderate cancer pain." International Journal of Clinical and Experimental Medicine 11(3): 2595-2602.

\section{Ongoing studies}

\section{Matsuoka 2017}

Matsuoka, H., et al. (2017). "Selection of opioids for cancer-related pain using a biomarker: a randomized, multi-institutional, open-label trial (RELIEF study)." BMC Cancer 17: 6.

\section{Nct 2017}

Nct (2017). "A Study to Compare the Titration Efficacy and Safety of Control-released Oxycodone and Immediate-released Oxycodone in Patients With Moderate to Severe Cancer Pain." https://clinicaltrials.gov/show/NCT03176199.

\section{Awaiting classification}

\section{Nct 2016}

"Opioids Titration Study in Advanced Cancer Patients in Hong Kong." https://clinicaltrials.gov/show/NCT03024515.

\section{Nct 2018}

"Individualized Pharmaceutical-care in Outpatients With Cancer Pain." https://clinicaltrials.gov/show/NCT03439904.

\section{Zhang 2016}

Zhang, Y. (2016). "Efficacy of oxycotin in the treatment of severe cancer pain by rectal administration." Cancer Nursing 39 (6 Supplement 1): $S 73$.

\section{ChiCTR1800014268}

Effects and efficacy of hydrochloride oxycodone controlled-release tablets with dose titration at 12h for cancer pain; ChiCTR1800014268; http://www.chictr.org.cn/showproj.aspx?.proj=24227 


\section{TK-641 Phase 3 Study}

JPRN-JapicCTI-111388; https://www.clinicaltrials.jp/user/showCteDetailE.jsp?japicld=JapicCTI-111388

\section{ChiCTR1800017461}

Efficacy and safety of different titration regimens for oxycodone hydrochloride sustained-release tablet in the treatment of cancer pain; ChiCTR1800017461. http://www.chictr.org.cn/showproj.aspx?proj=29451

\section{N DEX TERMS}

\section{Medical Subject Headings (MeSH)}

Analgesics, Opioid [administration \& dosage] [adverse effects] [ ${ }^{\star}$ therapeutic use]; Cancer Pain [ ${ }^{\star}$ drug therapy]; Constipation [chemically induced]; Delayed-Action Preparations; Drug Administration Schedule; Morphine [administration \& dosage] [adverse effects] [therapeutic use]; Nausea [chemically induced]; Neoplasms [ ${ }^{\star}$ complications]; Oxycodone [administration \& dosage] [adverse effects] [ ${ }^{\star}$ therapeutic use]; Pain Measurement; Quality of Life; Randomized Controlled Trials as Topic; Sleep Stages; Vomiting [chemically induced]

\section{MeSH check words}

Aged; Female; Humans; Male; Middle Aged 